\title{
Resident-oriented care in nursing homes
}

Citation for published version (APA):

Berkhout, A. J. M. B. (2000). Resident-oriented care in nursing homes: an evaluation study of the model of resident-oriented care, the implementation and the effects. [Doctoral Thesis, Maastricht University].

Datawyse. https://doi.org/10.26481/dis.20001013ab

Document status and date:

Published: 01/01/2000

DOI:

10.26481/dis.20001013ab

Document Version:

Publisher's PDF, also known as Version of record

\section{Please check the document version of this publication:}

- A submitted manuscript is the version of the article upon submission and before peer-review. There can be important differences between the submitted version and the official published version of record.

People interested in the research are advised to contact the author for the final version of the publication, or visit the DOI to the publisher's website.

- The final author version and the galley proof are versions of the publication after peer review.

- The final published version features the final layout of the paper including the volume, issue and page numbers.

Link to publication

\footnotetext{
General rights rights.

- You may freely distribute the URL identifying the publication in the public portal. please follow below link for the End User Agreement:

www.umlib.nl/taverne-license

Take down policy

If you believe that this document breaches copyright please contact us at:

repository@maastrichtuniversity.nl

providing details and we will investigate your claim.
}

Copyright and moral rights for the publications made accessible in the public portal are retained by the authors and/or other copyright owners and it is a condition of accessing publications that users recognise and abide by the legal requirements associated with these

- Users may download and print one copy of any publication from the public portal for the purpose of private study or research.

- You may not further distribute the material or use it for any profit-making activity or commercial gain

If the publication is distributed under the terms of Article $25 \mathrm{fa}$ of the Dutch Copyright Act, indicated by the "Taverne" license above, 


\section{Resident-Oriented Care in Nursing Homes}

An evaluation study of the model of resident-oriented care, the implementation and the effects 
Resident-Oriented Care in Nursing Homes

An evaluation study of the model of resident-oriented care, the implementation and the effects

Afke Berkhout

Thesis Maastricht University

Printing: Datawyse, Maastricht, The Netherlands

Cover illustrations: Photograph by Harrie Timmermans from the jubilee edition "Care in the Netherlands: picture of a period" [Zorg in Nederland: een tijdsbeeld] used with permission of Pensioenfonds PGGM (PGGM, 1994) and badge of the Dutch enrolled nurse (qualification level 3) by Peter de Grunt (Koninklijke Begeer, 1998)

Cover design: Datawyse, Maastricht, The Netherlands

Lay-out: Isel Bosma-van Noppen

(C) 2000 Berkhout, Afra Johanna Marie Bernadet

ISBN 90-9013983-4

Subject headings: resident-oriented care, implementation, job redesign, nursing homes 


\title{
Resident-Oriented Care in Nursing Homes
}

\author{
An evaluation study of the model of resident-oriented care, \\ the implementation and the effects
}

Proefschrift

ter verkrijging van de graad van doctor aan de Universiteit Maastricht,

op gezag van de Rector Magnificus, Prof. dr. A.C. Nieuwenhuijzen Kruseman volgens het besluit van het College van Decanen, in het openbaar te verdedigen

op vrijdag 13 oktober 2000 om 16.00 uur

door

Afra Johanna Marie Bernadet Berkhout

geboren op 3 december 1957 te Wageningen 


\section{Promotores:}

Prof. dr. H. Huijer Abu-Saad

Prof. dr. F.J.N. Nijhuis

\section{Co-promotor:}

Dr. N.P.G. Boumans

\section{Beoordelingscommissie:}

Prof. dr. J. van der Zee (voorzitter)

Prof. dr. M.H.F. Grypdonck (Universiteit Utrecht)

Prof. dr. H. Philipsen

Prof. dr. M.W. Ribbe (Vrije Universiteit Amsterdam)

Prof. dr. C. Spreeuwenberg

The study presented in this thesis was financed by the Landelijk Centrum Verpleging \& Verzorging (LCVV) and Maastricht Health Research Institute for Prevention and Care (Health), which participates in the Netherlands School of Primary Care Research (CaRe), acknowledged in 1995 by the Royal Dutch Academy of Science (KNAW).

Financial support for the printing of the thesis has been kindly provided by Twynstra Gudde Management Consultants, Health Care Group. 
Ter nagedachtenis aan mijn vader en moeder, Henk Berkhout (1910-1987) en Jo Berkhout-Terra (1917-1995) 

To Paul 



\section{CONTENTS}

1. INTRODUCTION

1.1 Introduction 1

1.2 Research questions and aims of the study 3

1.3 Overview of the thesis 5

2. THEORETICAL BACKGROUND OF JOB REDESIGN IN NURSING 7

$\begin{array}{lll}2.1 \text { Introduction } & 7 \\ 2.2 & \end{array}$

2.2 The work of nursing caregivers 8

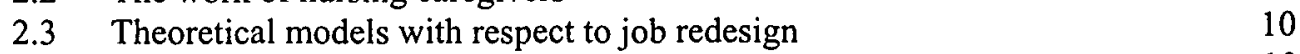

$\begin{array}{ll}2.3 .1 \text { Introduction } & 10\end{array}$

2.3.2 The Job Characteristics Model 11

2.3.3 The Job Demand-Control model and the Demand-Control-Support model 13

$\begin{array}{lll}2.4 & \text { The Socio-Technical Systems approach } & 17\end{array}$

$\begin{array}{ll}2.5 & \begin{array}{l}\text { Methodological issues in the measurement of job characteristics and } \\ \text { psychological and behavioural reactions }\end{array} \\ \end{array}$

2.6 Job redesign in nursing: from task- to patient-oriented care models 21

2.7 Design characteristics of patient-oriented care models 23

$\begin{array}{ll}2.8 \text { Outcomes of job redesign } & 24\end{array}$

2.9 Definitions and measurement of the research outcomes 26

$\begin{array}{ll}2.9 .1 \text { Introduction } & 26 \\ 2.9 .2 \text { charateristics } & 26\end{array}$

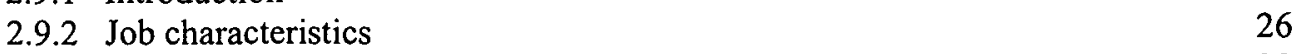

$\begin{array}{ll}2.9 .3 \text { Psychological and behavioural reactions } & 30\end{array}$

2.10 Empirical evidence of patient-oriented care models 33

$\begin{array}{ll}2.10 .1 \text { Introduction } & 33\end{array}$

$\begin{array}{ll}\text { 2.10.2 Design characteristics } & 34\end{array}$

2.10.3 Job characteristics 38

$\begin{array}{ll}2.10 .4 \text { Psychological and behavioural reactions } & 40\end{array}$

2.10.5 Conclusions $\quad 43$

2.11 Summary and conclusions 43

3. THEORETICAL BACKGROUND OF ORGANISATIONAL CHANGE 45

$\begin{array}{lll}3.1 \text { Introduction } & 45\end{array}$

3.2 Organisational change 46

$\begin{array}{ll}3.2 .1 \text { Introduction } & 46\end{array}$

3.2.2 Planned change 46

3.2.3 Chin \& Benne's typology of strategies of planned change 47

3.2.4 Models of planned change $\quad 48$

3.2.5 Approaches to change 49

3.3 Behavioural and motivational theories $\quad 51$

3.4 Conditions for organisational change 53

3.4.1 Introduction 53

$\begin{array}{ll}3.4 .2 \text { Successful organisational change } & 53\end{array}$

$\begin{array}{ll}3.4 .3 \text { Implementation structure } & 55\end{array}$

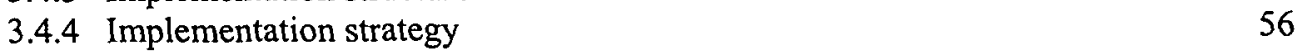


3.4.5 Control systems $\quad 57$

3.4.6 Motivation $\quad 58$

$\begin{array}{lr}3.4 .7 \text { Skills and capacities } & 59\end{array}$

$\begin{array}{ll}3.4 .8 \text { Role of the change agent and the supervisors } & 60\end{array}$

3.4.9 Implementation approach 61

3.5 A diagnostic change model 63

3.6 Summary and conclusions $\quad 67$

4. METHOD 69

4.1 Introduction $\quad 69$

4.2 Research model, research questions and hypotheses 69

4.3 Description and operationalisation of the research variables 72

$\begin{array}{ll}\text { 4.3.1 Introduction } & 72\end{array}$

4.3.2 Design characteristics $\quad 73$

4.3.3 Implementation characteristics $\quad 76$

$\begin{array}{ll}\text { 4.3.4 Job characteristics } & 77\end{array}$

4.3.5 Psychological and behavioural reactions 78

$\begin{array}{ll}\text { 4.3.6 Demographic and ward characteristics } & 79\end{array}$

4.4 Design of the study $\quad 80$

4.5 Description of the intervention 81

4.5.1 Introduction $\quad 81$

4.5.2 Resident-oriented care model $\quad 82$

4.5.3 Preconditions of the implementation $\quad 83$

4.6 Population of the study $\quad 84$

4.6.1 Introduction $\quad 84$

4.6.2 Selection criteria nursing homes $\quad 84$

$\begin{array}{ll}\text { 4.6.3 Selection criteria research wards } & 84\end{array}$

$\begin{array}{ll}\text { 4.6.4 Selection criteria nursing caregivers } & 85 \\ \text { Reseach procedure } & 85\end{array}$

4.7 Research procedure $\quad 85$

4.8 Response, dropout and baseline sample 86

4.9 Analyses $\quad 88$

5. DESIGN CHARACTERISTICS 91

5.1 Introduction 91

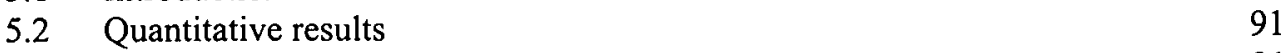

5.2.1 Analyses 91

5.2.2 Results 94

$\begin{array}{ll}5.3 & \text { Qualitative results } \\ & 105\end{array}$

$\begin{array}{ll}\text { 5.3.1 Analyses } & 105\end{array}$

$\begin{array}{ll}\text { 5.3.2 Results } & 106\end{array}$

$\begin{array}{lll}5.4 & \text { Summary } & 114\end{array}$

6. IMPLEMENTATION CHARACTERISTICS 117

$\begin{array}{lll}6.1 & \text { Introduction } & 117\end{array}$

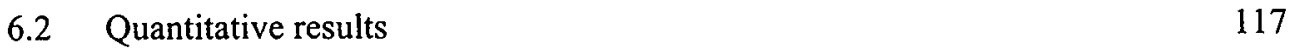

$\begin{array}{ll}6.2 .1 \text { Analyses } & 117\end{array}$

$\begin{array}{ll}6.2 .2 \text { Results } & 119\end{array}$

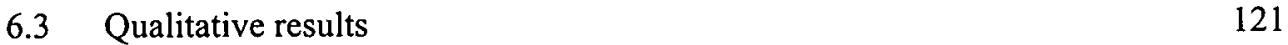


6.3.2 Results

6.4 Success conditions 131

6.5 Summary 134

7. JOB CHARACTERISTICS AND PSYCHOLOGICAL AND BEHAVIOURAL REACTIONS

$\begin{array}{lll}7.1 \text { Introduction } & 135\end{array}$

$\begin{array}{ll}7.2 \text { Job characteristics } & 135\end{array}$

$\begin{array}{ll}7.2 .1 \text { Analyses } & 135\end{array}$

$\begin{array}{lll}7.2 .2 & \text { Results } & 135\end{array}$

$\begin{array}{lll}7.3 & \text { Psychological and behavioural reactions } & 144\end{array}$

$\begin{array}{ll}\text { 7.3.1 Analyses } & 144\end{array}$

$\begin{array}{lll}7.3 .2 & \text { Results } & 145\end{array}$

$\begin{array}{lll}7.4 & \text { Summary } & 148\end{array}$

8. DISCUSSION 151

8.1 Introduction 151

8.2 Main findings 151

8.2.1 Introduction 151

8.2.2 Design characteristics 151

8.2.3 Implementation characteristics 153

8.2.4 Job characteristics and psychological and behavioural reactions 154

$\begin{array}{ll}\text { 8.3 Methodological reflections } & 157\end{array}$

$\begin{array}{ll}\text { 8.3.1 Introduction } & 157\end{array}$

8.3.2 Design of the study 157

$\begin{array}{ll}\text { 8.3.3 Population of the study } & 158\end{array}$

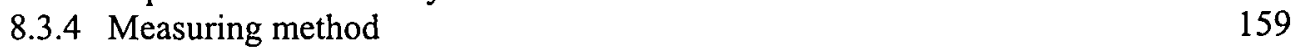

$\begin{array}{ll}\text { 8.3.5 Measuring instruments } & 161\end{array}$

8.3.6 Statistical analyses 162

8.4 Theoretical reflections 163

8.4.1 Introduction 163

8.4.2 Implementation of resident-oriented care models 163

8.4.3 Research outcomes 165

8.4.4 Interventions of job redesign in nursing in general 167

8.5 Implications 169

$\begin{array}{ll}\text { 8.5.1 Introduction } & 169\end{array}$

8.5.2 Implications for future research 169

$\begin{array}{ll}\text { 8.5.3 Practical implications } & 170\end{array}$

$\begin{array}{ll}\text { SUMMARY } & 173\end{array}$

$\begin{array}{lr}\text { SAMENVATTING } & 178\end{array}$

REFERENCES

$\begin{array}{ll}\text { APPENDICES } & 195\end{array}$

DANKWOORD / ACKNOWLEDGMENT 223

$\begin{array}{ll}\text { CURRICULUM VITAE } & 227\end{array}$ 



\section{InTRODUCTION}

\subsection{Introduction}

Nursing care is currently under great pressure. Examples of problems in maintaining quality of care and quality of work in nursing appear almost daily in the press and on radio and television. Underlying these problems there are some important developments which should be pointed out, such as the increased complexity of care due to technological changes, the growing number of patients in need of long-term care due to the ageing population, and shortages of nursing staff due to cost containment programs (Boumans, 1990; De Jonge, Janssen \& Landeweerd, 1994; De Jonge, Schaufeli \& Furda, 1995; Boeije, Van den Dungen, Pool, Grypdonck \& Van Lieshout, 1997; Van der Windt, Calsbeek \& Hingstman, 1999).

In the 1990s, careload intensified in nursing homes in particular. Underlying causes seem to be the increased admission of demented elderly with serious behaviour disturbance, elderly in need of very intensive complex somatic care and short-stay patients in need of rehabilitation (Van der Windt et al., 1999). As a consequence, not only did the amount of work increase, but care also became more complex and burdensome (Boeije, 1994; Van der Windt et al., 1999). In the second half of the 1990s careload slightly decreased among somatic and psycho-geriatric residents (Van der Windt et al., 1999). However, on the whole care has been intensified which increases the need for adequately educated and qualified staff with advanced education and skills (Van der Bent \& Van der Windt, 1998; Van der Windt et al., 1999).

In the last decade the health care sector was marked by a drastically decreased turnover and by an increased participation of women (returnees) in the labour market (Boeije et al., 1997; Van der Windt et al., 1999). However, among enrolled nurses in particular, forming the majority of workers in the Dutch nursing home sector, large shortages are predicted due to a dramatic decrease in the intake of students (Van der Bent \& Van der Windt, 1998; Van der Windt et al., 1999). The problem of these shortages is worsened by an increasing absenteeism due to illness in this sector, which was the highest in the total residential health care sector in the last decade (in $19978.2 \%$ versus $6.8 \%$ excluding absence through maternity leave) (Van der Windt et al., 1999). However, without compensating these shortages yet, recent figures indicate a slightly positive change in the intake of students (Tweede Kamer der Staten-Generaal, 1999).

Careload in combination with shortages among nursing staff can be considered as problematic because it increases workload. A number of studies have shown a negative impact of high workload on the well-being and health of nursing caregivers, such as less job satisfaction (Parkes, Mendham \& Von Rabenau, 1994; De Jonge, Van Breukelen, Landeweerd \& Nijhuis, 1999a), health complaints (Landeweerd \& Bou- 
mans, 1994; Parkes et al., 1994; De Jonge, Janssen \& Van Breukelen, 1996), burnout (De Rijk, Le Blanc, Schaufeli \& De Jonge, 1998; De Jonge et al., 1999a), self-reported stress (Landsbergis, 1988; Fox, Dwyer \& Ganster, 1993) and absenteeism (Landeweerd \& Boumans, 1994).

In an attempt to solve problems more structurally governmental actions since the mid1990s have been focused on improving quality of care, quality of work and work employment conditions (Boeije et al., 1997). For the fiscal year 2000, for the first time the care and cure sectors will both receive the same amount of governmental funding. To improve the work situation of nursing caregivers, funding will be used to reduce sick leave, decrease turnover, reduce the workload of nursing caregivers, stimulate the intake of students, and improve the image of the profession of nursing care. In addition, because they belong to high risk sectors, extra attention will be paid to reducing work pressure in nursing homes (Tweede Kamer der Staten-Generaal, 1999).

To stimulate health care organisations to get involved as much as possible in solving the problems themselves, two Dutch laws are of importance. Firstly, the Working Conditions Act 1998 prescribes that employers have to organise work so that it does not have a negative impact on the safety and well-being of the employees. Thus repetitive jobs and jobs lacking any influence on the work tempo have to be avoided (Staatsblad 1999, 184). Secondly, the Care Institutions Quality Act prescribes that health care organisations have to offer care of good quality, which has to be patientoriented, effective and efficient (Staatsblad 1996, 80). It could be argued that the relevant article in the Care Institutions Quality Act formalises the process of the last 20 years whereby nursing care has become more patient-oriented. In this line, patientoriented care models are increasingly considered as adequate instruments for improving quality of care in fostering continuity and coordination (e.g. Bekkers, De Bakker, Van Dartel, Meerman \& Van Vliet, 1990; Gardner, 1991; Alcock, Lawrence, Goodman \& Ellis, 1993). Further, they are considered of importance for improving the quality of work in fostering job enrichment (e.g. Bekkers et al., 1990; Boumans, 1990; Thomas, 1992; Vlerick \& Goeminne, 1994; Kivimäki, Voutilainen \& Koskinen, 1995). Following other residential health care facilities, nursing homes in the Netherlands have increasingly been implementing these patient-oriented care models, which are also called resident-oriented care models in this setting ' (Bekkers, 1993). The development of patient-oriented care models has taken place in the setting of general and psychiatric hospitals. Literature shows evidence that their implementation can lead to more job autonomy, social support and responsibility and more job demands as well (cf. Gardner, 1991; Thomas, 1992; Vlerick \& Goeminne, 1994; Kivimäki et al., 1995; Webb \& Pontin, 1996). In addition, positive psychological and behavioural reactions are noted, such as more job satisfaction and intrinsic work motivation and less health complaints and sickness absence (cf. McPhail, Pikula, Roberts, Browne \& Harper, 1990; Bond, Bond, Fowler \& Fall, 1991c; Heeremans, Boumans, Algera \& Landeweerd, 1994; Vlerick \& Goeminne, 1994; Kivimäki et al., 1995).

1) In case of nursing home care in this study use is made of the terms resident and resident-oriented care instead of patient and patient-oriented care. 
In general, the research literature singles out two main design characteristics of patient-oriented care models, namely: (1) patient assignment, i.e. assignment of patients to so-called primary nursing caregivers (PNC's) who become responsible for total nursing care 24 hours a day for the duration of stay of the patient (cf. Marram, Barrett \& Bevis, 1979; Manthey, 1980; Koene, Grypdonck, Rodenbach \& Windey, 1982); and (2) use of the nursing process, i.e. a cyclical and integrated process of taking nursing history, identifying nursing problems, determining goals, planning the actions, performing the actions and evaluating them (cf. Marram et al., 1979; Boekholdt, 1981; Koene et al., 1982; Molleman, 1989). As a consequence, somatic and psychosocial care are becoming integrated (cf. Marram et al., 1979; Manthey, 1980; Koene et al., 1982). Implementation of patient-oriented care models impacts on the tasks of nursing caregivers and on the communication on the nursing ward. With respect to the number of tasks, the implementation focuses on job enlargement (more tasks of the same level) and job enrichment (more co-ordination tasks) (cf. Marram et al., 1979; Manthey, 1980; Boekholdt, 1981; Koene et al., 1982; Molleman, 1989; Vlerick, 1996). As a consequence of job enrichment, communication improves by becoming more twosided and varied (cf. Marram et al., 1979; Manthey, 1980; Boekholdt, 1981; Koene et al., 1982). Nursing caregivers participate more in decision making and attention for integral care introduces mono- and multidisciplinary resident-oriented communication forms (Boekholdt, 1981; Koene et al., 1982; Molleman, 1989; Vlerick, 1996).

In implementing patient-oriented care successfully, the literature stresses the importance of considering the implementation, i.e. the process, itself (Manthey, 1980; Boekholdt, 1981; Koene et al., 1982; Bekkers et al., 1990; Van Zonneveld, 1993). Conditions such as the leadership style of supervisors and project co-ordinators and quality of information can positively impact on the product of implementation, i.e. the design and effects (Boekholdt, 1981; Boumans, 1990; Van Zonneveld, 1993).

\subsection{Research questions and aims of the study}

Until now, in the nursing home sector little systematic attention has been paid to the evaluation of the design of resident-oriented care models, the conditions for a successful implementation and the effects on job characteristics and on the psychological and behavioural reactions. However, research on these aspects is of particular importance in this sector for two reasons. Firstly, the majority of the patients admitted to this sector are chronically ill and in need of long-term complex nursing care. Offering this type of care is assumed to be demanding for nursing caregivers (Leppänen \& Oikinuora, 1987; McGrath, Reid \& Boore, 1989; Melchior, 1996). Secondly, the majority of nursing caregivers working in nursing homes are enrolled nurses or nursing aides, having a lower level of education compared to registered nurses (Boeije, 1994; Van der Windt et al., 1999). This means that they have restricted control over objective job conditions and less involvement in decision making with regard to these job conditions, yet they face high job demands such as shift work and responsibilities for others (De Jonge, 1995). The literature stresses that a combination of low job control and high job demands can lead to negative reactions such as job dissatisfaction, health complaints, physical and mental strain and burnout (e.g. Fox et al., 1993; Parkes et al., 
1994; De Jonge et al., 1996; De Jonge et al., 1999). It is unclear whether residentoriented care models in nursing homes are feasible and under what conditions they can be implemented successfully. Further, it is also unclear whether their implementation in this sector can lead to an improvement in the job characteristics of nursing caregivers and as a result in their psychological and behavioural reactions. So, our study was aimed to increase insight into three areas namely: (1) feasibility of resident-oriented care in nursing homes; (2) its success conditions; and (3) the effects on job characteristics of nursing caregivers and on their psychological and behavioural reactions. Therefore, our study was designed to answer the following three research questions:

Q1. To what extent are the various characteristics of resident-oriented care implemented?

Q2. What are the conditions for successfully implementing resident-oriented care?

Q3. What are the effects of the implementation of resident-oriented care on the job characteristics of nursing caregivers and on their psychological and behavioural reactions?

A non-equivalent control group pre-test post-test design was adopted for the study (cf. Cook \& Campbell, 1979; Polit \& Hungler, 1999). An experimental group, six wards implementing resident-oriented care, was compared with the control group, six wards without this implementation. Measurement was taken at three moments: one pre-test and two post-tests at six and sixteen months after the start of the implementation.

In figure 1.1 the conceptual framework of the study is presented. Our study covers both the process and the product of the implementation of a resident-oriented care model. On the left side of the model the process of the implementation of a residentoriented care model is presented. By studying the implementation characteristics we aimed to get insight into the conditions for a successful change (Q2). The success conditions are to be considered as the implementation characteristics. It is assumed that implementation characteristics can influence the effectiveness of the product of implementation and thus can lead to changes in the design characteristics and in the effects (Boekholdt, 1981; Bekkers et al., 1990; Van Zonneveld, 1993). The right side of the model presents the product of the implementation of a resident-oriented care model, that is the design characteristics, the job characteristics and the psychological and behavioural reactions. As a consequence of expected changes in the design characteristics (Q1), changes are hypothesised in job characteristics and in psychological and behavioural reactions of nursing caregivers in the experimental group (Q3) (Bekkers et al., 1990; McPhail et al., 1990; MacGuire \& Botting, 1990; Bond et al., 1991c; Degerhammer \& Wade, 1991; Thomas, 1992; Heeremans et al., 1994; Vlerick \& Goeminne, 1994; Kivimäki et al., 1995; Webb \& Pontin, 1996). Finally, demographic and ward characteristics such as age and careload are involved because they can impact on the results unintentionally (Boumans, 1990; De Jonge, 1995). 


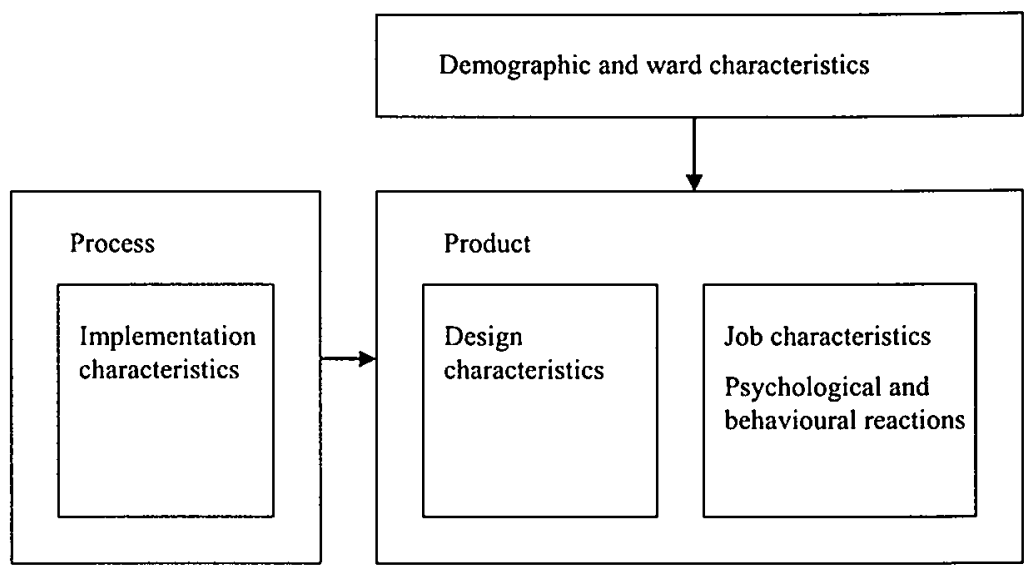

Figure 1.1 Conceptual framework

With respect to the conceptual framework of the study, one remark has to be made. In our study the design and implementation of a resident-oriented care model has to be considered as a black box. The researchers had no influence in this respect. Moreover, the organisational processes that took place, the aspects that were implemented and the underlying decisions could not be measured totally. In trying to measure the effectiveness of the implementation a model was constructed of four design characteristics mentioned in the literature as being key parts of a resident-oriented care model namely resident-assignment, use of the nursing process, tasks, and communication.

\subsection{Overview of the thesis}

The thesis is set up as follows. Chapter 2 discusses the theoretical background of the research questions 1 and 3. The discussion is focused on the work of nursing caregivers, on theoretical models of job enrichment in general and on different nursing care models. Based on empirical evidence with regard to job enrichment and patientoriented care models research variables are selected. In chapter 3 the theoretical background of research question 2 is discussed. Therefore models of organisational change are presented, underlying theories are reviewed, and conditions for a successful implementation are discussed. Based on these conditions, a diagnostic model is presented and research variables are chosen. Chapter 4 describes the method of the study. This chapter presents the research model, the variables and hypotheses, the design of the study, the intervention, the population of the study, the research procedures, and a general outline of the statistical techniques. In chapters 5,6 and 7 the results are presented with respect to the design characteristics, the implementation characteristics and the job characteristics and psychological and behavioural reactions respectively. Finally, in chapter 8 the main findings are presented and discussed in the light of the theoretical background and some methodological and theoretical issues are highlighted. Further, some recommendations are made for future research and for nursing practice. The thesis concludes with summaries in English and Dutch. 



\section{THEORETICAL BACKGROUND OF JOB REDESIGN IN NURSING}

\subsection{Introduction}

Nursing caregivers are exposed to many sources of psychological work-related stress (Gray-Toft \& Anderson, 1981; Leppänen \& Oikinuora, 1987; Hare, Pratt \& Andrews, 1988; Hipwell, Tyler \& Wilson, 1989; McGrath et al., 1989; Guppy \& Gutteridge, 1991; Seymour \& Buscherhof, 1991; Tyler, Carroll \& Cunningham, 1991). There is strong evidence that high stress levels among nursing caregivers can lead to dissatisfaction, somatic and psychosomatic symptoms and burnout (e.g. Estryn-Behar, Kaminski, Peigne, Bonnet, Vaichere, Gozlan, Azoulay \& Giorgi, 1990; Guppy \& Gutteridge, 1991; Boumans \& Landeweerd, 1992; Parkes \& Von Rabenau, 1993; Landeweerd \& Boumans, 1994; De Jonge, Le Blanc, Schaufeli \& Van der Linden, 1998).

Job redesign, by increasing job autonomy and social support, can moderate the stressful impact of job demands (Karasek, 1979; Johnson \& Hall, 1988; Boumans \& Landeweerd, 1992; Parkes et al., 1994; De Jonge et al., 1996; De Jonge et al., 1999a). This means that the workplace can be made healthier without necessarily lowering the job demands which is an appealing proposition for practitioners interested in intervening in the workplace (Karasek, 1979; Johnson \& Hall, 1988). In line with these assumptions, a lot of research in nursing care has concentrated on the issue of increasing job autonomy and social support. Recent interventions in the stressful nature of the work of nursing caregivers are often focused on an organisational change of the ward such as the implementation of patient-oriented care models (e.g. Molleman, 1989; Bekkers et al., 1990; McPhail et al., 1990; Bond et al., 1991c; Gardner, 1991; Thomas, 1992 and 1993; Heeremans et al., 1994).

In this chapter the theoretical background of job redesign in nursing will be stressed and related methodological issues will receive attention. First, some characteristics of the work of nursing caregivers are described (2.2). Second, some theoretical models with respect to job redesign and their empirical evidence are presented $(2.3,2.4)$ and some methodological issues in measuring job characteristics and psychological and behavioural reactions are discussed (2.5). Third, to highlight job redesign in nursing, a development is described from task to patient-oriented care models $(2.6)$ followed by a description of patient-oriented care models (2.7). Finally, to evaluate job redesign in nursing, research concepts are discussed $(2.8,2.9)$, followed by some empirical evidence of patient-oriented care models (2.10) and a summary and conclusions (2.11). 


\subsection{The work of nursing caregivers}

Job content in general is to be considered as a motivating work-related factor which can exert considerable influence on reactions such as job satisfaction and well-being (Karasek, 1979; Hackman \& Oldham, 1980; Trist, 1981; Johnson \& Hall, 1988). The nursing job is marked by a number of job-related and stress-producing risk factors such as lack of control of the job by the worker and responsibilities for others (Landsbergis, 1988; De Jonge, 1995). These seem to be related with the people-processing nature of the nursing job itself (e.g. Menzies, 1960; Gray-Toft \& Anderson, 1981; Leppänen \& Oikinuora, 1987; Hare et al., 1988; Hipwell et al., 1989; McGrath et al., 1989; Tyler et al., 1991) or with more organisational job characteristics (e.g. Menzies, 1960; Leppänen \& Oikinuora, 1987; Hare et al., 1988; McGrath et al., 1989; EstrynBehar et al., 1990; Guppy \& Gutteridge, 1991; Seymour \& Buscherhof, 1991; Tyler et al., 1991; Fox et al., 1993; Parkes \& Von Rabenau, 1993; Landeweerd \& Boumans, 1994; De Jonge et al., 1998).

The people-processing nature of the job itself is a source of stress for nursing caregivers. In 'people-processing organisations' the work process is focused on working with, through and on people. Boekholdt (1981) argues that due to the possibility that people can react directly to a treatment and due to general societal and political norms and values stressing individual worth, there is constant tension between individualisation and uniform work processes. Working on people produces insecurity about the work processes used and hard criteria for evaluation are often lacking, which makes work processes hard to control (Menzies, 1960; Boekholdt, 1981). Furthermore, 'people work' often implies intensive emotional experiences (Landsbergis, 1988; Janssen, De Jonge \& Bakker, 1999a). Important sources of stress seem to be feeling inadequately prepared for meeting the psycho-social demands of patients and their families and death and dying (Gray-Toft \& Anderson, 1981; Hipwell et al., 1989; Tyler et al., 1991). In this respect the long lasting and intense contacts with aged and often very ill patients such as in nursing homes, in hospices or in institutes for mental health care can constitute an extra source of stress (Leppänen \& Oikinuora, 1987; Hare et al., 1988). Moreover, Graham \& Livesley (1983) showed that difficulties in communication and management of elderly dying patients may add to the amount of stress experienced by staff after those patients die. Avoidance behaviour regarding the demands of patients in order to alleviate stress can lead to greater burnout in the long term (Menzies, 1960; Hare et al., 1988; McGrath et al., 1989).

Another source of stress is related to the system of parallel hierarchies of the professional bureaucracy in health care organisations, which is the working environment of most nursing caregivers (Leppänen \& Oikinuora, 1987; Brannon, 1990). On the one hand nursing caregivers need to respond to demands from the hierarchical organisation of administrators, such as working within tight schemes and schedules. On the other they need to respond to professional demands from the medical organisation of physicians, such as working in unexpected and urgent situations within professionally (and also legally) regulated directives and orders. Moreover, nursing caregivers have limited possibilities to influence decisions of administrators and physicians with regard to 
patient care and incongruent responsibilities can bring them into a conflict position, limiting their job control further (Leppänen \& Oikinuora, 1987; Landsbergis, 1988; Estryn-Behar et al., 1990). In addition, incongruity between actual work practices and expectations regarding maintenance of professional norms acquired during education and expectations regarding career development next to under-utilisation of skills can generate conflict about control (Menzies, 1960; Vredenburgh \& Trinkhaus, 1983; Landsbergis, 1988). Due to restricted job control, possibilities to deal with frustrations is limited creating stressful situations (Leppänen \& Oikinuora, 1987; Estryn-Behar et al., 1990; De Jonge, 1995). As a consequence, role ambiguity and role conflict may occur (Leppänen \& Oikinuora, 1987). In a study of McGrath et al. (1989) on occupational stress of nurses in Northern Ireland, almost $80 \%$ of the 171 nurses who responded said they felt unable to influence decisions at least sometimes and $85 \%$ indicated they felt powerless to change unsatisfactory situations. Finally, it was felt that the job did not always utilise their training and experience. The findings were supported by feelings of lack of personal accomplishment (McGrath et al., 1989).

A diversity of studies shows that low levels of job control or social support and high job demands can have a negative impact on levels of burnout and nurses' job satisfaction, intrinsic work motivation and health complaints (Landsbergis, 1988; Fox et al., 1993; Landeweerd \& Boumans, 1994; Parkes et al., 1994; De Jonge, 1995; De Rijk et al., 1998; Steen, Firth \& Bond, 1998; Janssen et al., 1999a). In stressing the importance of perceived job control, Perrewe \& Ganster (1989) and Fox et al. (1993) argue that if individuals do not perceive themselves to have job control, there is no reason why their psychological or behavioural reactions should be affected by influencing this control. In this respect, Fox et al. (1993) point out that to make patient demands more manageable nursing caregivers need more decision authority. However, the possibilities of increasing it seem to be limited in nursing. In their cross-sectional study among Canadian nurses, Hurrell \& McLaney (1989) found that increased task control, resource control and control over the physical environment were associated with greater job satisfaction independent of the level and type of perceived job demands. However, no effect was found for decision control. They explained this in relation to the presence of other occupational groups such as physicians. Physicians are viewed as having ultimate control due to the hierarchy in many health care professions. Therefore nurses may perceive very little decision making power (Hurrell \& McLaney, 1989).

Levels of control and responsibility seem to be related to the qualifications and education of nursing caregivers themselves. Parkes \& Von Rabenau (1993) found the lowest levels of discretion among nursing care assistants and enrolled nurses compared to senior nurses. Guppy \& Gutteridge (1991) found that stress scores of charge and staff nurses were significantly higher than the scores of lower qualified nurses such as stateenrolled nurses, nursing auxiliaries and nursing aides. This was explained by the different levels of responsibility. However, the higher levels of satisfaction among the higher-grade nurses compared to the lower grade nurses was explained by the different levels of job control too (Guppy \& Gutteridge, 1991). Estryn-Behar et al. (1990) concluded in their study that the basic knowledge differed between nursing aides and registered nurses, that their discussions with physicians were more exceptional, and that 
nursing aides showed higher levels of job stress. According to the authors, this was due to insufficient internal training (Estryn-Behar et al., 1990).

In conclusion, the work of nursing caregivers can be characterised by high job demands and difficulties in job control. This seems to be due to characteristics of the nursing job itself such as intense patient contacts. In addition, there is insufficient influence on administrative and patient care decisions. In this respect, dual responsibilities towards both the medical and hierarchical organisation and the gap between their own professional expectations and actual practice seems to restrict their control further. Levels of job control vary too with the qualifications and educational levels of nursing caregivers. The literature emphasises negative job-related effects on the wellbeing and health of nursing caregivers in case of high job demands and low job control (e.g. Fox et al., 1993; Parkes et al., 1994; De Jonge, 1995). Therefore, job redesign interventions emphasising job control in nursing seem to be of major importance. To gain insight into the mechanisms of job redesign in general some important theoretical models and approaches are presented.

\subsection{Theoretical models with respect to job redesign}

\subsubsection{Introduction}

In the last thirty years, job or work redesign has become increasingly important as a strategy for organisations to improve their productivity and quality of work (Karasek, 1979; Hackman \& Oldham, 1980; Trist, 1981; Johnson \& Hall, 1988; Karasek \& Theorell, 1990; Kuipers \& Van Eijnatten, 1996; De Sitter, Den Hertog, \& Dankbaar, 1997). In industrial and occupational psychology much evidence has been presented of the effects of work redesign on the well-being and health of employees (cf. Hackman \& Oldham, 1975, 1976, 1980; Karasek, 1979, i 989, 1990; Johnson \& Hall, 1988, 1994; Karasek \& Theorell, 1990 and 1996). In his thesis De Jonge (1995) points out two approaches in research on job redesign, namely the job enrichment approach and the social-technical systems (STS) approach. According to the job enrichment approach, job (re-)design is realised by intrinsic job-related conditions such as job autonomy, social support and responsibility so that a job is more challenging to the worker (e.g. Hackman \& Oldham, 1980; Johnson \& Hall, 1988; Karasek \& Theorell, 1990; De Jonge, 1995). The job enrichment approach is related to a number of theories and analytical models. Important examples are Herzberg's two-factor theory of satisfaction and motivation and the Job Characteristics Model (JCM) (Herzberg, Mausner \& Snyderman, 1959; Hackman \& Oldham, 1975, 1976, 1980). The Job Demand-Control model (JDC) (Karasek, 1979, 1989; Karasek \& Theorell, 1990) and its expanded version the Demand-Control-Support model (DCS) (Johnson \& Hall, 1988) appeared to be important for further research on the relation between job characteristics and health and well-being (De Jonge, 1995). Whereas Herzberg and Hackman and colleagues are explicitly focused on job redesign from the perspective of job enrichment, Karasek and colleagues are more focused on work-related reactions regarding health and well-being and therefore can be placed within the work redesign and stress tradition as well. The STS approach focuses on work redesign in integrating technical and social subsystems. 
The STS approach can be considered as a method for work redesign rather than an analytical or theoretical model. In this paragraph the JCM, JDC and DCS models are described first. The STS approach will be discussed in section 2.4 .

\subsubsection{The Job Characteristics Model}

\section{Description}

The JCM is a model of internal work motivation developed by Hackman \& Oldham $(1975,1976,1980)$. Their model is presented in figure 2.1.
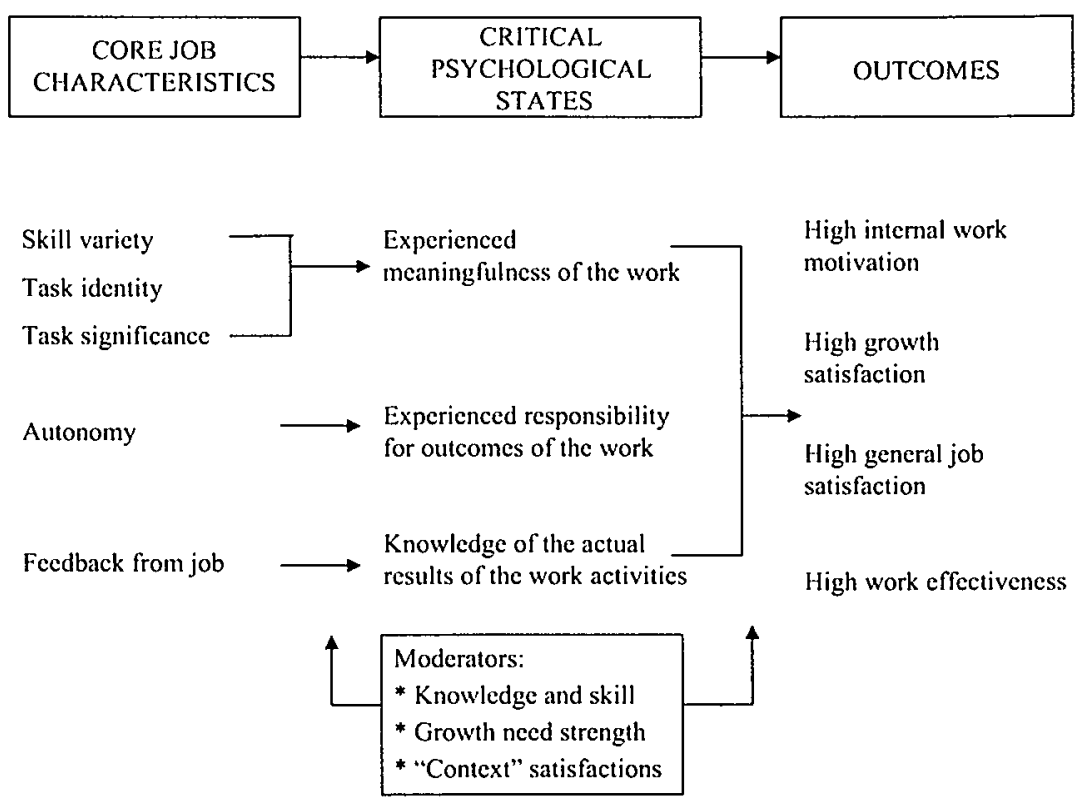

Figure 2.1 The Job Characteristics Model (derived from Hackman \& Oldham, 1980)

The JCM consists of three key-parts: (1) five core job characteristics; (2) three critical psychological states; and (3) the affective reactions of employees, i.e. personal outcomes. It is based on the assumptions that all core job characteristics are necessary for the presence of the critical psychological states and that the critical psychological states are necessary to result in affective reactions. Affective reactions can be moderated by individual growth need strength ('would like' and 'job choice'), the 'Growth Need Strength' (GNS) variable. The basic prediction is that people who have a high need for personal growth and development will respond more positively to a job high in motivating potential than people with low growth need strength. The theoretical interaction between job characteristics and individual differences is the central part of their theory. In line with the expectancy theory of Vroom (1964) (see also chapter 3), higher order need satisfactions in the JCM can be considered as rewards resulting of effective performance and thus incentives to perform effectively. The better and the 
harder an individual performs on a job perceived as highly motivational, the more opportunities he will feel for higher order need satisfactions. Later on, the moderators 'job relevant knowledge and skill' and 'satisfaction with the work context' were added to the model (Hackman \& Oldham, 1980).

\section{Empirical evidence}

A number of researchers tested the JCM or parts of it (e.g. Aldag, Barr \& Brief, 1981; Roberts \& Glick, 1981; Loher, Noe, Moeller \& Fitzgerald, 1985; Spector, 1985; Algera, Van der Flier \& Van der Kamp, 1986; Fried \& Ferris, 1986; Boumans, 1990; Wall \& Martin, 1996). This led several authors to make some critical reflections (cf. Fried \& Ferris, 1987; Boumans, 1990; Vogelaar \& Van der Vlist, 1995; Algera, 1997):

- Only a few studies performed causal modelling to test the validity of the model as a whole (e.g. Hackman \& Oldham, 1976; Algera et al., 1986). Most studies were focused on the direct relation between job characteristics and psychological and/or behavioural outcomes and/or the influence of the moderating variables. Especially the mediating role of the critical psychological states appeared to be dubious (e.g. Algera, 1981; Fried \& Ferris, 1987; Boumans, 1990; Vogelaar \& Van der Vlist, 1995).

- In general, most studies are focused on the effects on psychological outcomes such as job satisfaction and work motivation compared to more behavioural related outcomes such as sickness absence (Boumans, 1990; Landeweerd \& Boumans, 1994; Algera, 1997). The direct relationship between job characteristics and the psychological reactions (e.g. job satisfaction and work motivation) appeared to be robust in most of the studies (Fried \& Ferris, 1987; Landeweerd \& Boumans, 1994; Vogelaar \& Van der Vlist, 1995). Weaker but significant correlations were found with outcomes other than those specified in the model, such as general health complaints (Algera, 1983; Landeweerd \& Boumans, 1994), or with more behaviour-related outcomes, such as job performance, sickness absence or turnover (Algera, 1983; Loher et al., 1985; Fried \& Ferris, 1987; Landeweerd \& Boumans, 1994). Besides the five dimensions of the JCM, other predictors such as work pressure and social support also appeared to be determinants of employees' reactions (e.g. Algera, 1981; Boumans \& Landeweerd, 1992; Landeweerd \& Boumans, 1994).

- A few studies found some support for the moderating role of the growth need strength (GNS) variable (Loher et al., 1985; Spector, 1985; Boumans \& Landeweerd, 1992; Landeweerd \& Boumans, 1994). However, results of most studies are not convincing (e.g. Fried \& Ferris, 1987; Wall \& Martin, 1996). Moreover, Vogelaar \& Van der Vlist (1995) doubt the relevancy of measuring the GNS. They state that all workers, independent of their level of GNS, take advantage of job enrichment. Moreover, GNS is a measure taken at individual level while job redesign mostly involves interventions at group level. Therefore in case of job redesign, measurement of the GNS is questionable in their view. Another problem is the fact that the GNS itself can be influenced positively by job enrichment (Vogelaar \& Van der Vlist, 1995).

Following Fried \& Ferris (1987), Boumans (1990), Vogelaar \& Van der Vlist (1995) and Algera (1997), it can be concluded that with respect to the JCM most evidence is 
found for a direct relationship between job characteristics and psychological outcomes, and to a lesser extent behavioural outcomes. Furthermore, other predictors such as social support and work pressure appeared to be determinants of the reactions of employees. Evidence is less robust with respect to the mediating role of the three critical psychological states and with respect to the moderating role of the GNS. Moreover, the relevance of the latter is even doubted. Finally, only a few studies are known using an experimental research design to test the JCM in nursing (e.g. Kivimäki et al., 1995).

\subsubsection{The Job Demand-Control model and the Demand-Control-Support model}

\section{Description}

Karasek and colleagues developed an environmentally based stress-management model of job strain, the Job Demand-Control model (JDC). The JDC model, presented in figure 2.2, predicts that mental strain and job dissatisfaction result from external, job-related situations such as interactions of job demands and job control, also labelled as decision latitude.

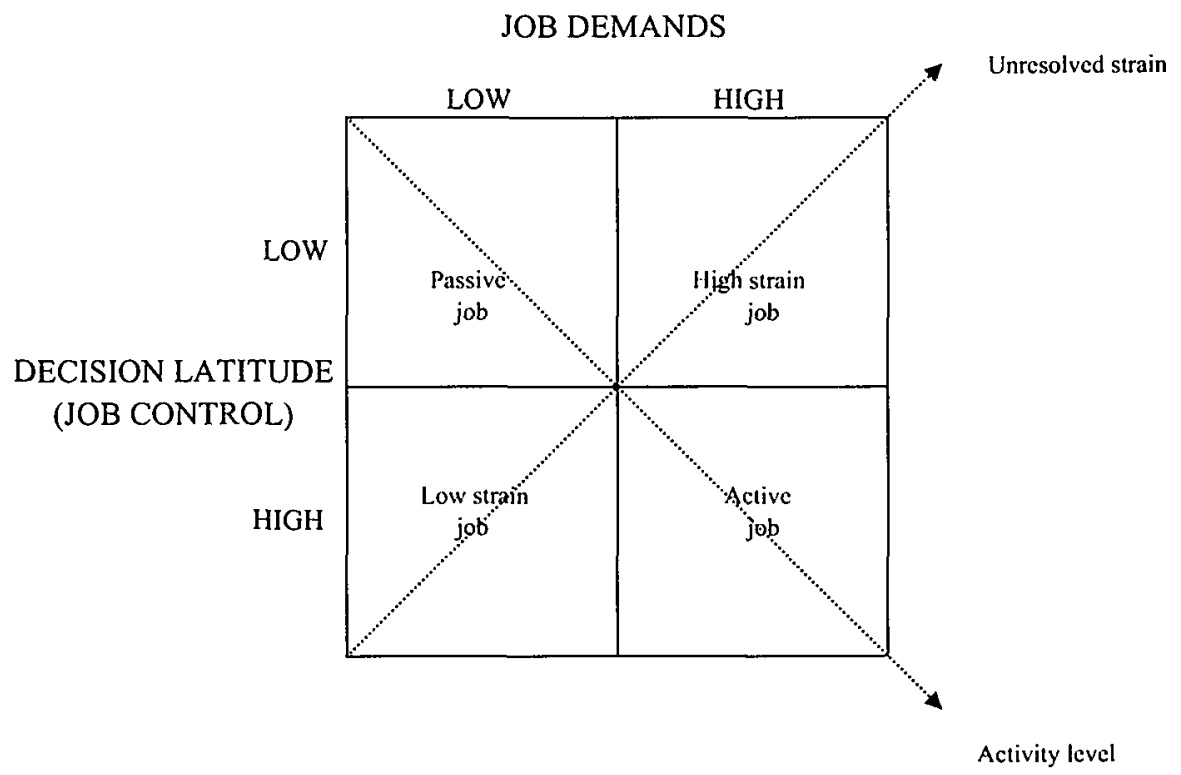

Figure 2.2 The Job Demand-Control model (derived from Karasek, 1979)

De Jonge (1995) points out in his literature review that the JDC model of Karasek is bridging in fact two research traditions namely the job redesign tradition (e.g. Hackman \& Oldham, 1980) and the occupational stress tradition (e.g. Caplan, Cobb, French, Harrison \& Pinneau, 1980; Kahn \& Boysiere, 1994). Issues relating to job control, considered as a job enrichment factor, as well as issues relating to job demands, considered as a job stressor, are combined in the JDC model. The JDC model is based on two related hypotheses: the so-called 'job strain' hypothesis and 'the learning' hypothesis (Karasek, 1979). The so-called 'job strain' hypothesis postulates that 
the risk of psychological strain and illness increases in case of high job demands and low job control, present in so-called 'high-strain' jobs (Theorell \& Karasek, 1996). The so-called 'learning' hypothesis postulates that the activity level (active learning, motivation, participation and personal growth) increases in case of high job demands and high job control, present in so-called 'active' jobs. When high job demands matches with the individual's control in dealing with these job demands, it is assumed that 'desirable stress' outcomes such as increased work motivation and learning opportunities will result (Theorell \& Karasek, 1996). In the remaining two cells of figure 2.2 situations with low job demands and low or high job control are labelled respectively as 'passive' and 'relaxed' job situations (Karasek, 1979). The important assumption underlying the JDC model is that job demands and job control combine interactively rather than additively in predicting job-related well-being and health (Karasek, 1979). So, job demands are assumed to foster action or release stress whereas job control is assumed to constraint on or modulate the release of stress to the alternative action. In this respect, it may be possible to improve job-related mental health without sacrificing productivity. This implies that job redesign is possible by increasing job control without changing job demands. Job redesign focused on more job control improves the worker's ability to make significant decisions about his task structure, increase his influence on organisational decisions and allow him discretion over the use of his existing and potential skills. In this respect it is noted that it is not the decision making itself that causes strain, but the constraints on decision making that are found in for example low status blue-collar jobs with little freedom (Karasek, 1979). If no action can be taken or if job control is low, the unreleased stress may cause psychological and physiological strain.

Evidence for additional variance of social support with respect to job demands and job control was found for cardiovascular disease (CVD), psychological strain variables and job and life satisfaction (Johnson \& Hall, 1988 and 1994; Melamed, Kushnir \& Meir, 1991; Fletcher \& Jones, 1993). Therefore, Johnson and Hall (1988) later extended the JDC model with the concept social support as presented in figure 2.3. The combined presence of job control and social support appeared to be important both as main effects and as moderators with respect to strain and CVD (Karasek, Triantis \& Chaudry, 1982; Johnson \& Hall, 1988, 1994; Johnson, Hall \& Theorell, 1989). To measure the effects, a variable was constructed called "iso-strain" which expressed a combination of social isolation and job strain (Johnson \& Hall, 1988). High iso-strain jobs are characterised by a combination of high job demands, low job control and low social support. Low social support is seen in isolated jobs (with fewer opportunities for social interaction) whereas high social support is seen in collective jobs (in which interaction with co-workers is integrated). In this respect the iso-strain hypothesis postulates that job-related health risks are due to high job demands, low job control and low social support. The learning hypothesis postulates that high job control and social support can moderate the negative effects of job demands. In later study, Johnson \& Hall (1994) argue that high collectiveness can be developed in jobs where employees are temporarily and spatially proximate, share job content and have balanced reciprocity with respect to resources. In this respect it can be argued that social support is a relevant factor in nursing due to the presence of individual and collective responsibility. 
DECISION

LATITUDE

(JOB CONTROL)

DECISION

LATITUDE

(JOB CONTROL)

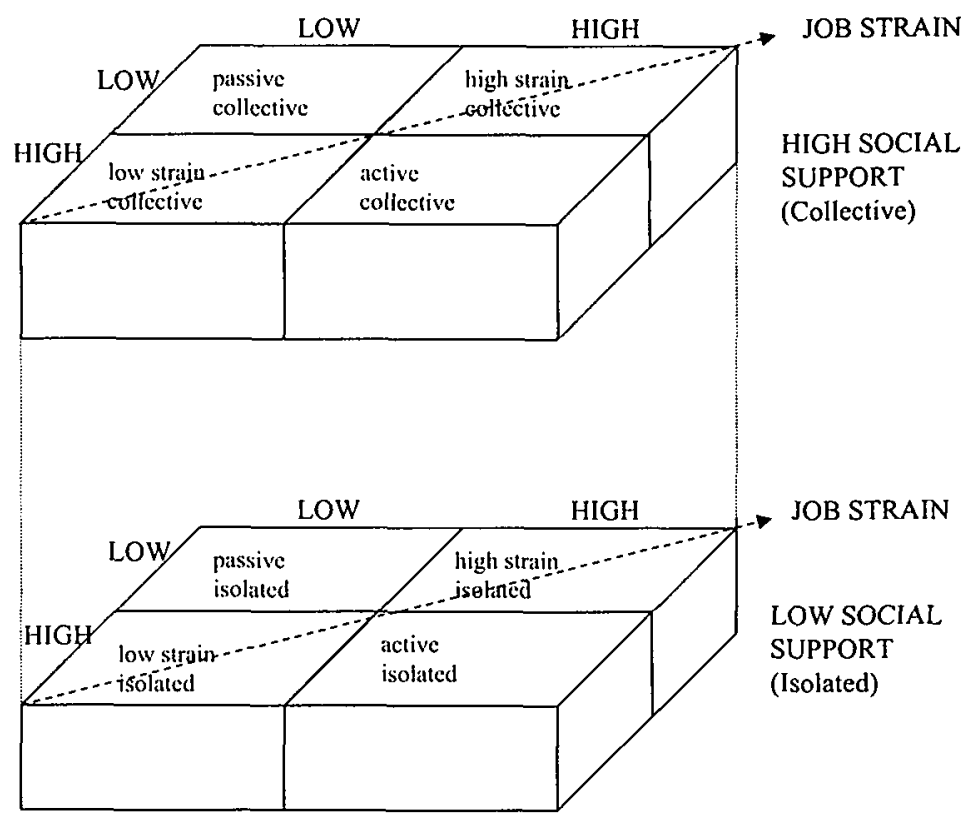

Figure 2.3 The Demand-Control-Support model (derived from Johnson \& Hall, 1988)

\section{Empirical evidence}

In the last decade the JDC and DCS models have been widely tested in diverse populations. More or less homogeneous populations have been investigated, such as blue collar workers (e.g. Andries, Kompier \& Smulders, 1996), white collar workers (e.g. Karasek, 1990; Carayon, 1993; Vahtera, Pentti \& Uutela, 1996), professionals (e.g. Melamed et al., 1991; Parkes et al., 1994; Schreurs \& Taris, 1998), and nurses (e.g. Landsbergis, 1988; Fox et al., 1993; De Jonge et al., 1996; De Rijk et al., 1998; Steen et al., 1998; De Jonge et al., 1999a; De Jonge, Mulder \& Nijhuis, 1999b). More heterogeneous samples of the full work force have also been studied (e.g. Dwyer \& Ganster, 1991; Fletcher \& Jones, 1993; Parkes et al., 1994; Wall, Jackson, Mullarkey \& Parker, 1996). The best support for the JDC and DCS models concerns the relation between the strain hypothesis and CVD (Theorell \& Karasek, 1996; Van der Doef \& Maes, 1998). Additive and interactive effects, low job control combined with high job demands in particular, appeared to be most robust as predictors for CVD (Karasek \& Theorell, 1990; Melamed et al., 1991; Parkes et al., 1994). However, empirical support for the JDC and DCS models is inconclusive (De Jonge, 1995; Van der Doef \& Maes, 1998):

- The large majority of the studies show additive effects of job control, job demands and social support on psychological outcomes (Hurrell \& McLaney, 1989; Perrewe \& Ganster, 1989; Karasek, 1990; Karasek \& Theorell, 1990; Melamed et al., 1991; Dwyer \& Ganster, 1991; Landsbergis, Schnall, Deitz, Friedman \& Pickering, 1992; Fletcher \& Jones, 1993; Parkes \& Von Rabenau, 1993; Parkes et al., 1994; Johnson, Hall, Ford, Mead, Levine, Wang, Nae-Yuh \& Klag, 1995; Andries et al., 1996; De Jonge et al., 1996; Wall et al., 1996; De Rijk et al., 1998; Schreurs \& Taris, 1998). 
Most studies have investigated the underlying job strain hypothesis. The learning hypothesis has been less investigated (Theorell \& Karasek, 1996). Regarding the type of relations, it appears that job demands are more associated with exhaustion, job control to depression and job dissatisfaction, and social support to well-being as well as to health-related measures (Karasek, 1979; Broadbent, 1985). Of the three dimensions, job demands show the most consistent negative effects on job as well as health-related outcomes (Schreurs \& Taris, 1998).

- Some evidence was found for first- and second-order interaction effects (Johnson \& Hall, 1988; Perrewe \& Ganster, 1989; Dwyer \& Ganster, 1991; Landsbergis et al., 1992; Fox et al., 1993; Parkes \& Von Rabenau, 1993; Parkes et al., 1994; Andries et al., 1996; De Jonge et al., 1996; Vahtera et al., 1996; Wall et al., 1996; De Rijk et al., 1998; De Jonge et al., 1999a, 1999b). However, this was not supported by an important number of other studies (Spector, 1987a; Landsbergis, 1988; Hurrell \& McLaney, 1989; Warr, 1990; Melamed et al., 1991; Carayon, 1993; Fletcher \& Jones, 1993; Johnson \& Hall, 1994). One of the reasons seems to be a lack of clarity and differences in the statistical method used (De Jonge et al., 1996; De Rijk et al., 1998).

- Conceptualisation and operationalisation of the concepts of job control and job demands have been widely criticised (Ganster \& Fusilier, 1989; Fletcher \& Jones, 1993; De Jonge, 1995; Wall et al., 1996; De Jonge et al., 1997; Schreurs \& Taris, 1998). For example, Schreurs \& Taris (1998) gave evidence that skill discretion and decision authority have in fact to be handled as two separate dimensions of job control or decision latitude. Moreover, there is the problem of conceptual and operational relatedness of the two concepts job control and job demands (Melamed et al., 1991; De Jonge et al., 1997). Components, which are also associated with job demands such as skill utilisation, responsibility and variety, are sometimes used as indicators of job control (Melamed et al., 1991). With respect to job demands Wall et al. (1996) point out that Karasek's (1979) concept of job control incorporates not only descriptive but affective variables as well. Especially in designs using selfreport techniques this can lead to spurious relations with outcome variables incorporating affective elements (Wall et al., 1996). Melamed et al. (1991) criticise global quantitative measures of job demands such as physical effort. In view of the rather low correlations with adverse job characteristics Melamed et al. (1991) question whether this general quantitative focus reflects all sources of work stress.

- Another weakness seems to be the lack of involvement of potential non-linearity of the associations between job control, job demands and social support on the one hand and well-being and health-related outcome measures on the other. The studies of Warr $(1990,1994)$ and De Jonge (1995) demonstrated some evidence of nonlinearity of these associations.

- Finally, relatively few studies evaluated the effects of job redesign interventions accordingly the assumptions of the JDC and DCS models (e.g. Theorell \& Karasek, 1996; Van der Doef \& Maes, 1998). In a review by Van der Doef \& Maes (1998) of fifty-one studies testing the JDC and DCS models, the majority were cross-sectional with only six case-control studies and three of them retrospective. 
In conclusion, there is broad empirical support for the JDC and DCS models regarding the main effects of job control, job demands and social support. However, the interactive effects are ambiguous. Most studies have been focused on the job strain hypothesis. The learning hypothesis seems to need more attention. Moreover, some problems exist with respect to the operationalisation of the concepts involved. Finally, no evaluation studies are found regarding job redesign interventions in nursing based on a longitudinal (quasi-) experimental design thereby using the concepts of the JDC or DCS model.

\subsection{The Socio-Technical Systems approach}

The JCM and the JDC and DCS models are primarily analytical models of job enrichment focused on the individual job rather than on the job at group level. Job enrichment approaches are also not explicitly focused on the way their principles have to be implemented. However, changing the task structure on micro-level is often problematic due to an unchanged and thus inconsistent embedding structure (Karasek, 1992). The STS approach is a work redesign method. It focuses on the quality of work and its structural and technical preconditions, on the work group as unit for work redesign and on establishing participative democracy on the shop floor (Emery \& Thorsrud, 1976; Trist, 1981; Kuipers \& Van Amelsfoort, 1990; Kuipers \& Van Eijnatten, 1996; De Sitter et al., 1997). This means improving both motivation of individual employees and productivity of the broader organisation. The STS approach was developed from planned change and action research projects and became an example for work redesign projects itself (e.g. Emery \& Thorsrud, 1976; Trist, 1981). So, STS gave structural and technical guidelines for work redesign as well as regarding the way in which it had to take place (Trist, 1981; De Sitter et al., 1997).

The core principle of the STS approach is the joint optimisation of the technical and social organisational subsystems which are considered as mutually dependent for the performance of a functional task of a work system (Trist, 1981). The level of this joint optimisation determines the levels of economic performance and job satisfaction (Trist, 1981). Trist (1981) summarises a number of design principles that apply to increasing the quality of work, namely optimum task grouping, increasing the task variety for the individual and with this the possibility for workers to develop multiple skills. An important precondition of the quality of work is sufficient job control capacity or control of the variance at source (Wall, Martin Corbett, Martin, Clegg \& Jackson, 1990; Kuipers \& Van Eijnatten, 1996). Job control capacity refers to two potentials: the power to regulate and the power to co-ordinate one's own work process, thereby using routine and non-routine procedures (Kuipers \& Van Eijnatten, 1996). Although the concept resembles (responsible) autonomy or latitude, it does not possess the more psychological connotation used in the JCM and JDC and DCS models (Van Eijnatten \& Van der Zwaan, 1998). According to the STS approach, job autonomy also refers to participation and involves issues such as joint decision making and worker empowerment in the organisation (Emery \& Thorsrud, 1976; Trist, 1981; De Jonge, 1995; De Sitter et al., 1997). In the literature control capacity is a determinant for performance, commitment, alienation and work pressure, which are considered as positive 
and negative indicators for quality of work (e.g. Wall et al., 1990). Although job satisfaction is often measured, it is considered as a less suitable outcome because it is especially viewed as a reflection of the adjustment of an individual to his work (Kuipers \& Van Eijnatten, 1996).

Essential part of the STS approach is work redesign by means of non-hierarchical organisational structures such as semi-autonomous work groups. Semi-autonomous work groups are based on the principle of self-regulation (Trist, 1981). Members of a group share responsibility and participate directly in the decision making concerning planning and performance of the work at their own level. Semi-autonomous work groups allow employees a high degree of control capacity or job autonomy in their work such as regarding the qualitative and quantitative goals, work period and work methods (cf. Trist, Higgin, Murray \& Pollock, 1963; Emery \& Thorsrud, 1976; Gulowsen, 1979; Trist, 1981; De Sitter et al., 1997). In line with this, supervision has to concern coordination of activities and management at distance. Supervisors and technical experts primarily are resources for the groups, rather than performers of authority or control (Trist, 1981; Gardell, 1982; Kuipers \& Van Eijnatten, 1996). Therefore important redesign principles are a flat organisation and participative leadership. Implementation of semi-autonomous work groups reveals significant improvements in measures such as autonomy (Wall \& Clegg, 1981), participation in decision making (Pearson, 1987), performance (Pearson, 1987), job satisfaction (Wall \& Clegg, 1981; Gardell, 1982; Pearson, 1987), work motivation and mental health (Wall \& Clegg, 1981; Gardell, 1982). In their review Houkes, Janssen, De Jonge \& Nijhuis (1997) concluded that most positive effects of autonomous work groups appeared on work motivation, job involvement and productivity. To a lesser extent positive effects were found on job satisfaction, mental health and sickness absence.

From the 1970s onwards, the STS became modernised. One point of criticism was focused on the process of work redesign. The strong domination of expert knowledge from outside the organisations was not in line with a growing need of organisations to cope with more interdependence and uncertainty in their environments. General standard solutions imposed from outside the organisation to solve local problems were no longer considered as suitable and acceptable (Trist, 1981; De Sitter et al., 1997). Modern STS strategies for work redesign involve participative self-design with adjustments to local needs; knowledge transfer and training-on-the-job for self-design; problem solving and learning by doing by organisation members themselves; congruence between the change and its process; and a balance between a directive redesign and a non-directive process approach (Trist, 1981; Kuipers \& Van Eijnatten, 1996; De Sitter et al., 1997; Van Eijnatten \& Van der Zwaan, 1998).

\section{Empirical evidence}

The main interest of the STS approach has never been primarily the development of theoretical assumptions but work redesign itself, thereby using analytical as well as prescriptive guidelines developed in action research (Hackman \& Oldham, 1980; Kuipers \& Van Eijnatten, 1996). As a consequence of this: 
- Theory-specified propositions are hardly generated and as a consequence of this development of a model including accompanying concepts and hypotheses has been limited until now. Only general principles are discussed (Hackman \& Oldham, 1980; Kuipers \& Van Eijnatten, 1996).

- Most evidence is based on effect evaluations of work redesign projects (Houkes et al., 1997). There is less systematic evidence from studies on the effects of job changes in terms of well-being and behaviour, yielding no substantial basis from which to generalise (Hackman \& Oldham, 1980; Wall \& Martin, 1996; De Sitter et al., 1997).

- There is less systematic empirical evidence of the validity and reliability of the application of guidelines to set up work redesign (Hackman \& Oldham, 1980; Trist, 1981; Wall \& Martin, 1996; Van Eijnatten \& Van der Zwaan, 1998). The main interest lay in work redesign itself instead of its accompanying process. Most projects are set up as action research and are specifically documented as case studies and thus more oriented on 'client' instead of 'scientific' demands.

In conclusion, the STS approach has been valuable for developing technical and structural principles for integral work redesign on work group and organisational level, accompanying guidelines for the process of work redesign and the assumption of participative democracy. In this respect it is proven to be a valuable addition on models focusing on redesign of the individual job. A major weakness is that empirical evidence is developed based on numerous separate work redesign projects. Less attention has been paid to a robust theoretical and conceptual base for the effects in terms of health and well-being. Finally, few effect evaluations are known based on STS experimental work redesign projects in nursing.

Before some job redesign projects in nursing are discussed, general methodological issues are highlighted with respect to the measurement of job characteristics and psychological and behavioural reactions. These issues are derived from empirical evidence found with respect to the three job redesign models and the STS approach and are discussed at the background of the evaluation of job redesign in nursing.

\subsection{Methodological issues in the measurement of job characteris- tics and psychological and behavioural reactions}

Based on the prior discussion of the three job redesign models and the STS approach, some important methodological issues arise concerning the evaluation of job redesign. These issues cover the measurement of job characteristics and psychological and behavioural reactions; choice of the study population; and study design.

\section{Measurement of job characteristics and psychological and behavioural reactions}

Data collection to study the effects of job characteristics is usually based on selfreported questionnaires and thus on perceived instead of objective job characteristics. According to Hackman \& Oldham $(1975,1976,1980)$, perceived job characteristics are the most important determinants of employee attitudes and behaviour, but are also 
a reflection of objective job characteristics. With respect to subjective, self-report measurement, some risks have to be mentioned such as common method variance (i.e. central tendency, acquiescencea and halo effect); social desirability and information bias; presence of an influencing third variable such as personality; and overlap in content between independent and dependent measures (Frese \& Zapf, 1988; De Jonge et al., 1997). This can lead to artificially high correlations between job characteristics and outcomes such as job satisfaction and the consequent risk of statistical artefacts, i.e. overestimation of the 'true' effects (e.g. Fried \& Ferris, 1987; Frese \& Zapf, 1988; De Jonge, 1995). In addition, most scales contain often global and distress-laden descriptions of job characteristics leading to insufficient or even biased information, which indicates a need for more precisely defined items (Spector, 1987b; Taber \& Taylor, 1990; Vogelaar \& Van der Vlist, 1995). A number of studies show support for reasonable strong correlations between objective and perceived job characteristics (Fried \& Ferris, 1987; Taber \& Taylor, 1990). So, in evaluating job redesign, besides self-report methods such as written questionnaires and interviews the use of more objective methods for data collection seem to be useful such as observations (Fried \& Ferris, 1987; Taber \& Taylor, 1990; Vogelaar \& Van der Vlist, 1995). However, some disadvantages of objective assessment of job characteristics have to be kept in mind too: (1) direct measurement is difficult to develop and to validate and has often an arbitrary character; and (2) ratings of observers such as peers, supervisors or researchers can be considered as human dependent and thus subjective (Algera, 1997; De Jonge, Kompier, Furda \& Reuvers, 1997). As a consequence, underestimation of the observed aspects has to be taken into account (Frese \& Zapf, 1988). Finally, adjustment and stability of outcome measures across time is an issue. Although job satisfaction can be influenced over the short or medium term, it has to be kept in mind that over the long term it tends to readjust to its original level (Vogelaar \& Van der Vlist, 1995; Kuipers \& Van Eijnatten, 1996).

\section{Choice of the study population}

Studies on the effects of job characteristics often use large samples and a variety of occupational groups to get a representative sample of the working population (e.g. Fried \& Ferris, 1986; Karasek, 1990; Fletcher \& Jones, 1993; Wall et al., 1996). According to Algera (1997), in this type of studies variance can be partly attributed to objective differences between jobs and partly to differences in individual perceptions of the same job. For this reason, De Jonge et al. (1997) recommend homogeneous study populations with respect to various confounders such as education and socioeconomic status, but heterogeneous with respect to the independent variable, such as the intervention variable. In reducing the influence of confounders such as biographical characteristics, differences in well-being and health may be more safely attributed to differences in job control and job demands (De Jonge et al., 1997).

\section{Study design}

The majority of the studies into job characteristics are largely cross-sectional or retrospective (Fried \& Ferris, 1987; Van der Doef \& Maes, 1998). As a consequence, no conclusions are possible about the direction, strength and causality of the postulated relationships (De Jonge et al., 1998). Studies with a longitudinal design are set up to follow attitudinal and behavioural changes of individuals over time and to establish 
causal order more reliably (De Jonge, 1995). Therefore, an experimental longitudinal design using a control group is to be preferred to study the effects of job redesign on well-being and health across time (De Jonge, 1995; Vogelaar \& Van der Vlist, 1995).

In conclusion, in evaluating job redesign interventions both subjective and objective measurements are needed to overcome particular methodological problems. This indicates the use of multiple methods such as written questionnaires, interviews and observations. Further, longitudinal experimental designs are necessary to study the effects of job redesign across time. Finally, study populations are preferred, which are homogeneous with regard to potential confounders such as biographical characteristics but heterogeneous with regard to exposure to an experimental condition.

\subsection{Job redesign in nursing: from task- to patient-oriented care models}

From the 1970s until today the organisation of nursing care expressed in task division and co-ordination can be characterised as an ongoing change process concerning tasks, job autonomy and responsibilities of nursing caregivers. To elucidate this, a historical overview will be sketched in this section.

\section{Functional nursing}

Until the seventies, nursing care in the Netherlands was organised according to Taylor's Scientific Management principles of task partition (Taylor, 1911). Nursing care models could be characterised as functional with a high degree of horizontally and vertically specialised tasks. Nursing caregivers performed a restricted number of tasks for all ward patients. Furthermore, the strong vertically specialised tasks brought forward a strict hierarchy in the ward organisation expressed in a complete separation of performance tasks and tasks regarding control and authority. Ward management was responsible for task allocation and nursing caregivers possessed shared responsibilities for task performance. Moreover, patient care was based on reductionism thereby stressing somatic and technical care (Boekholdt, 1990). Assumed advantages are related to high productivity and efficiency; specialisation; and limited skills, thus entailing the easy replacement of people (Boekholdt, 1990; Heeremans et al., 1994; Vlerick, 1996). According to Menzies (1960) functional nursing involves a disadvantageous psychological defence mechanism. With the strict partition of tasks intense social contacts with patients and colleagues can be avoided in order to lower distress and anxiety. As a consequence no personal relationships are built up leading to routine behaviour, monotony and depersonalisation (Menzies, 1960). Other disadvantages are shared responsibilities with no accountability or job autonomy; institutionalised and ritualised behaviour; large span of control; fragmentation of care; less knowledge of the patient as a whole; passive patient role; loss of acquired knowledge and skills; complex communication channels; and personnel and organisational problems due to restricted insertion of staff (Manthey, 1980; Boekholdt, 1981; Molleman, 1989; Heeremans et al., 1994; Vlerick, 1996; Pontin, 1999). 


\section{Team nursing}

In line with the views of Revisionism, which stresses the human being as an essential part of the work process, in the seventies nursing care became more oriented towards the position of patients and nursing caregivers. According to these views and out of the need for a reduced span of control team-oriented nursing care models were developed in America (Heeremans et al., 1994). This meant a division of the nursing ward into two or three independent teams. Within these teams task allocation was kept a central element supervised by an unit leader or ward sister. In this way an extra hierarchical level was established (Levert, 1973; Mercx, 1975; Manthey, 1980; Boekholdt, 1981; Bekkers et al., 1990; Heeremans et al., 1994). Except for a reduced span of control advantages and disadvantages were comparable to other functional nursing models.

\section{Patient-oriented care}

In the eighties a further delegation of job autonomy and responsibilities can be found. In line with principles of the contingency approach in general and the STS approach specifically, the organisational model of nursing care was considered as an open system influenced by demands from the environment and the social and technical subsystems (Boekholdt, 1981; Nievaard, 1982). Environmental demands in nursing care concern humanisation of work, cost containment, monitoring of quality of care and improvement of the working conditions (Heeremans et al., 1994). Technological demands are related to the task-oriented side of co-operation and communication, a holistic approach, job autonomy and problem- and goal-oriented acting (Nievaard, 1982; Heeremans et al., 1994). Finally, social demands are related to the socio-emotional side of co-operation and communication (Nievaard, 1982). Organisational models were based on the principle of patient assignment (Vlerick, 1996). In these so-called patient-oriented care models each nursing caregiver takes individual and integral care regarding the somatic and psycho-social needs of a limited number of assigned patients. This is realised by delegating responsibility for the co-ordination of care mostly for the length of stay, 24 hours a day, to so-called primary nursing caregivers (PNCs). Examples are primary nursing (United States), patient-oriented team nursing (i.e. team nursing with patient assignment) (The Netherlands) and integrated nursing (Belgium) (Marram et al., 1979; Manthey, 1980; Van Eindhoven, 1979; Grypdonck, 1980; Koene et al., 1982).

Implementation of these models is generally aimed at improving the quality of work of nursing caregivers and the quality of care (Vlerick, 1996). This is realised by increased responsibility and job autonomy, improved continuity and coordination of care and more participation of the patient in his/her own care process (McMahon, 1989; Bekkers et al., 1990; Boekholdt, 1990; Heeremans et al., 1994; Vlerick, 1996). In this respect patient-oriented care models are especially suitable in settings of long-stay care such as nursing home care. Evidence for this is found in a study of Gray-Toft \& Anderson (1981) who revealed that, despite relative large exposures to stress factors such as death and dying, low stress levels were seen among hospice staff compared to staff from medical and cardiovascular surgery departments. The authors explained this by the presence of ward characteristics such as patient assignment (Gray-Toft \& Anderson, 1981). Some disadvantages of patient-oriented care models can be mentioned too such as increased solo performance of nursing caregivers leading to less 
collective responsibility; less easy monitoring of quality of care; dependency of sufficient skills and capacities of individual nursing caregivers; more power and influence leading to less co-operation with other disciplines; and mutual rivalry and competition among nursing caregivers themselves (Bekkers et al., 1990; Heeremans et al., 1994; Jewell, 1996; McMahon, 1996).

First of all, development of patient-oriented care took place in general and psychiatric hospitals, assuming positive effects on job satisfaction, turnover and absenteeism among nursing caregivers, on the quality of care and on patient satisfaction (e.g. Heeremans et al., 1994; Kivimäki et al., 1995; Manley, Cruse \& Keogh, 1996). Based on the same assumptions, implementation of patient-oriented care models is also increasingly evident in nursing homes (Bekkers, 1993). Although the aim is to make these models suitable for nursing home practice, models implemented in general hospital still form the examples. In the following section the main design characteristics of patient-oriented care models will be presented.

\subsection{Design characteristics of patient-oriented care models}

The main design principle of a patient-oriented care model is horizontal and vertical job enrichment, the first often called job enlargement (Boekholdt, 1981; Molleman, 1989; Vlerick, 1996). With horizontal job enrichment different nursing tasks of a similar hierarchical level are integrated into one nursing job (Vlerick, 1996). In this way the division of performance tasks is minimised. The core principle of a patientoriented care model is vertical job enrichment, i.e. making nursing caregivers explicitly responsible for all phases of the nursing process including the co-ordination and evaluation of nursing care (Marram et al., 1979; Manthey, 1980; Koene et al., 1982; Vlerick, 1996). As a consequence, insight is obtained into a greater part of the production process, which means more job control (Molleman, 1992; Vlerick, 1996). Another consequence occurs at the next hierarchical level. In delegating co-ordination tasks to nursing caregivers, the function of the ward sister becomes less hierarchical and more supportive (Boekholdt, 1981; Koene et al., 1982; Molleman, 1989; Bekkers et al., 1990). In addition, in patient-oriented care models nursing is based on individual assessment of patients' needs (Manthey, 1980; Koene et al., 1982; Pontin, 1999). An integrated work process at the micro-level is thus developed by integrating somatic and psychosocial nursing care (cf. Marram et al., 1979; Manthey, 1980; Boekholdt, 1981; Koene et al., 1982). This type of job redesign follows in fact a core principle of the STS approach, namely optimum task grouping as a functional whole (Trist, 1981). These principles have made nursing a professional practice instead of a set of preexisting procedures (Manthey, 1980; Koene et al., 1982; Pontin, 1999). Although the organisation of care in a patient-oriented care model differs from a functional model, this difference is academic (Boekholdt, 1990). Boekholdt (1990) argues that in practice the models will never appear in a pure form but will vary between the extremes of the continuum functional versus patient-oriented nursing.

In most literature patient assignment is indicated as control in the first place and therefore is the main design characteristic of patient-oriented care models (Van Eindhoven, 
1979; Marram et al., 1979; Manthey, 1980; Koene et al., 1982). The extent of responsibilities delegated with this assignment depends on the period and intensity. Responsibilities can stretch from a shift to a total admission period and from parts to the total work process. In patient-oriented team nursing and in primary nursing, patient assignment is the main design characteristic, although the use of the nursing process is implicitly mentioned too (Marram et al., 1979; Manthey, 1980; Hegyvary, 1982). In their integrated nursing model, Koene et al. (1982) made the nursing process an explicit part of a patient-oriented care model.

Implementing these models changes not only the number of tasks of nursing caregivers but communication as well (cf. Marram et al., 1979; Manthey, 1980; Boekholdt, 1981; Koene et al., 1982; Molleman, 1989). As a consequence of horizontal and vertical job enrichment, more systematic care planning and attention for its integral character communication improves in becoming more two-sided and varied in structure (cf. Boekholdt, 1981; Koene et al., 1982). This is expressed by an increased participation in decision making and the introduction of monodisciplinary and multidisciplinary resident-oriented communication forms (Boekholdt, 1981; Koene et al., 1982; Molleman, 1989; Bekkers et al., 1990). The redesign of tasks and communication structure are in fact preconditions (e.g. Boekholdt, 1981; Koene et al., 1982; Heeremans et al., 1994). Delegating responsibility and accountability and improved communication are necessary for making patient assignment and the use of the nursing process effective.

In conclusion, patient- or resident-oriented nursing care models involve changes in four design characteristics, namely patient- or resident assignment, use of the nursing process, tasks, and communication (Mercx, 1975; Marram et al., 1979; Manthey, 1980; Boekholdt, 1981; Koene et al., 1982; Molleman, 1989; Boumans, 1990; Vlerick, 1996). In measuring these design characteristics we evaluate the implementation of a resident-oriented care model in nursing homes.

\subsection{Outcomes of job redesign}

With respect to research in psychology of work and health in general and job redesign in nursing in particular, two research approaches can be distinguished (Parkes \& Von Rabenau, 1993; De Jonge et al., 1997). The first considers explorative research, which is focused on the identification of specific job characteristics, their relative frequency and the strength of their associations with psychological and behavioural outcomes. The other approach involves more theoretically based research in that an established theoretical model of job redesign and its concepts are used. While the first approach contributes to enlarge insight into specific situations, the second approach contributes to enlarge insight into a broader theoretical framework (Parkes \& Von Rabenau, 1993; De Jonge et al., 1997). To incorporate job redesign interventions in nursing in a broader theoretical perspective we used the second approach as a basis for our study.

Our study is based on the DCS model and its concepts, for a number of reasons. Among the theoretical psychological models of well-being and health, the DCS model of Johnson \& Hall (1988) has been used in many cross-sectional and longitudinal stud- 
ies in the last decade. Moreover, the DCS model has proven to be a generally accepted and sound theoretical basis for describing psychosocial health risk characteristics of the work situation nowadays (e.g. Karasek \& Theorell, 1990; Parkes et al., 1994; Andries et al., 1996; De Jonge et al., 1997, 1999a and b). Additionally, the importance of the concepts used in the DCS model is evident because of their major role in other theoretical models in the psychology of well-being and health, which concern not only Hackman \& Oldham's JCM (Hackman \& Oldham, 1980) previously described, but Warr's Vitamins model (Warr, 1990, 1994) and the COR theory as well (Schreurs \& Taris, 1998; Janssen, Schaufeli \& Houkes, 1999b). Furthermore, the implementation of a resident-oriented care model can be placed within the tradition of job redesign leading to job enrichment for nursing caregivers. In research on this theme, job autonomy, job demands and social support are often pointed out as central outcomes (cf. Marram et al., 1979; Manthey, 1980; Boekholdt, 1981; Molleman, 1989). Therefore, the DCS model seems to be especially suitable to evaluate a job redesign intervention in nursing, the focus of our study. In addition we added the concept 'responsibility' because of its central characteristic in a resident-oriented care model (cf. Marram et al., 1979; Manthey, 1980; Boekholdt, 1981; Koene et al., 1982).

The choice for the variables related to reactions of health and well-being of nursing caregivers is based on several arguments. In the first place, there is considerable evidence in testing the DCS model with regard to job satisfaction and work motivation, health-related complaints and sickness absence. Of these studies, the majority have focused on job satisfaction (e.g. Hurrell \& McLaney, 1989; Perrewe \& Ganster, 1989; Dwyer \& Ganster, 1991; Melamed et al., 1991; Fox et al., 1993; Parkes \& Von Rabenau, 1993; Parkes et al., 1994; Wall et al., 1996; Schreurs \& Taris, 1998; De Jonge et al., 1999a). But also work motivation (De Jonge et al., 1999a), health complaints (Fox et al., 1993; Parkes \& Von Rabenau, 1993; Parkes et al., 1994; De Jonge et al. 1996, De Jonge et al., 1999b) and sickness absence (Dwyer \& Ganster, 1991; Vahtera et al., 1996) have been used to test the DCS model. Secondly, in both Hackman \& Oldham's JCM and Warr's vitamins model, job satisfaction (Hackman \& Oldham, 1980; Boumans \& Landeweerd, 1992; Landeweerd \& Boumans, 1994; Warr, 1990 and 1994; De Jonge et al., 1998), work motivation (Boumans, 1990) and sickness absence (Boumans, 1990; Landeweerd \& Boumans, 1994) have been used to evaluate the impact of job enrichment. Thirdly, according to Algera (1997), in empirical studies on job enrichment some variables are more used than others. In general, most studies use psychological reactions such as job satisfaction and work motivation compared to reactions such as health complaints and sickness absence (Algera, 1997). Perrewe \& Ganster (1989) argue that measuring health problems is of importance because dissatisfaction has been shown to lead to negative results in this respect. Therefore, following Boumans (1990) and Algera (1997), we included both health complaints and sickness absence in our study. Fourthly, different reactions seem to be predicted by specific job characteristics (Broadbent, 1985; Fried \& Ferris, 1987; Algera, 1997). For example, job demands seem to predict health-related psychological reactions in particular, such as health complaints, or behavioural reactions, such as frequency of sickness absence, whereas job autonomy or social support are more associated with attitudinal reactions, such as job satisfaction and work motivation (Boumans, 1990; Warr, 
1990; Dwyer \& Ganster, 1991; Spector \& Jex, 1991; Fox et al., 1993; Parkes \& Von Rabenau, 1993; Parkes et al., 1994; De Jonge, 1995; Landeweerd \& Boumans, 1994; Wall et al., 1996; De Jonge et al., 1998). So, to get a differentiated picture of specific effects of a work redesign intervention, it seems to be important to evaluate different reactions (Algera, 1997). Lastly, the four psychological and behavioural reactions seem to be especially suitable for evaluating job enrichment in nursing (e.g. Koene et al., 1982; Boumans, 1990; Fox et al., 1993; Parkes et al., 1994; De Jonge, 1995).

Following empirical evidence with regard to the causal chain between job characteristics and psychological and behavioural reactions, in our study we postulate that job enrichment in nursing care has positive effects on perceived job characteristics of nursing caregivers and as a result on their job-related psychological and behavioural reactions (e.g. Carayon, 1993; De Jonge, 1995; Vogelaar \& Van der Vlist, 1995). To be clear, our study is focused on an evaluation of the effects of a resident-oriented care model. Therefore, the study is not aimed at testing the DCS model itself.

\subsection{Definitions and measurement of the research outcomes}

\subsubsection{Introduction}

In the following section the definitions and measurement of the research outcomes are discussed. First, the four job characteristics are considered followed by the four psychological and behavioural reactions.

\subsubsection{Job characteristics}

From section 2.8 it appeared that job autonomy, job demands, social support and responsibility can be considered as central concepts in relation to health and well-being and are important outcomes regarding the evaluation of job enrichment in nursing in particular.

\section{Job autonomy}

Job autonomy has been the core component within the job redesign tradition as well as in the STS approach and therefore it is discussed at more length (Gardell, 1977; Cordery \& Wall, 1985; De Jonge, 1995). In many studies job autonomy is also formulated as job control (e.g. Spector, 1986; Ganster, 1989; Carayon, 1993; Fox et al., 1993; Wall et al., 1996; De Jonge et al., 1997; De Rijk et al., 1998) or as Karasek's term decision latitude (e.g. Warr, 1990; Parkes \& Von Rabeneau, 1993; Parkes et al., 1994). However, these concepts are not the same. According to Karasek decision latitude refers to '...the working individuals' potential control over his tasks and his conduct during the working day' (Karasek, 1979, pp. 289-290). It is measured by intellectual or skill discretion (opportunities to use high level skills) and decision authority or job autonomy (for making task level decisions) (Karasek, 1979; Karasek, Triantis \& Chaudry, 1982). Schreurs \& Taris (1998) showed that Karasek's unidimensional concept of decision latitude could best be treated as two separate dimensions, namely decision authority and skill discretion. According to Schreurs \& Taris (1998), decision 
authority resembles much of the job autonomy concept of Breaugh (1985), while skill discretion can be compared with Hackman \& Oldham's (1976) definition of skill variety. A distinction is made between the objective presence and the individual's perception or belief in that control. Ganster (1989), Perrewe \& Ganster (1989) and Fox et al. (1993) emphasise that the core of the construct is the individual's personal belief in his or her control over a work situation. Perceived control instead of more objectively assessed control such as derived from organisational indexes has a significant influence on stress felt in demanding work situations (Fox et al., 1993). As such it appears to be more likely a direct causal factor in explaining mental and physical health outcomes (Perrewe \& Ganster, 1989).

Carayon \& Zijlstra (1999) argue that some authors relate job control to worker participation in the organisation while autonomy is more associated with task or decision authority. In line with De Jonge (1995) we use the term job autonomy. This is because the term refers closely to the job redesign tradition as well as to STS principles of individual and work group autonomy (Gardell, 1977; Cordery \& Wall, 1985; De Jonge, 1995). Within the job redesign tradition the most widely used definition of job autonomy is that of Hackman \& Oldham (1976, pp. 258): 'the degree to which the job provides substantial freedom, independence and discretion to the employee in scheduling the work and in determining the procedures to be used in carrying it out'. This definition implies a timeframe, a content of tasks and plans and a freedom to decide the sequence of these tasks and plans (Frese, 1989). According to Breaugh (1985), this concept includes not only discretion but also working independently, which is viewed as different. Whereas discretion can be operationalised as opportunities for control and decision making in the work setting, independent working does not necessarily imply control (Breaugh, 1985; Parkes \& Von Rabenau, 1993). Breaugh (1985) considers job autonomy in terms of three distinct work facets, that is method, scheduling and criteria. Gardell (1977) bases his description of job autonomy on STS principles. Although he gives no strict definition of job autonomy, he describes the construct as a measure of 'the level of discretion and skill associated with a particular job...' (Gardell, 1977, p. 518). According to him, autonomy refers to a series of work characteristics such as discretion regarding working pace, working method, impact on production and quality and refers to requirements with respect to manual and social skills (Gardell, 1977). In line with Breaugh (1985) and Gardell (1977), De Jonge (1995) argues that job autonomy is a relative term and is restricted to facets of the worker' s task. De Jonge (1995, p. 13) defines autonomy as 'the worker's self-determination, discretion or freedom, inherent in the job, to determine several task elements'.

In many studies job autonomy is conceptualised and measured as a single dimension such as decision latitude (Karasek, 1979) or job autonomy (Hackman \& Oldham, 1980). This global nature leads to difficulty in interpretation (Breaugh, 1985; De Jonge, 1995). Developing multiple scales to assess different facets of autonomy and skill variety would seem necessary to enhance the consistency and validity of the concept autonomy and its effects (Breaugh, 1985). Karasek (1990) points out the multilevel character of control by making a distinction between control over the micro level task (in task change processes) and influence in the workplace decision making proc- 
esses at macro level (in job change processes). In a similar line Gardell (1977) discusses autonomy as a multilevel concept related to participation. First, he refers to the two levels of participation: (1) direct decision making influence for oneself, the personal level; and (2) decision making influence for the employees as a collective, the group level also called representative democracy. Second, he refers to the substance of participation distinguished between: (1) autonomy over work performance, job level; (2) decision making influence over the personal work situation, team/department level; and (3) decision making influence over general management policy, plant level. In fact De Jonge (1995) combines the views of Breaugh (1985) and Gardell (1977). He refers to job autonomy as a multifacet and multilevel concept consisting of (1) external opportunities (i.e. contextual autonomy, strategic autonomy, control over outcomes or control over work); and (2) internal opportunities (i.e. content autonomy, operational autonomy, control over activities, or control within the work) (De Jonge, 1995). De Jonge (1995) argues that this breadth is dependent on the management level. In case of the individual worker in a subsystem the internal and external opportunities are limited. The work group has more opportunities to determine tasks and as a consequence, the individual has, because he derives his autonomy from those of the group and can expand this in line with his skills, needs and hierarchical position (De Jonge, 1995).

\section{Job demands}

Definitions of job demands are present in job redesign research as well as in stress research. Karasek (1979) defines job demands as the aggregate of psychological stressors affecting work. Examples are workload, unexpected tasks and job-related personal conflict (Karasek, 1979). De Jonge (1995), who refers to job demands as either task requirements or task goals within a job, makes a distinction between quantitative and qualitative job demands. Quantitative job demands refer to items as time pressure and workplace and having a lot of work to do (Fox et al., 1993; Parkes \& Von Rabenau, 1993; Andries et al., 1996). Qualitative job demands refer to items such as interruption in tasks, need of frequent reorganisation of daily work programmes and conflicting demands (Estryn-Behar et al., 1990; Fox et al., 1993; Andries et al., 1996). Hurrell \& McLaney (1989) make a distinction between three types of job demands: task demands (quantity, variance and cognitive demands), role demands (role conflict, role ambiguity, responsibility for others) and interpersonal conflict (inter- and intragroup conflict). They found that all job demands were associated with greater satisfaction in the presence of task, resource and physical environment control, while no effects were found with decision control (Hurrell \& McLaney, 1989). Although physical requirements too can lead to fatigue, stress-related outcomes of the DCS model are associated with psychological demands (Fox et al., 1993). In excluding physical job demands the risk has to be mentioned of underestimating low level 'blue collar' job stressors (Andries et al., 1996).

\section{Social support}

According to House (1981), social support involves a process of mutual social interaction affected by a range of social, cultural and personal factors. In this respect House (1981) argues that intense competitive, evaluative or unequal social relationships are not conducive to supportive relationships. Furthermore, they do not necessarily produce individual or organisational achievement. House (1981) points out that there is 
considerable consensus about the general nature of social support but considerable disagreement over its specifics. House (1981) and later Johnson and Hall (1994) use the literature of Kahn \& Antonucci (1980) and Caplan (1981). They discern three key elements: affect, affirmation and aid. The affect and affirmation elements are often categorised as emotional and appraisal support (House, 1981; De Jonge, 1995). According to Kahn \& Antonucci (1980) and House (1981), the feedback element belongs to appraisal support because it validates the person's identity and fosters improved performance based on adequate self-esteem. The aid element points to the more instrumental or material sources of social support (House, 1981; De Jonge, 1995). Finally, according to House (1981), informational support, such as advice, suggestions and information, is another source of social support. In a similar vein, Boumans \& Landeweerd (1992) distinguish between structural measures (the presence/absence of relationships within the social network) and functional measures (the degree to which interpersonal relationships provide particular resources). In this respect affect and affirmation can be seen as structural measures, while aid seems to be more related to functional measures. House (1981) makes a distinction between formal or professional support, such as from professionals or self-help groups, and informal or nonprofessional support, such as from friends, spouses and work relations. With regard to our study, perceived work-related social support is the central focus. Work-related social support comes from supervisors and co-workers (House, 1981; Hare et al., 1988; Parkes \& Von Rabenau, 1993; Andries et al., 1996; De Jonge et al., 1998). House (1981) argues that social support from supervisors is formal as well as informal and involves emotional, informational, instrumental and appraisal support. Social support from co-workers belongs to the more informal sources of social support and is considered as most potential for preventing work stress (House, 1981).

There is evidence that social support is associated with well-being, such as job satisfaction, as well as to psychological health and sickness absence (Melamed et al., 1991; De Jonge et al., 1995; Vahtera et al., 1996; Moyle, 1998). Furthermore, Algera (1997) states that feedback for example is an important focus for interventions due to correlations with attitudinal as well as behavioural variables. However, Boumans \& Landeweerd (1992) argue that social support appears to be strongly associated with psychological and psychosomatic reactions while correlations with behavioural responses such as absence rates are seldom found. In their study they found significant positive correlations with job satisfaction and negative correlations with health complaints. No correlations were found with sickness absence. According to studies by House (1981), of the four resources emotional support seems to have the most positive influence on well-being and health.

\section{Responsibility}

According to Turner \& Lawrence (1965), autonomy and responsibility are both to be considered as objective discretionary task elements. The distinction between both concepts is that job autonomy is a behavioural activity, the discretion the worker is expected to exercise, whereas responsibility is merely a feeling, a mental state, for example uncertainty regarding the right decision to take when something goes wrong (Turner \& Lawrence, 1965). Turner \& Lawrence (1965) view personal responsibility as the feeling that a worker's own efforts are important in accomplishing the task at 
hand. In the JCM the distinction has been made to include job autonomy as one of the core job dimensions and experienced responsibility as one of the three critical psychological states. According to this model, experienced responsibility is directly influenced by job autonomy (Hackman \& Oldham, 1975, 1976, 1980). However, Hackman \& Lawler (1971) earlier had argued that autonomy is a necessary but not sufficient condition for feeling personal responsibility due to a number of factors in the work environment that affect the nature of work outcomes, such as the presence of personal control to achieve these outcomes. In studies evaluating the implementation of patientoriented care models, responsibility is often viewed as a positive outcome of job enrichment by making nursing caregivers accountable for all phases of the nursing process (Boekholdt, 1981; Koene et al., 1982; Molleman, 1989; De Jonge, Landeweerd \& Nijhuis, 1995a; Vlerick, 1996). However, in literature it is indicated that responsibility contains aspects of both job demands and decision making authority and thus can be defined as a stressor also (Karasek, 1979; Landsbergis, 1988). Similarly, Vlerick (1996) found that functional as well as patient-oriented care models correlate positively with burnout. He concluded that becoming responsible for patient care can be stressful when nursing caregivers do not possess or have opportunities to apply psycho-social skills (Vlerick, 1996).

\subsubsection{Psychological and behavioural reactions}

From section 2.8 it appeared that job satisfaction, work motivation, health complaints and sickness absence can be considered as important psychological and behavioural reactions directly associated with the central job characteristics of the DCS model and to other important models such as Hackman \& Oldham's JCM and Warr's vitamins model (Hackman \& Oldham, 1980; Warr, 1990, 1994). Furthermore, these outcomes can be considered as important for the evaluation of job enrichment in nursing.

\section{Job satisfaction}

Job satisfaction can be considered as a general job-related attitudinal outcome (Melamed et al., 1991). It is widely used as an indicator of positive and negative work experiences (Melamed et al., 1991; De Jonge et al., 1995). Some authors point out that a global unidimensional measure of job satisfaction is at least as reliable as multidimensional job satisfaction (Aldag \& Brief, 1978; Scarpello \& Campbell, 1983; Melamed et al., 1991; De Jonge, 1995). Moreover, a global rating on a five-point Likert scale can be a more inclusive measure of overall job satisfaction than a summation of many facet responses from a multidimensional scale (Scarpello \& Campbell, 1983; De Jonge, 1995). In this respect job satisfaction is the sum of the evaluations of a number of discrete elements of a job and reflects an overall affect of one's liking towards a job (Locke, 1969; Weaver, 1980). A global and general affect measure seems to be suitable when for example the success of a job redesign intervention in general has to be measured. When more specific information is needed with respect to different aspects of job satisfaction, a multidimensional measure is needed (e.g. Weaver, 1980). A single item to measure job satisfaction seems to reflect adequate reliability and stability, although too much stability may be an indication for an instrument's insensitivity to change (Weaver, 1980; Scarpello \& Campbell, 1983). In 
this respect, in the literature there is some criticism about using job satisfaction as an outcome measure for job enrichment. First, this criticism, among others stemming from STS advocates as discussed in section 2.4, focuses on the fact that an employee is adjusting his perception of job satisfaction until it is in agreement with reality (Vogelaar \& Van der Vlist, 1995; Kuipers \& Van Eijnatten, 1996). An initial increase therefore tends to decrease with time. Second, in regarding job satisfaction as a personrelated trait it can be considered as a stable characteristic over time (Watson \& Keltner Slack, 1993). Both criticisms consider job satisfaction as a less suitable outcome for evaluating job redesign interventions. However, as discussed in 2.8 , there is a lot of evidence that job satisfaction can be influenced by job redesign and thus it has to be considered as an important outcome of job change (Watson \& Keltner Slack, 1993; Vogelaar \& Van der Vlist, 1995).

\section{Work motivation}

Work motivation has been primarily explained from motivational as well as from job redesign theories but less from STS principles (Janssen, Nijhuis, Peeters \& De Jonge, 1996; Wall \& Martin, 1996). In theoretically underpinning work motivation, Janssen et al. (1996) point to the need theory of Maslow (1954) and the expectancy theory of Vroom (1964), further discussed in chapter 3. According to Maslow's theory, individuals first try to fulfil their lower order needs before trying to fulfil higher order needs. However, not only internal factors within individuals themselves but also the environment can influence intrinsic motivation (Janssen et al., 1996). The expectancy theory of Vroom (1964) postulates that the more an environment offers challenges in stimulating competence and support for independent functioning and personal growth, the more intrinsic motivation will appear. In this respect, job characteristics are expected to be a contribution to these highly rewarded outcomes (Janssen et al., 1996). Therefore, within job redesign theories, work motivation has always taken a prominent place (Hackman \& Oldham, 1975, 1976, 1980; Janssen et al., 1996; Thierry, 1997). De Jonge (1995) makes a distinction between job satisfaction and work motivation. $\mathrm{He}$ points out that the former concerns the sum of evaluations of job elements while the latter concerns the energising and directing of effort towards the attainment of outcomes (De Jonge, 1995). Hackman \& Oldham (1980) define work motivation as the extent to which an employee is internally motivated to perform his job well. According to them, a combination of the five core job characteristics determines the motivating potential of a job and contributes to the need for growth and so to intrinsic work motivation. Intrinsic work motivation refers to the need for self-fulfilment. Job enrichment can improve this process. However, not only too little enrichment but also too complex tasks can result in negative well-being and health (cf. Warr, 1990, 1994; De Jonge, 1995). On this basis, Janssen et al. (1996) define intrinsic work motivation as an orientation on the job that arises from an interaction between internal factors (i.e. the internal need a person has to perform well) and external factors inherent to the job, which contribute to a final goal (i.e. feelings of personal growth and intrinsic satisfaction). Further, they make a distinction between the condition (the extent of orientation towards a job) and the process (the factors and relations reflecting the way in which this orientation is reached). This definition is in line with Warr, Cook \& Wall (1979) who define intrinsic work motivation as 'the degree to which a person wants to work well in his or her job in order to achieve intrinsic satisfaction'(Warr et al., 1979, pp. 135). 
Following this line, in our study we will focus on the concept of intrinsic work motivation because we assume that nursing caregivers in general are not primarily driven by external rewards such as salary (Warr et al., 1979; Janssen et al., 1999a). As discussed in 2.8 , in the literature sufficient empirical evidence is found for direct effects of job characteristics such as autonomy and social support on intrinsic work motivation (e.g. De Jonge, 1995; Janssen et al., 1999a). To measure intrinsic work motivation, Janssen et al. (1996) recommend unambiguous operationalisation and direct measurement.

\section{Health complaints}

Experienced somatic and psychosomatic health complaints among nursing caregivers seem to be one of the more negative job-related psychological outcomes (Kompier \& Marcelissen, 1991; Boumans \& Landeweerd, 1992; Parkes \& Von Rabenau, 1993; Landeweerd \& Boumans, 1994; Parkes et al., 1994). Kompier \& Marcelissen (1991) distinguish several health complaints such as psychological problems, coronary vascular diseases, diseases of the immune system and of the muscular apparatus and other diseases such as of the gastro-intestinal system. They assume that various factors such as inheritance and personality traits determine which complaints will develop (Kompier \& Marcelissen, 1991). Algera (1983) has signalled that within the job enrichment tradition psychological and psychosomatic health complaints are often-neglected outcomes. In line with this, Boumans (1990) used perceived health complaints to study the impact of job characteristics. At the individual level she found less perceived psychosomatic health complaints if a job possessed sufficient feedback and autonomy and not too much work pressure, of which the latter appeared on the aggregated ward level too (Boumans, 1990). Besides physiological outcomes, Fox et al. (1993) used perceived illness and somatic health complaints to measure the extent to which nursing caregivers experienced such symptoms as insomnia, headache and stomach upset associated with job control and job demands. Illness and somatic health complaints appeared to be positively related with job characteristics such as frequency of stressful events and negatively related with nurses' beliefs in high control. A negative association was seen with job satisfaction (Fox et al., 1993). In their study Parkes et al. (1994) found more psychosomatic symptoms among lower qualified health care staff, such as unqualified care assistants and qualified nurses, compared to the higher qualified medical and professional staff. In line with Boumans (1990), Fox et al. (1993) and Parkes et al. (1994), we focus on perceived psychosomatic health complaints as an outcome for a job redesign intervention in nursing.

\section{Sickness absence}

According to the 'withdrawal hypothesis', employees use permanent (i.e. turnover) or less permanent (i.e. absenteeism and tardiness) flight responses as a coping mechanism to increased work-related stress (Dwyer \& Ganster, 1991). Sickness absence can be considered as a less permanent negative response of an employee to stressful work conditions, which could lead to absence behaviour (Smulders, 1980; Dwyer \& Ganster, 1991). Absence in general is a likely response to a variety of work stressors (Dwyer \& Ganster, 1991). In their study Dwyer \& Ganster (1991) make a difference between voluntary absence (unpaid) and involuntary absence (days off due to illness). It appeared that in case of low job control voluntary absence was positively associated with perceived demands, whereas tardiness and sick days were positively associated 
with objective demands (Dwyer \& Ganster, 1991). However, Smulders (1980) argues that sickness absences are not beyond the control of an individual and therefore not involuntary in character per se. Although the severity of illness of an employee determines for a major part the length of sickness absences, underlying attitudinal processes manifested in certain behaviour are determining factors too (Smulders, 1980; Dwyer \& Ganster, 1991). Job conditions, individual characteristics such as age and pressures to attend can influence whether an employee accepts, delays or refuses to play the sick role (Smulders, 1980). According to the literature, two basic absence measures can be assessed: (1) the number or frequency of absence spells per person (frequency measure); and (2) the (average) duration of these spells (duration measure) (Smulders, 1980). Frequency and duration measures are only partly determined by the same variables (Smulders, 1980). In general, frequency per employee (up to one year) seems to be especially influenced by job-related factors such as tasks, work-group organisation, delegation of responsibilities and working conditions such as workload, shift work and control measures. Average duration is more influenced by individual factors such as age or factors lying at a higher organisational or even national level such as physical working conditions, job-related personal and medical guidance and organisation of the national health care structure (Smulders, 1980). Subjective and objective measures appear to be rather highly correlated indicating the reliability of the subjective measure (e.g. Ten Vergert, 1987, $1=0.75$ ). Boumans $(1990)$ found in her study that on the individual level absence frequency is relatively low if work pressure is not too high, whereas on the aggregated ward level the task should be not too difficult and complex. In line with Smulders (1980) and Boumans (1990), we will use perceived frequency of sickness absence in our study.

\subsection{Empirical evidence of patient-oriented care models}

\subsubsection{Introduction}

A great many articles and reports are dealing with the design characteristics and the effects of patient-oriented care models such as team nursing with patient assignment, primary nursing and integrated nursing. However, a lot of the findings of these studies are equivocal or inconclusive and in-depth analysis revealed serious problems with respect to operationalisation, methodology, and a lack of clear statistical methods (Giovannetti, 1986; Bekkers et al., 1990; Thomas \& Bond, 1991). Therefore a comprehensive literature search was performed in Medline and Psychlit over the period 1970 until 2000. Studies were selected on the keywords 'primary nursing', 'integrated nursing' or 'patient-oriented (nursing) care'. For the benefit of comparability with regard to the health care setting, only those studies were involved which were carried out in residential health care facilities. All studies which were found were performed in general, academic and psychiatric hospitals. In tables 2.1 to 2.3 an overview of the results is presented. In this overview the names of the authors, the direction of change and the design of the study, presented by figures, is shown. Explanation of the figures is as follows (e.g. Cook \& Campbell, 1979):

1. Pre-test(s) post-test(s) design with non-equivalent groups(s);

2. Post-test(s) only design with non-equivalent groups(s); 
3. One group pre-test(s) post-test(s) design;

4. One group post-test(s) only design or correlational studies;

5. Qualitative study, case-study.

In the following subsections the empirical evidence is discussed. First of all, evidence with regard to the realisation of patient-oriented care models is discussed by means of the four design characteristics to be studied, i.e. patient assignment, use of the nursing process, tasks and communication. Next, the effects of the implementation of these models are discussed on the four job characteristics selected for study, namely job autonomy, job demands, social support and responsibility. Finally, effects on the four psychological and behavioural reactions job satisfaction, intrinsic work motivation, health complaints and sickness absence are discussed.

\subsubsection{Design characteristics}

In the literature some evidence was found concerning the realisation of the main design characteristics of a patient-oriented care model, namely patient assignment, use of the nursing process, tasks and communication. In table 2.1 an overview of the results is presented.

With regard to patient assignment, four out of five studies showed results in the expected direction (Molleman, 1989; Wilson \& Dawson, 1989; Bond, Bond \& Fowler, 1991b; Kivimäki et al., 1995). One study used a pre-test and a control group (Wilson \& Dawson, 1989). Molleman (1989) performed an evaluation study on the implementation of integrated nursing on wards in an academic medical hospital. Despite experienced improvements in nursing according to the principles of integrated nursing, differences in patient assignment between the experimental and control wards appeared to be small. In a study with a cross-over design, Wilson \& Dawson (1989) found an increased number of days on which patients were assigned to nursing caregivers. Bond et al. (1991b) found more assignment of patients to a primary nursing caregiver (PNC) already before their arrival. This finding was largely in line with the study of Kivimäki et al. (1995), who saw more nursing grouping and patient assignment on primary nursing wards compared to functional nursing wards. Finally, mixed results were found by Heeremans et al. (1994) who saw both a partial increase as well as a decrease after the implementation of integrated nursing in one experimental group.

Use of the nursing process was measured with respect to different aspects such as: documentation of nursing activities, assessment of nursing history and a nursing care plan including a nursing diagnosis and accompanying orders (Hegedus, 1980; Webb \& Pontin, 1997); data collection regarding the psychological and social situation of the patient (Boekholdt, 1981); use of nursing care plans and their evaluation (Perälä \& Hentinen, 1989; Kaban \& Thompson, 1990; MacGuire \& Botting, 1990; Alcock, Lawrence, Goodman \& Ellis, 1993; Heeremans et al., 1994). Eight out of thirteen studies showed results in the expected direction (Marram, Flynn, Abaravich \& Carey, 1976; Boekholdt, 1981; Molleman, 1989; Perälä \& Hentinen, 1989; Bekkers et al., 1990; Kaban \& Thompson, 1990; MacGuire \& Botting, 1990; Alcock et al., 1993). Two of 
them used a pre-test post-test design and a control group (Boekholdt, 1981; Bekkers et al., 1990). After the implementation of primary nursing, Marram et al. (1976) saw more observing and assessing of patients on primary nursing units compared to units with team nursing. Further it appeared that, compared to the team staff, charting of the primary nursing staff reflected more systematic, individualised care planning such as reporting patients' needs or making a diagnosis. Boekholdt (1981) performed an evaluation of the implementation of patient-oriented team nursing. He found more data collection with respect to the psychological and social situation of the patient on wards with patient-oriented team nursing compared to wards with functional nursing. Moreover, nurses indicated they were better informed about these aspects. Molleman (1989) found only slight differences between the experimental and control wards regarding the use of the nursing process. Perälä \& Hentinen (1989) performed a quasiexperimental study on the effects of primary nursing. They found an increased use of nursing care plans, which were more goal-oriented and better evaluated. Bekkers et al. (1990) performed a study with a quasi-experimental design on nursing wards of five general hospitals on the implementation of a patient-oriented care model. They found an increased use of the nursing process. In a study of Kaban \& Thompson (1990) on the effects of primary nursing on a psycho-geriatric unit, with the exception of its evaluation, the care plan audit indicated improvement in all areas such as problem identification and goal setting. This finding was confirmed in a qualitative study of MacGuire \& Botting (1990) on the effects of primary nursing. An improvement of written care plans was shown, care plans were more detailed, and nursing staff was better able to assess, plan and evaluate the nursing care plans. Finally, after the introduction of primary nursing Alcock et al. (1993) found a clinically significant increase in the formulation of patient care plans and in the evaluation of care.

A number of studies showed mixed effects (Hegedus, 1980), no change (Heeremans et al., 1994; Webb \& Pontin, 1997; Melchior, Halfens, Huijer Abu-Saad, Philipsen, Van den Berg \& Gassman, 1999) or contradictory results (Buesink, 1993). Three of these studies used a pre-test post-test design with non-equivalent groups (Hegedus, 1980; Heeremans et al., 1994; Melchior et al., 1999). Hegedus (1980) performed a chart audit to measure the extent to which nurses formulated a written nursing care plan after the implementation of primary nursing. Only documentation of nursing activities was increased on the primary nursing units compared to units with a functional or team nursing mode. No changes were found regarding assessment of nursing history and making a nursing care plan including a nursing diagnosis and accompanying orders. Heeremans et al. (1994) found hardly any significant differences between the experimental and control ward. A decrease was found in the use of nursing care plans in one experimental group and more evaluation of them was found in the other experimental group. A major problem in this study was the start of the implementation on the control wards between the first and second post-test and as a consequence the loss of control wards which had become experimental wards by then. Webb \& Pontin (1997) found only a few changes in the documentation. Only on one out of four wards was a significant increase found and problems in the documentation were still present or even greater at later stages. Melchior et al. (1999) found no increase in the use of the nursing process after the implementation of primary nursing in the intervention group 
compared to the control group. In a correlational study, Buesink (1993) found relatively low scores on the use of the nursing process after the implementation of integrated nursing.

With respect to the measurement of the variable tasks, different concepts are found such as professional versus technical tasks (Marram et al. 1976; Shukla, 1982; Molleman, 1989); co-ordination and policy tasks (Marram et al. 1976; Molleman, 1989; Buesink, 1993; Heeremans et al., 1994); direct versus indirect patient care (e.g. Giovannetti, 1980; Shukla, 1982; Chavigny \& Lewis, 1984; Degerhammer \& Wade, 1991; Gardner, 1991; Alcock et al., 1993; Thomas, 1993). Four out of twelve studies showed results in the expected direction (Marram et al., 1976; Molleman, 1989; Degerhammer $\&$ Wade, 1991; Heeremans et al., 1994). Only one study used a pre-test post-test design with non-equivalent groups (Heeremans et al., 1994). Marram et al. (1976) compared primary and team nursing with respect to professional and technical tasks. Most differences appeared with regard to professional tasks i.e. co-ordination of patient care, personalising care to the patient and the family and discharge planning. Delegation of these tasks was found more distributed among staff on primary nursing units compared to team nursing units. With regard to technical tasks, assisting patients with exercises and checking diagnostic results was more performed on primary nursing units. Molleman (1989) used the extent of job enlargement as an effect measure. He found not only job enlargement regarding technical nursing activities but also job enrichment regarding contributions to ward policy and independent acting. In the same line Heeremans et al. (1994) found an increase in the frequency of co-ordination and policy making tasks and in activities such as independent functioning and taking responsibility. Furthermore, less difficulty was found in performing these tasks. Degerhammer \& Wade (1991) found increased time spent in direct patient care and in verbal interaction between registered nurses and patients as well as increased time spent in indirect patient care and in administrative tasks. No changes were found in the group of enrolled nurses.

A number of studies showed mixed effects (Shukla, 1982; Chavigny \& Lewis, 1984; Gardner, 1991; Thomas, 1993), no change (Emans \& Den Boer, 1988; Alcock et al., 1993) or effects contradictory to the expectations (Giovannetti, 1980; Buesink, 1993). Only one study had a pre-test post-test design with non-equivalent groups (Gardner, 1991). After the implementation of integrated nursing Emans \& Den Boer (1988) noticed task enrichment such as an increase of responsibility for planning and evaluation of the own task. Hardly any change was found in participation in ward-oriented subjects and in intercollegiate assessment. In six studies the extent of time spent in patient care formed a central variable. Gardner (1991) found an increase in direct time spent in patient care on one out of three primary nursing wards compared to team nursing wards. On the other two primary nursing wards no changes were seen. Thomas (1993) conducted a comparative study on three nursing care models. On geriatric wards with primary nursing qualified nurses as well as nursing auxiliaries spent more time on direct patient care. Less time was spent on additional patient care and on ward activities. On wards with team and functional nursing modes more time was spent on domestic and administrative activities. Giovannetti (1980) and Shukla (1982) found less time 
spent in direct care on primary nursing units compared to other nursing models. However, Shukla found no differences in professional care time spent between the three types of nursing care. With respect to time spent on direct and indirect patient care Chavigny \& Lewis (1984) and Alcock et al. (1993) found no differences between primary nursing or team nursing. Moreover Chavigny and Lewis found that team nursing shows more contact with patients than primary nursing. Finally, Buesink (1993) found low scores on policy and co-ordination activities after the implementation of integrated nursing.

Table 2.1 Overview of the realisation of the design characteristics of patient-oriented care models

\begin{tabular}{|c|c|c|c|c|c|}
\hline Authors & Designs/nursing care models & $\begin{array}{l}\text { Patient } \\
\text { assign- } \\
\text { ment }\end{array}$ & $\begin{array}{l}\text { Use of the } \\
\text { nursing } \\
\text { process }\end{array}$ & Tasks & $\begin{array}{l}\text { Com- } \\
\text { muni- } \\
\text { cation }\end{array}$ \\
\hline Marram et al. (1976) & $2 /$ primary nursing vs. team nursing & & + & + & \\
\hline Giovannetti (1980) & $2 /$ primary nursing vs. team nursing & & & - & \\
\hline Hegedus $(1980)$ & $\begin{array}{l}\text { 1/primary nursing vs. team/functio- } \\
\text { nal nursing }\end{array}$ & & +10 & & \\
\hline Boekholdt (1981) & $\begin{array}{l}\text { 1/patient-oriented team nursing vs. } \\
\text { functional nursing }\end{array}$ & & + & & + \\
\hline Shukla (1982) & $\begin{array}{l}\text { 2/primary nursing vs. team nursing } \\
\text { vs. modular nursing }\end{array}$ & & & $0 \%$ & $0 /-$ \\
\hline Chavigny \& Lewis (1984) & $2 /$ primary nursing vs. team nursing & & & $0 /-$ & \\
\hline Emans \& Den Boer (1988) & 5/integrated nursing & & & 0 & \\
\hline Molleman (1989) & $\begin{array}{l}\text { 2/integrated nursing vs. functional } \\
\text { nursing }\end{array}$ & + & + & + & - \\
\hline Perälä \& Hentinen (1989) & $3 /$ primary nursing & & + & & \\
\hline Wilson \& Dawson (1989) & $\begin{array}{l}1 \text { cross-over/primary nursing vs. } \\
\text { team nursing }\end{array}$ & + & & & \\
\hline Bekkers et al. (1990) & $\begin{array}{l}\text { 1/patient-oriented nursing vs. func- } \\
\text { tional nursing }\end{array}$ & & + & & + \\
\hline Kaban \& Thompson (1990) & $3 /$ primary nursing & & + & & \\
\hline MacGuire \& Botting (1990) & 5/primary nursing & & + & & + \\
\hline Bond et al. (1991b) & $2 /$ primary nursing vs. team nursing & + & & & \\
\hline $\begin{array}{l}\text { Degerhammer \& Wade } \\
\text { (1991) }\end{array}$ & 4/primary nursing & & & + & \\
\hline Gardner (1991) & 1/primary nursing vs. team nursing & & & +10 & \\
\hline Alcock et al. (1993) & 3/primary nursing & & + & 0 & \\
\hline Buesink (1993) & 4/integrated nursing & & - & - & \\
\hline Thomas (1993) & $\begin{array}{l}2 / \text { primary nursing vs. team nursing } \\
\text { vs. functional nursing }\end{array}$ & & & $+1-$ & + \\
\hline Heeremans et al. (1994) & $\begin{array}{l}\text { 1/integrated nursing vs. functional } \\
\text { nursing }\end{array}$ & $+1-$ & 0 & + & + \\
\hline Kivimäki et al. (1995) & $\begin{array}{l}\text { 2/primary nursing vs. functional } \\
\text { nursing }\end{array}$ & + & & & \\
\hline \multirow{2}{*}{$\begin{array}{l}\text { Webb \& Pontin (1996) } \\
\text { Webb \& Pontin (1997) } \\
\text { Melchior et al. (1999) }\end{array}$} & 4/primary nursing & & & & $+1-$ \\
\hline & 4/primary nursing & & 0 & & \\
\hline Melchior et al. (1999) & $\begin{array}{l}\text { 1/primary nursing vs. functional } \\
\text { nursing }\end{array}$ & & 0 & & \\
\hline $\begin{array}{ll}+ & \begin{array}{l}\text { increased after the in } \\
\text { decreased after the in }\end{array} \\
\text { no differences } \\
+/-, 0 & \begin{array}{l}\text { some aspects improv } \\
\text { deteriorated or no dif }\end{array}\end{array}$ & $\begin{array}{ll}1 & \text { pre-test(s) po } \\
2 & \text { post-test(s) o } \\
3 & \text { one group pr } \\
4 & \text { one group po } \\
5 & \text { qualitative st }\end{array}$ & $\begin{array}{l}\text {-test(s) w } \\
y \text { with no } \\
\text { est(s) po } \\
\text {-test(s) or } \\
\text { y / case s }\end{array}$ & $\begin{array}{l}\text { hon equi } \\
\text { equivalent } \\
\text {-test(s) } \\
\text { / correlati } \\
\text { dy }\end{array}$ & $\begin{array}{l}\text { at groups } \\
\text { ups }\end{array}$ & \\
\hline
\end{tabular}

With respect to communication, different concepts were used such as variety and quality of communication (Boekholdt, 1981; Heeremans et al., 1994), openness of mutual 
communication (Boekholdt, 1981; Bekkers et al., 1990; MacGuire \& Botting, 1990), time spend in communication (Shukla, 1982; Thomas, 1993) and the extent of collegial communication regarding direct and indirect care and ward issues (Molleman, 1989; Web \& Pontin, 1996). The results of five out of eight studies were in the expected direction (Boekholdt, 1981; Bekkers et al., 1990; MacGuire \& Botting, 1990; Thomas, 1993; Heeremans et al. 1994). Three of these studies used a pre-test post-test design with non-equivalent groups (Boekholdt, 1981; Bekkers et al., 1990; Heeremans et al. 1994). Boekholdt (1981) found in the patient-oriented communication forms on the medical experimental ward in particular significantly more information regarding the psychological and social condition of the patient. However, in the last post-test less differences were seen. Further, slightly more openness of mutual communication between nurses was shown on the experimental wards compared to the control wards. This latter finding was confirmed by Bekkers et al. (1990) and MacGuire \& Botting (1990). Thomas (1993) found that qualified nurses as well as nursing auxiliaries in primary nursing wards spent more time in communication particularly in the afternoons. Finally, Heeremans et al. (1994) found increases in the quality of communication with ward sisters and in the collaboration and communication with medical doctors.

Three studies showed mixed results, no change and results contradictory to the expectations (Shukla, 1982; Molleman, 1989; Webb \& Pontin, 1996). On primary nursing units Shukla (1982) found the least amount of time spent on nurse-staff communication compared to units with modular or team nursing. No differences were found in nurse-patient or nurse-physician communication. Molleman (1989) studied collegial communication regarding direct and indirect patient care. No differences were shown between the experimental and control wards. Webb \& Pontin (1996) saw increases in quantity and quality of communication as well as difficulties and lack of clarity in the use of new communication systems.

\subsubsection{Job characteristics}

The implementation of patient-oriented care models is expected to change the central job characteristics used in the DCS model, i.e. job autonomy, job demands and social support. As we stated in 2.8, we added the concept 'responsibility' because of its central characteristic in a resident-oriented care model. In table 2.2 an overview of the results is presented.

With respect to job autonomy eleven studies were found with varying results and five of them with a quasi-experimental design (Boekholdt, 1981; McPhail et al., 1990; Gardner, 1991; Heeremans et al., 1994; Melchior et al., 1999). Five studies showed an increase in job autonomy with one of them using a pre-test post-test design and a control group (Buchel \& Van Roestel, 1986; Gardner, 1991; McCormack, 1992; Thomas, 1992; Vlerick \& Goeminne, 1994). However, Joiner, Johnson \& Corkrean (1981), McPhail et al. (1990) and Heeremans et al. (1994) found no effects of the implementation of patient-oriented care on job autonomy. The effects in the study of Melchior et al. (1999) varied. A significant increase was found after the implementation of 
differences in work (over)load and work pressure for nurses working in primary, team or functional nursing modes. Thomas (1992) found less work pressure in primary nursing wards compared to wards with team or functional nursing. With respect to job complexity, Melchior et al. (1999) found a decrease in the intervention group with high levels of complexity while it increased in the control group. In the intervention groups with medium or low levels of complexity no changes were found. They gave as an explanation that the higher level of autonomy in primary nursing enabled nurses to control and to manage their work and as a result they experienced it as less complex. Only the studies of McPhail et al. (1990) and Melchior et al. (1999) used a quasiexperimental design.

With regard to social support by supervisors or colleagues, measurement was performed by means of diverse concepts such as peer cohesion (McPhail et al., 1990) and supervisory support (Thomas, 1992; Alcock et al., 1993; Vlerick \& Goeminne, 1994) or even feedback (Joiner et al., 1981; Melchior et al., 1999). Vlerick \& Goeminne (1994) found more social support of supervisors on wards with a patient-oriented care model compared to wards with a functional model. McPhail et al. (1990) and Aicock et al. (1993) found no increase of peer cohesion and supervisory support after the implementation of patient-oriented care. However, Thomas (1992) confirmed that qualified nurses and nursing auxiliaries on primary nursing wards experienced more support from ward management compared to wards with team and functional nursing. Nursing auxiliaries experienced increased peer cohesion. Joiner et al. (1981) found significantly more feedback among registered nurses in wards with a primary nursing mode compared to wards with two other modalities namely team nursing and total patient care. However, Meichior et al. (1999) found no more feedback and support among primary nurses of the intervention group compared to the nurses of the control group. Only two studies had a pre-test post-test design (McPhail et al., 1990; Melchior et al., 1999).

Most studies investigated the concept responsibility. In eight out of nine studies an increase was found (cf. Emans \& Den Boer, 1988; Buchel \& Van Roestel, 1986; Molleman, 1989; Bekkers et al., 1990; MacGuire \& Botting, 1990; McCormack, 1992; Kivimäki et al., 1995; Webb \& Pontin, 1996). Only the study of Bekkers et al. (1990) used a pre-test post-test design with experimental and control groups. In the quasiexperimental study by Heeremans et al. (1994) no effects were found on responsibility.

\subsubsection{Psychological and behavioural reactions}

As a consequence of job enlargement and enrichment the implementation of residentoriented care models is expected to arouse positive psychological and behavioural reactions of nursing caregivers. In our study we focused on 'job satisfaction', 'work motivation', 'health complaints' and 'sickness absence'. Table 2.3 presents an overview. 
Table 2.3 Overview of the effects of patient-oriented care models on psychological and behavioural reactions

\begin{tabular}{|c|c|c|c|c|c|}
\hline Authors & Designs/nursing care models & $\begin{array}{l}\text { Job } \\
\text { satis- } \\
\text { faction } \\
\end{array}$ & $\begin{array}{l}\text { Work } \\
\text { motiva- } \\
\text { tion }\end{array}$ & $\begin{array}{l}\text { Health } \\
\text { com- } \\
\text { plaints }\end{array}$ & $\begin{array}{l}\text { Sickness } \\
\text { absence }\end{array}$ \\
\hline Marram et al. (1976) & $2 /$ primary nursing vs. team nursing & & & & - \\
\hline Marram et al. (1979) & $\begin{array}{l}\text { 1/functional and team nursing and case } \\
\text { method vs. primary nursing }\end{array}$ & + & & & \\
\hline Fairbanks (1980) & 1/primary nursing vs. team nursing & - & & & \\
\hline Giovannetti (1980) & 2/primary nursing vs. team nursing & - & & & \\
\hline Hegedus (1980) & $\begin{array}{l}2 / \text { primary nursing vs. team/functional } \\
\text { nursing }\end{array}$ & +10 & & & \\
\hline McGreevy \& Coates (1980) & $3 /$ primary nursing & + & & & \\
\hline Roberts (1980) & $2 /$ primary nursing vs. team nursing & $+/ 0 /-$ & & & 0 \\
\hline Steckel et al. (1980) & 2 primary nursing vs. other models & 0 & & & 0 \\
\hline Alexander et al. (1981) & $\begin{array}{l}2 / \text { primary nursing vs. other nursing } \\
\text { models }\end{array}$ & 0 & & & $0 /$ \\
\hline Betz (1981) & 1/primary nursing vs. tcam nursing & - & & & \\
\hline Bockholdt (1981) & $\begin{array}{l}\text { 1/patient-oriented team nursing vs. } \\
\text { functional nursing }\end{array}$ & - & & & $+1-a$ \\
\hline Carlsen \& Malley (1981) & $2 /$ primary nursing vs. team nursing & + & & & \\
\hline Chavasse (1981) & 4/primary nursing & + & & & \\
\hline Joiner et al. (1981) & $\begin{array}{l}2 / \text { team nursing vs. total patient care vs. } \\
\text { primary nursing }\end{array}$ & $0 /-$ & & & + \\
\hline Blair et al. (1982) & 1/primary nursing vs. another model & + & & & \\
\hline Parasuraman et al. (1982) & 5/primary nursing vs. team nursing & 0 & & & \\
\hline Sellick et al. (1983) & $2 /$ primary nursing vs. functional nursing & + & & & \\
\hline Chavigny \& Lewis (1984) & $2 /$ primary nursing vs. team nursing & 0 & & & + \\
\hline $\begin{array}{l}\text { Buchel \& Van Roestel } \\
\text { (1986) }\end{array}$ & $\begin{array}{l}2 / \text { integrated nursing vs. functional nurs- } \\
\text { ing }\end{array}$ & + & & & \\
\hline Metcalf (1986) & $1 /$ primary nursing vs. functional nursing & 0 & & & \\
\hline Athlin \& Norberg (1987) & 5/primary nursing & + & & & \\
\hline Blenkarn et al. (1988) & 3/primary nursing & + & & & \\
\hline Brock \& O'Sullivan (1988) & $\begin{array}{l}2 / \text { primary nursing vs. team/functional } \\
\text { nursing }\end{array}$ & + & & & \\
\hline Reed (1988) & $2 /$ primary nursing vs. team nursing & + & & & \\
\hline Wilson \& Dawson (1989) & $\begin{array}{l}1 \text { cross-over/primary nursing vs. team } \\
\text { nursing }\end{array}$ & 0 & & & 0 \\
\hline Bekkers et al. (1990) & $\begin{array}{l}\text { 1/patient-oriented nursing vs. functional } \\
\text { nursing }\end{array}$ & + & & & \\
\hline Kaban \& Thompson (1990) & 3/primary nursing & + & & & - \\
\hline McPhail et al. (1990) & $\begin{array}{l}1 \text { cross-over/primary nursing vs. team } \\
\text { nursing }\end{array}$ & & & & 0 \\
\hline Bond et al. (1991c) & $2 /$ primary nursing vs. team nursing & + & & & \\
\hline $\begin{array}{l}\text { Degerhammer \& Wade } \\
\text { (1991) }\end{array}$ & 4/primary nursing & + & & & \\
\hline McCormack (1992) & $5 /$ primary nursing & + & & & \\
\hline Furlong (1994) & 4/primary nursing & + & & & \\
\hline Heeremans et al. (1994) & $\begin{array}{l}\text { 1/integrated nursing vs. functional nurs- } \\
\text { ing }\end{array}$ & +10 & & 0 & 0 \\
\hline Vlerick \& Goeminne (1994) & $\begin{array}{l}2 / \text { patient-oriented nursing vs. functional } \\
\text { nursing }\end{array}$ & & & - & - \\
\hline Kivimäki et al. (1995) & $2 /$ primary nursing vs. functional nursing & +10 & + & & \\
\hline Manley et al. (1996) & 2/primary nursing vs. total patient care & +10 & & & \\
\hline
\end{tabular}

+ increased after the implementation l pre-test(s) post-test(s) with non equivalent groups

- decreased after the implementation 2 post-test(s) only with non equivalent groups

0 no differences

$+/-, 0$ some aspects improved, others $\quad 4$ one group post-test(s) only/ correlational

deteriorated or no difference 5 qualitative study / case study

a) No pre-test available 
An overview of the literature with respect to these four outcomes revealed that most studies investigated the effects on job satisfaction. An increase of job satisfaction after the implementation of a patient-oriented care model was found in seventeen out of thirty-one studies (cf. Marram et al., 1979; McGreevy and Coates, 1980; Carlsen \& Malley, 1981; Chavasse, 1981; Blair, Sparger, Walts \& Thompson, 1982; Sellick, Russell \& Beckmann, 1983; Buchel \& Van Roestel, 1986; Athlin \& Norberg, 1987; Blenkarn, d'Amico \& Virtue, 1988; Brock \& O'Sullivan, 1988; Reed, 1988; Bekkers et al., 1990; Kaban \& Thompson, 1990; Bond et al., 1991c; Degerhammer \& Wade, 1991; McCormack, 1992; Furlong, 1994). Only in three of these studies was a quasiexperimental design maintained (Marram et al., 1979; Blair et al., 1982; Bekkers et al., 1990). In ten studies no effects or contradictory effects were seen with five of them having a pre-test post-test design and control groups (cf. Fairbanks, 1980; Giovannetti, 1980; Steckel, Barnfather \& Owens, 1980; Alexander, Weisman \& Chase, 1981; Betz, 1981; Boekholdt, 1981; Parasuraman et al., 1982; Chavigny \& Lewis, 1984; Metcalf, 1986; Wilson \& Dawson, 1989). An increase combined with no change or even a decrease in job satisfaction was found by Hegedus (1980), Roberts (1980), Heeremans et al. (1994), Kivimäki et al. (1995) and Manley et al. (1996). Finally, Joiner et al. (1981) found no significant difference and less pay satisfaction on the primary nursing ward.

With respect to work motivation and health complaints only a few studies were found. An increase of work motivation was shown on wards with a patient-oriented care model compared to wards with a functional nursing model (Kivimäki et al., 1995). Only in the studies of Heeremans et al. (1994) and Vlerick \& Goeminne (1994) were effects on health complaints involved. Vlerick \& Goeminne (1994) found less health complaints on wards with patient-oriented care compared to wards with a functional mode. No change in health complaints was found in Heeremans et al.'s (1994) study after the implementation of integrated nursing on the experimental wards compared to the control wards.

Finally twelve studies were found on sickness absence. Sickness absence was measured differently, such as the number of hours reported (Marram et al., 1976) and duration and frequency of number of sick leave days (Boekholdt, 1981; Chavigny \& Lewis, 1984). In three studies a decrease was found in relation to a patient-oriented care model with none of them having a quasi-experimental design (Marram et al., 1976; Kaban \& Thompson, 1990; Vlerick \& Goeminne, 1994). Sickness absence was measured by Marram et al. (1976) as number of sickness hours. They found that units with team nursing reported more hours of sickness leave compared to units with primary nursing. This was confirmed by Kaban \& Thompson (1990) who found a decrease of sickness absence on wards with primary nursing. Vlerick \& Goeminne (1994) found a trend for less frequency of sickness absence on wards with a patientoriented care model compared to wards with a functional model $(p \leq 0.1)$. In the other studies, no change (Roberts, 1980; Steckel et al., 1980; Wilson \& Dawson, 1989; McPhail et al., 1990; Heeremans et al., 1994), mixed results (Alexander et al., 1981; Boekholdt, 1981) or an increase was found (Joiner et al., 1981; Chavigny \& Lewis, 1984). In four of these studies a quasi-experimental design was maintained (Boekholdt, 1981; Wilson \& Dawson, 1989; McPhail et al., 1990; Heeremans et al., 1994). 


\subsubsection{Conclusions}

It can be concluded that the implementation of patient-oriented care models is most evident with respect to patient assignment, responsibility and job satisfaction. However, the effects on the three job characteristics derived from the DCS model and on work motivation, health complaints and sickness absence are less investigated and more ambiguous. Possible explanations for the ambiguity seem to be related to the conceptualisation of 'patient-oriented care' and to the measurement methods (cf. MacDonald, 1988; Bekkers et al., 1990; Mead, 1990; Thomas \& Bond, 1991). First of all, unequivocal operationalisation of the design characteristics and of the concept patient-oriented care accordingly is lacking. A variety of elements are applied to the same concept. Next, a variety of measuring instruments is used, which makes interpretation of results rather difficult. In addition, of the forty-three studies presented here, only twelve studies appeared to have a (quasi-) experimental pre-test post-test control group design. Most studies are based on quantitative data. Qualitative data in combination with quantitative results is less evident. However, qualitative data can be supportive to illustrate, understand and interpret relationships found in quantitative data (cf. Polit \& Hungler, 1999). Finally, the majority is based on self-report questionnaires. Some studies use interviews or document analysis. As a consequence, the majority of the results is based on perceptions of respondents themselves and not on more objective methods such as observations. Triangulation is an important strategy to increase the validity and reliability of the data (cf. Polit \& Hungler, 1999). This can be achieved by using different data sources (data triangulation) or different data collection methods such as observations, interviews and questionnaires (method triangulation) (cf. Polit \& Hungler, 1999).

\subsection{Summary and conclusions}

The work of nursing caregivers can be characterised by high job demands and difficulties in job control. Problems seem to be inherent both to the nursing job itself and to more conditional factors. The literature highlights the negative impact of low job control in combination with high job demands on well-being and health of nursing caregivers. Job redesign interventions aimed at improving job control seem to be of major importance to counter-balance the negative impact of high job demands. Theoretical models such as the JCM and the JDC and DCS models as well as practical guidelines from the STS approach have proven to be important in generating knowledge with regard to the impact of job redesign interventions aimed at job enrichment. In nursing, patient-oriented care models are examples of job enrichment interventions. The main design characteristics are patient-assignment, use of the nursing process, increased amount of tasks and improved communication. In general the implementation of patient-oriented care models is aimed at improving the nursing caregiver's job characteristics and as a result at improving psychological and behavioural reactions. The concepts job autonomy, job demands and social support used in the DCS model of Johnson \& Hall (1988) can be considered important job characteristics influencing wellbeing and health. Responsibility is a main job characteristic of patient-oriented care models. Therefore, these four job characteristics seem to be appropriate for evaluating 
job enrichment in nursing in general and for the implementation of resident-oriented care models in nursing homes in particular. Job satisfaction, work motivation, health complaints and sickness absence can be considered as important psychological and behavioural reactions directly associated with the central job characteristics of the DCS model and to other models such as Hackman \& Oldham's JCM and Warr's vitamins model. Therefore, as outcomes of job enrichment these four reactions seem to be most suited for evaluating the nursing caregiver's reactions on the implementation of resident-oriented care models in nursing homes. It can be concluded that in evaluation studies on this theme the results are most evident with respect to patient assignment, responsibility and job satisfaction. The results with regard to the three job characteristics derived from the DCS model and to work motivation, health complaints and sickness absence are less investigated and more ambiguous. Conceptual as well as methodological problems seem to be underlying factors. Besides a sound theoretical framework it can be concluded that in evaluating the effects of resident-oriented care models in nursing homes a sound methodological design is needed. Use of a pre-test post-test design with a control group, a homogeneous study population concerning various confounders but heterogeneous with regard to the design characteristics and use of method and data triangulation seem to be of major importance in this respect. 


\section{THEORETICAL BACKGROUND OF ORGANISATIONAL CHANGE}

\subsection{Introduction}

Chapter two was focused on job redesign in general and on job redesign in nursing in particular. In this respect the more technical part of job redesign or the 'what' was stressed, namely the mechanisms of job redesign, its underlying concepts and some empirical evidence. However, advocates of the work redesign tradition such as Hackman and colleagues, Karasek and colleagues as well as STS researchers point out the importance of the change process itself (e.g. Hackman \& Oldham, 1980; Trist, 1981; Karasek, 1992; Kuipers \& Van Eijnatten, 1996). Therefore, in this chapter the process of change, that is the social part of change or the 'how' of job redesign and its conditions, will be discussed.

The importance of a change process was well described in the studies of Menzies (1960), Allegro \& Kanters (1975), Frank \& Hackman (1975) and Landsbergis \& Vivona-Vaughan (1995). Menzies (1960) found that resistance to an implementation of integrated ward teams could be traced back to lack of support of the organisational context and in particular the professional and social culture (Trist, 1981). Allegro \& Kanters (1975) concluded that job enrichment in itself appeared to be not sufficient enough but that the process of change was an important factor in its success. In this respect the change process has to incorporate a non-technical approach of job redesign, meaning that the change agent had to act as a coach instead of an expert and that individual employees or work groups had to participate in the redesign of their jobs (Allegro \& Kanters, 1975). Frank \& Hackman (1975) ascribed the failure of a job enrichment project to incongruity between theory and kind of change, absence of a prior diagnosis of target jobs and the surrounding systems, absence of contingency plans to handle problems that appeared, and lack of evaluation and revision of action plans during the project. From an occupational stress intervention project Landsbergis \& Vivona-Vaughan (1995) stressed the following obstacles for an effective intervention strategy: a department-wide instead of an agency-wide focus, the negative impact of a major agency-wide reorganisation and lack of formal management commitment.

From the previous it can be concluded that the implementation itself, i.e. the process, can be determining for its success. Therefore, to get some insight into factors of organisational change in this chapter, some definitions are presented and some strategies, models and approaches for organisational change are described (3.2). Next, underlying behavioural and motivational theories of change strategies are discussed (3.3). In applying these strategies and theories on job redesign in nursing some conditions for successful change are highlighted (3.4). Finally, in line with these conditions, a diagnostic model and its concepts are discussed and elaborated (3.5). This chapter closes with a summary and conclusions (3.6). 


\subsection{Organisational change}

\subsubsection{Introduction}

A job redesign intervention deliberately planned can only be achieved through a process of organisational change. In this section some definitions of organisational change are presented and some important strategies and models are described.

\subsubsection{Planned change}

In the literature organisational change is often used synonymously with planned change or organisational development (OD) (Burke, 1982; Cummings \& Huse, 1989; Cozijnsen \& Vrakking, 1995; Van der Vlist, 1997). There is no clear distinction between the two terms (Cozijnsen \& Vrakking, 1995; Van der Vlist, 1997). Planned change is the longest lasting tradition. Important representatives have been Lewin (1951), Lippitt, Watson \& Westley (1958), French (1969) and Bennis, Benne \& Chin (1973). Planned change can be broadly defined as '...processes of deliberately changing which meet criteria, already noted, such as the use of valid knowledge and the cultivation of collaborative relationships between the change agent and the client system...' (Bennis et al., 1973, pp. 61). According to Cozijnsen \& Vrakking (1995), planned change is methodical, uses social intervention techniques and establishes a relationship between the change agent and the client system. Van der Vlist (1997) relates planned change to a task-structural approach of change. This approach focuses on changes in task and organisational structures influencing behaviour of individual employees and their work relations. Means are expert knowledge and, in a later stage, participation. According to Van der Vlist (1997), planned change has a clear goal, but is less clear concerning the change process itself. In contrast, in OD the outcome is often not clear in advance, but explicit use is made of intervention methods such as participative leadership style, teamwork and equality in power (Cozijnsen \& Vrakking, 1995; Van der Vlist, 1997). An OD intervention often starts with a group dynamic process and achieves changes by means of the client system, which can be structural (Van der Vlist, 1997). Burke (1982, pp. 10) defines OD as '.... planned process of change in an organisation's culture through the utilisation of behavioural science technology, research and theory...' '. In line with this definition, Van der Vlist (1997) relates OD to the process approach which is focused on a change in the opinions, attitudes and behaviour of employees on the one hand and on organisational processes such as communication, decision making and problem solving on the other (Van der Vlist, 1997). Recent developments show that OD no longer has a dominant but rather a supportive role in organisational change integrating the process OD approach and the task-structural approach (Van der Vlist, 1997). In this process the STS approach and its principles has had a major impact on the development of planned change and OD (Landsbergis \& Vivona-Vaughan, 1995). These principles refer to: change directed to the organisation as a total system, individual change as well as work group change, participative versus top-down change; change based on theoretical models as well as tailored change based on models developed in practice; and use of behavioural and motivational theories (Bennis et al., 1973; Gardell, 1977; Hackman \& Oldham, 1980; 
Burke, 1982; Cummings \& Huse, 1989). There are a number of change strategies (cf. Chin \& Benne, 1973; Burke, 1982; Cummings \& Huse, 1989; Cozijnsen \& Vrakking, 1995; Van der Vlist, 1997). An often-cited typology of strategies of planned change is that of Chin \& Benne (1973). This typology gives a broad insight into the underlying perspectives of strategies used by change agents but in reality is often applied in different ways (Van der Vlist, 1997). Therefore, before some change models and approaches will be discussed, this typology is presented.

\subsubsection{Chin \& Benne's typology of strategies of planned change}

In trying to distinguish some general strategies for planned change, Chin \& Benne (1973) developed a typology of strategies, namely empirical-rational, power-coercive and normative-re-educative strategies (cf. Chin \& Benne, 1973; Benne \& Chin, 1986).

According to advocates of the planned change tradition such as that of the STS approach, the normative-re-educative strategy has to be preferred (Boekholdt, 1981; Boekholdt 1983a and b; Van Zonneveld, 1993; Cozijnsen \& Vrakking, 1995). The empirical-rational and normative-re-educative strategies both emphasise the importance of interpersonal relationships and social contexts within the communication process (Chin \& Benne, 1973). However, unlike the empirical-rational strategies, in the normative-re-educative strategies besides rational factors, non-rational factors, such as socio-cultural norms and the involvement with these norms are important in changing behaviour. Therefore, a change in behaviour will only be achieved by changing the attitudes, values and habits (Benne \& Chin, 1986; Van Zonneveld, 1993). According to Lewin (1951), representing this strategy, one-way information to a client is considered as insufficient to achieve change. Instead, re-education is an important medium because it concerns change of norms as well as a change of cognition, perception and skills. Moreover, change can only be achieved when clients participate in their personal re-education because the way in which a client considers himself has to be involved (Lewin, 1951; Chin \& Benne, 1973; Benne \& Chin, 1986). The involvement of individuals in the design of change, an exchange relationship with the change agent, the possibility to experiment and experienced-based learning by means of development and mutual adjustment are important instruments in this strategy (Boekholdt, 1983a). Chin \& Benne (1973) developed two variants, the problem solving and the growth model. Both are using temporary work groups, emphasising the concept of experienced-based learning and focusing on change stemming from the inside of the system. According to the first model, the problem-solving capabilities of a system (organisation or work group) have to be improved by stimulating the cognitive capacities. In the growth model growth and creativity of individuals is fostered by means of personal counselling and training and stimulation of verbal and non-verbal communication.

For a complex and far-reaching change such as the implementation of a patientoriented nursing care model empirical-rational and power-coercive strategies are less suitable (Boekholdt, 1981, 1983a). Empirical-rational strategies assume the rationality of human beings and give priority to their rational and individual self-interest if they have enough insight into their position. Informing individuals about the proposal for 
change and of the individual benefits and education to disseminate knowledge is an important instrument (Benne \& Chin, 1986). Boekholdt (1983a and b) argues that in nursing the empirical-rational strategy is most suitable in the case of clear and less complex changes such as administrative procedures or change of instrumentaltechnical activities. Power-coercive strategies may be considered as the hardest strategies to achieve change. It is assumed that in applying power or sanctions, human behaviour will change (Benne \& Chin, 1986). Compared to the empirical-rational strategies, knowledge is the central focus but the means are different. Conflict and negotiation strategies and legitimate power is used for effecting change (Cozijnsen \& Vrakking, 1995). According to Boekholdt (1983a and b), power-coercive strategies fit best to crisis situations. However, resistance is to be expected if rational argumentation and persuasion or power is the only mean used to achieve change (Boekholdt, 1983a). In the case of the implementation of a patient-oriented care model, Boekholdt (1983a) prefers the use of the normative-re-educative strategy for two reasons. Change to a patient-oriented care model affects not only work methods but values, norms and behaviours as well. In addition, core principles of patient-oriented care models are individual responsibility, professionalism and independence. So, to achieve a long lasting change strategies have to be congruent with the nature of the change to be able to foster it (Boekholdt, 1983a).

In literature different models of planned change are described which gives insight into the methodical aspects. As described below, Lewin (1951) has been important for the development of a variety of planned change models such as the Action Research (AR) model (Van Zonneveld, 1993; Cozijnsen \& Vrakking, 1995; Van der Vlist, 1997).

\subsubsection{Models of planned change}

According to Lewin (1951), organisational behaviour is the result of a balance between dynamic forces, pushing for change, and restraining forces, striving to maintain the status quo. A so-called state of 'quasi-stationary equilibrium' is reached when both sets of forces are in balance and current levels of behaviour are maintained. Change, as a modification of those forces that keep a system's behaviour stable, is achieved by increasing those forces pushing for change or by decreasing those forces striving to maintain the status quo or by a combination of both (Cummings \& Huse, 1989). What is called the unfreezing process is necessary to achieve a moving to the change whereas a refreezing process has to guarantee maintenance of a certain level of performance (Cozijnsen \& Vrakking, 1995). Lewin (1951) argues that modifying those forces maintaining the status quo gives less resistance than increasing those forces pushing for change. Therefore, he considers the first strategy as more effective for change. Lewin's (1951) three-step planned change model of unfreezing, moving and refreezing was the basis for the development of the Action Research model (AR) (e.g. French, 1969; Schein, 1980).

According to most OD authors, AR has the best fit to OD in having its own research method (Burke, 1982; Shani \& Bushe, 1987; Cummings \& Huse, 1989). Lewin, often seen as the founder of this approach, advocated a strategy for studying and simultane- 
ously changing (or developing) systems (Shani \& Bushe, 1987). Shani \& Bushe (1987) define AR as an inquiry process in which behavioural and social science knowledge is integrated with existing organisational knowledge to generate new knowledge that is generalisable and usable. In fact it is a variety of joint activities of research, action and development between the client system and the change agent at different stages of the change process (Shani \& Bushe, 1987; Cummings \& Huse, 1989; Landsbergis \& Vivona-Vaughan, 1995). AR uses groups and views every interaction between the change agent and the client as an intervention that may affect the organisation (Cummings \& Huse, 1989). Within AR, specific on-site interventions are developed by outside experts in collaboration with management thereby emphasising both sound diagnosis based on research and intervention objectives (Cummings \& Huse, 1989; Landsbergis \& Vivona-Vaughan, 1995). Originally, AR was aimed at assessing results for both continued on-site diagnosis and action planning as well as for generating new knowledge to be used elsewhere by means of case studies (French, 1969; Cummings \& Huse, 1989). Later adaptations of OD approaches place major emphasis on planned change (Frohman, Sashkin \& Kavanagh, 1976; Burke, 1982; Cummings \& Huse, 1989). The AR model is a cyclical and iterative process of research and action involving eight overlapping and interacting phases. Problem identification (Lewin's unfreezing), data gathering and joint diagnosis is stressed prior to the phases of joint action planning, action and data gathering and assessment to evaluate the results (Lewin's refreezing) (Cummings \& Huse, 1989). In the expert-dominated approach of AR the role of the change agent was primarily focused on collecting, interpretation and feedback of data, whereas the researcher was responsible for studying the effects of the intervention (Van Zonneveld, 1993; Van der Vlist, 1997). Interpretation of the results was the job of the researcher or of both the researcher and the change agent (Van der Vlist, 1997). Later on, a more participatory approach of AR was developed (PAR). In PAR the roles of the researchers, change agent and organisational members are integrated and their equality is stressed in all phases of the intervention and research process (De Jonge, 1995; Landsbergis \& Vivona-Vaughan, 1995; Van der Vlist, 1997). A review by Karasek (1992) concerning occupational stress revealed that interventions in this respect using PAR showed more positive outcomes.

\subsubsection{Approaches to change}

To implement an organisational change effectively there are different approaches for structuring change and motivating social systems accordingly (Chin, 1973; Van der Vlist, 1997). In the planned change tradition three approaches are distinguished, the system approach, the developmental approach and the intersystem approach (Chin, 1973; Boekholdt, 1981; Cozijnsen \& Vrakking, 1995; Van der Vlist, 1997). The approaches vary in their orientation on organisational systems or on the change process itself and can vary in the degree of participation and in the involvement of the change agent (Chin, 1973; Boekholdt, 1981; Van der Vlist, 1997).

The system approach is based on STS principles and emphasises organisational redesign (Chin, 1973; Boekholdt, 1981; Van der Vlist, 1997). In this approach change is focused on adjustment and initiated and controlled by the organisational top (Chin, 
1973; Van der Vlist, 1997). Intervention goals (mostly STS work designs) are predetermined with less freedom to fill in the change strategy and therefore less participation (Van der Vlist, 1997). The change agent is viewed as an external expert focused on organisational redesign (Chin, 1973; Boekholdt, 1981; Van der Vlist, 1997). As participation is seen as problematic, the change agent uses mainly empirical-rational or power-coercive strategies (Van der Vlist, 1997). The system approach is most suitable when urgent action is needed as in crises or when the change is complex and farreaching as in reorganisations (Van der Vlist, 1997). The approach can be related to the diffusion/adoption perspective, which stresses adaptation of primarily technical blueprint innovations into practice by means of persuasion, information and education by the change agent (Cozijnsen \& Vrakking, 1995). According to Van der Vlist (1997), the system approach is incongruent with modern STS principles of participative decision making. Due to redesign complexity changes have to be developed by external leading to resistance against their imposed character (Van der Vlist, 1997).

The developmental approach assumes constant change of a system over time (Chin, 1973). Unlike the system approach, this approach views the organisation as a resource of change potential with knowledge and experience instead of shortcomings (Van der Vlist, 1997). Change is viewed as natural and unique because the actual situation of the organisation itself is the starting point (Chin, 1973; Van der Vlist, 1997). Therefore, in line with the normative-re-educative approach as discussed in 3.2.3, participation has a natural position (Van der Vlist, 1997). Intervention goals are the removal of barriers performed by an external change agent (Chin, 1973). So, the approach is also related to the empirical-rational strategy, in which the change agent, as in the system approach, has an expert role. Unlike the first approach, though, the developmental approach is problem-oriented and thus takes more time for change while its changes are hard to analyse (Boekholdt, 1981). According to Van der Vlist (1997), the approach is suitable in organisations that are functioning moderately, where crises are absent, and where there is sufficient trust in management. However, changes are often less fundamental and take a long time especially in the initial phase (Van der Vlist, 1997).

For the implementation of a patient-oriented care model, the intersystem approach seems to be most suited (Boekholdt, 1981, 1983a and b; Van Zonneveld, 1993). In the intersystem approach both approaches are combined in that the interdependence of organisational systems as well as the change potential is emphasised (Chin, 1973). Change is predetermined, but largely viewed as a rational choice induced and controlled by the client system itself or by the change agent. The change agent is part of the actual situation and, as a facilitator, helps the client system by improving his intervention goal (Chin, 1973). Unlike the system approach, this approach is more oriented on relational issues and therefore more applicable to process problems such as leadership and communication (Chin, 1973). Like the second approach, the model is dynamic because it is focused on the change potential of the system itself (Chin, 1973; Boekholdt, 1981). Unlike the two other approaches and in line with principles of the normative-re-educative strategy, the intersystem approach considers both the change agent and the client system as autonomous and interdependent participants in a collaborative change process characterised by development and mutual adjustment (Chin, 
1973; Boekholdt, 1981). Van Zonneveld (1993) argues that the implementation of a patient-oriented care model is a process innovation in which a blueprint is lacking because of the unique organisation-related translation, which needs a participative approach. In this respect Van Zonneveld (1993) relates this approach to the so-called implementation perspective, where a blueprint innovation is custom-made in adjusting and embedding it in the unique situation of the organisation (Van Zonneveld, 1993; Cozijnsen \& Vrakking, 1995).

Affecting human behaviour is an important instrument in change strategies (Cummings \& Huse, 1989; Cozijnsen \& Vrakking, 1995). Resistance, fear and disturbed interpersonal communication can result from trying to change individual or group behaviour and with this underlying norms and values (Cozijnsen \& Vrakking, 1995). Therefore, in the following section some important behavioural and motivational theories are discussed.

\subsection{Behavioural and motivational theories}

Organisational change concerns interventions within and between groups of individuals and is based on their acceptance (Van Zonneveld, 1993). Van Zonneveld (1993) points out that despite many guidelines there is a lack of clarity about which intervention has to be chosen for which situation. In short, there is no umbrella theory of organisational change (Burke, 1982; Cummings \& Huse, 1989). However, from the foregoing strategies it can be concluded that change is based on influencing individuals, work groups or total systems and therefore grounded in behavioural sciences such as psychology and sociology (Boekholdt, 1981; Burke, 1982; Cozijnsen \& Vrakking, 1986; Cummings \& Huse, 1989; Kapteyn, 1996). Looking at the normative-reeducative strategy in particular, it can be argued this has been based on Maslow's need-theory, McGregor's theories X and Y and Argyris's theory focussing on reeducation in processes of OD. To understand certain aspects of organisational behaviour these theories are discussed thereby using the three-level classification of Burke (1982), that is individual, group and organisational level.

\section{Theories on individual level}

In chapter 2 we already explained job-related motivation from the individual perspective. The need theory of Maslow (1954), the satisfaction-motivation theory of Herzberg (Herzberg et al., 1959) and the goal-oriented expectancy theory of Vroom (1964) are important motivational theories in this respect (Burke, 1982; Thierry, 1997). Maslow (1954) explains human motivation in terms of individuals' experienced needs and thus from internal factors. It is assumed that individuals first try to fulfil their lower order needs before trying to fulfil higher order needs. Therefore, motivation is determined by the lowest unsatisfied need. Partly in line with Maslow (1954), Herzberg's theory deals with two motivational factors, those providing satisfaction in meeting the higher order needs, so-called intrinsic work factors, satisfiers or motivators, and those preventing dissatisfaction in meeting the lower order needs, so-called extrinsic work factors, dissatisfiers or hygiene factors (Herzberg et al., 1959). Unlike Maslow, Herzberg's theory is more related to satisfaction (Burke, 1982; Thierry, 
1997). The expectancy theory of Vroom (1964) is, in contrast with the theories of Maslow and Herzberg, more focused on external sources of motivation (Burke, 1982). It is postulated that motivation is dependent on the value of certain rewards given by individuals and their expectancy that their efforts will lead to the obtainment of this reward $(\mathrm{E} \times \mathrm{V})$. If one of the two factors is absent, no motivation will result (Burke, 1982).

\section{Theories on group level}

Burke (1982) argues that in changing individual behaviour or attitude without accordingly changing the group this individual belongs to, he will probably come under pressure to get back into line. In emphasising change of interpersonal and group competence by means of training and education, Argyris's theory has been important (Argyris, 1971; Argyris \& Schon, 1978). In line with McGregor's (1960) theory X and Y, Argyris (1971) distinguishes two organisational value systems, that is a bureaucratic/ pyramidal value system oriented on rationality, authority, punishment/reward (theory $\mathrm{X}$ ) and a humanistic/democratic value system emphasising interpersonal relationships and commitment (theory Y). Argyris (1971) argues that as the first value system is dominant in most organisations, it causes a lot of problems, whereas a humanistic/ democratic approach would lead to a grown-up relationship with employees and thus to more effectiveness. Later on, a distinction was made between pattern $\mathrm{A}$ and $\mathrm{B}$ behaviour (Argyris \& Schon, 1978; Burke, 1982). Pattern A behaviour, based on theory $\mathrm{X}$, concerns incompetent behaviour and is characterised as intellectual, conforming, individually oriented, involving closed communications, and mistrusting. As the opposite, pattern B behaviour, based on theory Y, concerns interpersonal competent behaviour and is viewed as emotional, experimenting, group-oriented, with open communications, and trusting. Pattern B behaviour, considered as the most effective in realising change, has to be stimulated by means of training and re-education. More recently, in trying to increase human effectiveness problem solving has developed as an instrument for change (Burke, 1982). These theories are valuable in that awareness can be developed of the group behaviour most desired and to be influenced which can make interventions more effective.

\section{Theories on organisational level}

Change oriented to the whole organisational system is discussed by theorists such as Lawrence and Lorsch (1967) and Likert (1967). In their contingency theory Lawrence and Lorsch (1967) postulate that change has to be contingent with the organisational environment. According to them, there is no best organisational structure and no best way of management. The more complex and turbulent an environment, the more an organisation structure should be differentiated to monitor the changes and decentralised to make decisions on the spot (Lawrence and Lorsch, 1967). One of Likert's (1961, 1967) theoretical values refers to his advocacy of participative management. In assessing seven management functions Likert (1967) described four management models from autocratic to participative. Participative management reflects, in line with Argyris's pattern B behaviour, participative leadership, motivation based on Maslow's principles, an open and two-way communication, co-operative and trusting, interpersonal relations, group decision making, mutually established goals and decentralised control (Likert, 1967; Burke, 1982). 


\subsection{Conditions for organisational change}

\subsubsection{Introduction}

The literature reveals a variety of reasons for failing interventions such as top-down technical solutions, lack of long-term support of top management, inability to delegate authority, passive instead of active involvement of employees or lack of supervisor support (Hackman \& Oldham, 1980; Karasek, 1992). Karasek (1992) concluded in a summary of 19 international case studies on stress prevention that the success of work redesign programmes appeared to be often related to workers' participation. To create self-sustaining work redesign programmes work groups have to be established to foster worker involvement. Additionally, broad institutional support is necessary, expressed in sufficient economic and technical resources (Karasek, 1992). The literature is unclear about which intervention is best (Van Zonneveld, 1993). In general, most guidelines concern the role of the change agent and the participation of employees. Cummings \& Huse (1989) give some reasons for this lack of clarity. In the first place, an organisational change programme is mostly evaluated as a whole and not with regard to the effects of the different interventions separately. In the second place, in most cases interventions are developed while empirical knowledge of their effects is lacking (Cummings \& Huse, 1989). For this reason a prescriptive approach for successful change is often criticised (e.g. Koopman \& Pool, 1986; Wissema, Messer \& Wijers, 1991; Van Zonneveld, 1993). The STS approach has been of major importance in developing general guidelines with respect to the social processes of work redesign (e.g. Hackman \& Oldham, 1980). To get some insight into conditions for successful change, it is therefore important to consider the STS guidelines as discussed in chapter 2 and the theoretical background as discussed in 3.2 and 3.3 .

\subsubsection{Successful organisational change}

The most important STS guidelines refer to the degree and level of participation. These concern the involvement of members of various organisational levels, use of semi-autonomous work groups and the principles of self-regulation and participative decision making. An ideal is to develop local STS outcomes that maximally accommodate the 'tacit knowledge' of the employees involved (Trist, 1981; Kuipers \& Van Eijnatten, 1996; De Sitter et al., 1997; Van Eijnatten \& Van der Zwaan, 1998). The guidelines concerning participation can be explained from the previously discussed behavioural and motivational theories. The need theory of Maslow (1954) and the expectancy theory of Vroom (1964) postulate that an individual is only motivated and thus willing to change if there is an unfulfilled need, if the change leads to some valued reward and if the individual believes that his efforts will lead to this reward. Therefore, according to the normative-re-educative strategy, the behaviour of individuals, including their attitudes, motives and values, has to be the central focus of change. To achieve this, a client has to be involved in the change process itself because the way he views himself has to be involved. In this respect, the intersystem approach as well as PAR offer opportunities in that the change agent and the client system are both participants in the change process. In order to achieve effective change a 
grown-up interpersonal relationship between the individual and the work group is also stressed in Argyris's humanistic/democratic approach (Argyris, 1971). Therefore an individual has to be viewed as committing, authentic and looking for interpersonal relationships or has to be stimulated to act in this way. Finally, advocating participation on organisational level Likert's (1967) idea of participative management fosters effective organisational behaviour while Lawrence and Lorsch (1967) emphasise decentralised decision making in dealing effectively with a complex and turbulent environment. Especially in case of a far-reaching change affecting individual's behaviour participation is a necessity. So, it may be concluded that the degree and level of participation are important conditions for a successful change.

According to the STS approach, there has to be congruence between the nature of change and its process. In line with the contingency theory of Lawrence \& Lorsch (1967), Chin (1973) points out that the choice for a certain approach has to be dependent on assumptions about how events and people can achieve change. In case of urgency and crises in which participation can impede the progress, a system approach offers better opportunities with the change agent in the role of an external expert (Chin, 1973). An intersystem approach offers more opportunities if more complex and far-reaching changes are the goal with regard to human behaviour. In this approach the change agent is an internal facilitator and due to their autonomy and interdependence the change agent and the client system, as in PAR, equally take part in the change process (Chin, 1973). In this respect STS advocates a balanced choice between a directive system approach and a non-directive developmental approach. So, leadership style and role of supervisors and change agents have to be considered in relation to the nature of change. In the case of an increase in job-related autonomy and control, supervisors have to be facilitators, trainers and forward-planners instead of exerting authority, while change agents have to be co-learners instead of experts (Trist, 1981; Kuipers \& Van Eijnatten, 1996; De Sitter et al., 1997; Van Eijnatten \& Van der Zwaan, 1998). So, an appropriate implementation approach can be considered as a condition for a successful change to achieve congruency between the implementation and the nature of change. Therefore, the role of the change agent and supervisors has to be appropriate. Furthermore, the implementation strategy has to be effective and finally, in supporting the implementation strategy and structure, there have to be effective control systems.

In line with the discussion above, in a broader perspective an implementation approach (i.e. top-down or bottom-up) has to be congruent with the culture and the systems of the organisation itself. The degrees of freedom for change are largely determined by the technical and organisational structures and processes in which tasks and roles are embedded (De Sitter et al., 1997). The importance of congruency is stressed by the contingency theory of Lawrence \& Lorsch (1967) in postulating that change has to be contingent with the organisational environment. In achieving this congruency an effective implementation has to be chosen.

According to the STS, a balanced choice between a directive design approach and a non-directive developmental approach means an educational programme. Therefore, 
basic knowledge of methods of analyses, design principles and strategies has to be transferred to organisation members themselves to achieve successful work redesign. Problem solving, learning by doing, and training-on-the-job are seen as instruments (Trist, 1981; Karasek, 1992; Kuipers \& Van Eijnatten, 1996; De Sitter et al., 1997; Van Eijnatten \& Van der Zwaan, 1998). Lewin (1951) and Argyris \& Schon (1978) are strong advocates of training and education to improve individual, interpersonal and group competence in achieving effective change. Individuals have to be stimulated to experiment in trying new behaviour and seeking to learn from these attempts. In line with this the normative-re-educative strategy stresses an increase of problem solving capacities by training supervisors and change agents and by releasing and fostering growth in individuals themselves. So, appropriate skills and capacities of people directly involved and means to increase these have to be considered as important in achieving a successful change.

In conclusion, from the STS principles and the theories as discussed in 3.2 and 3.3 some concrete conditions for successful change can be derived (cf. Chin \& Benne, 1973; Hackman \& Oldham, 1980; Boekholdt, 1981; Trist, 1981; Karasek, 1992; Van Zonneveld, 1993; Kuipers \& Van Eijnatten, 1996; De Sitter et al., 1997; Van Eijnatten $\&$ Van der Zwaan, 1998). Without the pretension of being complete, these conditions seem to be related to the:

- Implementation structure;

- Implementation strategy;

- Control systems;

- Motivation of people directly affected by the implementation;

- Skills and capacities of people directly involved and means to increase these;

- Role of the change agent and the supervisors;

- Implementation approach.

In the following subsections these conditions will be further elaborated.

\subsubsection{Implementation structure}

The structure of the implementation is an important factor for success because it determines the level of participation of those directly affected by the change (Boekholdt, 1981; Burke, 1982; Wijnen, Renes \& Storm, 1988; Van Zonneveld, 1993). This means a choice between a structure within or outside the formal decision making structure such as a temporary project structure (Wijnen et al., 1988; Kapteyn, 1996). In a temporary project structure the formal organisation can delegate authorities to the project organisation at different stages of the implementation (Wijnen et al., 1988). Kapteyn (1996) argues that in this way possibilities are offered to realise an effective form of participation without far-reaching consequences for the formal decision making structure. To guarantee enough support, Boekholdt (1983b) notes that different organisational levels have to be involved including the top management level. According to Wijnen et al. (1988), the choice of the structure depends on the type of change and the organisation culture and policy. In this respect, they emphasise the risk of over- 
formalisation and bureaucratisation. Reasons to establish a project structure are lack of experience with the type of change, intense co-operation between different departments, achievement of a unique result with restricted means (Wijnen et al., 1988; Kapteyn, 1996). If an organisation does not often deal with large scale and complex projects and the change impacts on both the work process and organisational structure, Wijnen et al. (1988) advise a participative decision making project structure. In this case the project management, represented by a steering group and work groups, is responsible for the co-ordination and evaluation of the project. The formal organisation is responsible for the initiation, performance and the total control including the budget and action planning (Wijnen et al., 1988). A participative decision making structure is often used at the implementation of a patient-oriented care model (Boekholdt, 1981; 1983a and b; Molleman, 1989; Van Zonneveld, 1993). In Van Zonneveld's (1993) study, it appeared that a majority of the hospitals had a project organisation to implement a patient-oriented care model. However, no significant correlation was found between the presence of a project organisation and the success of the project. It appeared that in some hospitals the project organisation was only known among those who were actively involved (Van Zonneveld, 1993).

So, the degree of participation is supported with the appropriate level of participation expressed in the implementation structure such as the presence of work groups on project and ward level.

\subsubsection{Implementation strategy}

A clear implementation strategy is essential in a change process. According to Boekholdt (1981) a clear strategy can positively influence the maintenance and embedding of the change. In describing a number of successful implementation strategies Cozijnsen \& Hoksbergen (1986) and Vrakking (1986) mention a step-by-step approach and the supply of a rapid performance of each step. Other important factors are clear goals, a realistic action plan, avoidance of distracting factors and sufficient organisational support expressed in financial and personnel means (Burke, 1982; Aird \& Sale, 1990; Van Zonneveld, 1993). Cozijnsen \& Vrakking (1986) distinguish three major phases in a change strategy: an innovation phase comprising a research and a development phase; an initiating phase comprising a diffusion and an adoption phase; and an implementation phase comprising an implementation and an incorporation phase. The authors mention that compared to the first two phases, the last phase is less extensively described in literature although the last phase is important in stressing the innovation to be user-friendly and applicable (Cozijnsen \& Vrakking, 1986). In this respect Kapteyn (1996) distinguishes two approaches often used in policy making, a synoptic approach and an incremental approach. In a synoptic approach the implementation takes place at one moment whereas the incremental approach concerns a stepwise implementation. In a combination of the two approaches top management determines the outlines of the change, which are elaborated into concrete steps by the lower management. For a synoptic approach it is necessary to have a comprehensive overview of all relevant aspects. In practice this is often difficult to realise. In contrast, an incremental or stepwise implementation has the advantage in that the implementation will be more 
controllable and people get time to get used to the different steps. In studies of Bekkers (1993) and Van Zonneveld (1993) it appeared that a stepwise approach was used most during the implementation of a patient-oriented care model but that there was ambiguity with respect to the content and order of the different steps.

Another important success factor is the length of the total implementation and the tempo in which each phase is started (Burke, 1982; Cozijnsen \& Hoksbergen, 1986; Van Zonneveld, 1993). Van Zonneveld (1993) argues that a patient-oriented care model can be best implemented stepwise but at a fast tempo to realise an early success. For that he advises starting each new step within a period of two months (Van Zonneveld, 1993). It appeared from his study that projects differed in the speed of implementation. Most projects overran their action plan due to distractions such as little preparation time, resistance, personnel changes, little coaching and the complexity of some steps such as implementing the use of the nursing process. In his study the total project time varied form 1 to 8 years. A longer project time appeared in hospitals with a more successful change (Van Zonneveld, 1993). Furthermore, enough organisational support expressed in sufficient financial and personnel means appeared to be a success factor (Van Zonneveld, 1993). He concluded that if no means are reserved, the chance of success is limited. Extra means concerned availability of staff personnel to support the implementation and extra nursing staff in the early implementation stages to support the work process and to avoid disturbances mentioned above. However, there was an absence of clarity regarding the optimal investment. Finally it was concluded that, although extra personnel was necessary for the implementation, a patient-oriented model was not more labour-intensive (Van Zonneveld, 1993).

So, the implementation strategy has to be effective expressed in an incremental or synoptic implementation approach, realistic action plan, time period, avoidance of distracting factors, stability of supervisors and organisational support such as financial and personnel means.

\subsubsection{Control systems}

To control change processes effective communication, information and evaluation are essential to create clarity and foster acceptance (Wijnen et al., 1988; Cummings \& Huse, 1989; Van Zonneveld, 1993; Cozijnsen \& Vrakking, 1995). According to Van Zonneveld (1993), information has to be focused on implementation goals, planning, demands and results. Effective information and communication are dependent on individual perception, selection and judgement (Cummings \& Huse, 1989; Kapteyn, 1996). Therefore, Cummings \& Huse (1989) make a distinction between the overt level, what is actually said and the covert or hidden level. To achieve more transparency in this respect, Kapteyn (1996) stresses the importance of people in key positions who can perform a signal function and can relate information from various sources. In his study Van Zonneveld (1993) found a positive correlation between the quality of information and the success of the implementation. Furthermore, he concluded that the quality of information was the best predictor for a successful change compared to leadership style and willingness (Van Zonneveld, 1993). In this respect Cozijnsen \& 
Vrakking (1995) stresses the importance of a sound communication strategy. At the start of a change process and where there is much resistance, continuing information during a long period is necessary (Cozijnsen \& Ezerman, 1986). For that the formal communication channels as well as special information meetings need to be used.

Although its importance is recognised, both in the literature and in practice, little attention has been paid to the evaluation of change projects (Van Zonneveld, 1993; Cozijnsen \& Vrakking, 1995; Kapteyn, 1996). To control, steer and improve a change process, it is essential to conduct evaluations using quantitative as well as qualitative criteria (Cozijnsen \& Vrakking, 1995; Kapteyn, 1996). According to Cozijnsen \& Vrakking (1995), evaluations have to concern the effectiveness of the diagnosis, the change strategy and the actions. Kapteyn (1996) argues that to control the change process interim and final evaluations are needed by the project or ward management or the affected members themselves. In addition, evaluations are necessary to exert control over the daily processes and activities (Kapteyn, 1996). Although stressing the importance of both hard and soft evaluation criteria especially in non-profit organisations, soft criteria are hard to measure (Cozijnsen \& Vrakking, 1995). In his study Van Zonneveld (1993) concluded that systematic evaluations with hard evaluation criteria were seldom performed. Most evaluations took place verbally in team and function meetings and for example not on project level (Van Zonneveld, 1993).

So, to support the implementation effective control systems are needed expressed in sound communication and information systems such as formal communication channels and special information means and evaluation systems such as interim and final evaluations on project and ward level. In particular, a better information quality regarding the implementation seems to contribute to a more successful implementation of resident-oriented care.

\subsubsection{Motivation}

Sufficient motivation of nursing caregivers involved is an important aspect of change processes in nursing (e.g. Boekholdt, 1981; Burke, 1982; Koene et al., 1982; Zaltman \& Linn, 1986; Wissema et al., 1991). A social change takes place only when the innovation is diffused and symbolically or actively is adopted by a sufficient number of members so its influence is noticeable (Boekholdt, 1981; Zaltman \& Linn, 1986). In line with Lewin's principles as discussed in section 3.2, forces pushing for change will foster new behaviour while forces striving to maintain the status quo are considered as endangering effective change. In this respect Wissema et al. (1991) make a distinction between willingness to change, which is passive, temporary and organisation-related, and disposition to change, which is active, anticipating, continuing and individualrelated. According to Wissema et al. (1991), resistance to change is not based on unchangeable personality traits but on lack of understanding of what is wanted, why and how. The authors concluded that willingness to change is dependent on the extent the change is motivated (Wissema et al., 1991). Similarly, Burke (1982) argues that resistance is often aimed at an expected loss of the known and of personal choice. Loss of the known means acceptance of the newness and the need to cope, which will consti- 
tute stress (Burke, 1982). Another source of resistance stems from the imposed character of a change (Burke, 1982). The degree of freedom at the introduction of an organisational change is proportional to the amount of choice people feel in determining and implementing the change. Lack of commitment can result, if people have not been involved in the action planning, have had no influence on its content, or have had no choice in whether to contribute to it (Burke, 1982; Wissema et al., 1991). Burke (1982) argues that the lack of psychological commitment does not necessarily cause active resistance but at best passive compliance (Burke, 1982; Wissema et al., 1991). As discussed before, overt and covert acceptance play an important role in change processes. In this respect Burke (1982) makes a distinction between participative communication and participative decision making. While participative communication is only aimed at the contribution of information to a decision making process, the participative decision making process concerns all implementation phases (Burke, 1982). Comparable with the discussion in section 3.2, instrumental use of information as in the empiricalrational strategy is not considered as effective to achieve behavioural change.

So, an appropriate degree of participation of people directly affected by the implementation is reflected in motivation expressed in their behaviour such as their willingness to change.

\subsubsection{Skills and capacities}

In line with the empirical-rational and normative re-educative strategy in acquiring appropriate skills and capacities for an effective change, individual behaviour can be positively affected by means of re-education and training (Cozijnsen \& Vrakking, 1995). In the implementation of a patient-oriented care model, training plays a major role. According to Boekholdt (1981), training oriented on social skills is an important success condition because it supports the establishment of a mutual relationship between individuals intensely involved. In this respect, Keiser \& Bickle (1980) performed a study on attitudinal change as a motivating factor at the implementation of primary nursing. It appeared that nursing caregivers, who showed a greater attitudinal change, were more likely to engage in behaviour related to that change. According to the authors, the results imply that training is most effective at the correspondence between the source of the behavioural deficiency and the educational activities to remedy this deficiency (Keiser \& Bickle, 1980).

Cozijnsen \& Vrakking (1995) argue that education and training have to be an integral part in an organisation. In this respect they argue that in case of change, it is necessary to educate people affected by the change as well as of those managing it (Cozijnsen \& Vrakking, 1995). In line with STS principles, Cozijnsen \& Vrakking (1995) propose a learning climate in which learning by doing, experimentation, and risk-taking behaviour is evident. In a further elaboration of these principles the organisation as a learning system comes into perspective. According to Senge (1990), an advocate of the learning organisation, the characteristic of a learning organisation is its expanding potential to create its future continuously. This is achieved not only by adaptive learning, essential for an organisation's survival, but by generative learning as well (Senge, 
1990). To realise an educational programme characterised by generative learning, Cozijnsen \& Vrakking (1995) advise top-down support of top management, continuing education and training-on-the-job programmes.

Thus, the appropriate skills and capacities of people directly involved and the means to increase these, expressed in training and knowledge transfer such as special training of ward management and nursing caregivers and training-on-the-job by supervisors and ward sisters, have to be considered as important in achieving the attitudes most suited and as a consequence successful change.

\subsubsection{Role of the change agent and the supervisors}

In literature the leadership style of the change agent and the ward management are considered as important success factors for change (Cummings \& Huse, 1989; Boumans, 1990; Bekkers et al., 1990; Van Zonneveld, 1993; Cozijnsen \& Vrakking, 1995; Kapteyn, 1996). Van Zonneveld (1993) argues that this importance is probably overestimated. In his study leadership style appeared to be only a marginal predictor of success of the implementation (Van Zonneveld, 1993). In observing different leadership styles with regard to the change agent a distinction is often made between an expert or instrumental approach and a process or social-emotional approach (Boumans, 1990; Van Zonneveld, 1993; Kapteyn, 1996; Peiró, González-Romá, Ramos \& Zornoza, 1996). An expert approach is technically oriented and problems are considered as relating to a lack of knowledge of the client. The role of the change agent is to give information and to solve problems. A process approach is oriented on fostering the problem solving potential of the client system itself. In this role the change agent is an advisor, stimulator and coach. According to Boekholdt (1981), a process approach of the change agent is to be preferred during the implementation of a patient-oriented care model because the involvement of those most affected is fostered. Van Zonneveld (1993) concluded that in most hospitals implementing a patient-oriented care model a process approach of the change agent was used which was considered as most effective by the responders (Van Zonneveld, 1993).

In line with the prior discussion, Boumans (1990) makes a distinction between instrumental leadership (initiating structure) and social-emotional leadership (consideration) of supervisors (Hackman \& Oldham, 1980; Peiró et al., 1996). Instrumental leadership is characterised by task structuring and production-oriented aspects such as structuring employees' tasks, scheduling activities, assigning tasks and setting performance standards. Social-emotional leadership is characterised by attention for comfort, wellbeing, two-way communication and job satisfaction (Boumans, 1990; Peiró et al., 1996). Studies showed that both leadership styles are empirically independent (Boumans, 1990; Peiró et al., 1996). Van Zonneveld (1993) distinguishes two leadership styles of supervisors: a conservative authoritarian style which is procedural, theoretical, policy-oriented and controlling and an innovative stimulating (relation-oriented) style which is being up-to-date, practical, interested and able to arrange things. An innovative stimulating supervisor appeared to be more successful in implementing changes compared to a conservative authoritarian supervisor (Van Zonneveld, 1993). 
In the literature the most effective leadership style is a preferred theme for discussion (e.g. Boekholdt, 1981; Boumans, 1990; Van Zonneveld, 1993, Kapteyn, 1996). However, the choice of one leadership style has to be questioned (Koene et al., 1982; Van Zonneveld, 1993). An instrumental leadership style is often related to strategic or structural problems. A socio-emotional or process style is often advised in case of interpersonal or cultural problems and during the early phase of implementation in which interpersonal relationships and problem solving are important (Boekholdt, 1981; Van Zonneveld, 1993). However, in his literature review Van Zonneveld (1993) points out that when problems are related more to interpersonal relations a process style is less successful. Therefore, it is argued that the most effective style depends on the innovation phase and the kind of problem (Koene et al., 1982; Van Zonneveld, 1993). In this perspective Kapteyn (1996) advocates a so-called situational leadership style. Depending on the demands of the situation a changeable combination of both taskoriented (steering) and relation-oriented (supportive) leadership is used. The demands are expressed in capabilities and willingness of employees. If employees have fewer capabilities and less willingness, instructions are needed by means of much taskoriented leadership combined with a little relation-oriented leadership. So, in new situations a task-oriented leadership is preferred. If employees have more security, task-oriented leadership is less effective due to limited space for new initiatives while personal support is important (cf. De Jong, Voorendonk, Boogaarts, Le Blanc, Den Ouden \& Spuijbroek, 1996; Kapteyn, 1996). However, both conceptually and empirically the model is weak (De Jong et al., 1996). In particular, criticism is directed at the assumption of the effectiveness of low support when capabilities are fewer and willingness is less. According to De Jong et al. (1996) in practice this may lead to a vicious circle of unpleasant behaviour of leader and employee.

In general, the literature is not clear about the ideal form of leadership style (e.g. Boumans, 1990). With regard to instrumental leadership in particular, there is less clarity. However, there seems to be an indication that more socio-emotional and less instrumental leadership of supervisors is associated with a more successful implementation of patient-oriented care (Boekholdt, 1981; Boumans, 1990; Van Zonneveld, 1993).

In conclusion, an appropriate role of the change agent and supervisors expressed in their leadership style is needed for a successful change. In particular, more socioemotional and less instrumental leadership seems to contribute to a more successful implementation of resident-oriented care.

\subsubsection{Implementation approach}

According to STS principles the implementation has to be congruent with the kind of change (e.g. Kuipers \& Van Eijnatten, 1996). Moreover, in a broader perspective there has to be congruency between the organisation culture and systems and the change. According to Killman, Saxton \& Serpa (1986), the organisational culture can affect a change process positively by directing the behaviour of employees in the expected direction. If this culture is not congruent with the type of change, this can influence its success. Hoffart, Schultz \& Ingersoll (1995) found in a study on the implementation of 
a professional care model that the more an organisation is oriented towards functional procedures, the more difficulties appear in a change with regard to the delegation of responsibilities (Hoffart et al., 1995).

Two implementation approaches can be identified: a top-down or autocratic approach and a bottom-up or participative approach. Comparable with the system approach discussed previously, in a top-down approach the top management of the organisation retains responsibility for all phases of the implementation (Bekkers, 1993). Burke (1982) argues that the top-down approach is the best form in situations of crisis, when time is precious or discussion does not work. It is also most effective in organisations where a strong managerial style is valued or where top-down autocratic management fits with the culture like the army where, in line with the power-coercive strategy, authority is accepted and directives are clear (Chin \& Benne, 1973; Burke, 1982). As in the intersystem approach discussed earlier, in a bottom-up approach employees have a decisive impact on what is implemented and on how it is implemented (Bekkers, 1993). In fact, both approaches determine the role of the change agent. According to Burke (1982), depending on the situation a participative approach is likely to have greater success than an autocratic approach due to greater commitment. In pointing out advantages and disadvantages, Killman et al. (1986) mention that in a bottom-up approach the decision making process is often difficult resulting in a time consuming process. However, it often results in a long-lasting change appearing in open commitment and, even more important, hidden acceptance. Further, they argue that in a topdown approach a behavioural change is easier to achieve due to the imposed character of change. However, the result is often an openly formally accepted behaviour while at the same time a hidden acceptance is lacking (Killman et al., 1986). Therefore, the literature indicates preference for an approach depending on the stage of change: in the beginning a top-down approach for stimulating new behaviour and during the progress of change more participation of those directly involved (Burke, 1982; Killman et al., 1986). With regard to the implementation of patient-oriented care models, Bekkers (1993) found that in nursing homes more than half of the cases used a top-down strategy whereas only fifteen percent used a bottom-up strategy. No conclusion could be drawn about the relation between the approach used and specific bottlenecks found (Bekkers, 1993). In a study of the implementation of patient-oriented care models in hospitals, Bekkers, Van Dijk \& Van Roekel (1994) saw no differences between the results achieved by means of a top-down model or a participative model. But compared to a bottom-up model, in a top-down model fewer disturbances and less turnover among supervisors were observed during the implementation (Bekkers et al., 1994).

In line with STS principles and advocating the contingency approach, Hackman \& Oldham (1980) argue that a change has to be an integral part of the organisation. They state that due to its interdependency a job redesign affects many organisational subsystems (Hackman \& Oldham, 1980). Hackman \& Oldham (1980) argue that if account is not taken of this interdependency in a job redesign, it can lead to so-called small change or vanishing effects. A small change effect appears when different subsystems of an organisation form barriers for a job redesign such as the possibilities to increase responsibilities. A vanishing effect appears when changes in a job have more conse- 
quences than the organisation can handle (Hackman \& Oldham, 1980). It can be argued that congruency with the organisation is expressed in organisational choices such as the extent of organisational integration, the extent of implementation and irreversibility. The implementation of a patient-oriented care model is mostly restricted to a change in the nursing sector on ward level (Boekholdt, 1981; Molleman, 1989; Bekkers et al., 1990 and 1994; Van Zonneveld, 1993; Heeremans et al., 1994; Ariëns, Berkhout \& Boumans, 1999). In Van Zonneveld's (1993) study, it appeared that in most hospitals the implementation was initiated as small-scale local experiments. Furthermore, it appeared that patient-oriented care projects took in the second to fifth place of relative importance. Due to the medical culture in most hospitals cure-related projects are considered as more important than care-related projects (Van Zonneveld, 1993). With respect to the irreversibility, Van Zonneveld (1993) argues that during the process a change can win identity whereas the contra powers have less chance. His study also showed that in almost half of the hospitals the change was presented as irreversible. In the case of a reversible change, it was perceived as irreversible by most employees due to its impact on attitudes, resulting in their not wanting to go back to the old situation (Van Zonneveld, 1993).

So, an appropriate implementation approach is important in achieving a successful change expressed in a top-down or a bottom-up approach, extent of organisational integration, extent of implementation and irreversibility of the change.

\subsection{A diagnostic change model}

In the previous section we pointed out a number of conditions for successful change. Now the question is to place these conditions in a model that enables us to analyse the implementation, i.e. the process, in a more structural way. A diagnostic model often used in the literature is the McKinsey '7-S' framework developed by Peters \& Waterman (1982) assisted by Pascale \& Athos (1981) concerning the conceptual development. Initially, the model was used as a diagnostic framework for research of the characteristics of excellent organisations (Peters \& Waterman, 1982). Following a similar line, the model can be used to analyse organisational change because it has a broad perspective in that it is composed of factors on various levels.

The 7-S model is based on the principle that effective organisations are related to seven factors, namely structure, strategy, systems, staff, skills, style and so-called shared values (Peters \& Waterman, 1982). As shown in figure 3.1, these factors are grouped in an atomic model to emphasise their interrelations (Peters \& Waterman, 1982). The seven factors represent the organisation on two levels, that is the obvious level or the hardware, i.e. structure, strategy, systems, and the less obvious level or the software, i.e. staff, skills, style and shared values (Peters \& Waterman, 1982). According to Pascale \& Athos (1981), most organisations and scientists are focused on structure, strategy and systems and their interrelations due to their susceptibility to quantitative and systematic investigation. However, Pascale and Athos (1981) consider the four "softer" elements staff, skills, style and shared values or, superordinate goals in Pascale \& Athos's (1981) terms, as indispensable parts of an organisation's commit- 
ment to long-term success because both individual and organisational requirements are related. Kapteyn (1996) views this attention for softer 'person-oriented' aspects as an innovation. According to Cozijnsen \& Vrakking (1995) the 7-S model fits in a time period (1974-1985) in which organisational change shifted its emphasis from individual and group level to organisational level and from a 'one best way of organising' to a contingency-based approach.

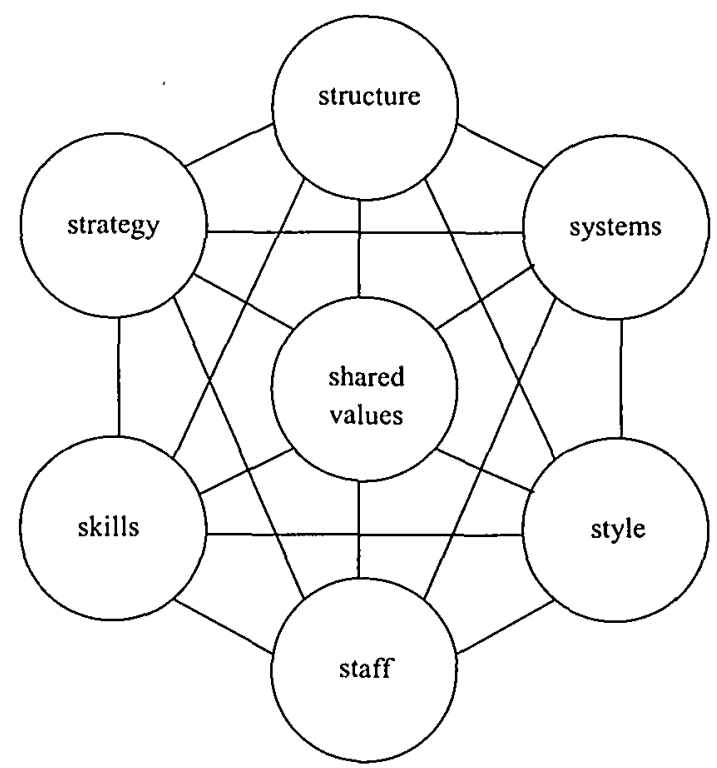

Figure 3.1 The 7-S model (derived from Peters \& Waterman, 1982)

According to Kapteyn (1996), the 7-S model has a more practical than theoretical significance in that it is an easily manageable framework to diagnose and analyse organisational processes from a broad perspective. Kapteyn (1996) argues that the strength of the model lies in the fact that the seven factors are global in that they are not filled in exactly but have to be related to concrete organisational processes. Therefore the model is especially suitable to analyse the organisational context of change processes (Kapteyn, 1996). In Cozijnsen \& Hoksbergen's (1986) opinion, the success of the change can be determined by analysing the way in which the variables are filled in. As we shall see, the conditions for successful change we elaborated in section 3.4 can be easily classified in this model. Therefore, to get insight into the change processes and the organisational context of the implementation of a resident-oriented care model, we use the 7-S model as an evaluative framework. In the following the conceptualisation of the seven factors is presented and filled in with the success conditions to be studied.

\section{Structure}

'...Structure refers to the way in which an organization is organized...' (Pascale \& Athos, 1981, pp. 123). This means the division of tasks, clustering of departments, coordination, hierarchy and functions. The actual division of informal power and influ- 
ence also forms a part of this aspect (Pascale \& Athos, 1981; Cozijnsen \& Hoksbergen, 1986; Kapteyn, 1996).

As discussed in 3.4, the implementation structure gives insight into the level of participation. This means the choice of a project structure such as work groups on project and ward level, decision making procedures and assignment of tasks and responsibilities (cf. Boekholdt, 1981 and 1983b; Burke, 1982; Wijnen et al., 1988; Van Zonneveld, 1993; Kapteyn, 1996). Therefore, in our study we describe the factor structure by means of the project organisation.

\section{Strategy}

'...Strategy pertains to an organization's plan of action that causes it to allocate its scarce resources over time to get from where it is to where it wants to go...' (Pascale \& Athos, 1981, pp. 123). Strategy means explicitly or implicitly formulated policy and plans (Kapteyn, 1996).

As discussed in 3.4, an implementation strategy is determined by its nature, synoptic or incremental, realistic action plan, time period, avoidance of distracting factors, stability of supervisors and organisational support such as financial and personnel means (cf. Boekholdt, 1981, 1983a and b; Burke, 1982; Cozijnsen \& Hoksbergen, 1986; Vrakking, 1986; Bekkers et al., 1990 and 1994; Bekkers, 1993; Van Zonneveld, 1993; Cozijnsen \& Vrakking, 1995; Kapteyn, 1996). Consequently, in our study we used the aspects mentioned above to identify the implementation strategy used. Of these aspects, time period will not be studied separately due to the experimental character of the study and hence the fixed length of the period.

\section{Systems}

'...Systems refer to how information moves around within the organisation...' (Pascale \& Athos, 1981, pp. 124). Systems may concern formal procedures and routines to steer the organisation on a daily base such as decision making, planning, evaluation, administrative and judgement systems as well as more informal systems or more projectrelated special systems (cf. Pascale \& Athos, 1981; Cozijnsen \& Hoksbergen, 1986; Kapteyn, 1996).

As discussed in 3.4, control systems such as information, communication and evaluation systems within the organisation can be considered as important in steering and controlling an implementation (cf. Cozijnsen \& Ezerman; 1986; Wijnen et al., 1988; Cummings \& Huse, 1989; Van Zonneveld, 1993; Cozijnsen \& Vrakking, 1995; Kapteyn, 1996). This concerns qualitative sound information about the content and nature of changes and their likely consequences such as the goals, the planning and the demands regarding the individual functioning of employees and an evaluation of the results (Wijnen et al., 1988; Van Zonneveld, 1993). Therefore, in our study we investigated the systems by studying the information and communication systems, such as formal communication channels and special information means and their quality, and evaluation systems, such as interim and final evaluations on project and ward level. In particular, we postulate that better information quality of the implementation contrib- 
utes to a more successful implementation of resident-oriented care (Van Zonneveld, 1993).

\section{Staff}

'...Staff pertains to demographic characteristics of the people who live in the organization...' (Pascale \& Athos, 1981, pp. 124). Staff, not meant in line-staff terms, refers to individual characteristics such as their capacities, education, but also their behaviour expressed in motivation and morale (Pascale \& Athos, 1981; Kapteyn, 1996).

Motivation expressed in functioning and behaviour determined by degree of participation of people directly affected is an important aspect for change processes in general and the implementation of a patient-oriented care model in particular (cf. Boekholdt, 1981; Burke, 1982; Koene et al., 1982; Zaltman \& Linn, 1986). As discussed in 3.4, motivation of individual employees is expressed in behaviour of staff, such as their willingness to change. Therefore, in our study the factor staff is considered by means of their willingness to change.

\section{Skills}

'...Skills refer to those things which the organization and its key personnel do particularly well - the distinctive abilities that truly set them apart from competition...' (Pascale \& Athos, 1981, pp. 124). According to Kapteyn (1996), the strengths and weaknesses of the whole organisation are stressed more than the skills of individuals, although Pascale \& Athos (1981) note that skills apply on both the organisational and interpersonal level.

A change climate can be fostered in an organisation in which learning has an integral place (cf. Cummings \& Huse, 1989; Senge, 1990; Cozijnsen \& Vrakking, 1995). This can stimulate the development of capacities and skills of individual employees. As discussed in 3.4, to affect the behaviour of organisational members in the expected direction, re-education and training play a major role (cf. Boekholdt, 1981; Cozijnsen \& Hoksbergen, 1986; Karasek, 1992; Kuipers \& Van Eijnatten, 1996; De Sitter et al., 1997; Van Eijnatten \& Van der Zwaan, 1998). Therefore, in our study we investigate specific interventions with respect to training and knowledge transfer such as special training of ward management and nursing caregivers and training-on-the-job by supervisors and ward sisters.

\section{Style}

'...Style refers to the patterns of behavior of the top executive and the senior management team...Style refers also to that of the organization as a whole...' (Pascale \& Athos, 1981, pp. 124). Style refers to characteristics of the behaviour of the management and of the individual employee such as the way of co-operation, behavioural norms and habits, but it also refers to the cultural style of the organisation as a whole (Pascale \& Athos, 1981; Kapteyn, 1996).

As discussed in 3.4, there is clear consensus in the literature about the fact that the leadership style of the change agent and the supervisors is an important factor to achieve change (cf. Cummings \& Huse, 1989; Boumans, 1990; Bekkers et al., 1990; 
Van Zonneveld, 1993; Cozijnsen \& Vrakking, 1995; Kapteyn, 1996). Therefore, we investigated whether the leadership style of the change agent and the supervisors, such as socio-emotional or instrumental, is a determinant of change. In particular, we postulate that more socio-emotional and less instrumental leadership contribute to a more successful implementation of resident-oriented care (cf. Boekholdt, 1981; Boumans, 1990; Van Zonneveld, 1993).

\section{Shared values or superordinate goals}

'...Superordinate goals (which include the spiritual or significant meanings and shared values of the people within an organization) refer to the overarching purposes to which an organization and its members dedicate themselves... this factor pertains to values or goals that "move men's hearts" and that genuinely knit together individual and organizational purposes...' (Pascale \& Athos, 1981, pp. 126). According to Kapteyn (1996), shared values, refer to basic values of the organisation and its members i.e. its culture such as joint visions, ideologies, values, attitudes and norms.

As discussed in 3.4, an organisational culture is an important determinant for a successful change. It can be expressed in the mission, the binding elements and the societal reason for existing (Kapteyn, 1996). With respect to an implementation, it is very difficult to measure the cultural aspects. Therefore, we have chosen to study related aspects such as the implementation approach, i.e. top-down or bottom-up, extent of organisational integration, extent of implementation and irreversibility of the change (cf. Burke, 1982; Cozijnsen \& Hoksbergen, 1986; Killman et al., 1986; Bekkers et al., 1994; Kuipers \& Van Eijnatten, 1996).

\subsection{Summary and conclusions}

Organisational change concerns interventions within and between groups of individuals. Different strategies, models and approaches for structuring change effectively and motivating social systems accordingly are involved. For their development behavioural and motivational theories are of importance. Strategies for organisational change can be oriented on organisational systems or on the change process itself and can vary in their emphasis on participation and involvement of change agents and people directly affected by the change. In particular, the normative-re-educative strategy, (Participative) Action Research and the intersystem approach bear resemblances to STS guidelines, which seem to be important for the implementation of resident-oriented care models. These concern: their emphasis on an sufficient degree and level of participation of people directly affected by the change; congruence between the nature of change on the one hand and the project and formal organisation on the other; participative and supportive roles of the change agent and the management; sound communication, information and evaluation means; and education and training focused on experience-based learning. Based on these principles we were able to elaborate a number of success conditions to gain more insight into the importance of implementation characteristics for realising a resident-oriented care model successfully. For diagnosing the implementation characteristics and in this way the success conditions, the McKinsey 7-S model developed by Peters \& Waterman (1982) seems to be a suitable framework 
to use. In conclusion, we related the 7-S model to our elaborated success conditions by operationalising the seven factors, that is structure, strategy, systems, staff, skills, style and shared values as follows:

- Structure: effective implementation structure expressed in work groups on project and ward level with people directly affected by the change.

- Strategy: effective implementation strategy expressed in an incremental or synoptic implementation approach, realistic action plan, avoidance of distracting factors, stability of supervisors, and organisational support such as financial and personnel means.

- Systems: effective control systems expressed in sound communication and information systems such as formal communication channels and special information means and their quality and evaluation systems such as interim, and final evaluations on project and ward level.

- Staff: appropriate motivation of people directly affected by the implementation expressed in their behaviour such as their willingness to change.

- Skills: appropriate skills and capacities of people directly involved and means to increase these expressed in training and knowledge transfer such as special training for ward management and nursing caregivers, and training-on-the-job by supervisors and ward sisters.

- Style: appropriate role of the change agent and the supervisors expressed in their leadership style such as socio-emotional and instrumental leadership.

- Shared values: appropriate implementation approach expressed in a top-down or bottom-up approach, extent of organisational integration, extent of implementation, and irreversibility of the change. 


\subsection{Introduction}

In the previous two chapters the concepts of the study were elaborated on. In this chapter the method of the study will be discussed. This chapter concerns successively a presentation of the research model, the research questions and the hypotheses (4.2), the description and operationalisation of the research variables (4.3), the design of the study (4.4) and a description of the intervention (4.5). Subsequently, the population of the study (4.6) and the research procedure (4.7) are presented. Finally, the chapter closes with the response, dropout rates and baseline sample (4.8) and a brief overview of the main analyses (4.9).

\subsection{Research model, research questions and hypotheses}

In figure 4.1 the research model is presented.

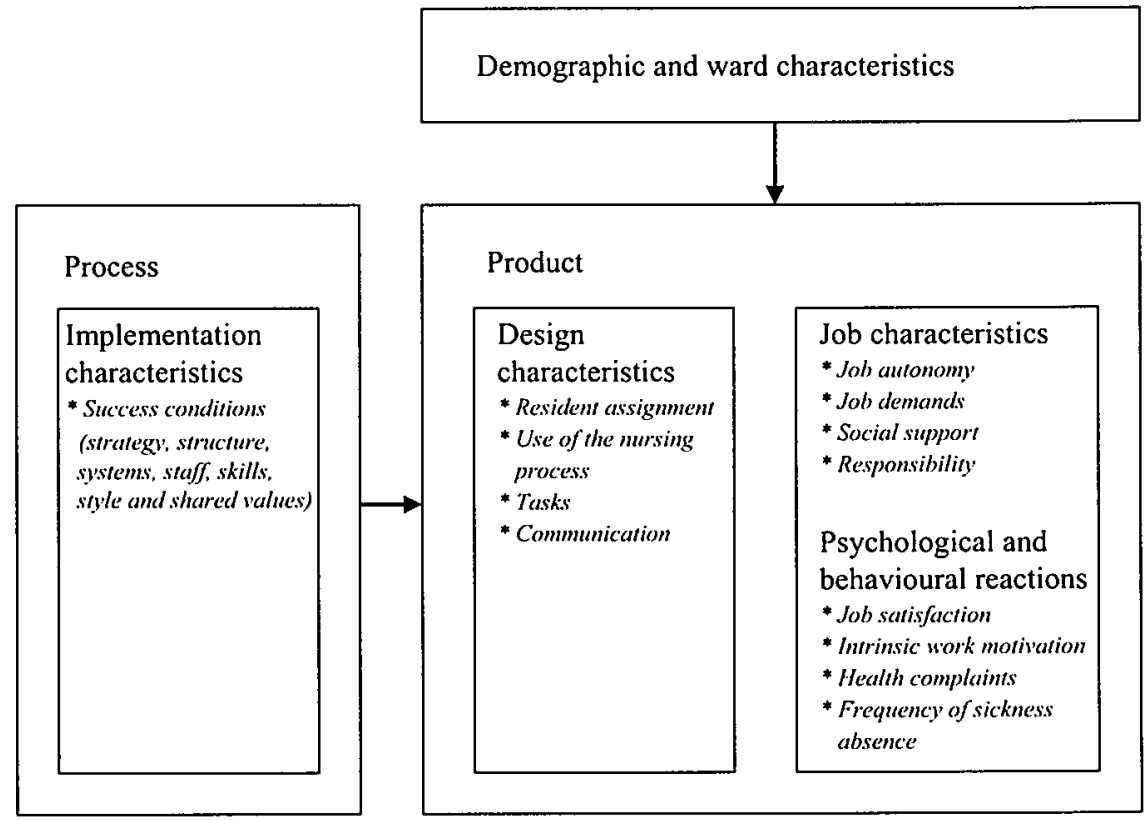

Figure 4.1 Research model

Our study encompasses the evaluation of the product (i.e. the design and the effects), the 'what' as well as the process, the 'how' of the implementation of a residentoriented care model. On the right side of the model the product of implementation is 
assessed by means of the design characteristics and the effects, i.e. the job characteristics and the psychological and behavioural reactions. On the left side the process of implementation of a resident-oriented care model is presented, which is measured by a number of implementation characteristics. These implementation characteristics are the success conditions such as style and systems. Finally, at the top of the right side of the model demographic and ward characteristics are presented. In the literature it is assumed that characteristics such as age and careload can unintentionally contribute to the results, which makes correction necessary (cf. Boumans, 1990; De Jonge, 1995; Polit \& Hungler, 1999).

With regard to the product, changes in four main design characteristics of the model of resident-oriented care are measured, that is resident assignment, use of the nursing process, tasks and communication. The research question for this part is:

Q1. To what extent are the various characteristics of resident-oriented care implemented?

As a result of the implementation, the following changes are expected in the four main design characteristics: (1) increased resident assignment; (2) increased use of the nursing process; (3) extended amount of tasks; and (4) improved communication (e.g. Boekholdt, 1981; Molleman, 1989; Wilson \& Dawson, 1989; Bekkers et al., 1990; Thomas, 1993; Heeremans et al., 1994). Therefore, to answer research question 1, the following hypotheses were formulated:

H1a) Resident assignment will increase in the experimental group compared to the control group after the implementation of resident-oriented care.

HIb) Use of the nursing process will increase in the experimental group compared to the control group after the implementation of resident-oriented care.

HIC) Number of tasks will extend in the experimental group compared to the control group after the implementation of resident-oriented care.

HId) Communication will improve in the experimental group compared to the control group after the implementation of resident-oriented care.

In the literature it is assumed that the success of the implementation, i.e. the product, can be influenced by the implementation itself, i.e. the process, (e.g. Hackman \& Oldham, 1980; Pascale \& Athos, 1981; Trist, 1981; Peters \& Waterman, 1982; Karasek, 1992; Cozijnsen \& Vrakking, 1995; Kapteyn, 1996; Kuipers \& Van Eijnatten, 1996). Therefore, it is postulated that a number of characteristics of the implementation will affect the product of implementation. The research question for this part is thus:

\section{Q2. What are the conditions for successfully implementing resident-oriented care?}

The implementation, i.e. the process, will be evaluated by means of a number of success conditions derived from the literature which we related to the factors of the 7-S model as discussed and presented in chapter 3 (cf. Pascale \& Athos, 1981; Peters \& Waterman, 1982). The seven success conditions structure, strategy, systems, staff, skills, style and shared values will be evaluated qualitatively. Further, systems and style will also be studied quantitatively by means of the variables information quality 
and social-emotional and instrumental leadership style (Boekholdt 1981, 1983a and b; Koene et al., 1982; Bekkers et al., 1990 and 1994; Boumans, 1990; Van Zonneveld, 1993; Kapteyn, 1996). With regard to instrumental leadership in particular, the literature is not clear about the ideal form (e.g. Boumans, 1990). However, in general there seems to be an indication that better information quality and more socio-emotional and less instrumental leadership of supervisors are associated with a more successful implementation of resident-oriented care (Boekholdt, 1981; Boumans, 1990; Van Zonneveld, 1993). Therefore to answer research question 2, the following hypotheses were formulated:

H2a) Better information quality with regard to the implementation on the experimental wards will lead to a more successful implementation of resident-oriented care.

H2b) More social-emotional leadership of supervisors on the experimental wards will lead to a more successful implementation of resident-oriented care.

H2c) Less instrumental leadership of supervisors on the experimental wards will lead to a more successful implementation of resident-oriented care.

The product of implementation of a resident-oriented care model can be considered as a job enrichment intervention within the work of nursing caregivers. As a consequence, changes are to be expected on the experimental wards with respect to job characteristics most related to this type of intervention, that is job autonomy, job demands, social support and responsibility. In addition, as a further consequence of this job enrichment intervention, changes are assumed on the experimental wards in psychological and behavioural reactions namely job satisfaction, intrinsic work motivation, health complaints and frequency of sickness absence. Therefore, the following research question is formulated:

Q3. What are the effects of the implementation of resident-oriented care on the job characteristics of nursing caregivers and on their psychological and behavioural reactions?

Concerning the job characteristics the following can be assumed. On the one hand, job autonomy and responsibility of nursing caregivers are expected to increase as a result of the implementation of a resident-oriented care model. On the other, the delegation of co-ordination tasks to nursing caregivers will be more demanding because of more complex and mentally exacting tasks. Finally, due to increased solo performing of nursing caregivers there will be an increased need for social support and as a result an increased level of actual social support (e.g. McCormack, 1992; Thomas, 1992; Vlerick \& Goeminne, 1994; Kivimäki et al., 1995; Webb \& Pontin, 1996). In line with these assumptions, to answer the first part of research question 3 the following hypotheses were formulated:

H3a) Job autonomy will increase in the experimental group compared to the control group after the implementation of resident-oriented care.

$H 3 b)$ Job demands will increase in the experimental group compared to the control group after the implementation of resident-oriented care. 
H3c) Social support will increase in the experimental group compared to the control group after the implementation of resident-oriented care.

H3d) Responsibility will increase in the experimental group compared to the control group after the implementation of resident-oriented care.

With regard to the psychological and behavioural reactions, the following can be assumed. The implementation of a resident-oriented care model is expected to result in increases in job autonomy, job demands, social support and responsibility. As a consequence, positive work-related psychological and behavioural reactions are assumed, that is job satisfaction, intrinsic work motivation, health complaints and frequency of sickness absence (e.g. Bekkers et al., 1990; Kaban \& Thompson, 1990; Bond et al., 199 Ic; Vlerick \& Goeminne, 1994; Kivimäki et al., 1995). Finally, it is postulated that based on the assumptions of the DCS model the increase in job demands will not lead to negative job-related reactions due to the moderating influence of more job autonomy and social support. (e.g. Johnson \& Hall, 1988; Fox et al., 1993; Parkes et al., 1994; De Jonge et al., 1996, 1999a and b). Therefore, to answer the second component of research question 3 the following hypotheses were formulated:

H3e) Job satisfaction will increase in the experimental group compared to the control group after the implementation of resident-oriented care.

H3f) Intrinsic work motivation will increase in the experimental group compared to the control group after the implementation of resident-oriented care.

H3g) Health complaints will decrease in the experimental group compared to the control group after the implementation of resident-oriented care.

$H 3 h$ ) Frequency of sickness absence will decrease in the experimental group compared to the control group after the implementation of resident-oriented care.

\subsection{Description and operationalisation of the research variables}

\subsubsection{Introduction}

To get an insight into the product as well as process of the implementation, measurement was done of the implementation characteristics, design characteristics, job characteristics and psychological and behavioural reactions. The design characteristics, three implementation characteristics, the job characteristics and the psychological and behavioural reactions were measured quantitatively. All design and implementation characteristics were measured qualitatively as well, to get insight into the extent and into the nature of the results. Use of qualitative data alongside quantitative data can help to open up the black box question by illustrating and interpreting the intervention results (Polit \& Hungler, 1999). Further, they can provide insight into the experiences and processes underlying the experimental effects (cf. De Bakker, 1988; Maso, 1989; Polit \& Hungler, 1999).

Most of the instruments used were validated in other studies and if necessary, existing instruments were adjusted to the setting of nursing home care or new instruments were constructed. Appendix 1, table 1.1 shows the dimensions of the research variables measured by the quantitative questionnaires, the factors derived from factor analyses, 
number of items, theoretical range and the means, standard deviations and coefficient $\alpha$ 's on the pre-test.

\subsubsection{Design characteristics}

\section{Quantitative measurement design characteristics}

The quantitative measurement of the design characteristics was performed by means of written questionnaires filled in by nursing caregivers. To measure these design characteristics no suitable instruments were found. With respect to 'resident assignment', 'use of the nursing process' and 'communication' existing instruments used in general hospitals were adjusted to the specific setting of nursing home care (Mast, Roelink, Boumans \& Berkhout, 1997). With respect to 'tasks' a new instrument was constructed. To improve the face and content validity, the scales were first evaluated regarding relevance, appropriateness and completeness by a panel of ten experts on nursing home practice and on nursing care organisation (cf. Polit \& Hungler, 1999). After making adjustments the scales were further evaluated in a pilot study on feasibility and user friendliness. Finally, to investigate the psychometric properties exploratory factor analyses and reliability analyses were conducted (Berkhout, Boumans, Van Breukelen, Nijhuis \& Huijer Abu-Saad, 1998a). With exploratory factor analysis observed variables are reduced into a few underlying latent factors whereby the data are explored without a detailed measurement model in advance (Tabachnik \& Fidell, 1989; De Jonge, 1995). In fact, with factor analysis the convergent and discriminant validity of the underlying constructs is identified (Polit \& Hungler, 1999). In this study a principal components analysis was conducted on the pre-test data $(n=210)$, using oblique factor rotation Oblimin, because of expected correlations between factors per scale. For principal components analysis using oblique factor rotation all the variance in the observed variables contributes to a factor solution permitting a limited extent of correlation between factors per scale, determined by a variable delta or $\delta$. In our study the default option $(\delta=0)$ was used permitting a fairly high correlation (cf. Tabachnik \& Fidell, 1989). Final factor solutions were based on the following criteria: eigen values of 1 or more, factor loadings of 0.3 or more, factors with the highest loadings with a minimal difference of 0.2 when loading on two or more factors and importance and coherence of the items with regard to the total factor. Except for one factor, all extracted factors were interpretable with explained variances ranging from $7.1 \%$ to $36.1 \%$. Appendix 2, tables $2.1-2.4$, presents an overview of the factor structures and loadings, eigen values, explained variance and factor correlations. With reliability analyses we assessed the internal consistency of our instruments (Polit \& Hungler, 1999). The internal consistency assesses the extent to which an instrument is reliable or free from random error (Tabachnik \& Fidell, 1989; Polit \& Hungler, 1999). In our study the coefficient $\alpha$ (Cronbach) was used to assess the internal consistency. All coefficient $\alpha$ 's appeared to be acceptable on the pre-test $(n=210)$ ranging from 0.66 to 0.91 (Nunnally, 1978) (see also appendix 1, table 1.1).

\section{Resident assignment}

With resident assignment residents are each allocated to a so-called primary nursing caregiver (PNC) who bears responsibility for the total nursing care for this resident 
mostly from admission until discharge (see also chapter 2). This responsibility covers the planning, performance and evaluation of the resident's care (cf. Van Eindhoven, 1979; Marram et al., 1979; Manthey, 1980; Koene et. al, 1982). The scale "resident assignment" uses a 5-point Likert scale to measure the extent to which residents are allocated to a PNC. The original scale was derived from Roodbol (1993). After adjustments and factor analyses a two-factor structure could be derived. One factor was excluded from further analyses due to a lack of clarity with regard to content. The other factor "resident assignment" comprised 10 items and yielded a good pre-test coefficient $\alpha$ of 0.91 (i.e. the extent of assignment of residents to a primary nursing caregiver from admission until discharge).

\section{Use of the nursing process}

The nursing process can be described as a cyclical and integrated process which consists of five phases: taking nursing history, identifying nursing problems, determining goals, planning the actions, performing the actions and evaluating them (see also chapter 2) (e.g. Koene et al., 1982). For the benefit of the co-ordination and continuity of nursing care the nursing process is reported in a resident-dossier including a nursing care plan (cf. Marram et al., 1979; Manthey, 1980; Hegyvary, 1982; Koene et al., 1982). To measure 'use of the nursing process' a scale "methodical nursing" was derived from Verkooijen \& Halfens (1992). After adjustments and factor analysis two 14-item and 9-item factors could be derived measured on a 5-point Likert scale: "use of nursing care plans and their evaluation" (i.e. charting and, if necessary, adjusting the nursing care plan for the assigned resident) and "taking nursing history, nursing problems, goals and actions" (i.e. defining nursing problems for all residents separately). The two factors showed reasonable pre-test coefficient $\alpha$ 's of 0.88 and 0.85 .

\section{Tasks}

A key-part in a resident-oriented care model is horizontal and vertical job enrichment leading to an extension of nursing tasks performed for the same resident and to more involvement of nursing caregivers in decision making issues on the ward (see also chapter 2) (cf. Marram, 1979; Manthey, 1980; Boekholdt, 1981; Koene et al., 1982; Molleman, 1989). To measure the extent of "resident- and ward-oriented tasks" a new scale was constructed. After a face validity check, a pilot study and factor analysis, a two-factor 8-item and 7-item structure using a 5-point Likert scale could be derived. Both factors showed good pre-test coefficient $\alpha$ 's of 0.79 and 0.80 , for "residentoriented tasks" (i.e. charting and keeping up of nursing care plans) and "ward-oriented tasks" (i.e. co-ordination of daily nursing care activities on the ward) respectively.

\section{Communication}

According to Koene et al. (1982), the communication has to foster co-ordination and continuity of care, a resident-oriented attitude of nursing caregivers and the responsibility of the total team. As a consequence of resident-oriented care the communication structure becomes more extensive and thus more varied. Moreover, due to a higher participation of nursing caregivers in decision making the communication becomes more two-sided and therefore of higher quality (see also chapter 2) (cf. Boekholdt, 1981). The scale "communication" was based on an instrument of Van Zonneveld (1993) and measures changes in the variety and quality of communication. After ad- 
justments and factor analyses the following three factors could be derived: "quality of communication forms" (i.e. clear agreements about the approach of residents), "variety of resident-oriented communication forms" (i.e. social health of residents) and "variety of ward-oriented communication forms" (i.e. mutual co-operation on the ward). The factors, measured with 14,9 and 7 items on a 5-point Likert scale, showed acceptable pre-test coefficient $\alpha$ 's of $0.86,0.91$ and 0.68 .

\section{Qualitative measurement design characteristics}

Triangulation is the use of multiple methods or sources to improve the likelihood that findings converge on an accurate presentation of reality to be found credible and thus sort out "true" from "error" information. In our study we used multiple triangulation techniques (Polit \& Hungler, 1999). The qualitative measurement of the design characteristics was performed on the experimental wards only by means of interviews with all project co-ordinators and supervisors, participant observations and analysis of the residents' dossiers. Data were supplemented with minutes of the steering and advisory group meetings. With respect to the interviews a semi-structured questionnaire of Bekkers et al. (1990) was used. Questions were focused on the expected and actual realisation of the four design characteristics such as: "How is the present situation on your ward (supervisors) / on the experimental wards (project co-ordinators) with respect to resident assignment and the ward organisation?" Additional questions were asked with regard to (changes in) developments on the control wards related to resident-oriented care to get insight into possible intervention contamination. Interviews were performed at all three measuring moments. Except for one interview, which was reported in writing, all interviews were recorded on tape. The response rate was $100 \%$. One respondent was project co-ordinator and supervisor. This respondent was interviewed as project co-ordinator with extra attention for the implementation on his ward. The participant observations were performed on the basis of a topic list of Bekkers et al. (1990). This topic list was used to achieve enough depth and thus credibility of the data (Polit \& Hungler, 1999). By means of this topic list the nature and scope of change (what and how far) was observed. Participant observations were aimed at getting insight into the nursing care model on the experimental wards. At each measuring moment all experimental wards were observed twice for two days by two different observers independently. In the pre-test each experimental ward was observed twice for one day. Before the first post-test the observations were discussed with the observers. Before the last post-test, pilot observations were performed coached by an observer of the first post-test. Observations were conducted during the dayshift. Observers performed bedside nursing in assisting two different nursing caregivers per dayshift thereby working in uniforms as nursing aides without bearing responsibility. All observers were registered nurses. In addition to assisting in nursing care, ward meetings were attended. Finally, analysis of the residents' dossiers was conducted with the same topic list of Bekkers et al. (1990) used for the participant observations. To do this five residents' dossiers were selected at random per experimental ward. Permission was asked for studying the residents' dossiers and attending the ward meetings. By using two researchers for analysing the data, peer debriefing was possible to establish more data credibility (Polit \& Hungler, 1999). In addition member checking was conducted with the project co-ordinators informally during data collection as well as for- 
mally, after ending data collection and analysing to establish further data credibility. Table 4.1 presents an overview of the subjects on the topic list.

Table 4.1 Subjects on topic list for participant observations

\begin{tabular}{llll}
\hline Resident assignment & Use of the nursing process & Tasks & Communication \\
\hline Organisational model & Report system & Nature / scope tasks super- & Nature \\
Nature and extent of resi- & Report of the phases of the & visors & Subjects \\
dent assignment & nursing process & Nature / scope tasks ward & Participants \\
Composition ward units & Application of principles & sisters & Frequency \\
Composition duty rosters & of the nursing process & Nature / scope tasks pri- & Resident orientedness \\
& & mary nursing caregivers & \\
& & Nature / scope tasks other & \\
& & nursing caregivers & \\
\hline
\end{tabular}

\subsubsection{Implementation characteristics}

The implementation itself, i.e. the process, was measured quantitatively concerning three implementation variables, that is information quality and socio-emotional and instrumental leadership, and qualitatively with respect to all seven elaborated success conditions. Therefore, at each measurement written questionnaires were distributed among nursing caregivers, and interviews were conducted with key members of the implementation, that is supervisors and project co-ordinators (cf. Boekholdt, 1981; Bekkers et al., 1990; Van Zonneveld, 1993).

\section{Quantitative measurement implementation characteristics}

\section{Information quality}

Effective communication about the process of change is an important condition for a successful implementation (see chapter 3) (Van Zonneveld, 1993). Effective communication was measured by means of its quality with an instrument derived from Van Zonneveld (1993). Questions were asked about the opinion of nursing caregivers about the clarity of information with regard to the objectives, the consequences, the expected results and the different phases of implementation (such as clarity of information with regard to the objectives of the implementation of resident-oriented care). The scale contains 4 items measured on a 5-point Likert scale showing a good pre-test coefficient $\alpha$ of 0.88 .

\section{Leadership style}

The leadership style of a supervisor can be considered another important condition for a successful implementation (see chapter 3) (e.g. Bekkers et al., 1990; Boumans, 1990; Van Zonneveld, 1993; Kapteyn, 1996). In line with Boumans (1990), in our study social-emotional leadership and instrumental leadership are distinguished. Boumans (1990) derived the scale from the "Leadership Behaviour Questionnaire" of Stogdill (1963). The scale scored on a 5-point Likert scale measures social-emotional leadership (openness for criticism of nursing caregivers) and instrumental leadership (determining what job has to be done and how it has to be done). The two dimensions were measured with 11 and 9 items and both showed reasonable pre-test coefficient $\alpha$ 's of 0.88 and 0.75 . 


\section{Qualitative measurement implementation characteristics}

\section{Success conditions}

To get insight into the success conditions of the implementation, interviews were performed with project co-ordinators and supervisors of the experimental wards. For this aim, we used the same semi-structured interview list from Bekkers et al. (1990) as was used to collect the qualitative data of the design characteristics. Questions were asked with regard to the success conditions. Additional questions were asked concerning other developments influencing the results. An example is: "What were the strengths and weaknesses concerning the implementation on your ward (supervisors) / on the experimental wards (project co-ordinators) and with what means did you confront the weaknesses?"

\subsubsection{Job characteristics}

The job characteristics derived from the DCS model, job autonomy, job demands and social support (Johnson \& Hall, 1988), and with the addition of responsibility, were used to evaluate the effects of the implementation of a resident-oriented care model (see chapter 2) (e.g. Thomas, 1992; Vlerick \& Goeminne, 1994; Kivimäki et al., 1995; Webb \& Pontin, 1996).

\section{Job autonomy}

Job autonomy was defined in line with De Jonge (1995, pp. 13) as: "the workers' selfdetermination, discretion or freedom, inherent in the job, to determine several task elements" (see chapter 2). The core elements are the workers' actual control within and over his work with respect to certain job aspects such as the pace of work, the method of working, scheduling and procedures and the work goals. A one-dimensional scale "job autonomy" was derived from De Jonge (1995) measuring the extent to which a nursing caregiver experiences job autonomy. The 10 items are assumed to represent two latent factors namely contextual job autonomy (i.e. the opportunity that the work offers to raise or lower the pace of work yourself) and content job autonomy (i.e. the opportunity that the work offers to determine the work goals yourself). A good pre-test coefficient $\alpha$ of 0.82 was shown.

\section{Job demands}

Job demands were defined as task requirements or task goals within a job (see chapter 2) (De Jonge, 1995). Job demands give an indication of the extent of experienced workload of an individual person. In our study job demands refer to qualitative demands such as complexity or difficulty and to quantitative demands such as number of requirements within a limited time space. The scale "job demands" was derived from De Jonge (1995) and assesses the quantitative job demands (i.e. the pressure of time to carry out the work) and qualitative job demands (i.e. the complexity of the work) on an 8 -item 5-point Likert scale. It showed a good pre-test coefficient $\alpha$ of 0.88 . 


\section{Social Support}

In our study perceived work-related social support has been used because of the assumption that with social support positive outcomes are increased and negative outcomes are diminished (see chapter 2) (De Jonge, 1995). The scale "social support" was based on an instrument of De Jonge (1995) who derived it from a Dutch questionnaire on organisational stress ("Vragenlijst Organisatie Stress-Doetinchem" - VOS-D; Bergers, Marcelissen \& De Wolff, 1986). The scale measures social support of colleagues and supervisors in the work situation (i.e. the opportunity to talk about problems at work with them). A 10-item 4-point Likert scale was used showing a good pretest coefficient $\alpha$ of 0.84 .

\section{Responsibility}

Responsibility concerns the accountability for care (see chapter 2) (De Jonge et al., 1995a). The scale "responsibility" was derived from De Jonge et al. (1995a) and measures nursing caregivers' responsibility for several care aspects (i.e. continuity and co-ordination). A 5-item 5-point Likert scale was used with a good pre-test coefficient $\alpha$ of 0.84 .

\subsubsection{Psychological and behavioural reactions}

Three psychological reactions and one behavioural reaction of nursing caregivers were used to evaluate the effects of the implementation of a resident-oriented care model, that is job satisfaction, intrinsic work motivation, health complaints and frequency of sickness absence (e.g. Bekkers et al., 1990; Bond et al., 1991c; Kivimäki et al., 1995).

\section{Job satisfaction}

Job satisfaction is considered as a global and unidimensional construct. It is defined as the sum of the evaluations of the different elements of a job and reflects an overall affect of one's liking towards a job (see chapter 2) (Locke, 1969; Weaver, 1980; De Jonge, 1995). Job satisfaction is measured with one item on a 5-point Likert scale: "as a whole I am satisfied with my work".

\section{Intrinsic work motivation}

In line with Warr et al. (1979), we used the concept intrinsic work motivation as "the degree to which a person wants to work well in his or her job in order to achieve intrinsic satisfaction" (see chapter 2) (Warr et al., 1979, pp. 135). The concept encompasses challenging and worthwhile work aspects such as job autonomy and social contacts and includes possibilities for growth (Janssen et al., 1996, 1999a). The scale "intrinsic work motivation" is derived from a translation by Janssen (1992) of the intrinsic work motivation scale of Warr et al. (1979) and is measured by 6 items on a 5point Likert scale (i.e. "I feel a sense of personal satisfaction when I do this job well"). The pre-test coefficient $\alpha$ of 0.66 was acceptable.

\section{Health complaints}

In line with Boumans (1990), we used perceived psychosomatic health complaints to study the impact of the implementation of a resident-oriented care model on health (see chapter 2). Psychosomatic health complaints were measured with the reduced 
"Questionnaire for the study of experienced health" ("Vragenlijst voor Onderzoek van de Ervaren Gezondheid" - VOEG; Dirken, 1967). This questionnaire consists of 21 items measured on a dichotomous scale (yes $/$ no) with scores ranging from $0-21$. The pre-test coefficient $\alpha$ of 0.82 was good. The health complaints concern fatigue and cardiovascular and gastric complaints and complaints concerning the kinetic apparatus.

\section{Frequency of sickness absence}

In line with Boumans (1990), we used the frequency of sickness absence (see chapter 2). Frequency of sickness absence is considered as a measure for a negative subjective work evaluation (Smulders, 1980; Dwyer \& Ganster, 1991). In our study frequency of sickness absence was measured over the last half year as follows: "How often did you report sick during the last half year?"

\subsubsection{Demographic and ward characteristics}

Demographic and ward characteristics are to be considered as extraneous variables and are not allowed to vary (Polit \& Hungler, 1999). They refer to background variables such as age, gender, type of organisation, type of ward and careload. These variables may confound the results and are therefore involved in the analyses (Boumans, 1990; De Jonge, 1995).

\section{Demographic characteristics}

The following demographic variables were measured: age, gender, education, degree of employment, ward experience and working hours. From the literature it is known that these variables are most often used in describing study populations (Boumans, 1990; De Jonge, 1995). Yet, these characteristics can confound the results. For example, job satisfaction was shown to correlate significantly with age and ward experience (cf. Boumans, 1990; De Jonge, 1995). So, we used them as control variables in the analyses.

\section{Ward characteristics}

Differences between type of wards, organisations and careload can play a confounding role, which should be corrected for (e.g. De Jonge et al., 1999a). Besides confounding, according to Cook \& Campbell (1979), interaction between setting and treatment (type of group, i.e. experimental versus control group) constitutes a threat to external validity (see further section 4.5). In our study two types of ward (somatic versus psychogeriatric care) and three types of organisation ( $\mathrm{A}, \mathrm{B}$ or $\mathrm{C}$ ) were included and thus can interact with treatment (experimental versus control) and which could lead to effectmodification. Therefore type of ward and type of organisation were included as control variables in the analyses to correct for confounding and interaction effects with type of group (experimental versus control group).

Careload was measured with an instrument often used in nursing homes in the Netherlands, the so-called "SIVIS-help index" (SIG, 1994). This index gives an indication of careload on the nursing ward. With twelve items measured on 3- and 5-point scales, resident's functioning in daily living is measured. To reflect sufficient versus insuffi- 
cient functioning the scales had to be dichotomised. This instrument was used in a study on the effects for residents filled in by another sample of nursing caregivers of the same research wards (cf. Berkhout, Boumans \& Landeweerd, 1998b; Ariëns et al., 1999). The reported pre-test coefficient $\alpha$ appeared to be good $(\alpha=0.83, n=91)$. For the current study all further analyses were performed with careload data derived from the previously mentioned sample aggregated on ward level.

Table 4.2 Overview of the measuring methods

\begin{tabular}{|c|c|c|}
\hline What & How & Who \\
\hline $\begin{array}{l}\text { Design characteristics } \\
\text { - Resident assignment } \\
\text { - Use of the nursing process } \\
\text { - Tasks } \\
\text { - Communication }\end{array}$ & $\begin{array}{l}\text { Quantitative } \\
\text { - Questionnaires } \\
\text { Qualitative } \\
\text { - Interviews } \\
\text { - Participant observations } \\
\text { - Charting resident's dossiers }\end{array}$ & $\begin{array}{l}\text { - Nursing caregivers } \\
\text { - Project co-ordinators } \\
\text { - Supervisors (exp. wards) } \\
\text { - Experimental wards } \\
\text { - Residents (exp. wards) }\end{array}$ \\
\hline $\begin{array}{l}\text { Implementation characteristics } \\
\text { - Information quality } \\
\text { - Lcadership style }\end{array}$ & $\begin{array}{l}\text { Quantitative } \\
\text { - Questionnaires }\end{array}$ & - Nursing caregivers (exp. wards) \\
\hline - Success conditions & $\begin{array}{l}\text { Qualitative } \\
\text { - Interviews }\end{array}$ & $\begin{array}{l}\text { - Project co-ordinators } \\
\text { - Supervisors (exp. wards) }\end{array}$ \\
\hline $\begin{array}{l}\text { Job characteristics } \\
\text { - Job autonomy } \\
\text { - Job demands } \\
\text { - Social support } \\
\text { - Responsibility }\end{array}$ & $\begin{array}{l}\text { Quantitative } \\
\text { - Questionnaires }\end{array}$ & - Nursing caregivers \\
\hline $\begin{array}{l}\text { Psychological and behavioural reac- } \\
\text { tions } \\
\text { - Job satisfaction } \\
\text { - Intrinsic work motivation } \\
\text { - Health complaints } \\
\text { - Frequency of sickness absence }\end{array}$ & $\begin{array}{l}\text { Quantitative } \\
\text { - Questionnaires }\end{array}$ & - Nursing caregivers \\
\hline $\begin{array}{l}\text { Demographic and ward characteris- } \\
\text { tics } \\
\text {-Demographic characteristics (i.c.age, } \\
\text { gender, education, degree of em- } \\
\text { ployment, ward experience and } \\
\text { working hours) } \\
\text { - Ward characteristics (i.c. type of } \\
\text { group, type of ward, type of organisa- } \\
\text { tion, and careload) }\end{array}$ & $\begin{array}{l}\text { Quantitative } \\
\text { - Questionnaires }\end{array}$ & - Nursing caregivers \\
\hline
\end{tabular}

Table 4.2 presents an overview of the measuring methods. At three measurements data were collected by means of written questionnaires distributed among nursing caregivers of all research wards and by means of interviews with project co-ordinators and supervisors, participant observations and charting of the residents' dossiers on the experimental wards.

\subsection{Design of the study}

A non-equivalent control group pre-test post-test design was adopted for this study which is presented in figure 4.2. Among the quasi-experimental designs, this is the strongest design because of the possibility to investigate equality between the experi- 
mental and control groups with regard to the research variables at baseline (cf. Cook \& Campbell, 1979; Polit \& Hungler, 1999). Due to the impossibility of randomisation in our study, some threats with regard to validity have to be considered which are discussed in section 4.6. Three nursing homes were included in our study. At three measuring moments, before the implementation and 6 and 16 months after the start six experimental wards ( 3 somatic and 3 psycho-geriatric wards with implementation) were compared with the six control wards ( 3 somatic and 3 psycho-geriatric wards without implementation). So, the implementation phase involved 16 months $(6+3+7$ months).

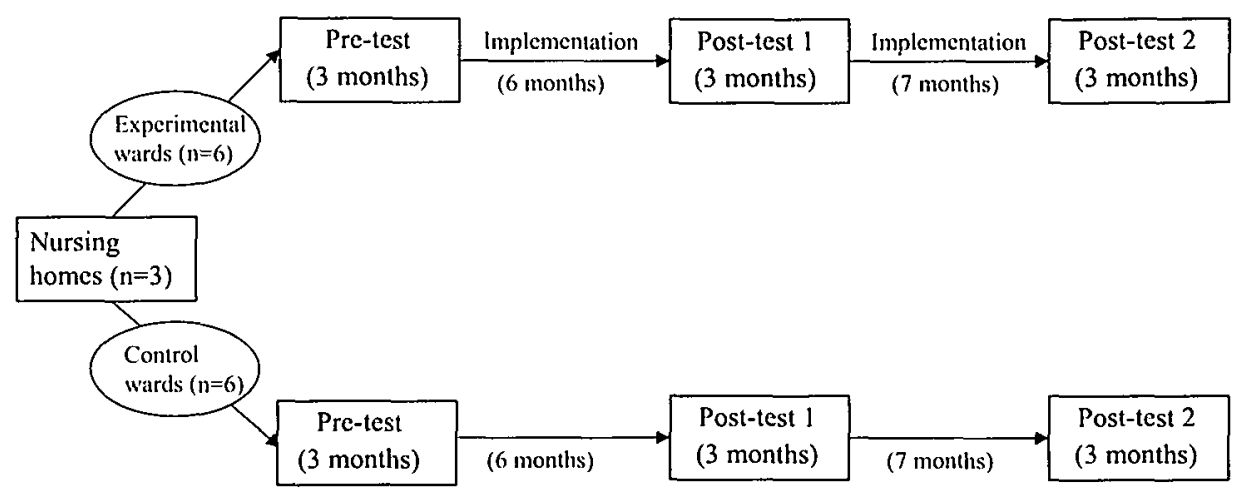

Figure 4.2 The design of the study

\subsection{Description of the intervention}

\subsubsection{Introduction}

The reliability of an intervention pervasive in most kinds of field experiments can be a threat to internal validity in quasi-experimentation, namely statistical conclusion validity (i.e. drawing valid conclusions about whether two variables covary) (Cook \& Campbell, 1979). In this respect Cook \& Campbell (1979) argue that the way an intervention is implemented can differ depending on the persons implementing it or the occasion under which it is implemented. Lack of standardisation both within and between persons implementing it will inflate error variance and decrease the chance of obtaining true differences. In controlling this threat, an intervention has to be made as standard as possible (Cook \& Campbell, 1979). Therefore, to reach maximal uniformity we defined in outline the design characteristics of a resident-oriented care model to be implemented by the nursing homes and some preconditions for its implementation. To gain insight into the planned and unplanned variability of the design and its implementation a project structure was set up. Aims were for the nursing homes being able to co-ordinate the elaboration and implementation of the resident-oriented care model, and for the researchers being informed in this respect (cf. Cook \& Campbell, 1979). This project structure entailed both a steering and an advisory group. The steering group comprised members of the nursing management of the three nursing homes and 
the researchers of Maastricht University. Main tasks were initiation, co-ordination and steering of the development of the design and the implementation on project level. The advisory group involved supervisors of the experimental wards, the project coordinators of the three nursing homes and the researchers of Maastricht University. The main tasks of the advisory group were initiation, co-ordination, and monitoring of the development of the design and the implementation on ward level by means of exchanging information and mutual advising. Agreements were made between the participating nursing homes and the researchers concerning their mutual responsibilities. The nursing homes were responsible for a further elaboration of the model, the implementation and effects. The researchers were responsible for the scientific evaluation and had an advisory task. To prevent researcher's bias towards the effects, no responsibility was taken for the elaboration of the resident-oriented care model and its implementation (Polit \& Hungler, 1999). In the following subsections the characteristics of a resident-oriented care model to be implemented by the nursing homes and the preconditions for its implementation as being defined by us in outline are presented.

\subsubsection{Resident-oriented care model}

The characteristics of the resident-oriented care model to be elaborated and implemented in the three nursing homes were based on the four design characteristics selected in our study, namely resident assignment, use of the nursing process, tasks and communication.

\section{Resident assignment}

Resident assignment was defined as the assignment of residents to so-called PNC's and the delegation of accompanying responsibilities and accountabilities (Marram et al., 1979; Manthey, 1980; Koene et al., 1982; Molleman, 1989; Bond et al., 1991b; Kivimäki et al., 1995). To assure co-ordination and continuity of care, this responsibility entails the planning, performance and evaluation of nursing care for a continuous period (if possible from admission until discharge). The integration of somatic and psychosocial care and an individual approach to the resident were emphasised, elaborated in the following ways:

- Division of the ward into organisational units in which residents were assigned;

- Adjustment of daily practice to meet the principles of resident-oriented care;

- Adjustment of duty rosters to guarantee continuity.

\section{Use of the nursing process}

For the nursing process the following five phases were distinguished: taking nursing history, identifying nursing problems, determining goals, planning the actions, performing the actions and evaluating them (Marram et al., 1979; Manthey, 1980; Koene et al., 1982; Molleman, 1989; Alcock et al, 1993). For the co-ordination and continuity of nursing care the phases had to be reported in a resident's dossier including a nursing care plan. 


\section{Tasks}

The delegation of the responsibility and accountability for the total nursing care of assigned residents to PNCs was considered as the key part (Marram et al., 1979; Manthey, 1980; Boekholdt, 1981; Koene et al., 1982; Molleman, 1989; Degerhammer \& Wade, 1991; Gardner, 1991; Thomas, 1993; Heeremans et al., 1994; Vlerick, 1996). As a consequence it was assumed that the supervisor would be less involved in direct care and more focused on policy issues and on coaching and supporting the nursing caregivers on the ward. The role of the ward sisters would be more focused on coaching, training on-the-job and stimulating of nursing caregivers in their role of PNCs. As such they would act more as the "primus interpares" and less hierarchical.

\section{Communication}

The communication structure had to support the co-ordination and continuity of care, an individual approach to residents and the individual as well as team responsibility (Marram et al., 1979; Manthey, 1980; Boekholdt, 1981; Koene et al., 1982; Bekkers et al., 1990; MacGuire \& Botting, 1990; Thomas, 1993; Bekkers \& Hogeling, 1994; Heeremans et al., 1994). Therefore the following communication forms were considered as important:

- Patient- or resident-oriented communication forms: multi- or mono-disciplinary meetings to co-ordinate total nursing care of the individual residents and to elaborate care plans;

- Profession-oriented communication forms: collegial consultation or 'intervision' to foster collegial support and to guarantee quality of individual performance;

- Organisation-oriented communication forms: team- or ward-oriented meetings to co-ordinate team or ward level policy in relation to organisation-wide policy.

These design characteristics were mainly structural. Besides, the development of a resident-oriented view was considered important to strengthen the focus of the implementation and to stimulate a resident-oriented attitude of nursing caregivers (Pontin, 1999).

\subsubsection{Preconditions of the implementation}

The responsibilities of the three nursing homes involved the elaboration and implementation of a resident-oriented care model. Therefore, following Wijnen et al. (1988), we advised each nursing home to install an accompanying project structure and appoint a project co-ordinator in order to prepare, monitor and support the implementation and to avoid extra workload for the formal organisation. As such, project and work groups had to be set up to elaborate a general implementation model including a realistic action plan. The responsibility also entailed monitoring, coaching and support of the implementation on the experimental wards. Project co-ordinators had to be appointed to co-ordinate the implementation in their organisations. Finally, we recommended extra education by means of special meetings and training-on-the-job in order to clarify the tasks, roles and function of nursing caregivers in a resident-oriented care model. 


\subsection{Population of the study}

\subsubsection{Introduction}

In this section the selection criteria are discussed with regard to the nursing homes, the research wards and the nursing caregivers. In appendix 3 characteristics of the nursing homes (table 3.1) and of the research wards (table 3.2) are presented.

\subsubsection{Selection criteria nursing homes}

Our study was aimed at the evaluation of the model of resident-oriented care in nursing homes, the implementation and the effects. Therefore, willingness to change and motivation to meet the implementation requirements on the experimental wards were selection criteria for the nursing homes approached for participation. Next, to establish an experimental design, in each nursing home both experimental and control wards had to be selected, the latter ones being committed to not implementing (parts of) a resident-oriented care model until the last post-test was finished. Furthermore, to establish a pre-test post-test design, implementation of a resident-oriented care model or parts of it should not have been implemented before (Cook \& Campbell, 1979). Finally, potential bias due to type of ward or regional factors was controlled for by selecting combined nursing homes with somatic as well as psycho-geriatric care in the south and the north of the Netherlands (Boumans, 1990; De Jonge, 1995).

\subsubsection{Selection criteria research wards}

In each nursing home two somatic and psycho-geriatric experimental wards and two somatic and psycho-geriatric control wards were selected. For reasons such as commitment, wards were assigned to the experimental or the control condition by the management of the nursing homes. So, randomisation could not be performed. Therefore, some threats concerning internal and external validity had to be considered. Cook \& Campbell (1979) define internal validity as "the approximate validity with which we infer that a relationship between two variables is causal or that the absence of a relationship implies the absence of a cause" (Cook \& Campbell, 1979, pp. 37). For quasiexperimental designs in particular, selection has to be considered as a major threat to internal validity, i.e. presence of intervention effects due to pre-existing differences between groups and not to the intervention itself (Cook \& Campbell, 1979; Polit \& Hungler, 1999). To reduce the threats, wards were selected on base of not having a resident-oriented care model, comparability of type of ward and careload, number of beds and bed occupation and personnel structure. Another threat to internal validity is contamination, i.e. the diffusion or imitation of treatment in the control group (Cook \& Campbell, 1979). Furthermore, Cook \& Campbell (1979) point out on risks of compensatory equalisation of treatments, rivalry or resentful demoralisation when the control group receives a treatment perceived as less desirable at a later stage or no treatment at all. Therefore, to minimise the risks of contamination, the commitment of the nursing homes was asked to maintain the status quo on the control wards. To get more insight into this problem the steering and advisory groups were asked for regular re- 
porting and feedback regarding developments on the control wards. Finally, by means of interviews, project co-ordinators were asked to describe the state of affairs on the control wards per measurement. To analyse differences between the two groups with respect to demographic variables and careload and with regard to attrition, confounders need to be detected and controlled for (Polit \& Hungler, 1999). External validity is defined as "the approximate validity with which we can infer that the presumed causal relationship can be generalised across alternate measures of cause and effect and across different types of persons, settings and times" (Cook \& Campbell, 1979, pp. 37). To ensure representativeness, nursing wards were selected with general longstay nursing home care. Another threat to external validity involves interactions of treatment with type of ward and/or type of organisation. In trying to minimise this risk a matched design was established by stratifying the nursing wards. From each nursing home an equal number of general long-stay somatic and psycho-geriatric wards were selected in both the experimental and control group (Cook \& Campbell, 1979; Polit \& Hungler, 1999). Finally, instability of data can be considered as one of the threats to statistical conclusion validity: this entails drawing false conclusions about population covariation from unstable sample data (Cook \& Campbell, 1979). Therefore, wards with foreseen re-organisations, renovations, changes in ward management or other planned changes, were excluded from the research.

\subsubsection{Selection criteria nursing caregivers}

To ensure internal validity of the observations of the work situation, a homogenous sample was selected (Cook \& Campbell, 1979). From the total population of nursing caregivers of the research wards only those nursing caregivers were included in the final sample with ward experience of more than three months, who had graduated as a registered or enrolled nurse, and who were working as a bedside nurse (cf. Boumans, 1990; De Jonge, 1995).

\subsection{Research procedure}

Before each measurement, the research procedure was communicated and data collection was planned with supervisors and project co-ordinators. In addition, all nursing caregivers of the research wards were informed by means of letters about the measurement procedures. Verbal information was given during ward meetings, day shifts or coffee breaks. All nursing caregivers, actually present on the ward during the three measuring periods werc approached for participation in the quantitative measurements. Employees absent due to illness, pregnancy or holidays were not approached for participation. Written questionnaires were not distributed to home addresses. In one organisation, questionnaires were filled in during working hours on the wards. After each measurement the measurement procedures were evaluated together with project co-ordinators and supervisors. In these evaluations subjects were discussed such as dealing with confidential data. 


\subsection{Response, dropout and baseline sample}

The response is shown in table 4.3. The wave response at the three measurements varied around $96 \%$. Application of the inclusion criteria took place afterwards (see 4.6). The sample was followed as a cohort during 22 months. Only those nursing caregivers who had participated in the pre-test were involved in the analyses of the two post-tests. In the end, 210 (pre-test), 167 (post-test 1) and 147 (post-test 2) nursing caregivers were involved in the analyses.

Table 4.3 Response nursing caregivers

\begin{tabular}{|c|c|c|c|c|c|c|}
\hline \multirow[t]{2}{*}{ Measurement } & \multirow{2}{*}{$\begin{array}{c}\text { Recipients } \\
\text { n }\end{array}$} & \multicolumn{2}{|c|}{ Wave response } & \multirow{2}{*}{$\begin{array}{c}\text { Participants } \\
\text { included } \\
n\end{array}$} & \multicolumn{2}{|c|}{$\begin{array}{l}\text { Continuous participants in- } \\
\text { cluded after pre-test }\end{array}$} \\
\hline & & $\mathrm{n}$ & $\%$ & & $\mathrm{n}$ & $\%$ \\
\hline pre-test total & 286 & 275 & $96 \%$ & 210 & - & - \\
\hline experimental & 144 & 136 & $94 \%$ & 101 & - & - \\
\hline control & 142 & 139 & $98 \%$ & 109 & - & - \\
\hline post-test I total & 277 & 268 & $97 \%$ & 201 & 167 & $80 \%$ \\
\hline experimental & 141 & 136 & $96 \%$ & 97 & 79 & $78 \%$ \\
\hline control & 136 & 132 & $97 \%$ & 104 & 88 & $81 \%$ \\
\hline post-test 2 total & 300 & 289 & $96 \%$ & 219 & 147 & $70 \%$ \\
\hline experimental & 149 & 142 & $95 \%$ & 103 & 69 & $68 \%$ \\
\hline control & 151 & 147 & $97 \%$ & 116 & 78 & $72 \%$ \\
\hline
\end{tabular}

Differential attrition from groups being compared is always a threat to internal validity in case of a long follow-up (Cook \& Campbell, 1979; Polit \& Hungler, 1999). According to Cook \& Campbell (1979), the possibility of a selection artefact resulting from differential attrition can be best empirically assessed in two ways. First, an analysis is conducted of the proportion of respondents, originally assigned to each condition that actually provide post-test data. Differences in the proportion across treatments indicate a differential dropout. Second, an analysis is conducted of the pre-test scores in each treatment group computed on basis of all those who provided post-test data. This gives an indication of whether the dropouts differed across groups on background characteristics that are likely to affect the post-test scores (Cook \& Campbell, 1979). Before the analyses of the differences between the experimental and control groups, the influence of dropout was investigated with respect to type of group (experimental versus control), the demographic and ward characteristics and all pre-test scores of the study variables by means of a Chi-square test and logistic regression analyses. Therefore, analyses were conducted on all pre-test included participants $(n=210)$ in comparing the groups who did not respond in post-test 1 and 2 to the group who responded in the pretest. With respect to dropout in the first and last post-test, a Chi-square test revealed no differences in proportion between the experimental and control groups indicating no differential dropout (post-test $1: \chi^{2}=0.204, p=0.652$; post-test $2: \chi^{2}=0.263, p=0.608$ ). Tables 4.4 and 4.5 show the final models of logistic regression of dropout in the two post-tests. The demographic variables, careload and all research variables were entered as covariates in the initial regression model. Stepwise deletion took place of covariates $p>0.1$ except for "type of group" and covariates $p \leq 0.10$, which were retained in the final regression model. Preliminary check showed no multicollinearity between predictors. 
Table 4.4 Final logistic regression model dropout post-test $1^{\text {in }}$

\begin{tabular}{|c|c|c|c|c|c|c|}
\hline Variable & $\mathrm{B}$ & Std. Error & $\chi^{2}$ (Wald) & Sig. & $\begin{array}{l}\text { Log likeli- } \\
\text { hood ratio } \\
(-2 \log \text { LR })\end{array}$ & $\begin{array}{l}\text { Sig. } \log \\
\text { LR }\end{array}$ \\
\hline Type of group & -0.1413 & 0.4042 & 0.1222 & 0.7267 & & \\
\hline Age & 0.0761 & 0.0321 & 5.6387 & 0.0176 & 6.605 & 0.0102 \\
\hline Health complaints & -0.1231 & 0.0584 & 4.4476 & 0.0349 & & \\
\hline Ward oriented-tasks & -0.6259 & 0.2911 & 4.6225 & 0.0316 & 4.951 & 0.0261 \\
\hline Constant & 1.7433 & 1.4645 & 1.4169 & 0.2339 & & \\
\hline
\end{tabular}

a) $\operatorname{model} \chi^{2}=15.981, p=0.003$

b) drop-out post-test 1:0=non-responders $(n=43), 1=$ responders $(n=167)$

c) type of group: 0 =control wards, $1=$ experimental wards

Table 4.5 Final logistic regression model dropout post-test $2^{\text {a.b }}$

\begin{tabular}{|c|c|c|c|c|c|c|}
\hline Variable & B & Std. Error & $\chi^{2}$ (Wald) & Sig. & $\begin{array}{l}\text { Log likeli- } \\
\text { hood ratio } \\
(-2 \log \text { LR) }\end{array}$ & $\begin{array}{l}\text { Sig. } \log \\
\text { LR }\end{array}$ \\
\hline Type of group" & -0.2833 & 0.3808 & 0.5534 & 0.4569 & & \\
\hline Type of ward & -1.0734 & 0.3895 & 7.5928 & 0.0059 & 8.110 & 0.0044 \\
\hline Age & 0.0578 & 0.0265 & 4.7712 & 0.0289 & & \\
\hline Job autonomy & 0.6802 & 0.3539 & 3.6931 & 0.0545 & & \\
\hline Qual. of communic. forms & -0.7127 & 0.3844 & 3.4374 & 0.0637 & & \\
\hline Health complaints & -0.1051 & 0.0530 & 3.9313 & 0.0474 & & \\
\hline Nursing care plans & 0.8062 & 0.3049 & 6.9891 & 0.0082 & & \\
\hline Nursing history & -1.0083 & 0.4002 & 6.3467 & 0.0118 & & \\
\hline Freq. of sickness absence & -1.6490 & 0.8013 & 4.2355 & 0.0396 & & \\
\hline Constant & 2.7358 & 2.1739 & 1.5838 & 0.2082 & & \\
\hline
\end{tabular}

a) model $\chi^{2}=36.336, p=0.000$

b) drop-out post-test 2: $0=$ non-responders $(n=63), 1=$ responders $(n=147)$

c) type of group: $0=$ control wards, $1=$ experimental wards

d) type of ward: $0=$ somatic wards; $1=$ =psycho-geriatric wards

As is seen in both tables, using a $\mathrm{p} \leq 0.01$ to correct for multiple testing (two-tailed), the drop-out in the experimental group was almost the same as, and not significantly different from, the drop-out in the control group at both post-tests (post-test 1: Waldtest $=0.122, \mathrm{p}>0.7$; post-test 2 : Wald-test $=0.55, \mathrm{p}>0.4$ ). In addition, none of the predictors was significantly associated with drop-out in the first post-test. In the second posttest, type of ward seemed to be associated with drop-out. On the psycho-geriatric wards a larger dropout was shown than on the somatic wards (Wald-test $=7.59$, $\mathrm{p} \leq 0.01)$.

In table 4.6 a brief description is given of the baseline sample (see appendix 4 , tables 4.1 to 4.3 for a more detailed description of the sample at all three measurements). In the pre-test $(\mathrm{n}=210)$ women formed the majority of the sample $(90 \%)$ and the mean age was over 31 years $(93 \%)$. Mean ward experience was over 5 years and most of the participants had mid-level education (59\%). The mean degree of employment (of a full-time equivalent) was over $71 \%$ and the majority (95\%) of the nursing caregivers were working variable working hours. These demographic sample characteristics are comparable to sample characteristics found in other large-scale cross-sectional studies in the Netherlands (Boumans, 1990; De Jonge, 1995; Van der Windt et al., 1999). On the pre-test no significant differences were found between the experimental and control groups on gender, age, ward experience, degree of employment (of the fulltime equivalent), education and working hours. 
Table 4.6 Description of the baseline sample

\begin{tabular}{llll}
\hline Demographic characteristics & $\begin{array}{l}\text { Experimental group } \\
\mathrm{n}=101\end{array}$ & $\begin{array}{l}\text { Control group } \\
\mathrm{n}=109\end{array}$ & $\begin{array}{l}\text { Total group } \\
\mathrm{n}=210\end{array}$ \\
\hline percentage of women & $90 \%$ & $96 \%$ & $93 \%$ \\
mean age & 31.8 years $(8.3)$ & 31.6 years $(8.9)$ & 31.7 years $(8.6)$ \\
mean ward experience & 5.6 years $(4.2)$ & 4.8 years $(3.7)$ & 5.2 years $(4.0)$ \\
mean degree of employment & $71.9 \%(25.9 \%)$ & $70.9 \%(25.5 \%)$ & $71.4 \%(25.6 \%)$ \\
percentage of midlevel education & $54 \%$ & $64 \%$ & $59 \%$ \\
percentage of variable working hours & $94 \%$ & $95 \%$ & $95 \%$ \\
\hline
\end{tabular}

a) standard deviations in parentheses

\subsection{Analyses}

The aim of the study was to evaluate the model, the implementation and the effects of resident-oriented care by means of three measuring moments, a pre-test and two posttests. During the first post-test the intervention had not yet been fully implemented, so intervention effects could expected to be only marginally. While we wanted to estimate a true intervention effect, which could only be investigated on the last post-test, the first post-test was used as a secondary descriptive measurement to discuss the short- and long-term effects of the implementation. This serves to reduce the risk of committing of multiple testing error too. To analyse the quantitative data, descriptive and inferential statistics were used. With regard to descriptive statistics, means and standard deviations were used to describe the differences between the experimental and control groups on the pre-test and both post-tests. For testing the hypotheses multilevel analyses would be the most suitable technique. However, for this study it was not found to be feasible for reasons of the small $\mathrm{n}$. So, with respect to inferential statistics, analyses of covariance (ANCOVA) and regression analyses were used to investigate the differences between the experimental and control groups in the pre-test and last post-test. Before the regression analyses on the last post-test, first- and second-order interaction effects were studied between condition (experimental versus control) on the one hand and type of ward (somatic versus psycho-geriatric) and/or type of organisation (A, B versus $C$ ) on the other hand with ANCOVAs and regression analyses.

All demographic and ward characteristics and the pre-test value of the dependent variable at hand were entered into the analyses as covariates in order to control for them, since they may confound the effects on the dependent variables (cf. Boumans, 1990; De Jonge, 1995; Polit \& Hungler, 1999). Finally, rank correlations were conducted to investigate the associations between the quantitative variables of the implementation characteristics and the extent to which a resident-oriented care model is realised on the experimental wards. To analyse the qualitative data, a topic list of Bekkers et al. (1990) and the 7-S model of Peters \& Waterman (1982) were used for analysing the design and implementation characteristics respectively. In figure 4.3 the analyses are shown in outline per research question. 


\begin{tabular}{|c|c|}
\hline $\begin{array}{l}1 . \\
a\end{array}$ & $\begin{array}{l}\text { To what extent are the various characteristics of resident-oriented care implemented? } \\
\text { Quantitative analyses }\end{array}$ \\
\hline - & $\begin{array}{l}\text { Means and standard deviations for describing the pre-and post-tests differences between the ex- } \\
\text { perimental and control groups regarding the design characteristics; }\end{array}$ \\
\hline - & $\begin{array}{l}\text { Analyses of covariance (ANCOVA) to investigate the pre-test differences between the experimental } \\
\text { and control groups regarding the design characteristics corrected for the covariates type of ward, } \\
\text { type of organisation, gender, age, education, degree of employment, ward experience, working hours } \\
\text { and careload; }\end{array}$ \\
\hline - & $\begin{array}{l}\text { Analyses of covariance (ANCOVA) to investigate the presence of last post-test first-and second- } \\
\text { order interaction effects regarding the design characteristics corrected for the covariates type of } \\
\text { ward, type of organisation, gender, age, education, degree of employment, ward experience, working } \\
\text { hours and careload and the pre-test value of the dependent variable at hand; }\end{array}$ \\
\hline • & $\begin{array}{l}\text { Regression analyses to investigate the last post-test differences between the experimental and control } \\
\text { groups regarding the design characteristics corrected for the covariates type of ward, type of organi- } \\
\text { sation, gender, age, education, degree of employment, ward experience, working hours and careload } \\
\text { and the pre-test value of the dependent variable at hand. }\end{array}$ \\
\hline$b$ & Qualitative analyses \\
\hline - & $\begin{array}{l}\text { Description of the pre- and post-tests interviews with the project co-ordinators and supervisors of the } \\
\text { cxperimental wards regarding the design characteristics by means of the topic list of Bekkers et al. } \\
\text { (1990). }\end{array}$ \\
\hline - & $\begin{array}{l}\text { Description of the pre- and post-tests participant observations on the experimental wards regarding } \\
\text { the design characteristics by means of the topic list of Bekkers et al. (1990). }\end{array}$ \\
\hline - & $\begin{array}{l}\text { Description of the residents' dossiers of the experimental wards on the pre- and post-tests by means } \\
\text { of the topic list of Bekkers et al. (1990). }\end{array}$ \\
\hline 2. & What are the conditions for successfully implementing resident-oriented care? \\
\hline$a$ & Quantitative analyses \\
\hline - & $\begin{array}{l}\text { Rank correlations on ward level (experimental wards) between the pre-test and last post-test of the } \\
\text { implementation characteristics information quality and socio-emotional and instrumental leadership } \\
\text { on the one hand and the last post-test of the extent of resident-oriented care on the other. }\end{array}$ \\
\hline$b$ & Qualitative analyses \\
\hline$\bullet$ & $\begin{array}{l}\text { Description of the pre-and post-tests interviews with the project co-ordinators and supervisors of the } \\
\text { experimental wards regarding the implementation characteristics by means of the 7-S model of Pe- } \\
\text { ters \& Waterman (1982). }\end{array}$ \\
\hline 3. & $\begin{array}{l}\text { What are the effects of the implementation of resident-oriented care on the job characteristics of } \\
\text { nursing caregivers and on their psychological and behavioural reactions? } \\
\text { Quantitative analyses }\end{array}$ \\
\hline - & $\begin{array}{l}\text { Means and standard deviations for describing the pre- and post-tests differences between the ex- } \\
\text { perimental and control groups regarding the job characteristics and the psychological and behav- } \\
\text { ioural reactions; }\end{array}$ \\
\hline$\bullet$ & $\begin{array}{l}\text { Analyses of covariance (ANCOVA) and regression analyses to investigate the pre-test differences } \\
\text { between the experimental and control groups regarding the job characteristics and the psychological } \\
\text { and behavioural reactions corrected for the covariates type of ward, type of organisation, gender, } \\
\text { age, education, degree of employment, ward experience, working hours and carcload. }\end{array}$ \\
\hline - & $\begin{array}{l}\text { Analyses of covariance (ANCOVA) and regression analyses to investigate the presence of last post- } \\
\text { test first-and second-order interaction effects regarding the job characteristics and the psychological } \\
\text { and behavioural reactions corrected for the covariates type of ward, type of organisation, gender, } \\
\text { age, education, degrec of employment, ward experience, working hours and careload and the pre-test } \\
\text { value of the dependent variable at hand. }\end{array}$ \\
\hline - & $\begin{array}{l}\text { Regression analyses to investigate the last post-test differences between the experimental and control } \\
\text { groups regarding the job characteristics and the psychological and behavioural reactions corrected } \\
\text { for the covariates type of ward, type of organisation, gender, age, education, degree of employment, } \\
\text { ward experience, working hours and careload and the pre-test value of the dependent variable at } \\
\text { hand. }\end{array}$ \\
\hline
\end{tabular}

Figure 4.3 Overview of the analyses per research question 


\section{DESIGN CHARACTERISTICS}

\subsection{Introduction}

This chapter provides an answer to the first research question, which is the extent to which the various characteristics of a resident-oriented care model are implemented. In this respect we try to test the four hypotheses formulated in chapter 4:

HIa) Resident assignment will increase in the experimental group compared to the control group after the implementation of resident-oriented care.

HIb) Use of the nursing process will increase in the experimental group compared to the control group after the implementation of resident-oriented care.

HIc) Number of tasks will extend in the experimental group compared to the control group after the implementation of resident-oriented care.

H1d) Communication will improve in the experimental group compared to the control group after the implementation of resident-oriented care.

The results are presented in two parts: first the quantitative results are presented (5.2) followed by the qualitative results (5.3). Both sections start with more detailed information about the data analyses. This chapter closes with a summary (5.4).

\subsection{Quantitative results}

\subsubsection{Analyses}

In this section a more detailed description of the quantitative analyses is presented. To analyse the quantitative data, descriptive as well as inferential statistics were used. As is shown in figure 5.1 the following procedure was used for the quantitative analyses:

a) Means and standard deviations were used to describe the pre- and post-tests differences between the experimental and control groups.

b) To get insight into pre-test differences between the experimental and control groups analyses of covariance (ANCOVA) were carried out. For that, the last post-test sample excluding the drop-outs was used $(n=147)$.

c) Prior to the regression analyses, the presence of last post-test first- and second-order interaction effects between type of group (experimental versus control group) on the one hand and type of ward (somatic versus psycho-geriatric) and/or type of organisation (A, B versus $\mathrm{C}$ ) on the other hand were investigated with ANCOVA, linear or logistic regression analyses. If interaction was found, a separate regression analysis was done within each level of the factor interacting with type of group. Stratification took place as presented in figure 5.2 .

d) To investigate last post-test differences between the experimental and control groups linear and logistic regression analyses were used. 


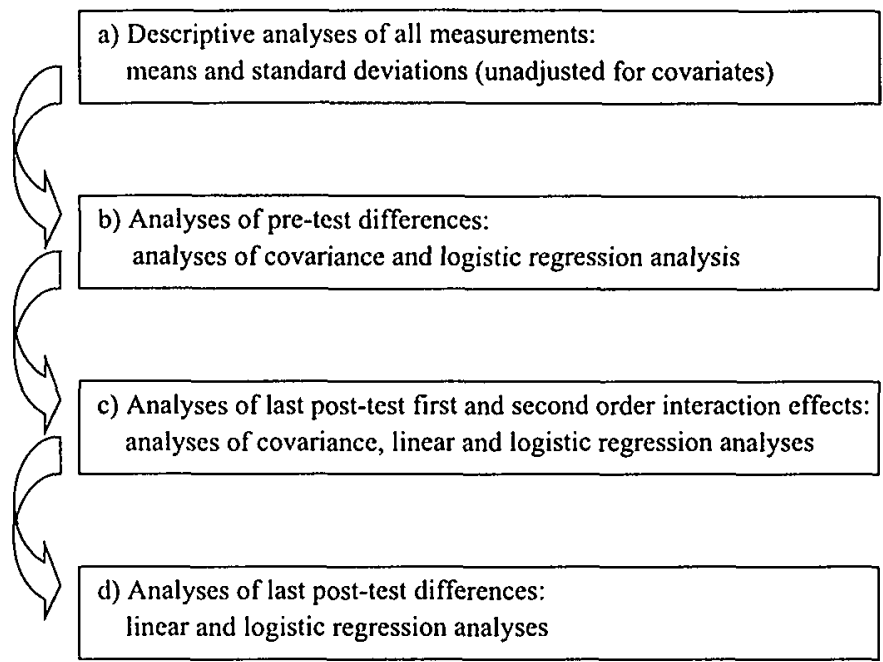

Figure 5.1 Overview procedure of the quantitative analyses

- "Type of group" with "type of ward" (first-order interaction): regression analyses per somatic and psycho-geriatric ward (two regression analyses).

- "Type of group" with "type of organisation" (first-order interaction): regression analyses per organisation $A, B$ and $C$ (three regression analyses).

- "Type of group" with "type of ward" and "type of group" with "type of organisation" (two first-order interactions): regression analyses for each somatic and psycho-geriatric group per organisation A, B and $\mathrm{C}$ (six regression analyses).

- "Type of group" with "type of organisation" with "type of ward" (second-order interaction): regression analyses per organisation $\mathrm{A}, \mathrm{B}$ and $\mathrm{C}$ to investigate the presence of first-order interaction effects namely "type of group" with "type of ward" (three regression analyses). With a non-significant first-order interaction effect, final regression analyses took place for the organisation as a whole. With a significant-first order interaction effect for that organisation, stratification took place and finally, regression analyses were performed for the somatic and psycho-geriatric group of this organisation separately (cf. Kleinbaum, Kupper, Muller \& Nizam, 1998).

Figure 5.2 Procedure for stratification

The method of regression analyses allows describing the strength and direction of the association between type of group (experimental versus control group) and several other independent variables and the dependent variable (cf. Kleinbaum et al., 1998). In other words, the regression method allows controlling for possible confounding variables such as age and the pre-test. By correcting for covariates as much as possible, power can be increased due to a reduced variability in scores, i.e. of error variance. This results in a decreased standard deviation of the sampling distributions and thus a greater experimental control (Tabachnik \& Fidell, 1989). In our study, type of group (experimental versus control), type of ward (somatic versus psycho-geriatric), type of organisation (A, B and C), the pre-tests of the biographic variables, the aggregated preand last post-tests of careload in the pre- and last post-test analyses respectively and, in the analyses of the last post-test, the pre-test value of the dependent variable at hand, 
were entered as covariates into all ANCOVAs and regression analyses (Berkhout et al., 1998a and b; Berkhout, Boumans, Nijhuis \& Huijer Abu-Saad, in preparation). Entering type of ward and type of organisation enabled us to correct for differences between somatic and psycho-geriatric wards and organisations. In the analyses of the last post-test the pre-tests of the biographic variables were used to exclude possible intervention effects and the last post-test of careload was used because, independent of the intervention, the resident population was expected to change during the measurement period. In checking this we did not find an intervention effect on the last post-test of careload on individual level in the study on the effects for residents $(B=-0.188$; $p=0.725, n=92)$ nor on aggregated level $(B=0.377 ; p=0.304, n=12)$ both corrected for the pre-test (Berkhout et al., 1998b). So, the aggregated last post-test on careload could be used as a covariate in the last post-test analyses.

Regression analyses were treated hierarchically based on manual backward elimination of non-significant covariates ( $p>0.1$ ). It was started with a complete model including all covariates and potential interactions. First, potential interaction effects were tested. The least significant interactions were removed from the model until only significant interactions remained. Stratification took place in case interaction effects were significant and when type of group with respect to size or direction was dependent of type of ward or type of organisation. Second, the main effects, i.e. type of group and the pre-test of the dependent variable at hand, were tested by removing non-significant covariates one after the other if $p>0.10$. Besides "type of group" and "the pre-test of the dependent variable at hand", significant covariates of $\mathrm{p} \leq 0.01$ remained in all final regression models. So, the sparsest model was sought to get the best estimate for the assumed model. It has to be noticed that "type of organisation" was measured by two dummy variables, which were tested simultaneously. To reduce the risk of multiple testing errors, a strict level of $\mathrm{p} \leq 0.01$ was used for conclusions about effects. To prevent the risk of committing type II errors, results of $0.01 \leq \mathrm{p}<0.1$ are mentioned as indicative. Regression analysis permits insight into violation of important assumptions. The following assumptions were checked: linearity of the effects of continuous covariates, absence of collinearity between predictors (all VIFs $<10$ ), normality of the residuals, absence of influential cases (Cook's distance). No serious violations were found, except for some influential cases. If an influential case was found, the regression analysis was repeated without this case to check the robustness of the treatment effect. With respect to social support some problems appeared with respect to collinearity, which are discussed in chapter 7. Finally, in investigating interaction effects strong correlations (collinearity) can appear between the linear and interaction terms. This problem was solved by centering the linear terms before computing the interaction terms (Aiken \& West, 1991).

The current study concerns a quasi-experiment with non-equivalent groups, which means that baseline differences have to be taken into account. Analysing the last posttest corrected for the pre-test can reflect some underadjustment for real baseline differences. Analysing the change scores only (post-test 2 - pre-test) would reflect an overadjustment for baseline differences. So, conclusions about significance will be found somewhere in the middle. Therefore, in case of baseline differences, we com- 
pared the results found in the last post-test analyses (corrected for the pre-test) and the analyses of the change scores. No problems were revealed in that both types of analyses led to comparable conclusions.

Because the focus of the implementation was a job redesign intervention for PNCs in particular, we performed additional subgroup analyses to investigate the effects for this group and for nursing caregivers with no residents assigned separately. The criterion for becoming a PNC was an employment degree of $70 \%$ or more. Based on this, we constructed a dichotomous variable "nurse function" comprised of two subgroups. One subgroup $(n=79)$ consisted of PNCs from the experimental group and a comparable group nursing caregivers from the control wards with an employment degree of $70 \%$ or more. The other subgroup $(n=68)$ consisted of associate nursing caregivers of the experimental group with no residents assigned and a comparable group nursing caregivers from the control wards with an employment of less than $70 \%$. Before performing the subgroup analyses, we investigated the presence of interaction effects between "type of group" and "nurse function" (PNCs and associate nursing caregivers versus their control groups). Because of the importance to detect interaction effects a level of $\mathrm{p} \leq 0.1$ was established to prevent type II errors. With respect to the design characteristics interaction effects were found between "type of group" and "nurse function" with respect to "resident-oriented tasks" $(\mathrm{F}=2.757, \mathrm{p}=0.099, \mathrm{df}(1,119), \mathrm{n}=142)$ and "variety of ward-oriented communication forms" ( $F=2.949, p=0.089, \mathrm{df}(1,116), \mathrm{n}=139)$ indicating that a subgroup analysis was useful for these two variables (see for results in subsection 5.2.2).

Quantitative measurement of the design characteristics was taken by means of eight variables (see chapter 4 ). In the following subsection the quantitative analyses are presented for these variables. In order to test the hypotheses final results regarding the last post-test differences between the experimental and control groups are presented onetailed. Appendix 5, tables 5.1 a to 5.4e, shows all final regression models (two-tailed).

\subsubsection{Results}

\section{Resident assignment}

Table 5.1 and figure 5.3 show the expected increase of resident assignment in the experimental group in both post-tests compared to the pre-test and to the control group. This increase has clearly started in the first post-test. Next, some slight increase is seen in the last post-test of the control group too.

The ANCOVA showed no differences at baseline between the experimental and control groups $(F=0.730, p=0.394, \mathrm{df}(1,125), \mathrm{n}=143)$. Further, on the last post-test two first-order interactions were found between "type of group" and "type of organisation" $(\mathrm{F}=29.612, \mathrm{p}=0.000, \mathrm{df}(2,118), \mathrm{n}=137)$ and between "type of group" and "type of ward" ( $F=63.802, \mathrm{p}=0.000, \mathrm{df}(1,118), \mathrm{n}=137)$. So, stratification took place per organisation for the somatic and psycho-geriatric group separately and thus six regression analyses were conducted (see also appendix 5, tables 5.1a-f). 
Table 5.1 Resident assignment (unadjusted means)

\begin{tabular}{llllllllllr}
\hline & pre-test & \multicolumn{3}{c}{ post-test 1 } & \multicolumn{4}{c}{ post-test 2 } \\
& Mean & SD & $\mathrm{n}$ & Mean & SD & $\mathrm{n}$ & Mean & SD & \multicolumn{1}{c}{$\mathrm{n}$} \\
\hline experimental group & 1.53 & 0.78 & 100 & 4.08 & 0.51 & 79 & 4.21 & 0.42 & 69 \\
control group & 1.61 & 0.85 & 106 & 1.58 & 0.79 & 87 & 1.81 & 1.04 & 71 \\
total group & 1.57 & 0.82 & 206 & 2.77 & 1.42 & 166 & 2.99 & 1.44 & 140 \\
\hline
\end{tabular}

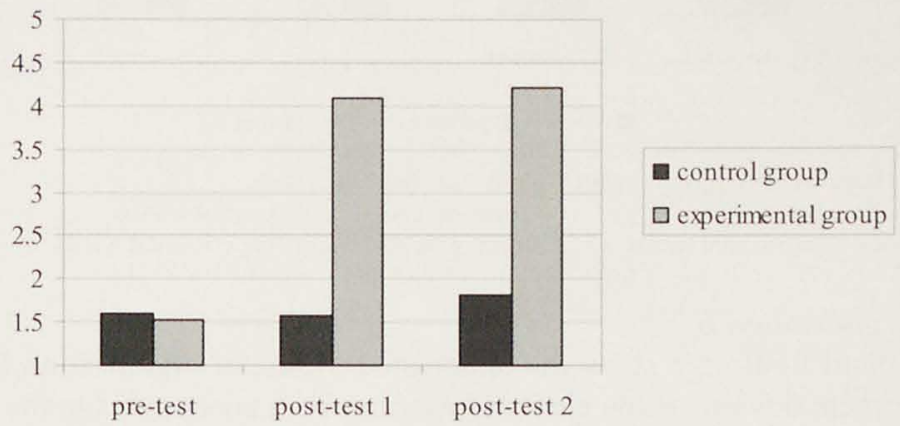

Figure 5.3 Resident assignment (unadjusted means)

\section{Results organisation $A$}

Table 5.2 and figure 5.4 show the unadjusted means of organisation A. Besides the expected increase on the experimental wards, the increase in the last post-test on resident assignment on the somatic control ward is surprisingly large and leads one to suspect treatment contamination between experimental and control wards.

Possibly due to this high score of the somatic control ward, no significant difference was found between the somatic experimental and control wards in the last post-test (adjusted mean difference $\mathrm{B}=0.164, \mathrm{p}=0.205$ ). On the psycho-geriatric wards, as expected, significantly more resident assignment was found in the last post-test on the experimental ward compared to the control ward after the implementation (adjusted mean difference $\mathrm{B}=3.076, \mathrm{p}=0.000$ ) (see also appendix 5, tables 5.1 $\mathrm{a}-\mathrm{b}$ ).

Table 5.2 Resident assignment organisation A (unadjusted means)

\begin{tabular}{|c|c|c|c|c|c|c|c|c|c|}
\hline & \multicolumn{3}{|c|}{ pre-test } & \multicolumn{3}{|c|}{ post-test 1} & \multicolumn{3}{|c|}{ post-test 2} \\
\hline & Mean & SD & $\mathrm{n}$ & Mean & SD & $\mathrm{n}$ & Mean & SD & $\mathrm{n}$ \\
\hline somatic experimental ward (somex) & 1.38 & 0.62 & 17 & 3.55 & 0.48 & 15 & 4.03 & 0.53 & 13 \\
\hline somatic control ward (somco) & 1.33 & 0.54 & 13 & 1.31 & 0.34 & 10 & 3.79 & 0.39 & 9 \\
\hline total somatic group & 1.36 & 0.58 & 30 & 2.65 & 1.20 & 25 & 3.93 & 0.47 & 22 \\
\hline p.g. experimental ward (pgex) & 1.63 & 0.62 & 17 & 4.39 & 0.29 & 14 & 4.41 & 0.45 & 11 \\
\hline p.g. control ward (pgco) & 1.43 & 0.64 & 17 & 1.50 & 0.59 & 16 & 1.36 & 0.30 & 11 \\
\hline total psycho-geriatric group & 1.53 & 0.63 & 34 & 2.85 & 1.54 & 30 & 2.88 & 1.60 & 22 \\
\hline
\end{tabular}




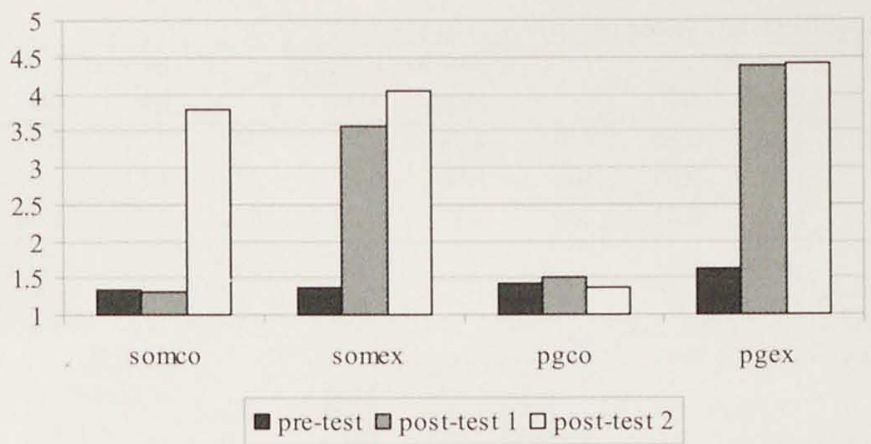

Figure 5.4 Resident assignment organisation A (unadjusted means)

somco: somatic control wards pgco: psycho-geriatric control wards somex: somatic experimental wards pgex: psycho-geriatric experimental wards

\section{Results organisation $B$}

Table 5.3 and figure 5.5 show the unadjusted means of organisation $\mathrm{B}$. The scores on the experimental wards show clear increases in both post-tests. On the psycho-geriatric control ward scores are moderately high from the pre-test onwards. Before the implementation a start had been made with resident assignment on this ward probably leading to relatively higher pre- and post-test scores.

Table 5.3 Resident assignment organisation B (unadjusted means)

\begin{tabular}{llllllllll}
\hline & pre-test & \multicolumn{3}{c}{ post-test 1 } & \multicolumn{4}{c}{ post-test 2 } \\
& Mean & SD & $\mathrm{n}$ & Mean & SD & $\mathrm{n}$ & Mean & SD & $\mathrm{n}$ \\
\hline somatic experimental ward (somex) & 2.04 & 1.17 & 12 & 4.38 & 0.35 & 11 & 4.20 & 0.42 & 9 \\
somatic control ward (somco) & 1.56 & 0.55 & 11 & 1.31 & 0.38 & 11 & 1.58 & 0.70 & 10 \\
total somatic group & 1.81 & 0.94 & 23 & 2.84 & 1.61 & 22 & 2.82 & 1.46 & 19 \\
p.g. experimental ward (pgex) & 1.13 & 0.32 & 15 & 4.09 & 0.31 & 10 & 3.92 & 0.30 & 10 \\
p.g. control ward (pgco) & 2.23 & 0.86 & 19 & 2.56 & 0.72 & 14 & 2.19 & 0.80 & 11 \\
total psycho-geriatric group & 1.74 & 0.87 & 34 & 3.20 & 0.96 & 24 & 3.01 & 1.07 & 21 \\
\hline
\end{tabular}

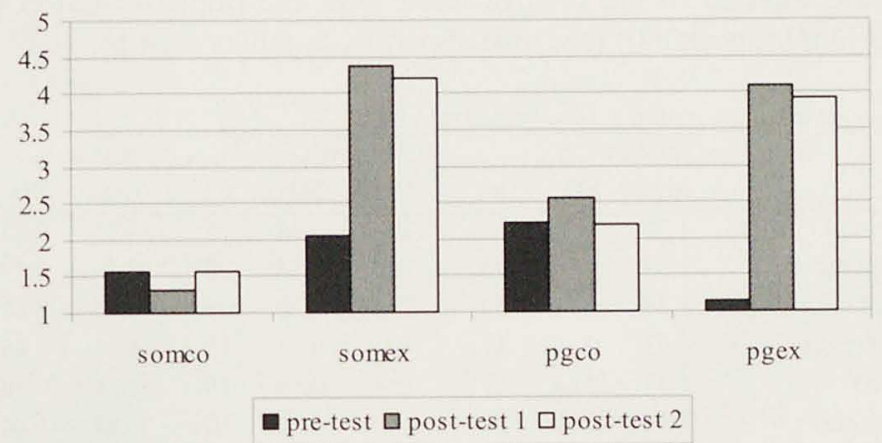

Figure 5.5 Resident assignment organisation B (unadjusted means)

somco: somatic control wards somex: somatic experimental wards pgco: psycho-geriatric control wards pgex: psycho-geriatric experimental wards 
The somatic experimental ward (adjusted mean difference $\mathrm{B}=2.707, \mathrm{p}=0.000$ ) and the psycho-geriatric experimental ward as well (adjusted mean difference $\mathrm{B}=2.108$, $\mathrm{p}=0.000$ ) revealed significantly more resident assignment compared to their control wards in the last post-test (see also appendix 5, tables 5.1c-d).

\section{Results organisation $C$}

Apart from the clear increases on the experimental wards in both post-tests, the unadjusted means of both control wards presented in table 5.4 and figure 5.6 show slight decreases in the last post-test on resident assignment.

Table 5.4 Resident assignment organisation C (unadjusted means)

\begin{tabular}{llllllllll}
\hline & \multicolumn{3}{c}{ pre-test } & \multicolumn{3}{c}{ post-test 1 } & \multicolumn{4}{c}{ post-test 2 } \\
& Mean & SD & $\mathrm{n}$ & Mean & SD & $\mathrm{n}$ & Mean & SD & $\mathrm{n}$ \\
\hline somatic experimental ward (somex) & 1.91 & 0.93 & 22 & 4.08 & 0.51 & 17 & 4.28 & 0.36 & 15 \\
somatic control ward (somco) & 1.70 & 0.99 & 24 & 1.48 & 0.84 & 21 & 1.44 & 0.91 & 19 \\
total somatic group & 1.80 & 0.96 & 46 & 2.64 & 1.49 & 38 & 2.69 & 1.60 & 34 \\
p.g. experimental ward (pgex) & 1.10 & 0.25 & 17 & 4.10 & 0.55 & 12 & 4.38 & 0.23 & 11 \\
p.g. control ward (pgco) & 1.30 & 0.89 & 22 & 1.29 & 0.78 & 15 & 1.09 & 0.14 & 11 \\
total psycho-geriatric group & 1.21 & 0.69 & 39 & 2.54 & 1.57 & 27 & 2.74 & 1.69 & 22 \\
\hline
\end{tabular}

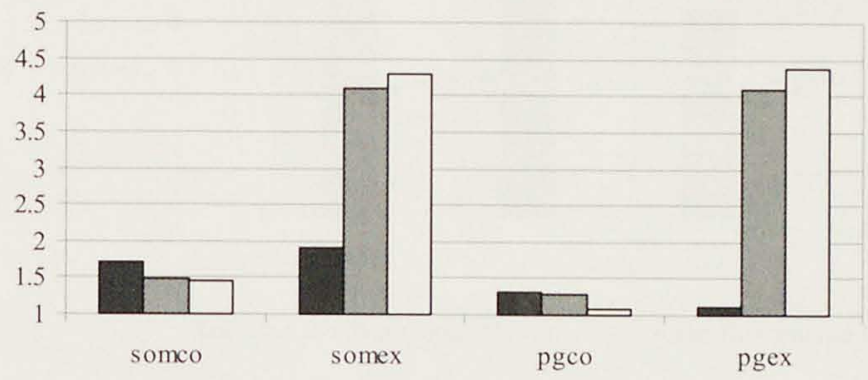

pre-test $\square$ post-test $1 \square$ post-test 2

Figure 5.6 Resident assignment organisation C (unadjusted means)

somco: somatic control wards

pgco: psycho-geriatric control wards

somex: somatic experimental wards

pgex: psycho-geriatric experimental wards

On the somatic wards (adjusted mean difference $\mathrm{B}=2.992, \mathrm{p}=0.000$ ) as well as on the psycho-geriatric wards (adjusted mean difference $\mathrm{B}=3.437, \mathrm{p}=0.000$ ) the extent in resident assignment has increased on the experimental wards compared to the control wards in the last post-test (see appendix 5, tables 5.1e-f).

So, in conclusion, except for the results on the somatic wards in organisation A, hypothesis la concerning the postulated increase in resident-assignment on the experimental wards is confirmed.

\section{Use of the nursing process}

Use of the nursing process was measured by two variables, "use of nursing care plans and their evaluation" and "taking nursing history, nursing problems, goals and actions". 


\section{Use of nursing care plans and their evaluation}

Table 5.5 and figure 5.7 show that in the pre- and first post-test the scores in the control group are slightly higher compared to the experimental group. However, in the first post-test the sores in the experimental group are slightly increased with a further increase in the last post-test. The scores in the control group are also increased in the first post-test, but this increase was not as large as in the experimental group. The experimental group also reveals a clear catch-up effect in the last post-test compared to the control group.

Table 5.5 Use of nursing care plans and their evaluation (unadjusted means)

\begin{tabular}{lllrllrllr}
\hline & pre-test & \multicolumn{4}{c}{ post-test 1 } & \multicolumn{4}{c}{ post-test 2 } \\
& Mean & \multicolumn{1}{l}{ SD } & \multicolumn{1}{c}{$\mathrm{n}$} & Mean & SD & \multicolumn{1}{c}{$\mathrm{n}$} & Mean & \multicolumn{1}{l}{ SD } & \multicolumn{1}{c}{$\mathrm{n}$} \\
\hline experimental group & 3.25 & 0.71 & 99 & 3.56 & 0.64 & 78 & 3.67 & 0.64 & 69 \\
control group & 3.43 & 0.80 & 106 & 3.65 & 0.69 & 87 & 3.56 & 0.71 & 77 \\
total group & 3.34 & 0.76 & 205 & 3.61 & 0.66 & 165 & 3.61 & 0.67 & 146 \\
\hline
\end{tabular}

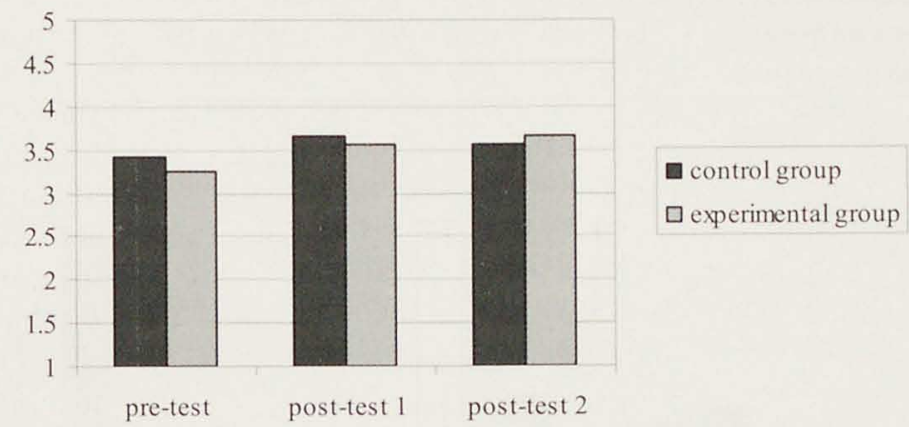

Figure 5.7 Use of nursing care plans and their evaluation (unadjusted means)

ANCOVA revealed a significant baseline difference between the experimental and control groups $(\mathrm{F}=10.303, \mathrm{p}=0.002, \mathrm{df}(1,125), \mathrm{n}=143)$. In the control group nursing care plans are more frequently used and evaluated compared to the experimental group. Further, on the last post-test no significant interactions were found, so analyses were performed on the total sample of the last post-test. In the last post-test a significant difference is shown between the experimental and control groups. Compared to the control group, nursing care plans are more used and evaluated in the experimental group after the implementation (adjusted mean difference $\mathrm{B}=0.246, \mathrm{p}=0.008$ ). So, the catch-up effect in the experimental group seems to be fundamental (see also appendix 5 , table 5.2a).

\section{Taking nursing history, nursing problems, goals and actions}

Table 5.6 and figure 5.8 present the unadjusted means on this variable. Again the control group reveals higher pre-test scores compared to the experimental group. On this dimension of the nursing process too, the experimental group shows a slight catch-up effect in the scores on both post-tests compared to the control group. The control group reveals a slight decrease in scores on the last post-test. Finally, the pre-test scores are relatively high on this dimension. 
Table 5.6 Taking nursing history, nursing problems, goals and actions (unadjusted means)

\begin{tabular}{|c|c|c|c|c|c|c|c|c|c|}
\hline & \multicolumn{3}{|c|}{ pre-test } & \multicolumn{3}{|c|}{ post-test 1} & \multicolumn{3}{|c|}{ post-test 2} \\
\hline & Mean & SD & $\mathrm{n}$ & Mean & SD & $\mathrm{n}$ & Mean & SD & $\mathrm{n}$ \\
\hline experimental group & 4.15 & 0.77 & 100 & 4.28 & 0.55 & 79 & 4.39 & 0.48 & 69 \\
\hline control group & 4.36 & 0.57 & 108 & 4.31 & 0.76 & 86 & 4.19 & 0.85 & 77 \\
\hline total group & 4.26 & 0.68 & 208 & 4.30 & 0.67 & 165 & 4.28 & 0.70 & 146 \\
\hline
\end{tabular}

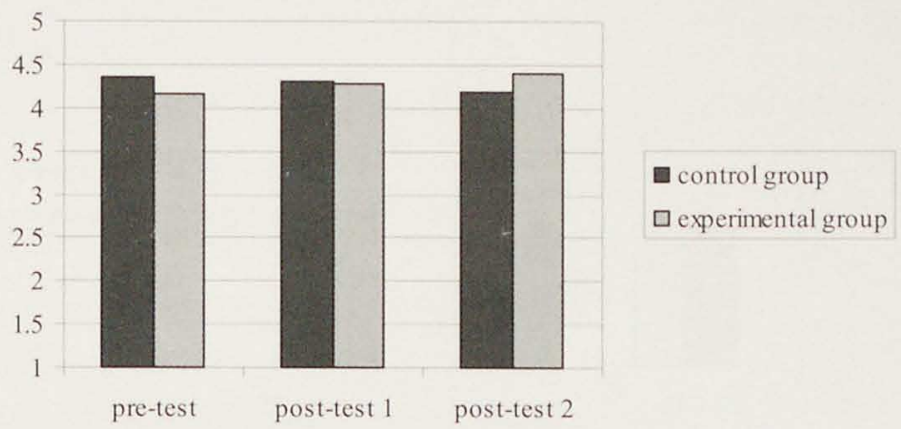

Figure 5.8 Taking nursing history, nursing problems, goals and actions (unadjusted means)

Although ANCOVA revealed no significant baseline difference, the control group is in favour again. There is a slight indication for a higher initial performance of taking nursing history, nursing problems, goals and actions in the control group compared to the experimental group $(\mathrm{F}=6.521, \mathrm{p}=0.012, \mathrm{df}(1,127), \mathrm{n}=145)$. Further, no significant interaction effects were found, so stratification was not needed. The catch-up effect in the experimental group compared to the control group appeared to be substantial in the last post-test. As expected, in the experimental group, taking nursing history, nursing problems, goals and actions is significantly higher performed after the implementation compared to the control group (adjusted mean difference $\mathrm{B}=0.308, \mathrm{p}=0.002$ ) (see also appendix 5, table 5.2b).

So, in conclusion hypothesis $1 \mathrm{~b}$ concerning an increase in the use of the nursing process in the experimental group can be confirmed.

\section{Tasks}

Tasks are measured by means of "resident-oriented tasks" and "ward-oriented tasks".

\section{Resident-oriented tasks}

Table 5.7 and figure 5.9 show the unadjusted means on this variable. There is increase in the scores in the experimental group compared to the control group, which is clearly started in the first post-test and maintained in the last post-test. However, the control group too shows a slight increase in the last post-test. 
Table 5.7 Resident-oriented tasks (unadjusted means)

\begin{tabular}{lllllllllll}
\hline & \multicolumn{3}{c}{ pre-test } & \multicolumn{3}{c}{ post-test 1 } & \multicolumn{4}{c}{ post-test 2 } \\
& Mean & SD & $\mathrm{n}$ & Mean & SD & $\mathrm{n}$ & Mean & SD & $\mathrm{n}$ \\
\hline experimental group & 2.65 & 0.72 & 98 & 3.29 & 0.74 & 79 & 3.32 & 0.81 & 69 \\
control group & 2.62 & 0.74 & 106 & 2.64 & 0.78 & 86 & 2.79 & 0.83 & 76 & \\
total group & 2.63 & 0.73 & 204 & 2.95 & 0.83 & 165 & 3.04 & 0.86 & 145 \\
\hline
\end{tabular}

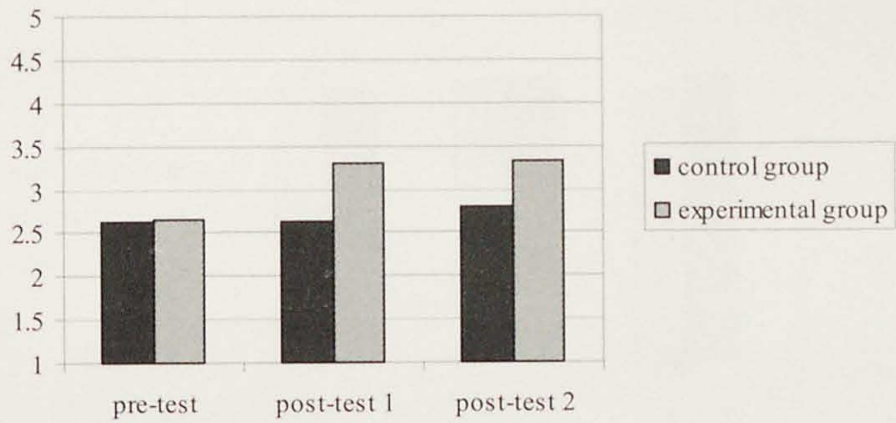

Figure 5.9 Resident-oriented tasks (unadjusted means)

ANCOVA revealed no baseline difference between the experimental and control groups $(\mathrm{F}=0.057, \mathrm{p}=0.811, \mathrm{df}(1,125), \mathrm{n}=143)$. Further, in the last post-test a significant first-order interaction effect was found between "type of group" and "type of ward" $(\mathrm{F}=11.103, \mathrm{p}=0.001, \mathrm{df}(1,123), \mathrm{n}=142)$. For this reason, stratification took place to "type of ward" and regression analyses were performed for the somatic and psycho-geriatric group separately. Table 5.8 and figure 5.10 presents the unadjusted means per type of ward.

\section{Results somatic wards}

From the unadjusted means of the somatic group presented in table 5.8 and figure 5.10 it can be seen that the experimental wards compared to the control wards show a catch-up effect started in the first post-test. However, this did not appear to be substantial. After the implementation no significant increase was found of resident-oriented tasks on the somatic experimental wards compared to the somatic control wards (adjusted mean difference $\mathrm{B}=0.099, \mathrm{p}=0.321$ ) (see also appendix 5 , table $5.3 \mathrm{a}$ ).

\section{Results psycho-geriatric wards}

As shown in table 5.8 and figure 5.10 , the largest increase in scores in the psychogeriatric group on the experimental wards took place in the first post-test. However, the psycho-geriatric control wards too show a slight increase on resident-oriented tasks but the scores of the control wards remain below those of the experimental wards. In the psycho-geriatric group the intervention did meet the expectations. In the last posttest a significant increase was found in resident-oriented tasks on the experimental wards compared to the control wards (adjusted mean difference $B=0.915, p=0.000$ ) (see also appendix 5, table 5.3b). 
As was indicated in 5.1, with respect to this variable an interaction effect on the last post-test was found between "type of group" and "nurse function". So, additional subgroup analyses were performed. As was expected, more resident-oriented tasks were performed after the implementation in the group PNCs of the experimental group compared to nursing care givers from the control group with at least $70 \%$ employment (adjusted mean difference $B=0.730, p=0.000$ ). No extra effects were found in the group associate nursing caregivers of the experimental group with no residents assigned compared to nursing caregivers of the control group who held an employment of less than $70 \%$ (adjusted mean difference $B=0.312, p=0.094$ ). However, there is a slight indication for performing more resident-oriented tasks in this group of nursing caregivers in the experimental group compared to the control group (see also appendix 5 , tables $5.3 \mathrm{c}-\mathrm{d})$.

Table 5.8 Resident-oriented tasks per type of ward (unadjusted means)

\begin{tabular}{lllllllllll}
\hline & \multicolumn{3}{c}{ pre-test } & \multicolumn{3}{c}{ post-test 1 } & \multicolumn{4}{c}{ post-test 2 } \\
& Mean & SD & $\mathrm{n}$ & Mean & SD & $\mathrm{n}$ & Mean & SD & $\mathrm{n}$ \\
\hline somatic experimental ward (somex) & 2.64 & 0.72 & 51 & 3.17 & 0.75 & 43 & 3.22 & 0.91 & 37 \\
somatic control ward (somco) & 2.81 & 0.71 & 48 & 2.75 & 0.69 & 42 & 2.93 & 0.74 & 41 & \\
total somatic group & 2.73 & 0.72 & 99 & 2.96 & 0.75 & 85 & 3.07 & 0.83 & 78 \\
p.g. experimental ward (pgex) & 2.65 & 0.74 & 47 & 3.45 & 0.71 & 36 & 3.43 & 0.67 & 32 & 35 \\
p.g. control ward (pgco) & 2.46 & 0.72 & 58 & 2.53 & 0.85 & 44 & 2.62 & 0.91 & 35 \\
total psycho-geriatric group & 2.54 & 0.73 & 105 & 2.94 & 0.91 & 80 & 3.01 & 0.90 & 67 \\
\hline
\end{tabular}

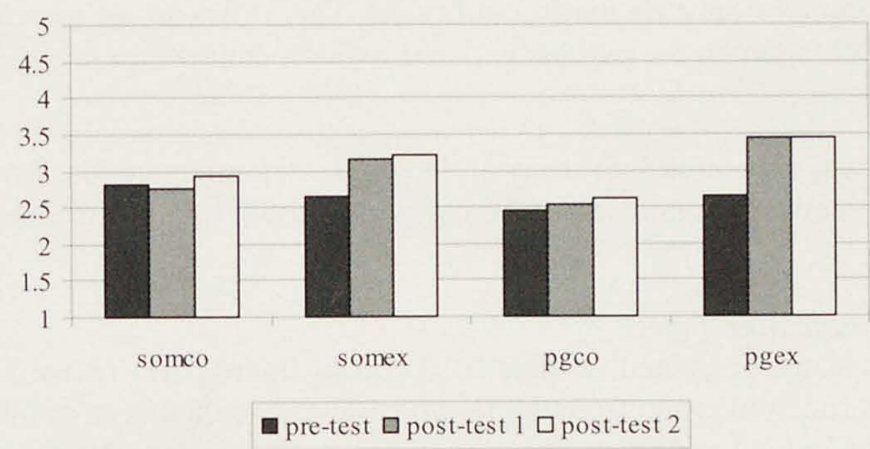

Figure 5.10 Resident-oriented tasks per type of ward (unadjusted means) somco: somatic control wards somex: somatic experimental wards pgco: psycho-geriatric control wards pgex: psycho-geriatric experimental wards

\section{Ward-oriented tasks}

From the scores in table 5.9 and figure 5.11 it can be concluded that after the implementation no large changes occurred in either the experimental or the control group.

Table 5.9 Ward-oriented tasks (unadjusted means)

\begin{tabular}{|c|c|c|c|c|c|c|c|c|c|}
\hline & \multicolumn{3}{|c|}{ pre-test } & \multicolumn{3}{|c|}{ post-test 1} & \multicolumn{3}{|c|}{ post-test 2} \\
\hline & Mean & SD & $\mathrm{n}$ & Mean & SD & $\mathrm{n}$ & Mean & SD & $\mathrm{n}$ \\
\hline experimental group & 3.04 & 0.79 & 99 & 3.15 & 0.69 & 78 & 3.08 & 0.74 & 69 \\
\hline control group & 3.02 & 0.77 & 105 & 3.09 & 0.79 & 87 & 3.04 & 0.67 & 74 \\
\hline total group & 3.03 & 0.78 & 204 & 3.12 & 0.74 & 165 & 3.06 & 0.70 & 143 \\
\hline
\end{tabular}




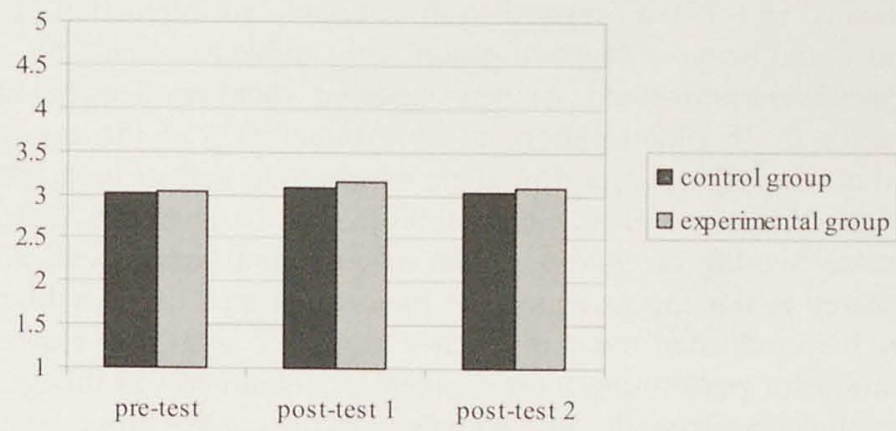

Figure 5.11 Ward-oriented tasks (unadjusted means)

ANCOVA showed no significant baseline difference between the experimental and control groups $(\mathrm{F}=0.001, \mathrm{p}=0.975, \mathrm{df}(1,124), \mathrm{n}=142)$. No interaction effects appeared in the last post-test, so analyses were performed on the total last post-test sample. With respect to ward-oriented tasks no significant difference appeared between the experimental and control groups in the last post-test (adjusted mean difference $\mathrm{B}=0.098$, $\mathrm{p}=0.160$ ). Thus, after the implementation the performance of ward-oriented tasks did not increase in the experimental group (see also appendix 5, table 5.3e).

So, in conclusion hypothesis 1c concerning an increase in the number of tasks in the experimental group can only be partly confirmed. This refers to an increase in resident-oriented tasks found on the psycho-geriatric experimental wards.

\section{Communication}

Communication was measured by means of "quality of communication forms", "variety of resident-oriented communication forms" and "variety of ward-oriented communication forms".

\section{Quality of communication forms}

The unadjusted means, presented in table 5.10 and in figure 5.12, reveal a slight decrease in the experimental group from the first post-test. The quality of communication forms seems to be judged as less good in the experimental group after the start of the implementation. The scores in the control group remained stable. In all measurements the control group shows higher scores compared to the experimental group.

Table 5.10 Quality of communication forms (unadjusted means scores)

\begin{tabular}{lllllllllll}
\hline & pre-test & \multicolumn{3}{c}{ post-test 1 } & \multicolumn{4}{c}{ post-test 2 } \\
& Mean & SD & $\mathrm{n}$ & Mean & SD & $\mathrm{n}$ & Mean & SD & $\mathrm{n}$ \\
\hline experimental group & 3.79 & 0.39 & 96 & 3.69 & 0.41 & 75 & 3.65 & 0.32 & 68 \\
control group & 3.84 & 0.44 & 105 & 3.83 & 0.44 & 85 & 3.83 & 0.40 & 75 \\
total group & 3.81 & 0.41 & 201 & 3.77 & 0.43 & 160 & 3.75 & 0.38 & 143 \\
\hline
\end{tabular}




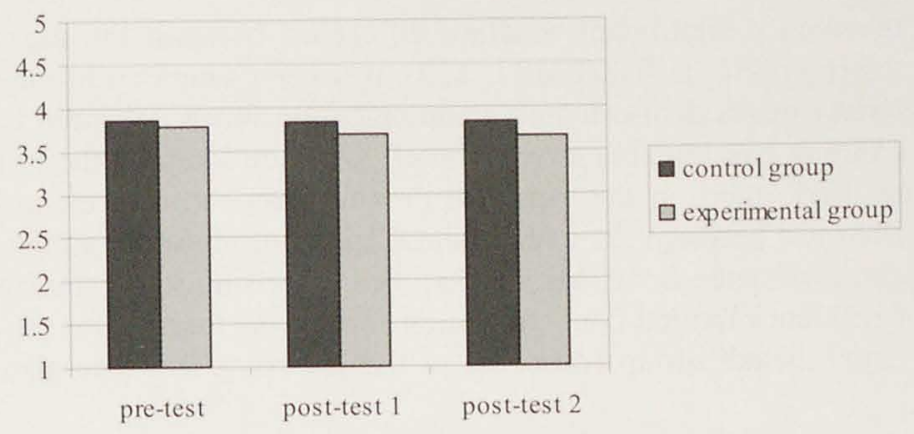

Figure 5.12 Quality of communication forms (unadjusted means)

No difference at baseline between the experimental and control groups appeared from ANCOVA $(F=2.732, p=0.101, d f(1,124), n=142)$. Further, no interaction effects were found, so analyses were performed on the total last post-test sample. Although the experimental and control groups showed no significant difference in the last post-test, there is an indication that after the implementation the quality of communication forms is judged less good in the experimental group compared to the control group (adjusted mean difference $B=-0.095, \mathrm{p}=0.047$ ) (see also appendix 5, table 5.4a).

\section{Variety of resident-oriented communication forms}

The unadjusted means are presented in table 5.11 and in figure 5.13. In the experimental and in the control group no large changes in the scores on variety of residentoriented communication forms occurred in either post-test. In all measurements the scores in the experimental group were lower than the scores in the control group. Finally, the scores in the pre-test are relatively high on this dimension.

Table 5.11 Variety of resident-oriented communication forms (unadjusted means)

\begin{tabular}{lllllllllll}
\hline & pre-test & \multicolumn{4}{c}{ post-test 1 } & \multicolumn{4}{c}{ post-test 2 } \\
& Mean & SD & $\mathrm{n}$ & Mean & SD & $\mathrm{n}$ & Mean & SD & $\mathrm{n}$ \\
\hline experimental group & 4.09 & 0.60 & 98 & 4.08 & 0.57 & 77 & 4.16 & 0.59 & 68 \\
control group & 4.24 & 0.60 & 107 & 4.24 & 0.55 & 87 & 4.19 & 0.61 & 77 \\
total group & 4.17 & 0.60 & 205 & 4.16 & 0.56 & 164 & 4.17 & 0.60 & 145 \\
\hline
\end{tabular}

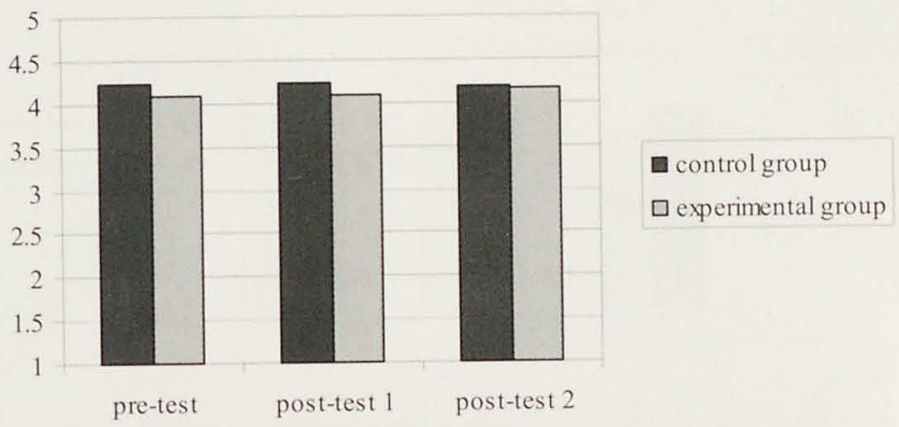

Figure 5.13 Variety of resident-oriented communication forms (unadjusted means) 
ANCOVA revealed a significant baseline difference between the experimental and control groups $(\mathrm{F}=7.456, \mathrm{p}=0.007, \mathrm{df}(1,125), \mathrm{n}=143)$. Compared to the experimental group, the variety of resident-oriented communication forms appeared to be larger in the control group at baseline. No interaction effects were found in the last post-test, so analyses were performed on the total last post-test sample. Regression analyses revealed no difference between the experimental and control groups in the last post-test (adjusted mean difference $\mathrm{B}=0.044, \mathrm{p}=0.33$ ). So, surprisingly, no significant increase in variety of resident-oriented communication forms was found after the implementation in the experimental group compared to the control group (see also appendix 5, table $5.4 \mathrm{~b})$.

\section{Variety of ward-oriented communication forms}

The unadjusted means presented in table 5.12 and in figure 5.14 show a slight increase in the experimental group, which is started in the first post-test, and hardly any change in the control group in both post-tests. Despite its slight increase, the scores of the experimental group remain below those of the control group.

ANCOVA revealed a significant baseline difference between the experimental and control groups $(\mathrm{F}=8.037, \mathrm{p}=0.005, \mathrm{df}(1,124), \mathrm{n}=142)$. On the pre-test the variety of ward-oriented communication forms appeared to be larger in the control group compared to the experimental group. Further, no interaction effects were found in the last post-test, so analyses did not need to be stratified. Finally, after the implementation no significant difference was found between the experimental and control groups in the last post-test (adjusted mean difference $\mathrm{B}=-0.047, \mathrm{p}=0.28$ ) (see also appendix 5 , table $5.4 \mathrm{c})$.

Table 5.12 Variety of ward-oriented communication forms (unadjusted means)

\begin{tabular}{lllllllllll}
\hline & \multicolumn{3}{l}{ pre-test } & \multicolumn{3}{c}{ post-test 1} & \multicolumn{4}{c}{ post-test 2} \\
& Mean & SD & $\mathrm{n}$ & Mean & SD & $\mathrm{n}$ & Mean & SD & $\mathrm{n}$ & \\
\hline experimental group & 3.05 & 0.55 & 99 & 3.21 & 0.60 & 76 & 3.30 & 0.56 & 68 \\
control group & 3.35 & 0.51 & 105 & 3.38 & 0.54 & 82 & 3.40 & 0.43 & 75 \\
total group & 3.21 & 0.55 & 204 & 3.30 & 0.57 & 158 & 3.35 & 0.50 & 143 \\
\hline
\end{tabular}

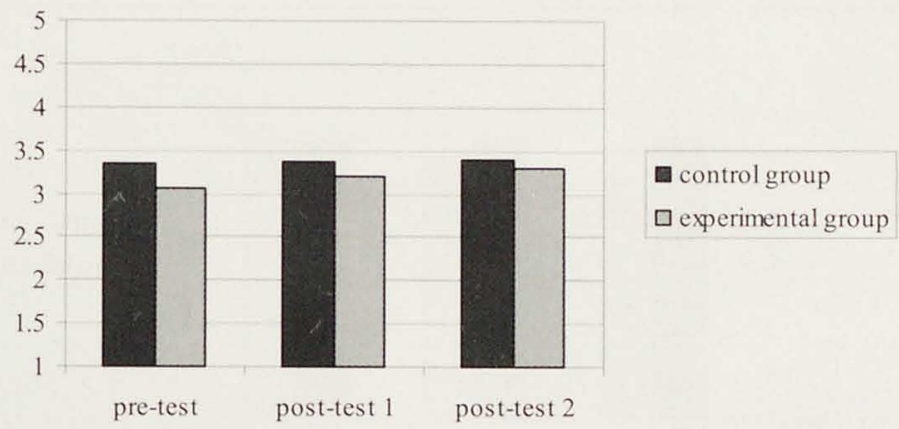

Figure 5.14 Variety of ward-oriented communication forms (unadjusted means) 
Due to an interaction effect on the last post-test between "type of group" and "nurse function" additional subgroup analyses were performed. In the group PNCs of the experimental group compared to nursing caregivers from the control group employed for $70 \%$, no extra effects were found with respect this variable (adjusted mean difference $\mathrm{B}=0.075, \mathrm{p}=0.248$ ). However, in the group associate nursing caregivers of the experimental group with no residents assigned compared to nursing caregivers of the control group employed for less than $70 \%$, significantly less variety of ward-oriented communication forms is perceived after the implementation (adjusted mean difference $\mathrm{B}=-$ $0.286, \mathrm{p}=0.003$ ) (see also appendix 5, tables 5.4d-e).

So, in conclusion hypothesis $1 \mathrm{~d}$ concerning an increase in the quality and variety of ward-oriented and resident-oriented communication forms in the experimental group cannot be confirmed.

On the whole, it can be argued that the intervention is partly successful concerning the four design characteristics. Major improvements are booked with respect to residentassignment, use of nursing care plans and their evaluation, taking nursing history, nursing problems, goals and actions and on the psycho-geriatric group with regard to resident-oriented tasks. For the group PNCs also an increase in resident-oriented tasks was found on the total experimental group. With regard to the communication forms the implementation shows less impact. Only in the group associate nursing caregivers is there less variety of ward-oriented communication forms.

\subsection{Qualitative results}

\subsubsection{Analyses}

In this section the qualitative results with regard to the design characteristics are presented. Data were collected on the six experimental wards by means of interviews with all project co-ordinators and supervisors, by participant observations and by analysis of the residents' dossiers.

Analysis of the qualitative data concerning the design characteristics was performed on the basis of the topic list of Bekkers et al. (1990) presented in chapter 4 (see table 4.1). The topic list of Bekkers et al. (1990) was not only used for collection of data derived from the participant observations but served also as a framework for analysis of all the other qualitative data with regard to the design characteristics derived from the interviews and the residents' dossiers. To gain insight into the implementation of the four different characteristics of a resident-oriented care model and the problems, decisions and corresponding actions in this respect, the interview transcripts of the recorded data were structured and summarised by means of this framework per measuring moment. So, the framework was used to perform data reduction and analysis. In addition, to increase further confirmability minutes of the soundboard and steering group meetings and process notes collected in informal meetings with supervisors and project co-ordinators completed data collection (Polit \& Hungler, 1999). Finally, the different drafts of the final reports were reviewed by colleagues involved at the data 
collection and the final draft was reviewed by the project co-ordinators of the three nursing homes.

In the following subsections, first the qualitative results regarding resident assignment, use of the nursing process, tasks and communication are presented. In the pre-test a general description was made based on all data sources (interviews, observations or the residents' dossiers). For both post-tests as far as possible all data sources are separately mentioned in the presentation of the results. In this respect first the results derived from the interviews and the residents' dossiers are presented followed by the results derived from the observations.

\subsubsection{Results}

\section{Resident assignment}

Pre-test

From the pre-test interviews it appeared that resident-assignment did not take place on the experimental wards. All wards were divided into two units with a ward sister per unit and a supervisor per ward. However, on the psycho-geriatric experimental ward of organisation B tasks were still performed for the total ward in a functional mode. The other wards were characterised by a functional mode of team nursing with toilet, drink and food rounds per team. On some wards characteristics of resident-oriented care were already present. On the somatic experimental ward of organisation $B$ residents were assigned per day to a team of nursing caregivers. In organisation $A$, in case of problematic care situations residents were assigned to a nursing caregiver for a longer period. Regarding the planning of personnel, the three organisations had in common that they did not make use of cyclical duty rosters with fixed patterns. It was usual to make a plan for one year ahead with fixed days for holidays, duty-free days and school modules of nursing students.

\section{Post-test 1}

The first post-test interviews revealed the implementation of resident assignment in all three organisations. In general this means the assignment of three to six residents to a PNC or a small group of PNCs. The criteria for becoming a PNC comprised an employment degree of $70 \%$ or more and having graduated as a registered or enrolled nurse. Nursing caregivers not meeting these criteria were not assigned any residents. In addition, all wards were divided into two units with a ward sister per unit. In general, in all three organisations resident-assignment took place arbitrarily mostly for the period of admission. In organisation B in the first six weeks of their admissions residents were first assigned to the ward sister before they were assigned to a PNC. This was for the ward sister to get a picture of the care needed by the resident. By means of the duty roster continuity of care was pursued. This means that during fixed days or a fixed number of days per week PNCs had to be on duty. In this respect, duty rosters were planned for a longer period in advance in a more cyclical way. The way in which residents were assigned differed per organisation. On the psycho-geriatric ward of organisation A residents were assigned to a group of nursing caregivers comprising two 
PNCs and three associate nurses. Associate nurses had an employment degree of less than $70 \%$. They were coupled with PNCs and had tasks delegated by PNCs. In the case of absence, associate nurses substituted PNCs. Organisations B and $\mathrm{C}$ used the $70 \%$ criterion too. In these organisations residents were assigned per nursing caregiver.

From the observations it was shown that resident assignment was most obvious during care giving in the morning hours. However, a task-oriented division of labour still was seen. Tasks were partly divided by means of resident assignment and partly by means of assignment of fixed tasks. Except for one ward, the psycho-geriatric experimental ward of organisation A, care taking by PNCs for their assigned residents was not yet the rule. Nursing tasks such as serving and helping with meals, helping in and out of bed and performing toilet rounds were often still assigned in a task-oriented and arbitrary way. Some nursing caregivers experienced continuous caregiving for the same resident as more demanding and boring.

In the first post-test problems appeared on one experimental ward. On the somatic experimental ward of organisation $\mathrm{A}$, the implementation did not take place as planned. A combination of management problems and a rather radical change of the ward organisation from two units to five independent groups to which residents were assigned, appeared to be too abrupt a transition for the ward. To regain stability on the ward the implementation was stopped for a period by the management of organisation A (see further chapter 6). Half-a-year before the last post-test the implementation was started again on this ward. The model for resident assignment was adopted from the psychogeriatric experimental ward of this organisation. The problems on this ward were probably one of the causes for an increase in resident-assignment not as large as was shown on the psycho-geriatric experimental ward (see also subsection 5.2).

\section{Post-test 2}

The interviews revealed that resident assignment had further been implemented on the experimental wards. In general, direct care was performed by the PNC. However, on most of the wards a number of these direct care tasks, such as giving a shower or serving meals were assigned arbitrarily to nursing caregivers. More professional tasks, such as medication serving, were mostly performed by a registered nurse such as the ward sister. The system of resident assignment appeared to be sensitive for changes in careload or sickness absence. Organisation $C$ changed their initial model by adopting the resident assignment model of organisation $\mathrm{A}$ of working with PNCs and associate nurses. This was done due to dissatisfaction with fewer responsibilities among nursing caregivers not being a PNC. In making these nursing caregivers and PNCs jointly responsible for residents' care more engagement was pursued which was somewhat confirmed by the indicative increase on resident-oriented tasks among the other nursing caregivers (see also subsection 5.2).

The observations confirmed that with resident assignment the ward organisation was more sensitive for disturbances. On wards with a large sickness absence and a lot of temporary employees resident assignment was hardly observable. In these cases tasks 
and not residents were assigned arbitrarily. Further, a variety of nursing caregivers were still involved in the direct care of residents. In addition, results of the observations confirmed task-oriented elements in the task division. As in the first post-test, resident assignment was observed most during care giving in the morning hours in particular. However, with caregivers lending each other a helping hand or in taking over care this assignment was sometimes abandoned. Further, despite a further implementation of resident assignment on all experimental wards, nursing care tasks often appeared to be assigned rather arbitrarily.

\section{Use of the nursing process}

\section{Pre-test}

The pre-test interviews revealed dissatisfaction among supervisors on all experimental wards with respect to the nursing report. Furthermore, in general nursing problems, goals and actions were seldom formulated and nursing care plans were hardly used. In organisation A, a new multidisciplinary resident's dossier was introduced nine months before the pre-test. However, reporting was not based on the phases of the nursing process. Nursing problems were not described and, if described, they were mostly not based on observed residents' behaviour or on an underlying diagnosed cause. Moreover, nursing problems could not be traced back in the planned nursing actions or in the nursing reports. In organisation B nursing caregivers and the other disciplines used separate report systems. An integral multidisciplinary resident's dossier including a multidisciplinary care plan did not yet exist. Reports of different residents were made by different nursing caregivers, which were all kept into one dossier. In practice, the different phases of the nursing process were not used either and nursing care plans were not kept up-to-date. In organisation $\mathrm{C}$ half a year before the pre-test an integral multidisciplinary resident's dossier was introduced on all wards accompanied by training regarding the use of the nursing process. However, use of this dossier and of the nursing process was not established either on the wards.

\section{Post-test 1}

The interviews revealed that all wards were in the middle of implementing the nursing process. On certain aspects some progress was shown. According to the supervisors, in general the dossiers appeared to be neater and more up-to-date. In general, use and reporting of the nursing process was practised by nursing caregivers supported by the ward sister. Due to the implementation of the nursing process a need arose to adjust the residents' dossiers. In organisation $\mathrm{A}$ the relation between the performed care and the multidisciplinary meeting was missed. Therefore, on the psycho-geriatric experimental ward a nursing plan was added to the multidisciplinary resident's dossier. In organisation B the current nursing plan did not stimulate defining nursing problems, goals and actions. This nursing plan was not part of the resident's dossier, which was missed by nursing caregivers. Moreover, an integral multidisciplinary resident's dossier was missed by nursing caregivers and the other disciplines. On the psychogeriatric experimental as well as control ward of organisation $C$ the resident's dossier was adjusted by adding an integral nursing care plan and a multidisciplinary appointments' page. 
However, based on the participant observations and analyses of the residents' dossiers, lack of application of the principles of the nursing process was still evident on most of the experimental wards. Nursing care plans did not appear to be filled in completely or adjusted and comprised merely nursing actions instead of nursing problems and goals. If formulated, nursing problems were more focused on general instead of residentspecific problems.

\section{Post-test 2}

The interviews indicated progress in all organisations with respect to the use of the nursing process. However, the desired result did not seem to have been attained yet. Most of the nursing caregivers indicated that they found it difficult to perform the nursing process in practice. Progress was seen with respect to reporting of nursing problems, goals and actions. PNCs were more aware of the method, which was noticed during the verbal report in particular. However, nursing caregivers needed a lot of support from the ward sister. In this respect, the coaching role of the ward sister appeared to be very important during the implementation. In all three organisations residents' dossiers were adjusted. On the psycho-geriatric wards of organisations $\mathrm{A}$ and $\mathrm{C}$ new nursing care plans were implemented. In organisation $B$ a start was made with the design of a new integral multidisciplinary resident's dossier. In the single rooms of the somatic experimental ward in organisation $\mathrm{C}$, the aim was to keep the residents' dossiers on the rooms of the residents themselves.

The participant observations and analyses of the residents' dossiers revealed that on most experimental wards use of the nursing process was not fully implemented yet. Nursing care plans and reports were not always based on nursing goals. Further, nursing care plans were still not up-to-date and care given did not always correspond with the planned care. Finally, in case of high workload nursing caregivers were inclined to fall back into the old task-oriented working method, thereby giving the nursing care plan second priority.

\section{Tasks}

\section{Pre-test}

Interviews indicated that at baseline the situation on all experimental wards could be characterised as hierarchical. Supervisors were responsible for total ward policy and quality. Their major tasks concerned co-ordination of tasks on ward level, monitoring the quality of care on the ward, consultations with other disciplines, meetings with family of the residents and chairing the multidisciplinary meeting. Supervisors were mostly not involved in direct care activities. However, in organisation B supervisors did give a helping hand in direct care in case of personnel shortage. Responsibilities of ward sisters concerned monitoring quality of direct care on their unit. They also performed direct care themselves. Major tasks concerned co-ordination of residents' care, preparation and attending multidisciplinary meetings, drawing nursing care plans and allocating tasks to nursing caregivers. In case of absence, the ward sister replaced the supervisor. In organisations $A$ and $C$ ward sisters performed doctor's rounds and maintained contact with the resident's family. In organisation B the supervisors performed 
these tasks. Nursing caregivers were responsible for direct care giving. Further, when nursing caregivers were not authorised to perform professional nursing tasks, supervisors or ward sisters performed these tasks.

\section{Post-test I}

The first post-test interviews indicated changes in the division of tasks. The distance between supervisors and residents and their family grew larger. Coaching and supporting of their employees had become a major part of the tasks of supervisors. Moreover, the position of the ward sister was considered as less hierarchical. Half of the ward sister's tasks concerned direct care giving and the other half concerned operational planning, assignment of residents and nursing tasks and coaching of PNCs. Coaching had become a very important task. Ward sisters became trainers-on-the-job of PNCs in making nursing care plans and in meetings with residents and family of residents. Except for organisation B in the first period of their admission, residents were not assigned to ward sisters, so ward sisters did not perform PNC tasks themselves. The responsibility of PNCs for the care planning of their assigned residents made them increasingly central for the resident and their family. The PNC prepared the multidisciplinary meeting together with the ward sister and, except for organisation B, represented their assigned residents in the multidisciplinary meeting. In organisation $\mathrm{B}$ the ward sister still presented the residents in this meeting. In case of absence, the PNC was substituted by another PNC in charge, a ward sister or an associate nurse. In general, the main tasks of nursing caregivers with no residents assigned, the associate nursing caregivers, concerned direct care giving. According to supervisors and project co-ordinators some positive results were already noticed in this period. Delegating the responsibility to PNCs allowed gaining more insight into residents' issues and contact between residents and their family was more intensified. In general PNCs experienced more responsibility for their assigned residents, showed more independence and undertook more initiatives. However, PNCs were still searching for clarity about their role and tasks. It appeared to be difficult for some PNCs to gain insight into their new role and to adjust to it. Some experienced the increased responsibility as more demanding resulting in more work pressure and insecurity. Furthermore, supervisors doubted the competence of some PNCs to perform nursing care independently. Also, nursing caregivers with no residents assigned experienced a decreased responsibility leading to dissatisfaction. In organisation B it was noticed that PNCs increasingly restricted their care to their assigned residents only. Due to this, insufficient attention was paid to joint responsibility for nursing care on the ward.

Results from the observations showed differences in functioning of supervisors. In organisations $\mathrm{A}$ and $\mathrm{C}$ supervisors seemed to be especially oriented on creating conditions and policy tasks. In organisation B supervisors appeared to be still involved in direct care giving. In all organisations ward sisters still performed co-ordination tasks that in fact should have been delegated to PNCs. It was observed that ward sisters (organisations $\mathrm{A}, \mathrm{B}$ and $\mathrm{C}$ ) or even supervisors (organisation $\mathrm{B}$ ) still attended doctor's rounds, meetings with other disciplines and more complex family meetings. PNCs were informed afterwards. As a result, family of residents and other disciplines often viewed supervisors and ward sisters as the main source of information. There was 
more direct contact between PNCs and other disciplines, such as psychologists, physiotherapists or occupational therapists. Finally, on most experimental wards PNCs did not always perform basic nursing care for their assigned residents themselves. These tasks were often assigned to nursing caregivers with no residents assigned or to nursing students.

\section{Post-test 2}

At the last post-test, in general, a further decrease of contacts between supervisors and residents and their family was indicated by the interviews. Supervisors seemed to be increasingly engaged in creation of preconditions, policy tasks and in monitoring the implementation. In all organisations supervisors chaired the multidisciplinary meetings. Furthermore, in organisation B supervisors did not perform direct care anymore. During the implementation, the coaching and supportive role of the ward sister became increasingly evident especially in elaborating nursing care plans by PNCs. The ward sisters' position too became less hierarchical due to an increased delegation of coordination tasks to PNCs such as doing doctor's rounds, consulting other disciplines, meetings with family and making nursing care plans. However, the position of the ward sister remained hierarchical with respect to operational planning and policy tasks such as resident assignment, daily personnel planning, keeping up-to-date of the residents' dossiers and informing nursing caregivers, residents and their family, and other disciplines. Finally, in case of a high sickness absence ward sisters often performed direct care. As a result less time remained to coach PNCs. To solve this problem, in organisation $\mathrm{A}$ it was decided to allocate residents to nursing caregivers with an employment of less than $70 \%$. With the exception of organisation A, no adjustments were made to the formal task and job descriptions in the nursing homes. Supervisors and project co-ordinators indicated that PNCs had grown in their new role. Responsibilities were better performed and there was more clarity about tasks. Further, ward officers and project co-ordinators indicated more job satisfaction among nursing caregivers and a stronger desire not to return to the old working method. This resulted from the experience of more responsibility and quality of care. On the psycho-geriatric ward in organisation A it was decided to pay special attention to direct care giving by PNCs themselves in stressing this as an explicit task of PNCs. Furthermore, differences in functioning between PNCs became more evident. Some insecurity remained among some nursing caregivers with regard to their functioning. Supervisors and project coordinators stressed the importance of continuous education of PNCs. However, in case of high work pressure care was given according to the old working method, at the cost of performing resident-oriented care in its intended form.

Observations revealed that the role of ward sisters still remained important with regard to co-ordination of resident's care. Ward sisters often kept performing tasks such as doing doctor's rounds or organising meetings with residents and their family or did this together with the PNC. Supervisors (organisation B) and ward sisters (organisations $A$ and $C$ ) appeared to be an important link between the resident and the other disciplines. As a result, interaction between PNCs and the other disciplines appeared to be largely determined by the supervisor or ward sister. For example, on the psychogeriatric ward of organisation B the supervisor still kept involved in direct residents' 
care. This supervisor experienced delegation of co-ordinating tasks to PNCs as difficult. Ward sisters in organisation B still presented the resident in the multidisciplinary meeting. In addition, supervisors or ward sisters, if possible in presence of the PNC, kept performing intakes and evaluation meetings mostly themselves. Therefore, compared to the two other organisations a larger distance was shown between the PNCs and the other disciplines in organisation B. In organisation B before and after each multidisciplinary meeting the ward sister informed the PNC about adjustments of the nursing care plans, which were further elaborated in collaboration with the ward sister. The PNCs of organisations A and C mostly performed the intake and evaluation meetings themselves sometimes under supervision of or together with the ward sister. Furthermore, if possible PNCs presented the assigned residents in the multidisciplinary meetings themselves. Therefore PNCs were scheduled on days when their assigned residents were discussed in the multidisciplinary meetings. Further, it was observed that PNCs increasingly performed direct nursing care for their assigned residents themselves. However, the attitudes of the PNCs differed. Depended of the attitude of the individual PNC the contact with the resident and his/her family was more intense. Residents in need for more care seemed to be cared for by the same nursing caregiver more often. This did not always mean the PNC but it could be a nursing caregiver most preferred by the resident. On the psycho-geriatric ward of organisation A the coordinating role of the PNC became evident. Family and other disciplines were more often referred to a PNC concerning all care issues of the assigned resident.

\section{Communication}

Pre-test

In all three nursing homes the interviews revealed a congruent picture with respect to the communication and its forms. Reports were mostly verbal and were focused on peculiarities in residents' care. Regular ward and unit meetings were held regarding quality of care or information exchange of other meetings. On all wards there were multidisciplinary meetings chaired by the supervisor. Other disciplines such as the physician, the physiotherapist and the occupational therapist participated in these meetings. The frequency varied from once per week to once per three weeks. Subjects concerned somatic as well as psychosocial aspects of residents' care. There was some dissatisfaction about mutual communication and feedback of the results to the wards. Discussions were considered too much discipline-oriented instead of integral and not aimed at general outlines. Before the implementation of resident-oriented care in organisations $\mathrm{A}$ and $\mathrm{C}$, the multidisciplinary meeting and the integral multidisciplinary dossier had been implemented. In organisation $\mathrm{A}$ the project co-ordinator and an external advisor introduced the multidisciplinary meeting and the integral multidisciplinary dossier.

\section{Post-test 1}

The interviews revealed changes in the communication structure in the first post-test. In preparing the nursing care PNCs were no longer informed primarily by means of the verbal report but by means of reading the residents' dossiers themselves. If necessary, clarifications were asked during the verbal reports. Next to this, monodisciplinary resident-oriented meetings were introduced in organisations $\mathrm{A}$ and $\mathrm{C}$ to support PNCs 
in making nursing care plans. Furthermore, these meetings were used to prepare and discuss the multidisciplinary meeting. Because PNCs in organisation B did not participate in the multidisciplinary meeting, they were informed afterwards by the ward sister. On the psycho-geriatric ward of organisation A a profession-oriented meeting was introduced supervised by the supervisor. This was to improve a resident-oriented attitude and knowledge and skills of nursing caregivers. In organisation $\mathrm{C}$ supervision of nursing caregivers was introduced to foster collegial consultation regarding residentoriented care.

Observations confirmed a decreasing importance of the verbal reports in favour of a written report by using the residents' dossiers. However, on many wards the verbal report appeared to be still an important source of information exchange.

\section{Post-test 2}

The interviews revealed a continued development in the communication, which was in greater depth. In general, the exchange of information appeared to be more efficient. On the psycho-geriatric ward of organisation A the verbal reports of the morning shift ceased. In general, the multidisciplinary meeting was further developed. Organisation $B$ differed from the two other organisations in that PNCs did not participate in the multidisciplinary meeting. In organisations $\mathrm{A}$ and $\mathrm{C}$ PNCs attended these meetings as much as possible and prepared these meetings themselves. In the discussions of the multidisciplinary meeting the interests of residents seemed to have taken a more prominent place. Furthermore, the role of the other disciplines seemed to have changed. Before the implementation, their role used to be merely informative while after the implementation their role became increasingly actively participative. Contacts between PNCs and the other disciplines were intensified and consultations between PNCs and physiotherapists or psychologists became more direct. According to these disciplines, PNCs were more informed, more independent and could be addressed as the primary person responsible for residents' care. However, in those contacts PNCs experienced themselves not always equal. Furthermore, other disciplines indicated more difficulties in arranging issues in case of absence of the PNC.

Observations revealed that the contribution of PNC to residents' care was most obvious during the multidisciplinary meeting. However, this contribution seemed to be especially dependent on the personal authority of the nursing caregiver in question. If the participants considered this as large, more room was made for a contribution and the PNC in question was more heard. Furthermore, the ward sister still presented the resident in this meeting sometimes. In case of complex issues, supervisors and ward sisters still took care of informing residents or their family. A resident-oriented attitude of nursing caregivers was clearly observable on the psycho-geriatric ward of organisation A. In this respect a clear example was seen in a discussion of a multidisciplinary meeting on this ward. This discussion was focused on a resident who did not like to be undressed for the night. The question was raised whether this resident should be undressed and the possibilities were discussed to let the resident go to bed fully dressed. 


\subsection{Summary}

\section{Resident assignment}

The quantitative intervention effect on "resident assignment" was determined by an interaction effect between "type of organisation" and "type of ward" and therefore stratification took place. The results showed more resident assignment on five out of six experimental wards compared to the control wards after the implementation ( $\mathrm{H} 1 \mathrm{a})$. In organisation A a contamination effect was detected on the somatic control ward. Due to this and to the less increase on the somatic experimental ward, in the somatic group of organisation A one hypothesised increase could not be confirmed. Next, due to fact that the psychogeriatric control ward of organisation B was started residentassignment before the start of the intervention, a high pre-test score was detected. However, the analyses of the last post-test and the change scores as well revealed the expected significant increase in resident allocation on the experimental ward of this group so, problems seem to be limited. The qualitative results confirmed the implementation of resident assignment in the experimental group. Residents are assigned to so-called primary nursing caregivers (PNCs) who are employed at least $70 \%$ of a fulltime job. In general no residents were assigned to nursing caregivers with an employment percentage of less than $70 \%$, so-called associate nursing caregivers. Continuity of care was strengthened by planning PNCs on fixed days or a fixed number of days per week. Resident assignment was most observable during direct care given in the morning hours. In the case of high sickness absence or work pressure, it was difficult to achieve. Moreover, with regard to some direct care tasks a task-oriented division of care was still present.

\section{Use of the nursing process}

On both variables measuring the nursing process the hypothesis was confirmed. As postulated, compared to the control group significant last post-test increases were found in the experimental group in "use of nursing care plans and their evaluation" and in "taking nursing history, nursing problems, goals and actions" (H1b). The relatively high baseline scores on "taking nursing history, nursing problems, goals and actions" thereby engendering the risk of ceiling effects did not cause the intervention effect failing to appear. The high baseline scores seem to be related to the introduction of the multidisciplinary residents' dossiers in organisations $\mathrm{A}$ and $\mathrm{C}$ accompanied by a training in organisation $\mathrm{C}$ before the start of the implementation. Next, the baseline differences in favour of the control group on both nursing process variables did not led to problems either, for the results of the last post-test and change scores were comparable. The interviews and observations showed that in all organisations the implementation of the nursing process went together with adjustments in the residents' dossiers. However, to bring the nursing process into practice appeared to be the most difficult part for ward sisters and nursing caregivers. The observations revealed that nursing care plans still were often incomplete or not up-to-date and the realised care was not always congruent with the planned care. Furthermore, in the case of high work pressure less attention was paid on the documentation in the residents' dossier. In this respect, compared to the participant observations and investigation of the residents' dos- 
siers, more progress was indicated from the questionnaires spread among nursing caregivers and from the interviews with project co-ordinators and ward offers.

\section{Tasks}

The quantitative results with respect to the two variables "tasks" were partly as was hypothesised ( $\mathrm{H} / \mathrm{c})$. On the psycho-geriatric experimental wards more "residentoriented tasks" were performed after the implementation compared to the psychogeriatric control wards. In contrast, in the somatic group no significant results were found. However, more resident-oriented tasks were performed by PNCs of the total experimental group compared to nursing caregivers with an employment of $70 \%$ or more in the control group. This increase was indicative in the group associate nursing caregivers. No increase was found in the extent of "ward-oriented tasks". The interviews and observations revealed that the role of supervisors had become less dominant with regard to direct care. The coaching and supporting role of supervisors and ward sisters towards PNCs grew increasingly important. Although some effects were according to the expectations, the qualitative results identified some problems. It was observed that in case of high work pressure PNCs did not perform all basic care for their own allocated residents themselves such as serving meals or medication or helping with a toilet round. In addition, co-ordinating tasks that should have been delegated to PNCs such as doctor's rounds, representing the resident in the multidisciplinary meeting or important family meetings were still often performed by the ward sisters themselves. In addition, PNCs did not always used these co-ordinating tasks themselves. PNCs indicated difficulties in adjusting themselves to their new role. Some PNCs experienced the increased responsibility as extra work pressure and showed more insecurity. Especially in case of high work pressure an inclination to fall back into the old working method was shown in decreased attention for resident assignment or the nursing process. In this respect, again the results of the questionnaires and interviews with the project co-ordinators and supervisors appeared to be more positive compared to the results derived from the participant observations.

\section{Communication}

Although not significant, the quantitative results indicated a decrease of the "quality of communication forms" in the experimental group after the implementation (H1d). No changes were found on the two other "communication" variables "variety of residentoriented communication forms" and "variety of ward-oriented communication forms" (H1d). In the group associate nursing caregivers less variety of ward-oriented communication forms was indicated. In all three nursing homes the multidisciplinary meeting was already present before the start of the implementation. Moreover, in organisation $A$ an intensive introduction accompanied by training had taken place just before the start of the implementation of resident-oriented care. On this background the moderately high baseline scores on variety of resident-oriented communication forms can be placed, thereby engendering the risk of ceiling effects. Besides the small changes in the experimental group on both variety of resident- and ward-oriented communication forms these factors appear to be underlying causes for the intervention effect failing to appear. On both variety of resident- and ward-oriented communication forms significant baseline differences in favour of the control group were found. However, based on the comparable results of the last post-test and change scores, these baseline differ- 
ences seem to be not leading to problems in this respect. The interviews indicated a positive change compared to the former situation with regard to the involvement of the nursing caregiver in the multidisciplinary meeting and in the contacts with other disciplines and the family. It was intended that after the implementation PNCs of organisations $\mathrm{A}$ and $\mathrm{C}$ themselves presented their assigned residents in the multidisciplinary meetings as far as possible. In general more direct communication was noticed between PNCs and other disciplines such as the physiotherapist and with residents' family. However, it was observed that in all organisations the ward sister appeared to be still an important communication channel in the multidisciplinary meeting as in contacts with physicians and problematic family contacts. Thus, in comparing the interviews and the observations, the interviews indicated a more positive change towards involvement of nursing caregivers in the resident- and ward-oriented communication. 


\section{IMPLEMENTATION CHARACTERISTICS}

\subsection{Introduction}

In this chapter we try to give an answer to the second research question concerning the conditions for successfully implementing resident-oriented care. To be more specific, we will describe a number of implementation characteristics by means of the seven factors of the 7-S model as discussed in chapter 3 . In line with chapter 5 , the results are presented in two parts: first the quantitative results $(6.2)$ followed by a presentation of the qualitative results (6.3). Next, the success conditions are discussed (6.4) followed by a summary (6.5). Sections 6.2 and 6.3 start with more detailed information about the data analyses.

\subsection{Quantitative results}

\subsubsection{Analyses}

As discussed in chapter 4, the factors style and systems of the 7-S model were measured qualitatively as well as quantitatively. They were measured quantitatively by means of the three implementation variables, information quality and social-emotional and instrumental leadership style. In order to get some quantitative insight into some important conditions for implementing a resident-oriented care model successfully and hence to answer a part of research question 2 , we aim to test the following three hypotheses:

H2a) Better information quality with regard to the implementation on the experimental wards will lead to a more successful implementation of resident-oriented care.

H2b) More social-emotional leadership of supervisors on the experimental wards will lead to a more successful implementation of resident-oriented care.

H2c) Less instrumental leadership of supervisors on the experimental wards will lead to a more successful implementation of resident-oriented care.

To obtain a general answer regarding the success of the implementation itself, calculation of a mean score "resident-oriented care model" of all eight design variables was performed. So, as not to lose information by dichotomising this new design variable in creating two groups (successful wards versus not successful wards), we calculated a mean score "resident-oriented care model". To give equal weights to all eight design variables, we used their mean scores by mediating them within persons. We could use the mean scores because of comparable ranges for all eight design variables $(n=147)$ (see for variable ranges appendix 1, table 1.1). 
To answer the research question concerning the conditions for successfully implementing a resident-oriented care model, we aggregated the data on ward level for several reasons. In the first place, it has to be noted that an association between the independent and dependent variables between persons within a ward can differ from the association between wards (cf. Boumans, 1990; De Jonge et al., 1999a). Within a ward, leadership style and resident-oriented care model are in fact to be considered as constants and therefore as ward characteristics (e.g. Algera, 1997; De Jonge et al., 1999a). The association between both variables caused by variation within that ward is due to variation between persons in their perceptions. The association between leadership style and resident-oriented care model between wards in fact entails the association between ward characteristics and thus obliges aggregation of individual data to data on ward level (using mean scores of nursing caregivers working on the same ward). The literature indicates that assessments on group level are more objective measures because of the reduction of individual variability and possible illusory answers (e.g. Boumans, 1990; De Jonge et al., 1999a). In the second place, to answer the research question concerning the most successful conditions for implementing a residentoriented care model, statements on ward level are necessary. This is in line with the level on which the implementation of a resident-oriented care model took place: the nursing ward (cf. Boumans, 1990). Therefore it was decided to aggregate the dependent variable (resident-oriented care model) and all independent variables (information quality, socio-emotional leadership and instrumental leadership) with the ward as unit of analysis. As procedure for analysis, multi-level analyses or regression analyses on aggregated level would be the most suitable techniques for answering the research question. However, the small number of experimental wards per organisation $(n=2)$ and the small number of organisations $(n=3)$ would lead to unreliable estimates of the three sources of variation (nursing caregivers, experimental wards and organisations) (e.g. Steen et al., 1998; De Jonge et al., 1999a). Due to the small sample $(n=6)$, and therefore the impossibility to correct for confounders and foreseen problems with regard to outliers, rank correlation analysis, i.e. Spearman's correlation coefficient rho, was most suited for answering research question 2 . This analysis measures an association between rank orders of the three independent implementation variables on the one hand and the dependent design variable on the other. It should be noted that in performing rank correlation analyses hypotheses tested should be treated as exploratory and interpreted with caution. A sound correction is not possible either for the pre-test or for covariates such as age or careload and causality can not be determined.

In the following subsection the results are presented. First, the means of the design variable "resident-oriented care model" on ward level are presented. For this we used the last post-test mean scores as well as the mean change scores (post-test 2 - pre-test). Presentation of the last post-test means only would reflect no adjustment for pre-test differences and thus an overestimation of the real results. Presenting the mean change scores only would reflect an overadjustment for pre-test differences and thus an underestimation of the real results due to possible regression to the mean. So, conclusions about results will be found somewhere in the middle. Second, rank correlations are presented between the pre-test and the last post-test scores of information quality, socio-emotional leadership and instrumental leadership on the one hand and the last 
post-test and change scores of the design variable "resident-oriented care model" on the other. To prevent type II errors due to a small sample size we tested our hypotheses by means of $\mathrm{p} \leq 0.10$. Finally, both leadership style in particular and information quality are in fact characteristics of the supervisor in question. Therefore, to be able to relate the pre-test scores of the three implementation variables to the last post-test and change scores of the design variable, replacements of supervisors have to be taken into account. In organisation A the supervisor of the somatic experimental ward was replaced after the pre-test. Therefore, this ward had to be excluded from the analysis. In organisation B the supervisor of the psycho-geriatric experimental ward had left the ward during the last post-test. However, we decided to retain this ward in the analyses because the data collection took place before the supervisor left. Therefore, rank correlations with the pre-test data of the implementation variables were conducted with five out of six experimental wards, thus except for the somatic experimental ward of organisation $\mathrm{A}$. The last post-test data were analysed for all six experimental wards.

\subsubsection{Results}

Table 6.1 presents the last post-test and mean change scores per ward of the summarised design variable "resident-oriented care model". Figures 6.1 and 6.2 show the last post-test and mean changes on ward level rank ordered on a line from the least to the most effective ward. The implementation of a resident-oriented care model appeared to be most effective on the psycho-geriatric wards of organisations $\mathrm{A}$ and $\mathrm{C}$ and least effective on the psycho-geriatric ward of organisation $B$. The largest positive change was shown on the psycho-geriatric ward of organisation $C$ with the smallest change on the psycho-geriatric ward of organisation $\mathrm{B}$. Taking both the highest last post-test means and the largest change scores into account, it can be concluded that the most effective implementation was seen on the psycho-geriatric wards of organisations $A$ and $\mathrm{C}$. Both experimental wards of organisation B were the least successful. The somatic wards of organisations $A$ and $C$ were moderately successful.

Table 6.1 Post-test 2 means and mean changes design variable on ward level

\begin{tabular}{lllllll}
\hline design variable "resident-oriented & \multicolumn{7}{c}{ Experimental wards } \\
care model" on ward level & A som & A pg & B som & B pg & C som & C pg \\
\hline post-test 2 means & 3.78 & 3.89 & 3.65 & 3.38 & 3.68 & 3.89 \\
mean changes (post-test 2 - pre-test) & 0.53 & 0.58 & 0.38 & 0.20 & 0.69 & 0.73 \\
\hline
\end{tabular}

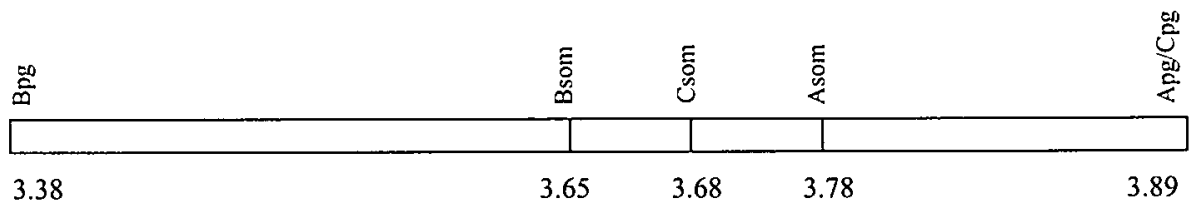

Figure 6.1 Rank ordered means post-test 2 design variable on ward level 


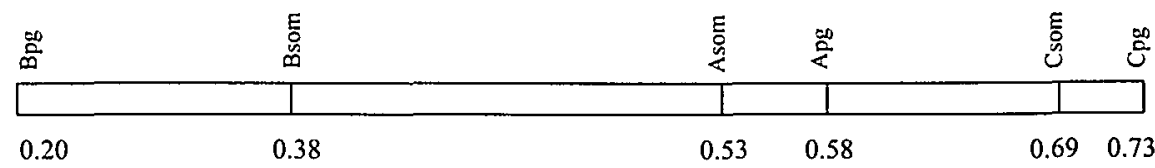

Figure 6.2 Rank ordered mean changes (post-test 2 - pre-test) design variable on ward level

Table 6.2 shows the aggregated rank correlation coefficients of the pre-tests of information quality and socio-emotional and instrumental leadership on the one hand and the last post-test of and change in the design variable "resident-oriented care model" on the other. No significant correlations were found between information quality and style of leadership, socio-emotional or instrumental, in the pre-test and the extent to which a resident-oriented care model was implemented in the last post-test or had changed in this respect.

Table 6.2 Rank correlation coefficients between the pre-tests of the implementation variables and the post-test 2 of and change in the design variable on ward level

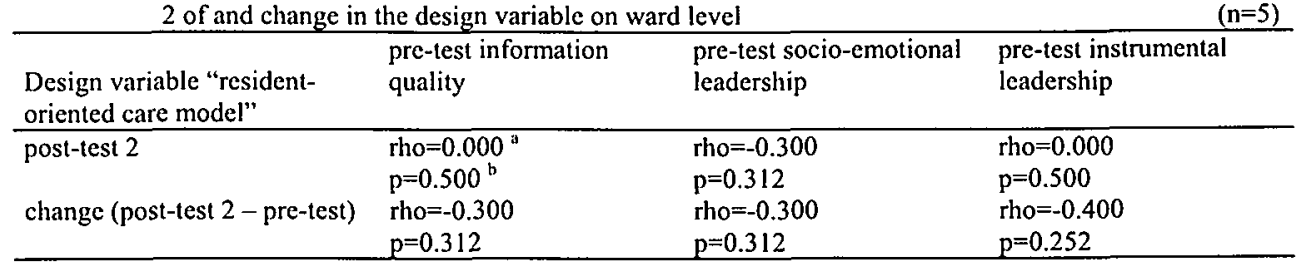

a) Spearman's correlation coefficient tho b) onc-tailed

Table 6.3 shows the aggregated rank correlation coefficients between the last post-tests of information quality and socio-emotional and instrumental leadership on the one hand and the last post-test of and change in the design variable "resident-oriented care model" on the other. A negative significant correlation was found between the extent of instrumental leadership in the last post-test and the extent to which a residentoriented care model was implemented in the last post-test. Furthermore, a negative significant correlation was found between the extent of instrumental leadership in the last post-test and the extent of a change towards a resident-oriented care model. In other words, less instrumental leadership in the last phase of the implementation seems to be related with a more successful implementation of a resident-oriented care model on the wards and a larger positive change in this respect. With respect to information quality or socio-emotional leadership no significant results were found.

Table 6.3 Rank correlation coefficients between the post-tests 2 of the implementation variables and the posttest 2 of and change in the design variable on ward level

\begin{tabular}{llll}
\hline $\begin{array}{l}\text { Design variable "resident- } \\
\text { oriented care model" }\end{array}$ & $\begin{array}{l}\text { post-test } 2 \text { information } \\
\text { quality }\end{array}$ & $\begin{array}{l}\text { post-test } 2 \text { socio- } \\
\text { emotional leadership }\end{array}$ & $\begin{array}{l}\text { post-test } 2 \text { instrumental } \\
\text { leadership }\end{array}$ \\
\hline post-test 2 & rho $=0.200^{\mathrm{a}}$ & rho $=-0.058$ & rho $=-0.886$ \\
& $\mathrm{p}=0.352^{\mathrm{b}}$ & $\mathrm{p}=0.457$ & $\mathrm{p}=0.009$ \\
rho $=0.029$ & $\mathrm{rho}=-0.771$ \\
& $\mathrm{pho=0.257}$ & $\mathrm{p}=0.478$ & $\mathrm{p}=0.036$ \\
\hline
\end{tabular}

a) Spearman's correlation coefficient rho

b) one-tailed 
Based on the results it can be concluded that only hypothesis $2 \mathrm{c}$ is partly confirmed. In formulating it cautiously, less instrumental leadership of supervisors on the experimental wards in the last post-test is associated with a more successful implementation of resident-oriented care. Due to the character of the analysis no conclusion can be made about the causality of this association.

\subsection{Qualitative results}

\subsubsection{Analyses}

In this section the qualitative results with regard to the "success conditions" of the implementation are presented. As described in chapter 3, the implementation, i.e. the process, was analysed by means of the 7-S model of Peters and Waterman (1982). We used this model to give a picture of the implementation by means of the so-called hard factors, structure, strategy and systems, and soft factors, staff, skills, style and shared values. As decisions with regard to the implementation in the three organisations were made on project level, the process is described per organisation. Therefore, data were structured and summarised according to the seven factors of the 7-S model per "type of organisation" (A, B and C). In this way, we sought insight into the differences between the three organisations. If the implementation approaches differ between the experimental wards, data are discussed per ward. In presenting the data it became clear that the implementation could be best discussed as a whole instead per measuring moment to prevent complexity. Moreover, this allowed us to do justice to the implementation as being a continuous process. In discussing the qualitative results, the quantitative results of information quality and socio-emotional and instrumental leadership are involved. This enables us to compare the data derived from the interviews with the project co-ordinators and supervisors and those from the questionnaires. For issues with regard to confirmability the reader is referred to chapter 5 .

\subsubsection{Results}

\section{Organisation A}

\section{Structure}

To prepare the implementation of the resident-oriented care model, work groups on project and ward level were installed. The work group on project level consisted of the nursing manager, the two supervisors of the experimental wards, the project coordinator and, in a later phase, the ward sister of the somatic experimental ward. The main tasks involved designing a resident-oriented care model and an implementation model in outline including an action plan, and co-ordinating and steering the implementation on the two experimental wards. At first, weekly meetings were held. Due to an increasing difference between the two experimental wards during the implementation, the frequency of these meetings decreased (see further strategy). In addition, two work groups on ward level were installed. Participants in these work groups were the supervisor, the two ward sisters and a PNC. The main tasks were a further elabora- 
tion of parts of the resident-oriented care model to be implemented such as tasks and responsibilities of PNCs.

\section{Strategy}

The implementation of the resident-oriented care model was incremental. In January 1996, it started with resident assignment to PNCs, adjustments of the duty rosters and the use of the nursing process. Before the implementation, the multidisciplinary meeting and multidisciplinary dossier had already been implemented. In the middle of 1996 some adjustments were made in the resident's dossier, extra attention was paid to the nursing process and a mono-disciplinary resident-oriented communication form was introduced. In the second half of 1996 the verbal report was stopped on the psychogeriatric ward. Finally, extra attention was paid to more direct caregiving tasks by PNCs themselves (see also chapter 5). Expected results concerned more residentoriented care, an increased quality of care, an increased job satisfaction and a closer collaboration with other disciplines. Problems were assumed regarding capacities of nursing caregivers to handle more responsibility, competition between PNCs and other nursing caregivers and more solo performance of PNCs. Further problems were assumed such as a tight schedule together with the complexity (of parts) of the implementation. Information and training were considered as means to solve these problems.

On the somatic ward immediately after the pre-test, distracting factors appeared. Together with the implementation, the ward had to prepare a transition from rehabilitation and long-stay care to long-stay care only, which had to be effectuated early 1997. The preparation of this change demanded much energy from employees. Moreover, due to the opening of an annex of the organisation in the middle of 1997, closing of beds and adjustments of the staffing had to be prepared on both somatic control and experimental wards. Furthermore, the start of the implementation on this somatic experimental ward, and the expectations accordingly, were too ambitious. It was intended to assign residents to five small groups of nursing caregivers and therefore to abandon the current division of the ward in two units. Lack of clarity among nursing caregivers was the result. Finally, difficulties between the supervisor and the two teams became obvious because the teams were not involved in ward level developments in general. As a result, the problems escalated after the pre-test. The implementation of resident-oriented care was considered the direct cause. Both teams lost confidence in the supervisor and in the project. To create more stability on the ward, the supervisor was relieved of his function and the implementation was stopped for half a year. A new interim supervisor was appointed. Because he had responsibilities to his own ward, it was not this new supervisor but one of the ward sisters who became responsible for the co-ordination of the implementation on the ward. A work group on ward level was installed with the ward sister, one PNC and a nutritionist's assistant to prepare the implementation. Finally, the time schedule and the corresponding expectations were adjusted. The implementation was restarted in the second half of 1996. In the period before the last post-test, a slow change took place towards more resident assignment and the use of the nursing process. This change was further hindered by a high sickness absence on this ward. On the psycho-geriatric ward the implementation 
went as planned without distracting factors or instability of the supervisor. One of the problems appeared to be a lack of role clarity among nursing caregivers. This was expressed in an inclination of PNCs to fall back into the old working method when there was high work pressure. So, real resident-oriented care seemed to be insufficiently developed. In this respect, the coaching role of the ward sister appeared to be very important for nursing caregivers for developing as a PNC. However, this coaching role needed attention. With regard to extra personnel and financial means to support the implementation on project level, a project co-ordinator was appointed to co-ordinate the implementation. On the psycho-geriatric ward no extra personnel was appointed to support the implementation. The somatic ward was supported with extra personnel to overcome the problems. Finally, before the first post-test experienced-based care was introduced in organisation $\mathrm{A}$ on all wards.

\section{Systems}

The organisation was informed by means of the formal channels such as the management team, supervisors' meetings, ward meetings and the multidisciplinary consultations. Information was also spread by means of the organisation's own magazine. Special information meetings were arranged for nursing staff, other disciplines, residents and their family. Finally, the residents' and family councils were informed. Information involved the model of resident-oriented care and its implementation. Quantitatively, on the somatic experimental ward the information quality was assessed as low during the implementation. The low perceived information quality probably reflected the problems on this ward. On the psycho-geriatric experimental ward the information quality was perceived as moderate. The way in which the project was evaluated differed also on the two experimental wards. On the psycho-geriatric ward, in the ward meetings interim evaluations were performed regularly by ward sisters and nursing caregivers. On the somatic ward interim and final evaluations were postponed during the time-out. Later on, interim evaluations re-started. Besides conducting interim evaluations, a final evaluation report was written by the project co-ordinator. For this purpose, on the somatic and psycho-geriatric ward a survey was conducted among employees. Data were collected regarding sufficiency of information, need for further education, PNC performance, the cyclical duty roster, the residents' dossier and personal opinions about the results of the implementation. This final report was presented to the management team.

\section{Staff}

In general, there appeared to be a large willingness to change among nursing caregivers. PNCs seemed to be pleased with the increased responsibilities. However, despite this willingness actual changes went slowly. A lot of nursing caregivers kept working according to former patterns. Some nursing caregivers experienced difficulty in functioning as a PNC. Willingness to change appeared to be related to the expertise of nursing caregivers themselves. In the first phase, on the somatic ward much resistance appeared not as a result of lack of motivation for implementing a resident-oriented care model but as a consequence of the problems between the supervisor and the teams. After the project was taken over by the ward sister and the new interim supervisor, nursing caregivers were more involved, resistance decreased and motivation in- 
creased. On the psycho-geriatric ward employees were involved in all phases of the implementation. For example, PNCs were involved in work groups on ward level, they could choose which residents would be assigned to them, and they could ventilate their ideas in a so-called 'ideas book'. Regarding other disciplines, at the start of the implementation their willingness to change was not very obvious. Physicians appeared to be more reticent compared to the other disciplines. Most disciplines had to get used to consulting PNCs, and not the ward sister anymore, regarding issues in resident's care.

\section{Skills}

Special training with regard to the implementation was arranged for ward managers, PNCs and other ward employees. This was carried out by the education co-ordinator of the organisation. The aims were to clarify a resident-oriented care model and its corresponding tasks, to improve knowledge and to remove uncertainties. For supervisors and ward sisters separately, two training sessions were arranged for one and a half days. They focused on using the nursing process and supporting the PNCs. Furthermore, two training sessions were organised for all nursing caregivers per ward. This training focused on the background of resident-oriented care and its practical use, tasks and roles, the importance of collegial communication and co-operation. Finally, two training sessions were arranged for PNCs. This training covered resident-oriented care, tasks and roles, communication with colleagues and residents and the use of the nursing process. In general, employees and PNCs in particular evaluated these trainings as superficial. Participants did not have the feeling of learning something new. Finally, on the psycho-geriatric ward one comeback session was arranged for PNCs. This training was well evaluated. By means of role-plays, practical issues were discussed with respect to communication, co-operation and the nursing process. The supervisor and ward sister of the psycho-geriatric ward supervised PNCs in making nursing care plans. In addition, the supervisor trained nursing caregivers in their resident-oriented attitude during the profession-oriented meeting. Finally, all PNCs got training-on-thejob regularly by the ward sister and one whole day's training-on-the-job given by the ward sister or project co-ordinator, and on the psycho-geriatric ward, by the supervisor. During the special training for PNCs, the problems with the supervisor escalated on the somatic ward. As a result, the nature of the training changed for the PNCs on the somatic ward. It was not longer focused on issues regarding the implementation but on ward-related problems.

\section{Style}

The approach of the project co-ordinator could be characterised as socio-emotional as being participative and supportive and low instrumental. The implementation was prepared jointly with the supervisors. During the implementation the project co-ordinator attended the multidisciplinary meetings and supported the supervisors by giving PNCs training-on-the-job, helping to adjust the nursing care plan and performing a final evaluation. In the first period of the implementation, supervisors indicated the need for more steering with respect to the direction of the implementation and decisions in this respect. However, this need decreased during the implementation due to an increased knowledge of supervisors themselves. With respect to the somatic experimental ward, extra support was given to the ward sister in co-ordinating the implementation. Quanti- 
tatively, in the pre-test the leadership style of the supervisor of the somatic experimental ward can be characterised as low socio-emotional and highly instrumental. According to the project co-ordinator, this leadership style appeared to be too directive. The top-down information style of the supervisor in question and little participation of the team in preparing the implementation seemed to be the main obstacles. The leadership style of the new interim supervisor can be characterised as highly socio-emotional and moderate instrumental in both post-tests. Quantitatively, on the psycho-geriatric ward the leadership style of the supervisor can be characterised as first moderately and later low socio-emotional and moderately instrumental. According to the project coordinator, the leadership style of this supervisor appeared to be open and confronting. By giving personal support in making nursing care plans, the supervisor was well informed about the implementation's progress and the functioning of PNCs. In case of problems in functioning, PNCs were spoken to directly. In case of lack of clarity, the supervisor made room for nursing caregivers to discuss problems and with this to get them used to the changes.

\section{Shared values}

The implementation was characterised primarily as top-down by the supervisors and the project co-ordinator. The implementation model and the action plan were designed by them in co-operation with the nursing manager of the organisation. Then, in work groups on ward level subjects such as tasks and responsibilities were further elaborated and during the implementation as much involvement of nursing caregivers as possible was created. Therefore, the implementation contained elements of a bottom-up approach too. The implementation was restricted to two experimental wards. However, from the start onwards, the organisation had chosen to implement a resident-oriented care model on all nursing wards, with the intention to make use of the experiences of both experimental wards. Therefore, the change towards a resident-oriented care model could be characterised as irreversible.

\section{Organisation B}

\section{Structure}

In organisation B, a work group on project level was installed in which the project coordinator and the two supervisors of the experimental wards participated. Subjects to be discussed were the communication structure on ward level and the tasks of the ward sister. In addition, meetings were held with the nursing manager of the organisation. In these meetings the general outline of the design of a resident-oriented care model was discussed such as the use of the nursing process and the adjustment of the residents' dossier and the implementation was prepared such as extra training. In contrast with organisation A work groups on ward level were not installed.

\section{Strategy}

The implementation can be characterised as incremental. The start of the implementation, in December 1995, concerned the assignment of residents, adjustments of the duty rosters and a start with the use of the nursing process. Beforehand, the project group determined criteria for resident assignment. In the second half of 1996, a further development of the residents' dossiers and the implementation of the nursing process 
were given the first priority (see also chapter 5). Results were expected with regard to an increase of resident-oriented care, an increase of quality of care and more job satisfaction and independence of nursing caregivers. Extra means to support the implementation on project level were allocated to the educational co-ordinator, who was given extra time to co-ordinate the project and to training of ward management. To support the experimental wards during the implementation, additional staff were appointed on the experimental wards for the performance of daily care tasks. In the middle of 1996 some distracting factors appeared. Due to a high sickness absence on both experimental wards, work pressure increased. Furthermore, ward sisters were replaced on the experimental wards. On the psycho-geriatric ward instability appeared with regard to the supervisor. Due to illness the supervisor left this ward during the second post-test. Afterwards it was concluded that there was made hardly any progress with respect to the implementation on this ward. For example, it appeared that no pilot was performed with the new multidisciplinary resident's dossier. Further, the nursing process was hardly implemented despite efforts by the project co-ordinator shortly before the last post-test to steer this supervisor to make more progress. Besides the implementation of resident-oriented care, some other developments were initiated in the organisation. The project "day rhythm" was introduced during the first post-test with the aim to increase the well-being of residents. This project was focused on normalisation of the day rhythm of residents by means of adjusting work and care-giving times. Further, the project "ward-related meal serving" was introduced. In this project serving times of meals no longer depended on the schedules of the central kitchen but could be determined by the wards themselves. Although these two projects can be viewed as enforcing resident-oriented care, they did demand extra adjustment of employees on the experimental wards to the new working schedules. As a consequence, extra workpressure was felt leading to an inclination to fall back into the old working method.

\section{Systems}

Before the implementation special meetings were arranged for the employees on the two wards. A special meeting was also arranged for all members of the multidisciplinary team. The supervisors informed residents and family on the ward. Occasionally information was spread by means of the residents' magazine of the organisation. Information for the rest of the organisation about the implementation took place by means of the formal channels such as the management team and the supervisors' meetings. Information covered the resident-oriented care model to be implemented and the implementation itself, i.e. the process. Quantitatively, the information quality on the somatic experimental ward was experienced as low in the pre-test and high in the last post-test. On the psycho-geriatric experimental ward the information quality appeared to be high in the pre-test and moderate in the last post-test. So, the last post-test scores on information quality did not clearly reflect the problems on this ward. Interim evaluations of the implementation progress took place on project level in meetings with the project co-ordinator and the supervisors. On ward level regular interim evaluations were conducted in meetings with nursing caregivers and supervisors. Additionally, the supervisor on the somatic experimental ward wrote a final evaluation report. Finally, a final evaluation report was written by the project co-ordinator, which was presented to the management team. In this report the implementation was evalu- 
ated. In contrast to organisation $\mathrm{A}$, the information for this report was not collected by asking nursing caregivers of the experimental ward directly about their experiences.

\section{Staff}

The willingness to change on the experimental wards was considered good. However, some resistance also existed. For example, on the psycho-geriatric ward in the early implementation phase there was open resistance against the division of the ward into two units. The introduction of joint coffee breaks with residents was another change that met a lot of resistance on this ward. However, uncertainty at the start of the implementation, according to the supervisor connected with this resistance, decreased after a while. As was indicated by the supervisors and the project co-ordinator, positive implementation results were noticed such as care being more attuned on the individual needs of the residents. Despite these positive results, some nursing caregivers had difficulty to abandon old working methods and change to the new ones. Among the other disciplines a wait-and-see attitude towards the implementation was evident. As in organisation A, physicians in particular had difficulties to adjust to more cooperation with nursing caregivers. With the introduction of an integral multidisciplinary resident's dossier, it was expected that some problems could be solved in this respect.

\section{Skills}

With respect to the implementation extra training was arranged. The training comprised different parts. All supervisors and ward sisters were trained first during five sessions of two hours. This was done because supervisors and ward sisters were considered as pioneers with the task to disseminate information and knowledge to the nursing caregivers on the ward. The aim was to practise the nursing process by means of case histories. In the first implementation phase no special training was organised for nursing caregivers. In the middle of 1996 special training was arranged for supervisors, ward sisters and nursing caregivers of the experimental wards with regard to the use of the nursing process. Further, after the pre-test, six training sessions were organised for a selected group of nursing caregivers of all wards of the organisation. Although in line with the principles of the implementation this training was not specially arranged in this respect. The main subjects involved observation and reporting, making nursing care plans and using the residents' dossiers. The training was arranged by the project co-ordinator. PNCs were coached by the ward sisters concerning the use of the nursing process. Supervisors did not give any training-on-the-job for PNCs.

\section{Style}

The two supervisors described the style of the project co-ordinator as socio-emotional as being participative and collegial and low instrumental. The project co-ordinator, who was also co-ordinator of education in the organisation, gave support to the supervisors by arranging and performing training for supervisors, ward sisters and PNCs. Quantitatively, the leadership style of the supervisor of the somatic ward can be characterised as low socio-emotional and highly instrumental. According to the project coordinator, this leadership style was considered well structured and providing clear steering with sufficient space for involvement of the nursing caregivers. There was 
clarity about responsibilities and roles within the teams. Quantitatively, the leadership style of the supervisor on the psycho-geriatric ward can be characterised as moving from first highly to later moderately socio-emotional and from first low to later highly instrumental. According to the project co-ordinator, this leadership style was not clear, which formed a problem for the ward sisters in particular. This supervisor had difficulties in delegating tasks to the ward sisters and in steering the implementation. As a result, the coaching role of the ward sisters and their position towards PNCs did not appear to be sufficiently developed.

\section{Shared values}

The supervisors and project co-ordinator characterised the implementation primarily as top-down. The project group designed the general outline and took the main decisions. On ward level no elaboration of the general outlines took place. It was argued that this method saved time and was congruent with the organisation culture. Nursing staff were informed as much as possible by the project co-ordinator. Involvement was created by means of group evaluations. Regular meetings were also held with ward employees before the implementation. A solid base of ward support was seen as an important factor for a successful implementation. The implementation was restricted to two experimental wards. In organisation $B$, it was the intention to implement a resident-oriented care model on all wards according to the implementation model on the experimental wards. So, the change towards a resident-oriented care model could be characterised as irreversible.

\section{Organisation $C$}

\section{Structure}

In organisation $\mathrm{C}$, a work group on project level was installed in which the nursing manager and the two supervisors of the experimental wards participated. The main subjects in the meetings were the design of a resident-oriented care model in outline such as resident assignment and the preparation of the implementation such as informing residents and their family, problems to be expected and the evaluation of the implementation. At the start meetings took place weekly, but later these meetings became less regular. Co-ordination of the implementation was delegated to the supervisor of the psycho-geriatric experimental ward. So, in contrast to the two other organisations, no separate project co-ordinator was appointed to co-ordinate the implementation. In general, meetings between the two supervisors of both experimental wards could be characterised as spontaneous instead of structural. Thus, the project structure can be characterised as loose, determined by open contacts. In line with the character of the project structure, no formal work groups on ward level were installed. The team was involved by means of discussions with regard to the project plan.

\section{Strategy}

The implementation can be characterised as incremental. It started with resident assignment in March 1996. Next, priority was given to renewed attention for the nursing process and the use of the resident's dossier. Before the implementation, the multidisciplinary meeting and the multidisciplinary dossier had already been implemented including the use of the nursing process accompanied by training. In the middle of 1996 
the resident's dossier was adjusted by adding a new multidisciplinary care plan, which was introduced as a pilot project on both the psycho-geriatric experimental and control ward. The somatic experimental ward did not participate in this pilot project because the supervisor felt that the ward was not ready. Resident assignment was adjusted by adopting the model of organisation A (see also chapter 5). Expectations with respect to the implementation at first concerned more resident-oriented care, i.e. more related to the needs of individual residents, an increase of quality of care and better co-operation with the other disciplines. After the first post-test some distracting factors appeared. On the somatic experimental and control wards residents and staff had to move to a new annex. The consequences were changes in existing teams. Then, renovations took place on both somatic wards, which meant the change of a number of rooms into single bedrooms. Due to these developments, work pressure was felt as high on both somatic wards and an increased sickness absence was perceived. Nursing caregivers felt frustrated because they had not enough time for care giving in a way they wanted to. In this respect, supervisors of both experimental wards felt the need to be continuously alert to prevent the nursing caregivers reverting to their former working methods. Finally, to support a resident-oriented working method, before the last post-test the "breakfast project" was introduced on all wards. This means that, to strengthen the residential function, the central kitchen no longer served breakfast on the wards. Instead, breakfasts were prepared on the nursing wards themselves. Unlike organisation $\mathrm{A}$ and $\mathrm{B}$, no instability with supervisors appeared in organisation C. Finally, both on project and ward level no extra means were allocated with respect to the implementation.

\section{Systems}

Information regarding the resident-oriented care model and its implementation was spread by means of the formal communication channels such as the management team and the supervisors' meeting. The supervisors' meeting was held monthly and was attended by other disciplines too. In this meeting the implementation progress became a fixed agenda item. From this meeting information was communicated to the management team. Further, in the meetings on ward level the implementation became a fixed agenda item too. Information was also spread monthly by means of the organisation magazine. Special information meetings were arranged for residents and family, nursing caregivers and the other disciplines. At the start of the implementation, during one week nursing caregivers of the experimental wards were informed through daily discussions about the implementation. Quantitatively, on the somatic experimental ward the information quality was considered in the pre-test as moderate and in the last posttest as low. On the psycho-geriatric ward the information quality was viewed as the highest of all experimental wards both in the pre- and last post-test. On this ward the supervisor, being the project co-ordinator, could inform the ward more directly. In addition, some evaluations were carried out. To do so, supervisors on the wards conducted interim evaluations with their nursing caregivers. In case of problems, practical solutions were sought. Important problems were put on the agenda of the ward meetings. Supervisors and ward sisters held separate evaluations with all PNCs too. Supervisors then made a final report, which was discussed in the supervisors' meeting. 


\section{Staff}

At the start of the implementation a large willingness to change among nursing caregivers was shown according to the supervisor and project-co-ordinator. For example, as in organisation $\mathrm{A}$, involvement among nursing caregivers was fostered by possibilities for expressing preferences for resident assignment and by the exchange of ideas and concrete proposals in small discussion groups with a ward sister and PNCs. However, part-time nursing caregivers in particular experienced the changes as difficult and showed a more wait-and-see attitude. Nursing caregivers were motivated to start more interesting work on the one hand, but they indicated uncertainty about their functioning on the other. In general, the other disciplines were positive to the implementation. Willingness to change in this group seemed to depend on the individual person and on the experienced workload. Among some disciplines, irritation was obvious due to the presence of multiple changes. The expected increase of quality of residents' care, a major project goal, was considered as a stimulus for a positive attitude.

\section{Skills}

Two years before the implementation all employees had attended a training course regarding the use of the nursing process. Therefore, in contrast to organisations $\mathrm{A}$ and $B$ no special training was arranged for the ward management and the nursing caregivers. It was decided to make special training dependent on a need for it or on the presence of certain problems. With regard to the pilot with the adjusted resident's dossier on both psycho-geriatric wards, PNCs were instructed six times by the supervisor. They were also supported individually by the ward sisters. Furthermore, supervisors and ward sisters gave training-on-the-job to PNCs by means of supervision in small discussion groups (somatic ward) and individually (psycho-geriatric ward). Due to increased responsibilities and collaboration with other disciplines, insecurity was observed among PNCs. Further, some doubts were present about the skills of PNCs to bear more responsibilities. At the last post-test both supervisors observed a better resident-oriented attitude and more involvement of PNCs at their assigned residents.

\section{Style}

Quantitatively, the leadership style of the supervisor of the somatic experimental ward can be characterised by highly socio-emotional and at first low and later moderately instrumental. The style of the project co-ordinator can be characterised as socioemotional as being participative and loose and low instrumental. Since the project coordinator was also supervisor of the psycho-geriatric experimental ward, he established the implementation in close collaboration with the supervisor of the somatic experimental ward. Quantitatively, the leadership style of the co-ordinator as a supervisor was at first moderately and later low socio-emotional and instrumental. Leadership style of supervisors was not discussed during the interviews. The project coordinator, being a supervisor too, was also a colleague of the supervisor of the other experimental ward. Therefore, it was decided to ask them no questions about the leadership style of their colleague because they could not be interviewed as independent third parties. 


\section{Shared values}

As in organisations $\mathrm{A}$ and $\mathrm{B}$, the two supervisors characterised the implementation as primarily top-down. The project group introduced the general outlines of the implementation. No formal work groups on ward level were present. However, nursing caregivers on the wards were involved informally in a further elaboration of the implementation model by means of regular interim evaluations and supervisory evaluations. This is in line with the project structure, which could be characterised as loose. Therefore also elements of a combined approach can be pointed out. Unlike the other organisations, before the last post-test in organisation $\mathrm{C}$ on most of the other wards, except for the control wards, a resident-oriented care model was implemented. Therefore, this change formed an integral part of the organisation and could be considered as irreversible.

\subsection{Success conditions}

This section aims to draw conclusions about the conditions for successfully implementing a resident-oriented care model. To that aim, a matrix was developed which is presented in table 6.4. The table shows the differences between the six experimental wards based on the results with regard to the success conditions structured by means of the 7-S model. In this way an attempt is made to distinguish between more and less successful experimental wards.

As is shown in table 6.4 , the experimental wards have a number of comparable conditions among the factors structure, strategy, systems, skills and shared values. The similarities concern: work groups on project level, an incremental implementation strategy, formal communication channels and special information means for diffusion of information, interim and final evaluations on project level, interim evaluations on ward level, training-on-the-job by ward sisters, a top-down approach and irreversibility of the change. Many of the differences are related to the type of organisation in question and thus to the choices made on project level, such as work groups on ward level, extra financial and personnel means on project level, special training of ward management, leadership style of project co-ordinators and the organisational integration of the implementation. Ward-related differences concern: action plan, distracting factors, stability of supervisors, extra financial and personnel means on ward level, information quality, final evaluations on ward level, willingness to change among nursing staff, special training of nursing caregivers, training-on-the-job by supervisors and their leadership style.

The question now arises what the most striking differences are between the least and most successful wards with respect to these conditions. To be able to relate the most successful wards with regard to the implementation of a resident-oriented care model to the success conditions, we first have to go back to the conclusions made in section 6.2. We concluded that the psycho-geriatric wards of organisations $A$ and $C$ revealed the highest last post-test scores on the design variable "resident-oriented care model". 
Table 6.4 Differences in success conditions between the experimental wards

\begin{tabular}{|c|c|c|c|c|c|c|}
\hline \multirow[b]{2}{*}{ Success conditions } & \multicolumn{6}{|c|}{ Experimental wards } \\
\hline & A som ${ }^{\prime}$ & $\mathrm{Apg}^{2}$ & B som & $\mathrm{B}$ pg & C som & C pg \\
\hline \multicolumn{7}{|l|}{ Structure } \\
\hline Work groups on project level & Yes & Yes & Yes & Yes & Yes & Yes \\
\hline Work groups on ward level & Yes & Yes & No & No & No & No \\
\hline \multicolumn{7}{|l|}{ Strategy } \\
\hline Synoptic vs. incremental & Incremental & Incremental & Incremental & Incremental & Incremental & Incremental \\
\hline Action plan & Delayed & On time & On time & Delayed & On time & On time \\
\hline Distracting factors & Yes & No & Yes & Yes & Yes & No \\
\hline Stability of supervisor & No & Yes & Yes & No & Yes & Yes \\
\hline $\begin{array}{l}\text { Extra financial and personnel } \\
\text { means project level }\end{array}$ & Yes & Yes & Yes & Yes & No & No \\
\hline $\begin{array}{l}\text { Extra financial and personnel } \\
\text { means ward level }\end{array}$ & Yes & No & Yes & Yes & No & No \\
\hline \multicolumn{7}{|l|}{ Systems } \\
\hline $\begin{array}{l}\text { Formal communication chan- } \\
\text { nels }\end{array}$ & Yes & Yes & Yes & Yes & Yes & Yes \\
\hline Special information means & Yes & Yes & Yes & Yes & Yes & Yes \\
\hline Information quality ${ }^{3}$ & Low & Moderate & $\begin{array}{l}\text { First low/ } \\
\text { later high }\end{array}$ & $\begin{array}{l}\text { First high/ } \\
\text { later mod- } \\
\text { erate }\end{array}$ & $\begin{array}{l}\text { First mod- } \\
\text { erate/ later } \\
\text { low }\end{array}$ & High \\
\hline $\begin{array}{l}\text { Interim evaluations project } \\
\text { level }\end{array}$ & Yes & Yes & Yes & Yes & Yes & Yes \\
\hline $\begin{array}{l}\text { Final evaluations project } \\
\text { level }\end{array}$ & Yes & Yes & Yes & Yes & Yes & Yes \\
\hline $\begin{array}{l}\text { Interim evaluations ward } \\
\text { level }\end{array}$ & Yes & Yes & Yes & Yes & Yes & Yes \\
\hline $\begin{array}{l}\text { Final evaluations ward level } \\
\text { Staff }\end{array}$ & No & Yes & Yes & No & Yes & Yes \\
\hline Willingness to change & $\begin{array}{l}\text { At first no, } \\
\text { later yes }\end{array}$ & Yes & Yes & $\begin{array}{l}\text { At first no, } \\
\text { later yes }\end{array}$ & Yes & Yes \\
\hline \multicolumn{7}{|l|}{ Skills } \\
\hline Special training ward mngt. & Yes & Yes & Yes & Yes & No & No \\
\hline Special training $n$. caregivers & Yes & Yes & Yes & Yes & No & Yes \\
\hline $\begin{array}{l}\text { Training-on-the-job by su- } \\
\text { pervisors }\end{array}$ & No & Yes & No & No & Yes & Yes \\
\hline $\begin{array}{l}\text { Training-on-the-job by ward } \\
\text { sisters } \\
\text { Style }\end{array}$ & Yes & Yes & Yes & Yes & Yes & Yes \\
\hline $\begin{array}{l}\text { project co-ordinators } \\
\text { Socio-emotional }\end{array}$ & \multicolumn{2}{|c|}{$\begin{array}{l}\text { Participative and suppor- } \\
\text { tive }\end{array}$} & \multicolumn{2}{|c|}{$\begin{array}{l}\text { Participative and colle- } \\
\text { gial }\end{array}$} & \multicolumn{2}{|c|}{ Participative and loose } \\
\hline Instrumental & Low & & Low & & Low & \\
\hline $\begin{array}{l}\text { supervisors } \\
\text { Socio-emotional }^{3}\end{array}$ & $\begin{array}{l}\text { First low/ } \\
\text { later high }\end{array}$ & $\begin{array}{l}\text { First mod- } \\
\text { crate/ later } \\
\text { low }\end{array}$ & Low & $\begin{array}{l}\text { First high/ } \\
\text { later mod- } \\
\text { erate }\end{array}$ & High & $\begin{array}{l}\text { First mod- } \\
\text { erate/ later } \\
\text { low }\end{array}$ \\
\hline Instrumental ${ }^{3}$ & $\begin{array}{l}\text { First high/ } \\
\text { later mod- } \\
\text { erate }\end{array}$ & Moderate & High & $\begin{array}{l}\text { First low/ } \\
\text { later high }\end{array}$ & $\begin{array}{l}\text { First low/ } \\
\text { later mod- } \\
\text { erate }\end{array}$ & $\begin{array}{l}\text { First mod- } \\
\text { erate/ later } \\
\text { low }\end{array}$ \\
\hline Shared values & & & & & & \\
\hline Top-down vs. bottom-up & Top-down & Top-down & Top-down & Top-down & Top-down & Top-down \\
\hline $\begin{array}{l}\text { Organisational integration } \\
\text { Irreversibility of the change }\end{array}$ & $\begin{array}{l}\text { Experiment } \\
\text { Yes }\end{array}$ & $\begin{array}{l}\text { Experiment } \\
\text { Yes }\end{array}$ & $\begin{array}{l}\text { Experiment } \\
\text { Yes }\end{array}$ & $\begin{array}{l}\text { Experiment } \\
\text { Yes }\end{array}$ & $\begin{array}{l}\text { Total org. } \\
\text { Yes }\end{array}$ & $\begin{array}{l}\text { Total org. } \\
\text { Yes }\end{array}$ \\
\hline
\end{tabular}


On the psycho-geriatric ward of organisation $\mathrm{C}$ the largest positive change was found (see table 6.1 and figures 6.1 and 6.2). On the psycho-geriatric experimental ward of organisation $\mathrm{B}$, the lowest last post-test score was found and moreover, this ward revealed the lowest change. In trying to make a clear distinction we used these three wards to be able to relate the success conditions to the least and most successful wards. Based on the differences regarding the success conditions presented in table 6.4 , the differences with respect to the psycho-geriatric ward of organisation $B$ (the least successful ward) on the one hand and the psycho-geriatric wards of organisations $\mathrm{A}$ and $\mathrm{C}$ (the most successful wards) on the other are summarised in table 6.5.

Table 6.5 Summarised differences in success conditions between the least and most successful experimental wards

\begin{tabular}{|c|c|c|}
\hline \multirow[b]{2}{*}{ Success conditions } & \multicolumn{2}{|c|}{ Experimental wards } \\
\hline & Least successful ward & Most successful wards \\
\hline \multicolumn{3}{|l|}{ Strategy } \\
\hline Action plan & Delayed & On time \\
\hline Distracting factors & Yes & No \\
\hline Stability supervisor & No & Yes \\
\hline $\begin{array}{l}\text { Extra financial and personnel } \\
\text { means ward level }\end{array}$ & Yes & No \\
\hline Systems & & \\
\hline $\begin{array}{l}\text { Final evaluations ward level } \\
\text { Staff }\end{array}$ & No & Yes \\
\hline $\begin{array}{l}\text { Willingness to change } \\
\text { Skills }\end{array}$ & At first no, later yes & Yes \\
\hline $\begin{array}{l}\text { Training-on-the-job by supervisors } \\
\text { Style }\end{array}$ & No & Yes \\
\hline $\begin{array}{l}\text { - Supervisors } \\
\text { Socio-emotional } \\
\text { Instrumental }\end{array}$ & $\begin{array}{l}\text { First high/later moderate } \\
\text { First low/later high }\end{array}$ & $\begin{array}{l}\text { First moderate/later low } \\
\text { Moderate to low }\end{array}$ \\
\hline
\end{tabular}

The summarised results show that the differences are related to the 7-S factors strategy, systems, staff, skills and style. In general it can be concluded that extra means on ward level does not seem to be a success condition of the implementation. Striking differences between the two most successful wards and the least successful ward concern the following success conditions. On the two most successful wards the instrumental leadership of supervisors was moderate in the pre-test and moderate to low in the last post-test. This finding is in line with the conclusion of paragraph 6.2 that a more successful implementation of resident-oriented care is associated with low instrumental leadership in the last phase of the implementation. Furthermore, no distracting factors were shown and the ward officers of these wards appeared to be stable during the implementation, designed a realistic action plan resulting in no delay and motivated nursing caregivers to be willing to change. In addition, nursing staff was directly supported by a training-on-the-job by the supervisors themselves. Nursing staff was involved in final evaluations on ward level, which formed the base for the final evaluation report. No conclusions can be made with regard to the ideal form of socioemotional leadership due to the absence of significant correlations with the last posttest of and the change in the design variable "resident-oriented care model". The lack of success of the least effective ward can partly be based on some distracting factors and problems in the functioning of the supervisor. After this supervisor had left the ward, it was concluded in the last post-test that less resident-oriented care was imple- 
mented than was planned and expected, resulting in a delay in the action plan which could not be recovered anymore. The leadership style of the supervisor in question appeared to be low instrumental in the pre-test but highly instrumental in the last posttest which, as was concluded in section 6.2 , is associated with a less successful implementation. Next, this supervisor gave no training-on-the-job to the PNCs and nursing caregivers were not directly involved in decisions regarding the implementation. In the early implementation phase this was reflected in less willingness to change. Furthermore, no final evaluations on ward level were conducted with nursing staff, as was later seen due to a delay in the action plan.

\subsection{Summary}

In answering the research question regarding conditions for a successful implementation of a resident-oriented care model, the following appeared. The six experimental wards showed a lot of similarities concerning the elaborated success conditions. The similarities were work groups on project level, an incremental implementation strategy, formal communication channels and special information means for diffusion of information, interim and final evaluations on project level, interim evaluations on ward level, training-on-the-job by ward sisters, a top-down approach and the choice for an irreversible change. Differences were related to decisions taken on project level and, in this respect, to type of organisation or to ward-related differences. In using quantitative analyses the most successful experimental wards with regard to the implementation of a resident-oriented care model including the largest change in this respect could be distinguished from the least successful wards. It was concluded that the most effective implementation and the largest change was seen on the psycho-geriatric wards of organisations $\mathrm{A}$ and $\mathrm{C}$. Both experimental wards of organisation $\mathrm{B}$ were least successful. The somatic wards of organisations $A$ and $C$ appeared to be moderately successful. On the most successful experimental wards, i.e. psycho-geriatric wards of organisations A and $\mathrm{C}$ compared to the least successful ward, i.e. the psycho-geriatric ward of organisation B success conditions appeared to be: no delay in the action plan; absence of distracting factors; stability of the supervisor; final evaluations on ward level; willingness to change among nursing staff; and training-on-the-job by supervisors themselves. Furthermore, as was hypothesised, wards with supervisors using less instrumental leadership in the last phase of the implementation appeared to have implemented resident-oriented care more successfully. In this respect, only hypothesis $2 c$ could be partly confirmed. This confirmation has to be interpreted with caution since no conclusions with regard to causality can be made. The hypotheses concerning information quality $(\mathrm{H} 2 \mathrm{a})$ and socio-emotional leadership $(\mathrm{H} 2 \mathrm{~b})$ were not confirmed in our study. 


\section{JOB CHARACTERISTICS AND PSYCHOLOGICAL AND BEHAVIOURAL REACTIONS}

\subsection{Introduction}

This chapter presents the quantitative effects of the implementation of a residentoriented care model on the job characteristics of nursing caregivers (7.2) and on their psychological and behavioural reactions (7.3). It aims to provide an answer to the third research question. The chapter closes with a summary (7.4).

\subsection{Job characteristics}

\subsubsection{Analyses}

The following four job characteristics were measured: "job autonomy", "job demands", "social support" and "responsibility". Thus, we try to test the four hypotheses formulated in chapter 4 :

H3a) Job autonomy will increase in the experimental group compared to the control group after the implementation of resident-oriented care.

H3b) Job demands will increase in the experimental group compared to the control group after the implementation of resident-oriented care.

H3c) Social support will increase in the experimental group compared to the control group after the implementation of resident-oriented care.

H3d) Responsibility will increase in the experimental group compared to the control group after the implementation of resident-oriented care.

In the following part the analyses are discussed per variable. In order to test the hypotheses the final results regarding the last post-test differences between the experimental and control groups are presented one-tailed. Appendix 6, tables 6.1 a to 6.4, presents the final regression models (two-tailed). For a detailed description of the general outline of the analyses the reader is referred to 5.2.1.

\subsubsection{Results}

\section{Job autonomy}

Table 7.1 and figure 7.1 show no change in the unadjusted means on job autonomy in both post-tests of the experimental and control groups. 
Table 7.1 Job autonomy (unadjusted means)

\begin{tabular}{llllllllll}
\hline & \multicolumn{1}{c}{ pre-test } & \multicolumn{3}{c}{ post-test 1 } & \multicolumn{4}{c}{ post-test 2 } \\
& Mean & SD & $\mathrm{n}$ & Mean & SD & $\mathrm{n}$ & Mean & SD & $\mathrm{n}$ \\
\hline experimental group & 2.82 & 0.53 & 101 & 2.78 & 0.48 & 79 & 2.80 & 0.53 & 69 \\
control group & 2.75 & 0.56 & 107 & 2.76 & 0.59 & 88 & 2.75 & 0.49 & 77 \\
total group & 2.78 & 0.54 & 208 & 2.77 & 0.54 & 167 & 2.78 & 0.51 & 146 \\
\hline
\end{tabular}

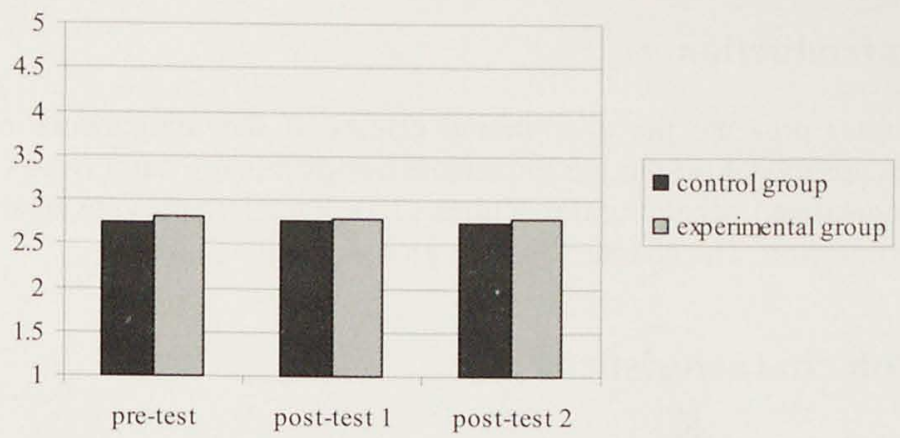

Figure 7.1 Job autonomy (unadjusted means)

ANCOVA revealed no baseline difference between the experimental and control groups $(\mathrm{F}=0.067, \mathrm{p}=0.796$, $\mathrm{df}(1,127), \mathrm{n}=145)$. Furthermore, no interaction effects were found in the last post-test between "type of group" on the one hand and "type of organisation" and "type of ward" on the other. Hence, analyses were performed on the total last post-test sample. Regression analyses revealed no significant difference between the experimental and control groups in the last post-test (adjusted mean difference $\mathrm{B}=0.028, \mathrm{p}=0.333$ ). Nursing caregivers in the experimental group showed no increase in job autonomy after the implementation compared to the control group (see also appendix 6, table 6.1a).

A closer investigation of the differences between the experimental and control groups with respect to the two latent factors underlying job autonomy, i.e. content and contextual job autonomy, revealed differing results. No differences were found with respect to content job autonomy, i.e. opportunities for nursing caregivers to determine working method, work goals, work order and work evaluation (adjusted mean difference $\mathrm{B}=0.001, \mathrm{p}=0.494$ ). However, a positive trend was found with respect to contextual job autonomy (adjusted mean difference $B=0.124, p=0.044$ ). Compared to the control group, after the implementation the experimental group revealed an indication for more opportunities to determine aspects such as leave times, amount and pace of work, working-hours and the kind of work to be done (see also appendix 6, tables 6.1b-c).

In conclusion, hypothesis $3 \mathrm{a}$, concerning an increase in job autonomy in the experimental group cannot be confirmed. However, a trend was found for an increase in contextual job autonomy in the experimental group. 


\section{Job demands}

Table 7.2 and figure 7.2 show slight increases in the unadjusted means on job demands in both post-tests in the experimental group as well as in the control group.

Table 7.2 Job demands (unadjusted means)

\begin{tabular}{lllllllllrr}
\hline & pre-test & \multicolumn{3}{c}{ post-test 1 } & \multicolumn{4}{c}{ post-test 2 } \\
& Mean & SD & $\mathrm{n}$ & Mean & SD & n & Mean & SD & \multicolumn{1}{c}{$n$} \\
\hline experimental group & 2.92 & 0.63 & 101 & 3.14 & 0.70 & 79 & 3.16 & 0.62 & 69 \\
control group & 3.09 & 0.69 & 109 & 3.19 & 0.70 & 88 & 3.27 & 0.64 & 78 \\
total group & 3.00 & 0.66 & 210 & 3.17 & 0.70 & 167 & 3.22 & 0.63 & 147 \\
\hline
\end{tabular}

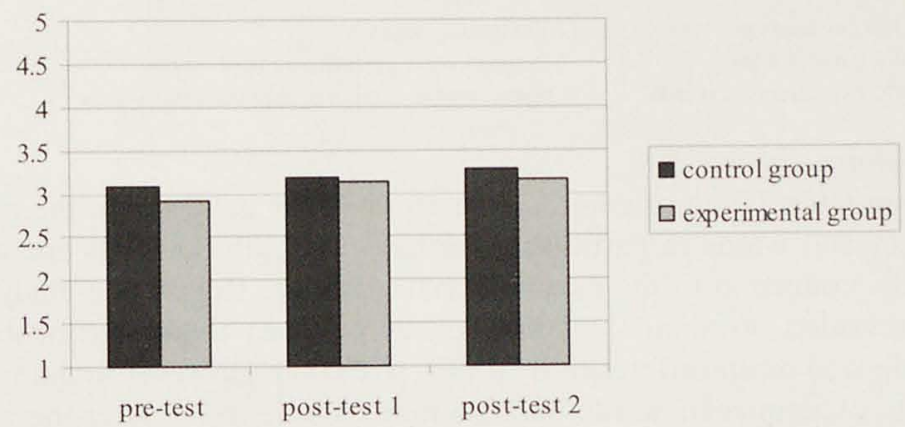

Figure 7.2 Job demands (unadjusted means)

Although differences at baseline were not significant, there is an indication that in the pre-test more job demands were experienced by nursing caregivers in the control group $(\mathrm{F}=4.889, \mathrm{p}=0.029, \mathrm{df}(1,129), \mathrm{n}=147)$. ANCOVA in the last post-test revealed a significant first-order interaction effect between "type of group" and "type of ward" $(\mathrm{F}=9.952, \mathrm{p}=0.002, \mathrm{df}(1,128), \mathrm{n}=147)$. Therefore stratification was performed and regression analyses were conducted for the somatic and psycho-geriatric groups separately.

Table 7.3 and figure 7.3 presents the unadjusted means per type of ward.

Table 7.3 Job demands per type of ward (unadjusted means)

\begin{tabular}{lllrlllllll}
\hline & Tre-test & \multicolumn{4}{c}{ post-test 1 } & \multicolumn{4}{c}{ post-test 2 } \\
& Mean & SD & \multicolumn{1}{c}{$\mathrm{n}$} & Mean & SD & $\mathrm{n}$ & Mean & SD & $\mathrm{n}$ \\
\hline somatic experimental ward (somex) & 3.14 & 0.46 & 52 & 3.45 & 0.70 & 43 & 3.35 & 0.61 & 37 \\
somatic control ward (somco) & 3.39 & 0.54 & 50 & 3.40 & 0.58 & 42 & 3.45 & 0.60 & 41 \\
total somatic group & 3.26 & 0.52 & 102 & 3.43 & 0.64 & 85 & 3.41 & 0.61 & 78 \\
p.g. experimental ward (pgex) & 2.69 & 0.70 & 49 & 2.77 & 0.50 & 36 & 2.93 & 0.56 & 32 \\
p.g. control ward (pgco) & 2.84 & 0.70 & 59 & 3.00 & 0.75 & 46 & 3.07 & 0.63 & 37 \\
total psycho-geriatric group & 2.77 & 0.70 & 108 & 2.90 & 0.66 & 82 & 3.01 & 0.60 & 69 \\
\hline
\end{tabular}




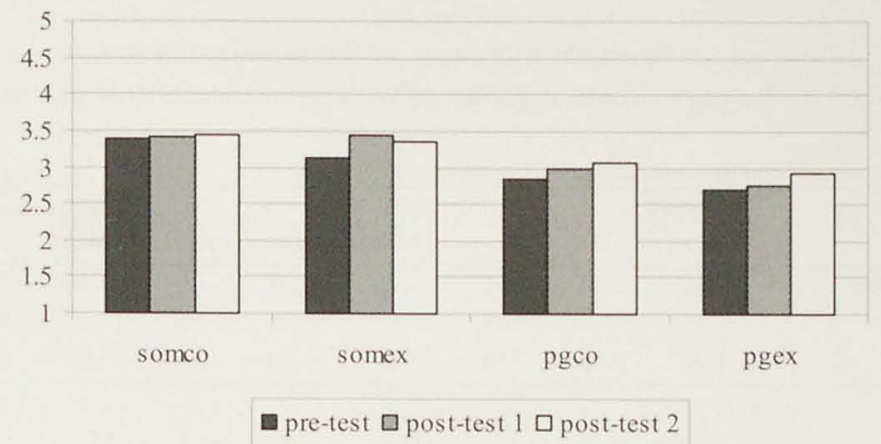

Figure 7.3 Job demands per type of ward (unadjusted means) somco: somatic control wards pgco: psycho-geriatric control wards somex: somatic experimental wards pgex: psycho-geriatric experimental wards

\section{Results somatic wards}

As shown in table 7.3 and figure 7.3 , the scores show increases in the first post-test on the experimental wards in particular. Further, more job demands are seen on the somatic wards compared to the psycho-geriatric wards. Regression analyses of the last post-test revealed no significant differences between the experimental and control groups (adjusted mean difference $\mathrm{B}=0.179, \mathrm{p}=0.071$ ). However, nursing caregivers on the somatic experimental wards indicate more job demands after the implementation of resident-oriented care compared to nursing caregivers on the control wards (see also appendix 6 , table 6.2a).

\section{Results psycho-geriatric wards}

As shown in table 7.3 and figure 7.3, on both post-tests increases in job demands are seen on the experimental wards and on the control wards. However, the differences are not significant in the psycho-geriatric group, on the last post-test there is an indication of fewer job demands on the experimental wards after the implementation compared to the control wards (adjusted mean difference $B=-0.225, p=0.029$ ) (see also appendix 6 , table 6.2b).

In looking more closely to the two underlying concepts of job demands, i.e. quantitative and qualitative job demands, the following results appeared. With respect to qualitative job demands after the implementation no differences appeared between the experimental and control groups (adjusted mean difference $B=0.008, p=0.463$ ). Due to a first-order interaction effect between "type of group" and "type of ward" with regard to quantitative job demands $(\mathrm{F}=10.278, \mathrm{p}=0.002$, $\mathrm{df}(1,128), \mathrm{n}=147)$, regression analyses were conducted for the somatic and psycho-geriatric group separately. In the somatic group no differences appeared between the experimental and control wards (adjusted mean difference $\mathrm{B}=0.177, \mathrm{p}=0.112$ ). In the psycho-geriatric group an indication was seen for less quantitative job demands on the experimental wards after the implementation (adjusted mean difference $\mathrm{B}=-0.268, \mathrm{p}=0.023$ ) (see also appendix 6 , tables $6.2 \mathrm{c}-\mathrm{e})$. 
Therefore, in conclusion hypothesis $3 b$, postulating an increase in job demands in the experimental group, cannot be confirmed.

\section{Social support}

Table 7.4 and figure 7.4 show no large changes in the unadjusted means of the experimental group in both post-tests. No substantial changes are seen in the control group either. Further, keeping in mind the four-point Likert scale, the scores are relatively high.

Table 7.4 Social support (unadjusted means)

\begin{tabular}{llllllllll}
\hline & pre-test & \multicolumn{3}{c}{ post-test 1} & \multicolumn{4}{c}{ post-test 2 } \\
& Mean & SD & $\mathrm{n}$ & Mean & SD & \multicolumn{1}{c}{$\mathrm{n}$} & Mean & \multicolumn{1}{l}{ SD } & \multicolumn{1}{c}{$\mathrm{n}$} \\
\hline experimental group & 3.33 & 0.37 & 101 & 3.26 & 0.30 & 77 & 3.26 & 0.26 & 69 \\
control group & 3.30 & 0.39 & 109 & 3.34 & 0.34 & 88 & 3.29 & 0.37 & 77 \\
total group & 3.31 & 0.38 & 210 & 3.30 & 0.32 & 165 & 3.27 & 0.33 & 146 \\
\hline
\end{tabular}

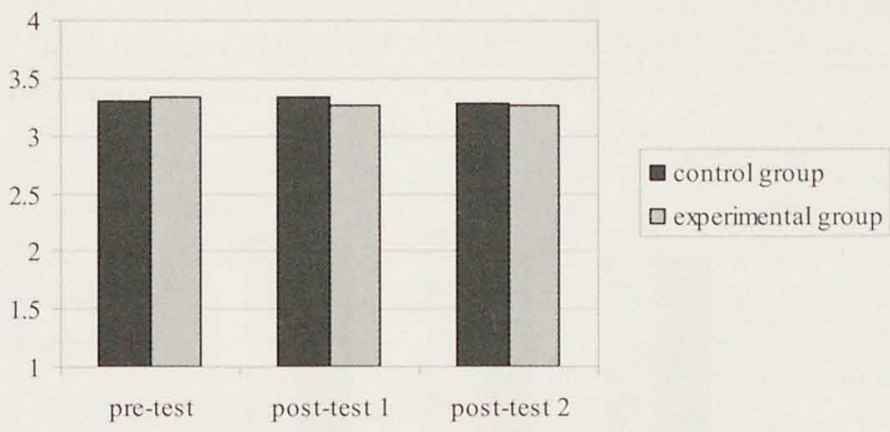

Figure 7.4 Social support (unadjusted means)

ANCOVA revealed no baseline difference between the experimental and control groups $(\mathrm{F}=1.879, \mathrm{p}=0.173, \mathrm{df}(1,129), \mathrm{n}=147)$. A second-order interaction effect appeared from ANCOVA in the last post-test $(F=9.380, p=0.003, d f(1,127), n=146)$. In other words, the intervention effect on social support was different per "type of organisation" (A, B and C) and probably per organisation per "type of ward" (somatic versus psycho-geriatric). In investigating the first-order interaction effects between "type of group" and "type of ward", we performed linear regression analyses for each organisation separately, thereby including type of group and type of ward and their interaction term in centred coding $(-1,+1)$. In investigating the first-order interaction effects per organisation, the final differences in organisation $\mathrm{A}$ and the differences per type of ward in organisation B problems of collinearity appeared between "type of group" and "type of ward" on the one hand and "careload" on the other. This problem was shown in loosing one of the predictors "type of group", "type of ward" or "careload" from the analysis and presence of high VIFs $(>27)$. Therefore, in these cases two separate analyses were performed: an analysis entering "type of group" or "type of ward" and excluding "careload" and an analysis excluding "type of group" or "type of ward" and entering "careload". The results of the second type of analyses are only presented if 
careload appeared to be a significant predictor of "social support". Final regression models with interaction terms are shown with centred regression coefficients (B's). To provide insight into their relative contribution, all final models without interaction terms are presented with non-centred regression coefficients.

\section{Results organisation A}

Table 7.5 and figure 7.5 present the unadjusted means of organisation A. The experimental group shows higher scores compared to the control group at all measurements but no major changes are seen in the experimental group whereas the control group shows a slight increase. In fact, the differences at pre-test appeared to be larger compared to those at the last post-test.

Table 7.5 Social support organisation A (unadjusted means)

\begin{tabular}{lllllllllll}
\hline & \multicolumn{1}{c}{ pre-test } & \multicolumn{3}{c}{ post-test 1 } & \multicolumn{4}{c}{ post-test 2 } \\
& Mean & SD & $\mathrm{n}$ & Mean & SD & $\mathrm{n}$ & Mean & SD & $\mathrm{n}$ \\
\hline experimental group & 3.29 & 0.32 & 24 & 3.27 & 0.34 & 27 & 3.26 & 0.21 & 24 \\
Control group & 3.02 & 0.38 & 23 & 3.06 & 0.28 & 27 & 3.14 & 0.18 & 23 \\
total group & 3.15 & 0.38 & 47 & 3.16 & 0.33 & 54 & 3.20 & 0.20 & 47 \\
\hline
\end{tabular}

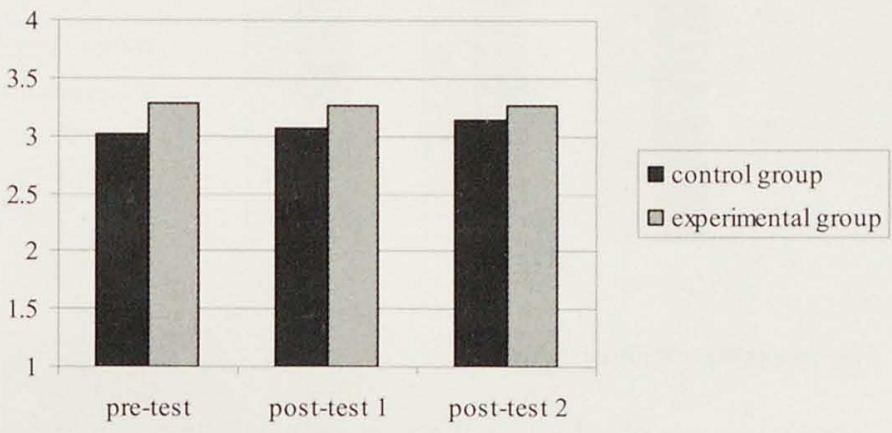

Figure 7.5 Social support organisation A (unadjusted means)

In organisation $\mathrm{A}$ regression analysis revealed no significant first-order interaction effect on the last post-test (adjusted mean difference $B=-0.039, p=0.164$ ). Although no significant difference was found between the experimental and control groups, a trend appeared (adjusted mean difference $B=0.080, p=0.09$ ). Nursing caregivers of the experimental group of organisation $\mathrm{A}$ indicate more social support compared to the control group (see also appendix 6 , tables $6.3 \mathrm{a}-\mathrm{b}$ ). In this analysis no correction took place for careload. However, in the additional analysis careload was not found to be a significant predictor for social support.

\section{Results organisation $B$}

In organisation B a first-order interaction effect appeared between "type of group" and "type of ward" (adjusted mean difference $B=0.216, p=0.000$ ). Therefore, in organisation B stratification took place and regression analyses were performed for the somatic and psycho-geriatric group separately. Table 7.6 and figure 7.6 present the unadjusted 
means for organisation B per type of ward. Hardly any change in the unadjusted means on the somatic experimental ward is shown, whereas the somatic control ward shows higher scores and moreover shows an increase in social support. Although the regression analyses of the last post-test of the somatic wards in organisation B revealed no significant differences, there is an indication that nursing caregivers of the somatic experimental ward in organisation B experience less social support after the implementation compared to their control group (adjusted mean difference $B=-0.297$, $\mathrm{p}=0.013$ ). In these analyses no correction took place for careload. The additional analysis did not show careload as a significant predictor for social support (see also appendix 6 , tables $6.3 \mathrm{c}-\mathrm{e})$.

Table 7.6 Social support organisation B per type of ward (unadjusted means)

\begin{tabular}{llllllllll}
\hline & pre-test & \multicolumn{3}{c}{ post-test 1 } & \multicolumn{4}{c}{ post-test 2 } \\
& Mean & SD & $\mathrm{n}$ & Mean & SD & $\mathrm{n}$ & Mean & SD & $\mathrm{n}$ \\
\hline somatic experimental ward (somex) & 3.10 & 0.42 & 12 & 3.19 & 0.19 & 11 & 3.12 & 0.27 & 9 \\
somatic control ward (somco) & 3.16 & 0.22 & 12 & 3.43 & 0.30 & 11 & 3.44 & 0.37 & 10 \\
total somatic group & 3.13 & 0.33 & 24 & 3.31 & 0.27 & 22 & 3.29 & 0.36 & 19 \\
p.g. experimental ward (pgex) & 3.45 & 0.29 & 15 & 3.33 & 0.21 & 10 & 3.26 & 0.21 & 10 \\
p.g. control ward (pgco) & 3.42 & 0.34 & 19 & 3.34 & 0.23 & 14 & 2.74 & 0.34 & 10 \\
total psycho-geriatric group & 3.43 & 0.32 & 34 & 3.33 & 0.21 & 24 & 3.00 & 0.38 & 20 \\
\hline
\end{tabular}

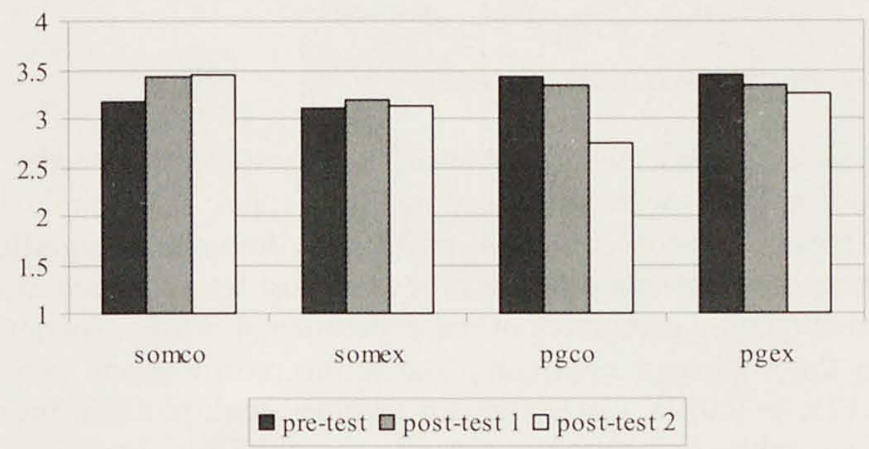

Figure 7.6 Social support organisation B per type of ward (unadjusted means) somco: somatic control wards somex: somatic experimental wards pgco: psycho-geriatric control wards pgex: psycho-geriatric experimental wards

The unadjusted means in table 7.6 and figure 7.6 reveal in the last post-test in the psycho-geriatric group a large decrease on the control ward in particular whereas the experimental ward shows a slight decrease. The regression analyses confirmed this result in showing a significant difference between the experimental and control wards in the last post-test (adjusted mean difference $B=0.520, p=0.000$ ). As expected, nursing caregivers from the psycho-geriatric experimental ward experience more social support after the implementation compared to the control ward. These results have to be interpreted with some caution. Since no correction for careload was possible while careload appeared to be a significant predictor in the additional analyses for social support (see also appendix 6 , tables $6.3 \mathrm{f}-\mathrm{g})$. 
Results organisation $C$

Table 7.7 and figure 7.7 show a slight decrease in the unadjusted means in the experimental group in first post-test in particular, which was slightly recovered in the last post-test, whereas in the control group no large changes are seen.

Table 7.7 Social support organisation C (unadjusted means)

\begin{tabular}{llllllllll}
\hline & pre-test & \multicolumn{4}{c}{ post-test 1 } & \multicolumn{4}{c}{ post-test 2 } \\
& Mean & SD & $\mathrm{n}$ & Mean & SD & $\mathrm{n}$ & Mean & SD & $\mathrm{n}$ \\
\hline experimental group & 3.39 & 0.33 & 26 & 3.25 & 0.34 & 29 & 3.30 & 0.32 & 26 \\
control group & 3.47 & 0.36 & 34 & 3.53 & 0.28 & 36 & 3.50 & 0.27 & 34 \\
total group & 3.43 & 0.35 & 60 & 3.41 & 0.33 & 65 & 3.41 & 0.31 & 60 \\
\hline
\end{tabular}

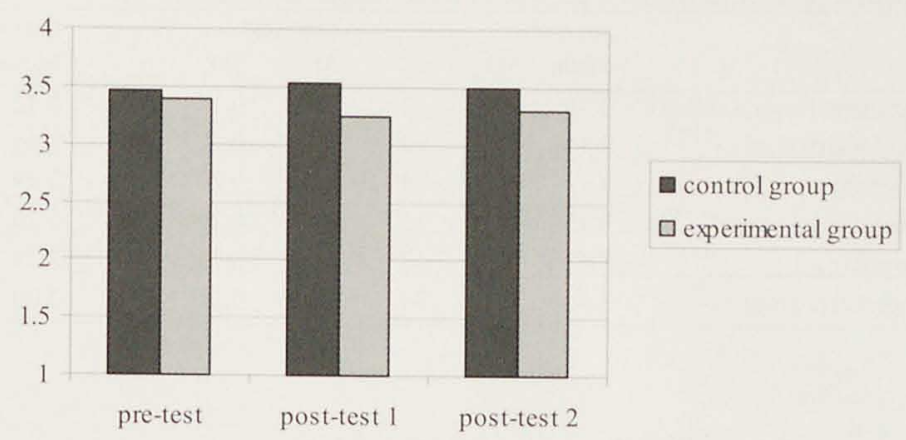

Figure 7.7 Social support organisation C (unadjusted means)

Regression analysis of the last post-test showed no significant first-order interaction effect, so regression analyses were performed on the total post-test sample of organisation $\mathrm{C}$ (adjusted mean difference $\mathrm{B}=0.044, \mathrm{p}=0.179$ ). Although no significant difference appeared from the regression analyses of the last post-test of organisation $C$, there is an indication that nursing caregivers of the experimental wards experience less social support after the implementation compared to the control group (adjusted mean difference $B=-0.125, p=0.024)$. Correction for careload took place in these analyses (see also appendix 6, tables 6.3h-i).

Investigation of the effects on social support for supervisors and colleagues separately yielded the following results. With respect to social support of supervisors, ANCOVA revealed a second-order interaction effect and a first-order interaction effect within organisation B. Separate regression analyses were performed for organisations A and $\mathrm{C}$ and within organisation B for the somatic and psycho-geriatric groups separately. Regression analyses revealed no difference between the experimental and control groups in organisations $A$ (adjusted mean difference $B=0.003, p=0.485$ ) and $C$ (adjusted mean difference $B=-0.074, p=0.187$ ). In organisation $B$ in the somatic group an indication was found for a decrease of social support of supervisors (adjusted mean difference $B=-0.350, p=0.021$ ) while in the psycho-geriatric group a significant increase was shown on the experimental ward compared to the control ward (adjusted mean difference $B=0.827, p=0.000$ ). With respect to social support of colleagues, no interaction effect was found and final regression analyses revealed no significant dif- 
ference between the experimental and control groups in the last post-test (adjusted mean difference $B=-0.045, \mathrm{p}=0.166$ ) (see also appendix 6 , tables $6.3 \mathrm{j}-\mathrm{s}$ ).

In conclusion, the results with regard to social support are mixed. Problems appeared with respect to interaction effects and collinearity. Only with respect to the psychogeriatric experimental ward of organisation B could hypothesis 3c, postulating an increase in social support in the experimental group, be confirmed.

\section{Responsibility}

In the unadjusted means of table 7.8 and figure 7.8 no major changes in both post-tests of responsibility are shown in the experimental and control groups. Furthermore, the pre-test means on responsibility are relatively high in both groups.

Table 7.8 Responsibility (unadjusted means)

\begin{tabular}{llllllllll}
\hline & pre-test & \multicolumn{3}{l}{ post-test 1 } & \multicolumn{4}{c}{ post-test 2 } \\
& Mean & SD & $\mathrm{n}$ & Mean & SD & \multicolumn{1}{c}{$\mathrm{n}$} & Mean & SD & \multicolumn{1}{c}{$\mathrm{n}$} \\
\hline experimental group & 4.01 & 0.56 & 101 & 4.01 & 0.59 & 79 & 4.06 & 0.58 & 69 \\
control group & 4.09 & 0.51 & 109 & 4.18 & 0.46 & 88 & 4.07 & 0.50 & 76 \\
total group & 4.05 & 0.54 & 210 & 4.10 & 0.53 & 167 & 4.06 & 0.54 & 145 \\
\hline
\end{tabular}

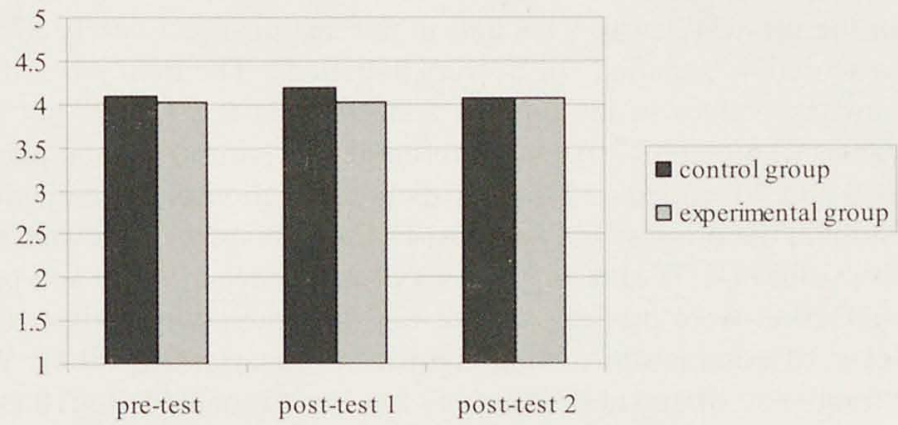

Figure 7.8 Responsibility (unadjusted means)

With ANCOVA no difference at baseline was found between the experimental and control groups $(\mathrm{F}=0.419, \mathrm{p}=0.519, \mathrm{df}(1,129), \mathrm{n}=147)$. Further, in the last post-test no interaction effects appeared, so analyses were performed on the total last post-test sample. In the last post-test no significant difference was found between the experimental and control groups (adjusted mean difference $\mathrm{B}=0.008, \mathrm{p}=0.462$ ) (see also appendix 6 , table 6.4).

It can be concluded that hypothesis $3 \mathrm{~d}$, postulating an increase in responsibility in the experimental group after the implementation, cannot be confirmed. 


\subsection{Psychological and behavioural reactions}

\subsubsection{Analyses}

In our study three psychological reactions were measured namely "job satisfaction", "intrinsic work motivation", "health complaints" and one behavioural reaction, that is "frequency of sickness absence". In this section we report the testing of the four hypotheses formulated in chapter 4:

H3e) Job satisfaction will increase in the experimental group compared to the control group after the implementation of resident-oriented care.

H3f) Intrinsic work motivation will increase in the experimental group compared to the control group after the implementation of resident-oriented care.

$\mathrm{H3g}$ ) Health complaints will decrease in the experimental group compared to the control group after the implementation of resident-oriented care.

H3h) Frequency of sickness absence will decrease in the experimental group compared to the control group after the implementation of resident-oriented care.

The variables "job satisfaction" and "frequency of sickness absence" showed problems with respect to high skewness and kurtosis levels. In preventing type I errors due to non-normality, transformation of these variables took place. With respect to "job satisfaction" in the pre-test nearly $91 \%$ and in the last post-test nearly $87 \%$ of the sample population scored 4 "satisfied" or 5 "very satisfied". The item job satisfaction showed normal skewness values in the pre-test and last post-test $(-1.03)$ but moderately high kurtosis values (2.65 and 2.70) and therefore dichotomization took place (scores 1 to 4 recoded as 0 and 5 recoded as 1 ). After dichotomization no fundamental problems existed anymore in the pre-test and last post-test with respect to skewness $(0.50$ and 1.20$)$ and kurtosis values $(-1.78$ and -0.57$)$. As a consequence, pre-test and post-test analyses on job satisfaction were performed with logistic regression analyses based on hierarchical backward elimination of non-significant covariates $(p>0.1)$. With respect the variable "frequency of sickness absence" $\log$ transformation $(\log 10(x+1))$ was performed due to high right skewness (4.99) and kurtosis levels (38.93) in the pre-test (Berkhout et al., in preparation). Although last post-test scores appeared to be within normal ranges, log transformation was done for the last post-test too. After transformation, no problems existed with respect to normality in the pre-test and last post-test (skewness 1.07 and 1.03 ; kurtosis 0.98 and 1.35 ).

Finally, with respect to "frequency of sickness absence", an interaction effect was found between "type of group" and "nurse function" ( $F=2.765, p=0.099, \mathrm{df}(1,124)$, $\mathrm{n}=147$ ). Therefore we performed additional subgroup analyses to investigate the effects for the group PNCs and for the associate nursing caregivers with no residents allocated separately.

In order to test the hypotheses the final results regarding the last post-test differences between the experimental and control groups are presented one-tailed. In appendix 6 , tables 6.5 to $6.8 \mathrm{c}$ the final regression models are presented (two-tailed). 


\subsubsection{Results}

\section{Job satisfaction}

Table 7.9 and figure 7.9 present the unadjusted means of the original variable measured on a 5-point Likert scale. No large changes in scores in the experimental group are found. Both the experimental and the control group show slight decreases in the first post-test in particular. Furthermore, the scores in the pre-test are relatively high in both groups.

Table 7.9 Job satisfaction (unadjusted means)

\begin{tabular}{|c|c|c|c|c|c|c|c|c|c|}
\hline & \multicolumn{3}{|c|}{ pre-test } & \multicolumn{3}{|c|}{ post-test 1} & \multicolumn{3}{|c|}{ post-test 2} \\
\hline & Mean & $\mathrm{SD}$ & $\mathrm{n}$ & Mean & $\mathrm{SD}$ & $\mathrm{n}$ & Mean & $\mathrm{SD}$ & $\mathrm{n}$ \\
\hline experimental group & 4.24 & 0.65 & 101 & 4.01 & 0.67 & 79 & 4.07 & 0.63 & 69 \\
\hline control group & 4.17 & 0.78 & 109 & 4.09 & 0.71 & 88 & 4.08 & 0.79 & 78 \\
\hline total group & 4.20 & 0.72 & 210 & 4.05 & 0.69 & 167 & 4.07 & 0.71 & 147 \\
\hline
\end{tabular}

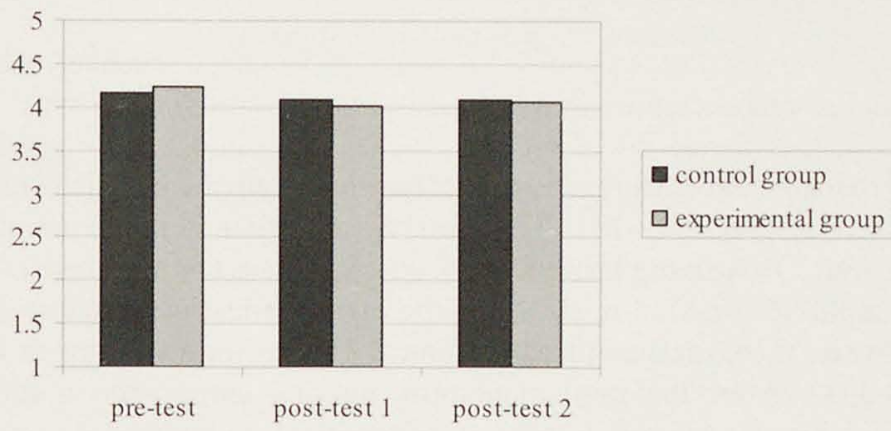

Figure 7.9 Job satisfaction (unadjusted means)

No difference at baseline appeared between the experimental and control groups from logistic regression analysis (adjusted mean difference $B=0.222$, Wald $=0.296, p=0.587$, $\mathrm{n}=146$ ). Further, no significant interaction effects were found, so stratification was not performed. Finally, from logistic regression analyses no differences were found between the experimental and control groups in the last post-test (adjusted mean difference $\mathrm{B}=-0.243$, Wald $=0.272, \mathrm{p}=0.301, \mathrm{n}=147$ ). This means that after the implementation job satisfaction was not increased in the experimental group compared to the control group (see also appendix 6, table 6.5).

So, it can be concluded that hypothesis $3 \mathrm{e}$, postulating an increase in job satisfaction in the experimental group, cannot be confirmed.

\section{Intrinsic work motivation}

In table 7.10 and figure 7.10 the unadjusted means on intrinsic work motivation are presented. In both the experimental group and the control group no large changes in scores are seen in both post-tests. In addition, the pre-test shows relatively high scores. 
Table 7.10 Intrinsic work motivation (unadjusted means)

\begin{tabular}{|c|c|c|c|c|c|c|c|c|c|}
\hline & \multicolumn{3}{|c|}{ pre-test } & \multicolumn{3}{|c|}{ post-test 1} & \multicolumn{3}{|c|}{ post-test 2} \\
\hline & Mean & SD & $\mathrm{n}$ & Mean & $\mathrm{SD}$ & $\mathrm{n}$ & Mean & SD & $\mathrm{n}$ \\
\hline experimental group & 3.99 & 0.45 & 101 & 3.92 & 0.42 & 79 & 3.95 & 0.48 & 69 \\
\hline control group & 4.04 & 0.44 & 109 & 3.97 & 0.52 & 88 & 4.01 & 0.51 & 77 \\
\hline total group & 4.02 & 0.44 & 210 & 3.95 & 0.47 & 167 & 3.98 & 0.50 & 146 \\
\hline
\end{tabular}

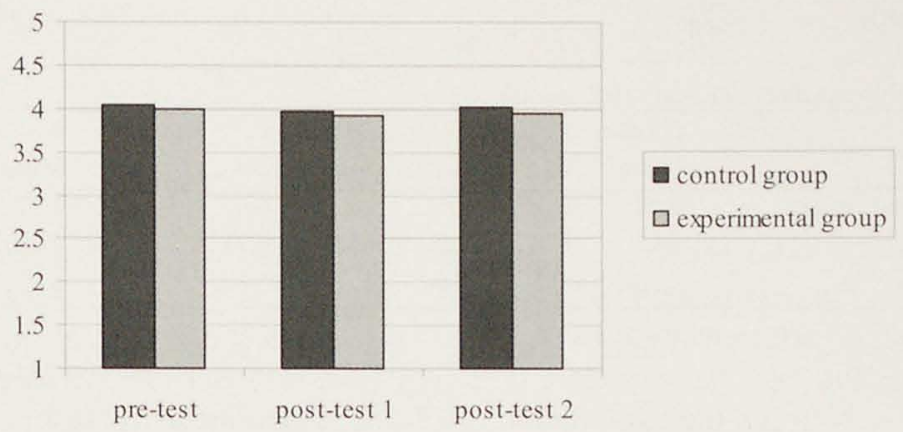

Figure 7.10 Intrinsic work motivation (unadjusted means)

ANCOVA revealed no difference at baseline between the experimental and control groups $(\mathrm{F}=0.201, \mathrm{p}=0.654, \mathrm{df}(1,129), \mathrm{n}=147)$. Further, no interaction effects were found from ANCOVA in the last post-test, so analyses were performed on the total last post-test sample. Regression analyses of the last post-test revealed no significant difference between the experimental and control groups (adjusted mean difference $B=-$ $0.029, \mathrm{p}=0.333$ ). After the implementation, nursing caregivers in the experimental group did not experience more intrinsic work motivation compared to nursing caregivers in the control group (see also appendix 6, table 6.6).

Thus, it can be concluded that hypothesis $3 \mathrm{f}$ regarding a postulated increase in intrinsic work motivation in the experimental group cannot be confirmed.

\section{Health complaints}

Table 7.11 and figure 7.11 show no large changes in health complaints in both posttests. The number of experienced health complaints remained almost the same in the three measurements.

Table 7.11 Health complaints (unadjusted means)

\begin{tabular}{|c|c|c|c|c|c|c|c|c|c|}
\hline & \multicolumn{3}{|c|}{ pre-test } & \multicolumn{3}{|c|}{ post-test 1} & \multicolumn{3}{|c|}{ post-test 2} \\
\hline & Mean & SD & $\mathrm{n}$ & Mean & SD & $\mathrm{n}$ & Mean & SD & $\mathrm{n}$ \\
\hline experimental group & 3.30 & 2.91 & 99 & 3.31 & 3.83 & 77 & 3.27 & 3.32 & 66 \\
\hline control group & 3.80 & 3.96 & 104 & 3.67 & 3.80 & 87 & 3.13 & 3.33 & 76 \\
\hline total group & 3.56 & 3.49 & 203 & 3.50 & 3.80 & 164 & 3.20 & 3.31 & 142 \\
\hline
\end{tabular}




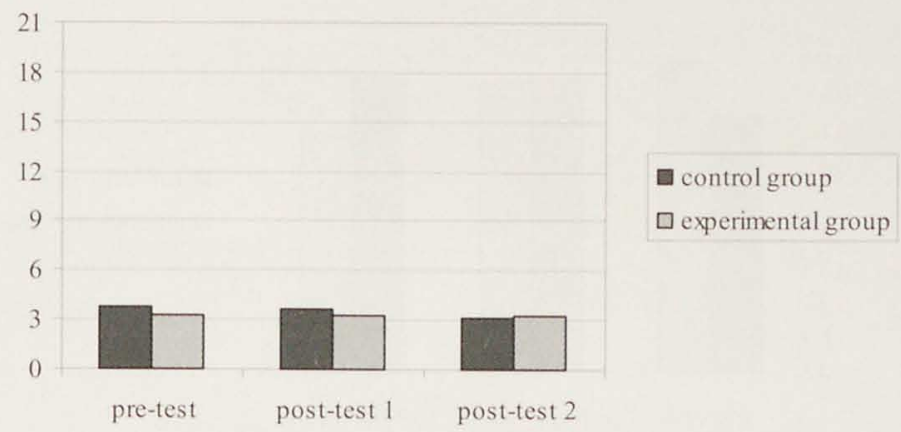

Figure 7.11 Health complaints (unadjusted means)

The ANCOVA did not show a significant baseline difference between the experimental and control groups $(\mathrm{F}=0.416, \mathrm{p}=0.520, \mathrm{df}(1,123), \mathrm{n}=141)$. Further, no significant interaction effects appeared from ANCOVA in the last post-test, so analyses were performed on the total last post-test sample. Regression analyses revealed no significant differences between the experimental and control groups in the last post-test (adjusted mean difference $\mathrm{B}=0.328, \mathrm{p}=0.187$ ). After the implementation, the number of experienced health complaints is not decreased in the experimental group compared to the control group (see also appendix 6, table 6.7).

Hence, it can be concluded that hypothesis $3 \mathrm{~g}$ postulating a decrease in health complaints in the experimental group cannot be confirmed.

\section{Frequency of sickness absence}

Table 7.12 and figure 7.12 present the original non-transformed scores of "frequency of sickness absence". The experimental group shows a decrease in scores in both posttests and in the last post-test in particular whereas the control group shows an increase in the first post-test and a stabilisation in the last post-test.

Table 7.12 Frequency of sickness absence* (unadjusted means)

\begin{tabular}{lllllllllrr}
\hline & pre-test & \multicolumn{3}{c}{ post-test 1 } & \multicolumn{4}{c}{ post-test 2 } \\
& Mean & SD & $\mathrm{n}$ & Mean & SD & n & Mean & SD & \multicolumn{1}{c}{$n$} \\
\hline experimental group & 0.90 & 1.42 & 101 & 0.84 & 0.91 & 79 & 0.68 & 0.76 & 69 \\
control group & 0.74 & 0.99 & 108 & 0.85 & 0.96 & 87 & 0.85 & 0.90 & 78 \\
total group & 0.82 & 1.22 & 209 & 0.84 & 0.93 & 166 & 0.77 & 0.84 & 147 \\
\hline
\end{tabular}

* Frequency rates over the last half-year 


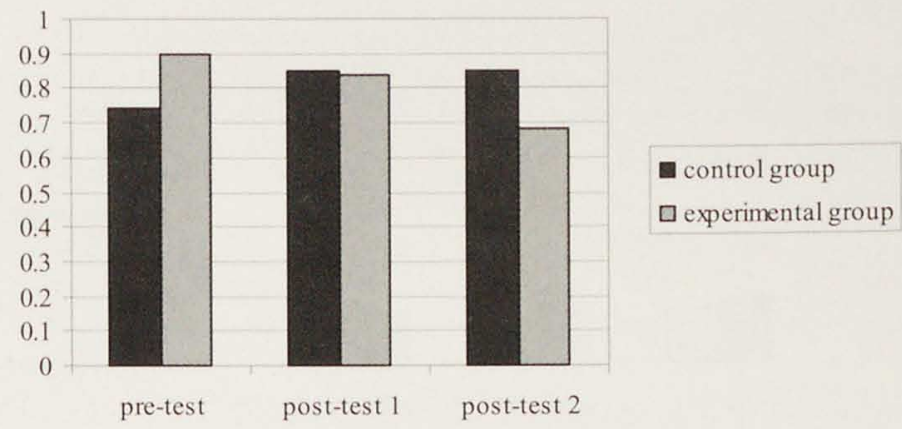

Figure 7.12 Frequency of sickness absence* (unadjusted means)

* Frequency rates over the last half-year

No significant difference at baseline between the experimental and control groups appeared from ANCOVA ( $\mathrm{F}=3.094, \mathrm{p}=0.081$, $\mathrm{df}(1,129), \mathrm{n}=147)$. However, there is an indication that at baseline the experimental group shows a higher frequency of sickness absence compared to the control group. Further, the ANCOVA of the post-test revealed no significant interaction effects, so stratification was not performed. Although regression analyses revealed no significant difference between the experimental and control groups in the last post-test, there is an indication for a decrease (adjusted mean difference $\mathrm{B}=-0.042, \mathrm{p}=0.081$ ). After the implementation, nursing caregivers in the experimental group give an indication for a lower frequency of sickness absence compared to the control group (see appendix 6 , table $6.8 \mathrm{a}$ ).

Finally, due to an interaction effect on the last post-test between "type of group" and "nurse function", additional subgroup analyses were performed. Although the differences were not significant, there is an indication that in the group PNCs of the experimental group frequency of sickness absence decreased compared to nursing caregivers from the control group with a degree of employment of $70 \%$ or more (adjusted mean difference $B=-0.087, p=0.027$ ). Further, no extra effects were found in the group associate nursing caregivers in the experimental group compared to nursing caregivers with a degree of employment of less than $70 \%$ in the control group (adjusted mean difference $\mathrm{B}=-0.054, \mathrm{p}=0.446$ ) (see appendix 6 , tables $6.8 \mathrm{~b}-\mathrm{c}$ ).

So, it can be concluded that hypothesis $3 \mathrm{~h}$ concerning the decrease in frequency of sickness absence cannot be confirmed. However, there is an indication for a decrease in frequency of sickness absence in the experimental group compared to the control group after the implementation of a resident-oriented care model, which is confirmed in the group PNCs separately.

\subsection{Summary}

With respect to the job characteristics most of the intervention effects did not appear. With respect to job autonomy (H3a) and responsibility ( $\mathrm{H} 3 \mathrm{~d})$, contrary to the hypothesised increases, no changes were found after the implementation in the experimental group. However, a closer look at the underlying concepts of job autonomy revealed an 
indication for more contextual job autonomy in the experimental group compared to the control group after the implementation. With regard to job demands the results differed due to an interaction effect between "type of group" and "type of ward". The hypothesis postulating an increase in job demands could not be confirmed (H3b). A trend was found for an increase in job demands on the somatic experimental wards after the implementation whereas on the psycho-geriatric experimental wards an indication was found for a decrease. No additional significant results were found with regard to the underlying concepts quantitative and qualitative job demands. The results with regard to social support were mixed too. Due to a second-order interaction effect between "type of group", "type of organisation" and "type of ward", stratification was necessary according to "type of organisation" and in addition, in organisation B stratification was necessary according to "type of ward". On the psycho-geriatric experimental ward of organisation B the postulated increase in social support was confirmed. Further, only indicative decreases or indicative increases were found on the experimental wards after the implementation, thereby not confirming our hypothesis $(\mathrm{H} 3 \mathrm{c})$. No significant results were found with regard to social support of supervisors and colleagues separately. With regard to the psychological and behavioural reactions, the hypotheses postulating increases in job satisfaction and intrinsic work motivation and decreases in health complaints and frequency of sickness absence could not be confirmed $(\mathrm{H} 3 \mathrm{e}-\mathrm{H} 3 \mathrm{~h})$. However, with regard to frequency of sickness absence, after the implementation an indication was found for less frequency of sickness absence in the experimental group compared to the control group. This result was confirmed in the group of PNCs. 



\section{Discussion}

\subsection{Introduction}

The previous chapters have reported our attempts to gain more insight into whether a resident-oriented care model could be effectively implemented in the nursing home sector and what the accompanying success conditions and the effects on job characteristics of nursing caregivers and on their psychological and behavioural reactions would be. In this final chapter the research questions are answered and discussed. The chapter starts with an overview of the main findings of the study (8.2). Further, some methodological (8.3) and theoretical reflections (8.4) are made. The chapter ends with some implications for future research and some practical implications (8.5).

\subsection{Main findings}

\subsubsection{Introduction}

In this section the main findings of the study are presented. These concern subsequently the findings of the design characteristics, the implementation characteristics, the job characteristics and the psychological and behavioural reactions.

\subsubsection{Design characteristics}

The implementation of a resident-oriented care model was considered in our study as a black box. The aspects that were implemented and the underlying decision making processes were not measured totally. Therefore, to measure the effectiveness of the implementation an intervention model in outline was designed with four design characteristics considered as key parts of a resident-oriented care model: resident assignment, use of the nursing process, tasks and communication expressed in the following hypotheses:

Hla) Resident assignment will increase in the experimental group compared to the control group after the implementation of resident-oriented care.

HIb) Use of the nursing process will increase in the experimental group compared to the control group after the implementation of resident-oriented care.

HIc) Number of tasks will extend in the experimental group compared to the control group after the implementation of resident-oriented care.

Hld) Communication will improve in the experimental group compared to the control group after the implementation of resident-oriented care.

The four design characteristics were operationalised as follows: resident assignment (Hla); taking nursing history, nursing problems, goals and actions ( $\mathrm{Hl} b$ ); use of nurs- 
ing care plans and their evaluation $(\mathrm{Hlb})$; resident-oriented tasks $(\mathrm{H} 1 \mathrm{c})$; ward-oriented tasks ( $\mathrm{Hlc}$ ); quality of communication forms ( $\mathrm{Hld}$ ) and variety of resident- and wardoriented communication forms (Hld). As a reflection of the implementation of a resident-oriented care model, increases were expected in all eight design variables.

Quantitative data showed clear increases on the experimental wards compared to the control wards in resident-assignment, in the two variables measuring the use of the nursing process and in the psycho-geriatric group on one of the task dimensions, that is in the number of resident-oriented tasks. With regard to the additional effects for PNCs, resident-oriented tasks increased on all the experimental wards. Further, it is interesting to note the indicative increase among the associate nursing caregivers of the experimental group (i.e. the nursing caregivers with no residents assigned) compared to their control group. The method with PNCs and associate nurses working together for assigned residents on a number of experimental wards seem to be reflected in more resident-oriented tasks for both PNCs and other nursing caregivers. In conclusion, hypotheses $1 \mathrm{a}, 1 \mathrm{~b}$ and with regard to resident-oriented tasks, lc could be confirmed. These findings are in line with studies of Alcock et al. (1993), Heeremans et al. (1994) and Kivimäki et al. (1995). Ward-oriented tasks did not change. This is contrary to the findings of Molleman (1989) and Heeremans et al. (1994), but in line with results of Emans \& Den Boer (1988) and Gardner (1991) who too saw increases in direct patient care rather than more concern with ward-related activities. Moreover, Thomas (1993) saw less time spent on additional patient care and ward activities. No changes appeared in the three communication variables, so we could not confirm hypothesis $1 \mathrm{~d}$. The trend, which was found for less quality of communication forms, appeared to be in line with findings of Molleman (1989) and Webb \& Pontin (1996), who also noticed difficulties in the use of new communication forms and clarity in this respect. Finally, in the group associate nursing caregivers less variety of ward-oriented communication forms was indicated. This could be due to their experience of low involvement in the implementation issues discussed in these communication forms during the measurement period.

The qualitative interviews with the supervisors and project co-ordinators confirmed the positive findings derived from the questionnaires. However, the observations revealed some discrepancies indicating a smaller change than was expected. For example, a task-oriented division of labour was still observed on the wards, such as serving meals or medication and giving a shower. Further, the nursing process was not completely implemented. Most of the nursing care plans were incomplete or not up-to-date. At the same time the planned care did not fully correspond with the realised care. Similarly, Davis, Billings \& Ryland (1994) and Webb \& Pontin (1997) too concluded that although nurses claim to use a nursing framework to structure their care such as the nursing process, this is not evident in the documentation. In our study it was also observed that PNCs did not always perform direct care or co-ordination of care themselves. An underlying reason might to be that the delegation of the co-ordination of care to PNCs was not properly achieved by the ward sister. For example, ward sisters often still participated in the resident's visit with the doctor or in the consultations with relatives and presented residents within the multidisciplinary consultation. In this re- 
spect, Bond, Bond, Fowler \& Fall (1991a) point out that the co-ordinating role of the PNC is largely determined by the tasks and role of the ward sister. To realise vertical job enrichment, ward sisters have to delegate co-ordination tasks and hence release a part of their hierarchical position, which is often achieved only with difficulty. Finally, it has to be pointed out that possibilities to perform resident-oriented care in its ideal form depend on the work pressure. In case of high work pressure, priority was given to basic care with less attention for the documentation in the residents' dossier and for continuity of care (i.e. as a PNC giving all basic care to the allocated residents ).

It might be concluded that quantitative as well as qualitative analyses showed that the intervention has been partly succeeded. Supervisors and nursing caregivers viewed resident-oriented care as being implemented on the experimental wards. However, observations revealed a more limited change. It might be that the answers derived from the interviews and written questionnaires could have been influenced by some social desirability.

\subsubsection{Implementation characteristics}

The characteristics of the implementation, i.e. the process, were evaluated by means of a number of success conditions which were related to the factors of the 7-S model, namely structure, strategy, systems, staff, skills, style and shared values (Peters \& Waterman, 1982). Three quantitative implementation variables were used, that is information quality and socio-emotional and instrumental leadership. In this respect the following hypotheses were tested:

H2a) Better information quality with regard to the implementation on the experimental wards will lead to a more successful implementation of resident-oriented care.

H2b) More social-emotional leadership of supervisors on the experimental wards will lead to a more successful implementation of resident-oriented care.

H2c) Less instrumental leadership of supervisors on the experimental wards will lead to a more successful implementation of resident-oriented care.

The experimental wards appeared to be comparable regarding a number of conditions. All six experimental wards used work groups on project level (structure). In addition, they had an incremental implementation strategy (strategy), used formal communication channels as well as special information means to inform the organisation and those directly involved, and performed interim and final evaluations on project level as well as interim evaluations on ward level (systems). Nursing caregivers were trained by means of training-on-the-job by ward sisters (skills), a top-down implementation approach was used and the change was considered as irreversible from the start onwards (shared values). By means of a summarised score of the mean scores of all eight design variables into the design variable "resident-oriented care model", a distinction was made between the least successful and most successful experimental wards with regard to the implementation of a resident-oriented care model. In this way we were able to relate the success of the implementation of a resident-oriented care model to a number of implementation characteristics as being success conditions. In contrast to 
the least successful ward, the two most successful wards were characterised by the following success conditions:

- No delay in performing the action plan;

- Absence of distracting factors;

- Stability of the supervisor;

- Final evaluations of the implementation on ward level;

- Willingness to change among nursing caregivers;

- Training-on-the-job of nursing caregivers by supervisors;

- Less instrumental leadership in the last post-test.

Furthermore, extra financial and personnel means on ward level did not seem to contribute to a more successful implementation. Looking at the success conditions more closely, they concern not only more hard structural factors such as strategy and systems but soft, socio-emotional factors as staff, skills and style as well. It can be further argued that success conditions are not related to the more organisational project level conditions but are linked to ward level conditions in particular. In line with the conclusions of Landsbergis \& Vivona-Vaughan (1995) the managing and coaching capacities of supervisors play a role of major importance at work redesign projects. The quantitative finding with regard to instrumental leadership was a confirmation of hypothesis $2 c$. This confirmation has to be interpreted with caution. With our analyses we could only test associations hence no conclusion with regard to causality could be made. However, our conclusion was in line with Boumans (1990), who too noticed that less instrumental leadership was related with more patient-oriented care. Unlike Van Zonneveld (1993), we were not able to confirm hypothesis $2 \mathrm{a}$, and like Boekholdt (1981) and Boumans (1990) we could not confirm hypothesis $2 b$.

It can be concluded that structural as well as socio-emotional conditions on ward level and, in particular the managing and coaching capacities of supervisors can be considered as instruments for a successful implementation of resident-oriented care. In particular, less instrumental leadership in the last phase of the implementation is associated with a more successful implementation of a resident-oriented care model.

\subsubsection{Job characteristics and psychological and behavioural reactions}

It was postulated that the implementation of a resident-oriented care model would positively impact on job characteristics of nursing caregivers and would lead to positive psychological and behavioural reactions. Theoretically this implementation can be considered as a job redesign intervention in nursing aimed at job enrichment. The Demand-Control Support model of Johnson \& Hall (1988) was used to determine job characteristics on which effects could be expected. In addition, responsibility was chosen as a central characteristic in a resident-oriented care model. So, we postulated increases on job autonomy, job demands, social support and responsibility as follows:

H3a) Job autonomy will increase in the experimental group compared to the control group after the implementation of resident-oriented care.

H3b) Job demands will increase in the experimental group compared to the control group after the implementation of resident-oriented care. 
H3c) Social support will increase in the experimental group compared to the control group after the implementation of resident-oriented care.

H3d) Responsibility will increase in the experimental group compared to the control group after the implementation of resident-oriented care.

The effects of the implementation on the four job characteristics appeared to be marginal. No effects were found with respect to job autonomy and responsibility, so we were not able to confirm hypotheses $3 \mathrm{a}$ and $3 \mathrm{~d}$. This is in contrast with findings of Gardner (1991), McCormack (1992), Thomas (1992), Vlerick \& Goeminne (1994), Kivimäki et al. (1995) and Webb \& Pontin (1996). However, McPhail et al. (1990) and Heeremans et al. (1994) too could not confirm increases in job autonomy and responsibility. Further, Melchior et al. (1999) found only increases in job autonomy where nursing caregivers of the intervention group showed low pre-test levels. As was observed, delegation of co-ordination tasks was not fully achieved. Therefore, it might be questioned whether an increase in autonomy or responsibility could be achieved if job enrichment is not sufficiently established. In this respect, it is worth mentioning the PNCs' insecurity in their function and the doubt expressed by the supervisors in the interviews with regard to their independent functioning. It might be argued that the tasks and responsibilities of the PNCs were not fully developed and internalised yet.

Another point of interest concerns the different results with regard to the two latent factors underlying the job autonomy scale, contextual and content job autonomy. No significant results or trends were found with respect to content job autonomy indicating no change in the worker's opportunities within given job standards, such as work method, goals and evaluations. However, a positive trend was found with respect to contextual job autonomy. Compared to the control group, after the implementation the experimental group indicated more contextual job autonomy, i.e. opportunities for nursing caregivers to determine aspects such as amount and pace of work, workinghours and the kind of work to be done. With respect to job demands, the results were mixed due to first-order interaction effects and hence hypothesis $3 \mathrm{~b}$ could not be confirmed. The results appeared to be indicative only. A trend was found for an increase on the somatic experimental wards as well as for a decrease on the psycho-geriatric experimental wards. In this respect, the Melchior et al.'s (1999) study was not conclusive either in showing a decrease in job complexity in the intervention group in the case of high pre-test levels only. With regard to the conceptual distinction between quantitative and qualitative job demands (see chapter 2), the question was raised whether a job enrichment intervention would have more impact on qualitative job demands in particular such as task complexity or difficulty (De Jonge, 1995). However, analysis of the differences between the experimental and control groups on quantitative and qualitative job demands separately yielded no extra intervention effects. With respect to social support, the effects appeared to be mixed too due to first- and secondorder interaction effects. The only significant result was an increase on the psychogeriatric ward of organisation B. Other results appeared to be indicative increases as well as decreases only. On the whole, slightly more confirmation was found for hypothesis 3c, which is in line with findings of Thomas (1992) and Vlerick \& Goeminne 
(1994). A study of the results of social support from supervisors and colleagues separately revealed no additional effects.

With respect to the psychological and behavioural reactions of nursing caregivers, we postulated increases on job satisfaction and intrinsic work motivation and decreases in health complaints and frequency of sickness absence as follows:

H3e) Job satisfaction will increase in the experimental group compared to the control group after the implementation of resident-oriented care.

H3f) Intrinsic work motivation will increase in the experimental group compared to the control group after the implementation of resident-oriented care.

$\mathrm{H3g}$ ) Health complaints will decrease in the experimental group compared to the control group after the implementation of resident-oriented care.

H3h) Frequency of sickness absence will decrease in the experimental group compared to the control group after the implementation of resident-oriented care.

Again the changes appeared to be small. Increases in job satisfaction and intrinsic work motivation, that is hypotheses $3 \mathrm{e}$ and $3 \mathrm{f}$, could not be confirmed. Although we found limited studies on work motivation (Kivimäki et al., 1995) and studies revealing less clear results with regard to job satisfaction (e.g. Heeremans et al., 1994; Kivimäki et al., 1995; Manley et al., 1996), based on a lot of other studies pointing on increases in job satisfaction, this was not as we had expected (e.g. Bond et al., 199lc; Degerhammer \& Wade, 1991; McCormack, 1992; Furlong, 1994). Hypotheses 3g and 3h could not be confirmed either. However, with regard to frequency of sickness absence, a trend was found for a decrease in the experimental group, which is in line with findings of Kaban \& Thompson (1990) and Vlerick \& Goeminne (1994). Considering the group of PNCs separately, the indicative decrease of frequency of sickness absence in the experimental group was confirmed. Although some congruence could be assumed between the results on frequency of sickness absence and health complaints as was seen in studies of Heeremans et al. (1994) and Vlerick \& Goeminne (1994), the trend for a decreased frequency of sickness absence was not reflected in less health complaints. Health complaints appeared to be not affected by the implementation.

It can be concluded that the effects of the implementation of a resident-oriented care model on job characteristics and on psychological and behavioural reactions are limited. An indication was found for more contextual job autonomy. Due to the interaction effects with regard to job demands and social support the results were mixed and therefore not conclusive. Slightly more confirmation was found for an increase in social support. An increase in responsibility was not supported by our data. Changes in psychological and behavioural reactions appeared to be small too. However, a trend was found for a lower frequency of sickness absence. 


\subsection{Methodological reflections}

\subsubsection{Introduction}

In the previous section we presented the main findings by summarising and discussing them briefly. However, our study shares some methodological limitations with other intervention studies, which need a more detailed discussion. First we will comment on the design of our study, followed by remarks on the study population, the measuring methods, measuring instruments and our statistical analyses.

\subsubsection{Design of the study}

Our study concerned a pre-test post-test design with non-equivalent groups (Cook \& Campbell, 1979). By the management of the three nursing homes the wards were assigned to the treatment (experimental versus control). Methodologically, randomisation is a necessary tool in guaranteeing internal and external validity. However, in studies on organisational change in nursing, randomisation is often difficult and artificial and from perspective of motivation and compliance even undesirable (e.g. Melchior et al., 1999). Therefore, use of control mechanisms as we did in our study is of major importance to prevent as well as correct for non-equivalence of the experimental and control groups. In this respect, we used selection criteria for selecting the wards, we controlled for various confounders and finally, we performed stratified analyses in case differences in type of ward and/or type of organisation affected the intervention effects. At baseline, no differences appeared between the experimental and control groups with respect to variables such as biographic characteristics and careload. However, presence of some selection bias must be noted. Organisations and wards that wanted to participate in our study and agreed with the selection criteria were in fact selected threatening external validity. A beneficial climate for the intervention in organisations $\mathrm{A}$ and $\mathrm{C}$ in particular might have been a reason for their participation. Prior to the implementation some elements of a resident-oriented care model had already been implemented in these two organisations such as the multidisciplinary resident's dossier, which was accompanied by a training in organisation C. Next, in all organisations the multidisciplinary meeting had been implemented. This can explain the rather high pre-test scores on both nursing process variables and on variety of resident-oriented communication forms, thereby engendering the risk of ceiling effects. However, on both nursing process variables intervention effects were found. The moderately high baseline scores on variety of resident-oriented communication forms and the small changes in the experimental group on both variety of resident- and wardoriented communication forms appears to be the reason for the intervention effect failing to appear. Baseline differences in favour of the control group appeared on both nursing process variables and on the variables variety of resident- and ward-oriented communication forms. In comparing the results of the last post-test analyses and the results of the analyses of the change scores, similar conclusions could be drawn.

Contamination in this type of research has to be considered as a potential problem (e.g. Molleman, 1989; Boumans \& Landeweerd, 1999; Melchior et al., 1999). With the aim 
to control for contamination, efforts were made at the start of the research project to involve additional control wards from an organisation not having a resident-oriented care model or with implementation plans in this respect. Due to rapid developments in the nursing home sector in general, we did not find an organisation that wanted to commit itself keeping up the status quo for more than two years. Moreover, involving another organisation with control wards only would increase the difficulty in comparing the experimental and control groups (e.g. Melchior et al., 1999). With regard to contamination in our study, we had to deal with the movement of personnel from experimental to control wards, diffusion of information by formal communication channels, supervisors managing experimental and control wards, and organisational decisions fostering the risk (e.g. Boumans \& Landeweerd, 1999; Melchior et al., 1999). In meetings of the steering and advisory groups and in interviews with project coordinators and supervisors we were able to monitor the problem as much as possible by registering all unconditional processes, including contamination. Further, we reported results not between times but after the last post-test in preventing to influence the results on the experimental and control groups as well. Finally, we investigated interaction effects. As such, we could detect contamination on the somatic control ward of organisation A, causing the intervention effect on resident assignment failing to appear. The problems found in the two other organisations were not leading to major problems in this respect.

Another point deals with the appropriateness of the time points and the measurement period for establishing intervention effects. Measurements were conducted for all three organisations on the same time points. However, organisation B (December 1995), A (January 1996) and C (March 1996) started with the intervention at different times and so different intervention periods were involved. This is a problem faced by many researchers and it is difficult to solve. A solution would be to make measurement points dependent on the start of the implementation. However, this would involve important disadvantages such as a differential influence of season fluctuations or unconditional macro level processes, i.e. a new collective labour agreement (e.g. De Jonge, 1995). So, we decided to assess the last post-test effects only to exclude incomplete or differentiated effects in the first post-test. With regard to the intervention period, it can be stated that this was appropriate. For reaching enough variance in variables, the measurement period of our study (between 11 and 14 months) was congruent with the advised period of minimal eight months in longitudinal study designs (De Jonge, 1995). Further, our intervention period was in line with other intervention studies covering measurement periods between 12 months (Betz, 1981; Alcock et al., 1993; Melchior et al., 1999) and 15 months (Bekkers et al., 1990; Heeremans et al., 1994).

\subsubsection{Population of the study}

All nursing caregivers working on the research wards were approached for participation. Due to clear information before and after each measurement period and close collaboration with supervisors and project co-ordinators we were able to reach high response rates. One of the problems with intervention studies is to establish a population sample sufficiently large to allow hypothesis testing while maintaining a manageable 
research design. In the stratified analyses of social support we were confronted with some power problems (Berkhout et al., 1998a and b). In studies addressing organisational change, effect size estimation is not usual. According to Polit \& Hungler (1999) effect sizes of $0.20<\gamma<0.40$ are most common for nursing studies. Therefore, accepting a rather strict significance criterion $\alpha(0.01)$ and a conventional power $\beta(0.80)$, the total sample size should encompass at least 292 respondents (Polit \& Hungler, 1999). So, in trying to prevent the risk on type II errors in our study we discussed trends based on $0.01<p \leq 0.1$.

As with most follow-up studies attrition was expected to be a problem (e.g. Melchior et al., 1999). However, as described in chapter 4, no selective dropout appeared in either post-test. The larger dropout in the last post-test on the psycho-geriatric wards was not considered as a major problem affecting the intervention results. In seeking high internal validity we tried to achieve a homogeneous sample (see chapter 4). Homogeneity was confirmed by the absence of differences between the experimental and control groups with respect to biographic characteristics. Although our study included registered nurses too, the majority of the sample concerned enrolled nurses $(99 \%)$. No nursing aides or nursing auxiliaries were involved. The main reasons for excluding them were less competence for resident's care, not being selected for the function of PNC and less capable of monitoring changes due to more evening and night shifts. Homogeneity can be disadvantageous too in restricting the range in study variables and thus in limiting variance (De Jonge, 1995). However, according to De Jonge (1995), health care workers provide much natural variance because of the presence of different specialities (i.e. somatic versus psycho-geriatric care). In seeking congruence between our study population and larger samples, we compared the scores with those of reference groups in so far they were available. As is shown in appendix 7, table 7.1, in general at baseline our study population appeared to be highly comparable and therefore was not assumed to lead to bias (Boumans, 1990; De Jonge et al., 1995; Janssen et al., 1999a). The sickness absence scores over the last half year in our study seem to be rather high compared to the scores of Boumans' (1990) study collected from nursing caregivers of general hospitals over a whole year. However, as indicated in chapter 1 , this result is in line with figures on national level. Compared to other clinical health care settings, the nursing home sector shows the highest frequency of sickness absence (e.g. Van der Windt et al., 1999).

\subsubsection{Measuring method}

To achieve an accurate representation of the working-method and the changes in this respect we used data triangulation, i.e. multiple data sources as nursing caregivers, supervisors, project co-ordinators and resident's dossiers, as well as method triangulation, i.e. multiple measuring methods as questionnaires, interviews, participant observations and document analyses (Polit \& Hungler, 1999). This enabled us to underpin the quantitative results of our study with more in-depth information derived from the qualitative data. Now the surplus value and the problems to overcome have to be discussed. 
In using structured interviews alongside questionnaires, we were able to collect more in-depth information on the effectiveness and the process of the intervention. We could not only highlight differences between organisations and experimental wards in more detail, but also indicate convergence between data. Questionnaires and interviews are self-report techniques and thus sensitive to social desirability which decreases validity (Maso, 1989). Social desirability is the tendency of respondents to misrepresent their responses consistently by giving answers that are congruent with social norms, a problem which is difficult to combat (Polit \& Hungler, 1999). In the results of the questionnaires and the interviews social desirability might have played a role. Compared to the observations and analyses of the resident's dossiers, questionnaires and interviews indicated a more positive change towards resident-oriented care. It might be that project co-ordinators and supervisors have positively reflected the intervention for they themselves were responsible for it. Positive answers of nursing caregivers in the questionnaires can be related to their high positive expectations with regard to the implementation of a resident-oriented care model.

Participant observations were used to generate more in-depth information. Our goal was to 'get backstage', to learn about the true realities of the experiences of nursing caregivers with the implementation of resident-oriented care and hence to add to validity (Maso, 1989). From the results of the observations we were able to give some explanations for intervention effects failing to appear. However, as with subjective judgements derived from self-report techniques some problems have to be mentioned with objective ('observers') judgements derived from participant observations. Potential biases concern the relation observed-observer and the observer him- or herself (Frese \& Zapf, 1988; Maso, 1989; Polit \& Hungler, 1999). First, awareness about the reason for observation, the status as study participants, anxiety and some distrust towards the observers can alter behaviour of the observed. As a result, reactivity can appear because people behave in line with what is expected. In our study this was difficult to combat for the experimental wards knew their status and the reason for observation. However, we tried to reduce reactivity as much as possible in using an open approach and by performing observations at the background in a non-distracting way (Maso, 1989). To reduce the impact on individual behaviour, observers worked with different nursing caregivers per ward per day. However, concealed observation was not possible and would have led to ethical problems (Polit \& Hungler, 1999). Second, differences between observers with respect to values, norms, frame of reference and interpersonal skills can impact on the objectivity of judgement and thus on the reliability of the observation method. To reduce these differences, all observers were registered nurses with sufficient experience in bedside nursing. Moreover, the observation method was talked through and pilot observations were performed in which new observers were trained by experienced observers. However, differences in judgement may have played a role. Third, observations were not performed double blind. The observed as well as the observers were aware of the status of the wards. Although we have no evidence for this being a problem, prior knowledge of the wards may have played a role in judging the results. Fourth, another point of interest is lack of a norm or standard to be able to perform observations more objectively. By using a topic list we reduced this problem somewhat in our study. However, observers experienced 
some judgement problems with regard to the extent of resident-oriented care. Finally, the representativeness of the observation moment plays a role. The day shift was chosen for observing the ward. During the day shift most of the direct care is performed and therefore it was assumed to be the best time for observing the working method. To make the results less dependent on the observation moment, all experimental wards were observed for two days by two observers independently. However, the observations were conducted within a limited period (the measurement period) and therefore the observation moment may have affected the observation results. For example, we encountered problems such as periods with high sickness absence, which had a noticeable effect on the working method of that moment.

\subsubsection{Measuring instruments}

In our study we used instruments which appeared to be valid and reliable in other studies, or, when not suitable, were newly developed or adapted to the setting of nursing homes. With respect to these measuring instruments some comments have to be made.

\section{Design characteristics}

With respect to the design characteristics, the items of the scales resident assignment, use of the nursing process and communication forms were adapted from other scales and adjusted or extended with items relevant for the nursing home setting. The scale 'tasks' was newly developed. A panel of experts improved face and content validity. Based on the results of factor and reliability analyses, all scales appeared to have sound psychometric properties and were useful to measure the design characteristics. A comment has to be made with regard to the scale tasks. This scale was supposed to measure job enrichment and job enlargement. The dimension resident-oriented tasks most reflected job enrichment. The dimension 'ward-oriented tasks' reflected indirect nursing tasks on ward level. These tasks seem to belong more to the domain of the ward sister instead of nursing caregivers. So, to make the scale ward-oriented tasks sensitive for job enlargement items have to be added with regard to the variety in performing direct care tasks. For the observations, a topic list of Bekkers et al. (1990) was used, which was adjusted to the setting of nursing home care. As already noted, some problems were faced in making objective judgements of the working method on the ward. To improve this, the topic list should be more standardised by developing standards and criteria for assessing the design characteristics more objectively.

\section{Implementation characteristics}

Implementation characteristics were measured quantitatively with the adjusted scale information quality of Van Zonneveld (1993) and the Leadership Behaviour Questionnaire (Stogdill, 1963) and qualitatively with the adjusted semi-structured questionnaire of Bekkers et al. (1990). These instruments appeared to be valid and reliable. With regard to the scale information quality and the interview list, some comments have to be made. Despite its proper psychometric qualities, the scale information quality seemed to be not sensitive enough to capture opinions regarding the information of the implementation. The items focus on global information quality of the implementation strategy. The scale can be made more sensitive by adding items with respect to differ- 
ent implementation phases and steps and important changes in the work of nursing caregivers. Finally, the semi-structured questionnaire of Bekkers et al. (1990), adjusted to the nursing home sector appeared to be a practical instrument to give an in-depth picture of the implementation. However, to structure the information by means of the 7-S model, further elaboration is needed with regard to the factors staff, style and shared values. In this respect the success conditions willingness to change, leadership style and implementation approach seemed to be sensitive to socially desirable answers in particular. In this respect questions have to be asked in more detail. In addition, quantitative measurement is needed to ensure a more robust study of the associations between the success conditions and the effectiveness of the implementation.

\section{Job characteristics and psychological and behavioural reactions}

All scales and items measuring job characteristics and psychological and behavioural reactions have proven to be valid and reliable in studies on quality of work in nursing (Boumans, 1990; De Jonge, 1995, Janssen et al., 1999a). However, some remarks are warranted with respect to their sensitivity. With respect to the scale job autonomy, it appeared to be worthwhile to consider the two underlying factors content and contextual job autonomy separately. This allowed us to gain insight into whether a job enrichment intervention entails a merely structural change or encompasses a change in job content too. The scale job demands is largely focused on quantitative rather than qualitative job demands. Only two out of eight items highlight qualitative job demands. To capture the demanding intervention effects of more co-ordination and communication, it seems worthwhile adding more items measuring qualitative job demands in particular. In nursing studies a common phenomenon are high positive scores on responsibility, social support, job satisfaction and intrinsic work motivation, as can be noticed in our sample and in the reference groups as shown in appendix 7, table 7.1 (e.g. Metcalf, 1986; McGrath et al., 1989). As McGrath et al. (1989) argue with regard to general job satisfaction, answers tend to be high because workers from professions with a strong vocational ethos such as nursing tend to respond positively. Rather high baseline scores might have led to some ceiling effects causing intervention effects failing to appear. With regard to responsibility and social support, nursing caregivers may response positively because their items reflect aspects, which are inherent in the nursing job. Adding some items reflecting extra responsibility and extra need for social support may have increased their sensitivity for the intervention. The single item job satisfaction appeared to be not discriminating enough. To increase the variance, a more differentiated format is needed such as report marks. With regard to intrinsic work motivation it seems to be more appropriate to use the original 7-point Likert scale of Warr et al. (1979) to establish a more differentiated response format too. Finally, with respect to the variable health complaints some conceptual problems appeared, which are discussed later.

\subsubsection{Statistical analyses}

To study the differences between the experimental and control groups, we used multivariate techniques due to the possible presence of interaction effects and confounding. To investigate first- and second-order interaction effects we used ANCOVA. This was 
followed by regression analyses to investigate first-order interaction effects in case a second-order interaction effect was determined and to study the main effects. Regression analyses are the preferred technique for study designs with unequal cell numbers as is often the case in social sciences (Kleinbaum et al., 1998). Although we considered our approach as robust, it held some disadvantages. First, due to the small sample of research wards, and therefore the impossibility to correct for confounders and foreseen problems with regard to outliers on aggregated level, rank correlation analysis had to be conducted for answering hypotheses $2 \mathrm{a}, 2 \mathrm{~b}$ and $2 \mathrm{c}$. However, a sound correction was not possible either for the pre-test or for other covariates. So, causality could not be determined properly and therefore the hypotheses could only be treated exploratory. Second, in the analyses type of ward and type of organisation were included as fixed factors (e.g. Kleinbaum et al., 1998). For generalisation to other type of wards and organisations a random effect approach using multi-level analyses would have been preferable. This was not feasible due to the small number of organisations and their systematic instead of random selection of wards (i.e. one psycho-geriatric and one somatic ward per experimental or control group within each organisation). The most serious consequence of fixed instead of random selection is underestimation of the standard errors of the intervention effects (e.g. Kleinbaum et al., 1998). In our study this could be due to heterogeneity of wards of the same type in the same organisation. We were not able to check this because only one ward was available per condition per organisation per type of ward.

\subsection{Theoretical reflections}

\subsubsection{Introduction}

In the following section some theoretical reflections are made with respect to intervention studies on the implementation of resident-oriented care models, the research outcomes and interventions of job redesign in nursing in general.

\subsubsection{Implementation of resident-oriented care models}

The implementation of resident-oriented care can be considered as a job redesign intervention in nursing. To enable generalisations to be drawn regarding the nature of the intervention and its effects the change was structured by means of four design characteristics, that is resident-assignment, nursing process, tasks and communication. The development of a resident-oriented view was also considered essential to strengthen the focus of the implementation and to stimulate a resident-oriented attitude. In this respect an attempt was made to resolve the dichotomy of resident-oriented care as both an organisational design and a view of nursing as a professional, human-centred practice (Koene et al., 1982; Bond et al., 1991a; Pontin, 1999). There are some points to discuss. First, Jupp (1994) and Webb \& Pontin (1997) concluded that primary nursing is being primarily used as a mode of organisation rather than a new philosophy of nursing. Based on the indicative increase in contextual job autonomy and the absence of a change in content job autonomy, it can be argued that the intervention in our study 
appeared to be structural too. Contextual job autonomy is largely determined by the organisational context in which nursing tasks have to be performed, thereby offering more possibilities to influence nursing caregivers' freedom positively. However, with regard to content job autonomy one might argue that job content of nursing caregivers is rather difficult to change. Job content is largely determined by the somatic and psycho-geriatric needs of the resident themselves and the medical standards. Webb \& Pontin (1996) too found in their qualitative interviews that PNCs experienced more continuity rather than a change in their way of working. Second, it has to be pointed out that delegating responsibility to nursing caregivers is often difficult to realise due to established hierarchical positions. In this respect Bowers (1989) argues that based on their hierarchical position supervisors or ward sisters always maintain responsibility and hence decision making power, such as in conflict situations or with the assignment of financial and personnel means (Bowers, 1989). In addition, as discussed in chapter 2 Hurrell \& McLaney (1989) argue that in nursing little decision making power is perceived because physicians are viewed as having ultimate control. In this respect, Metcalf (1986) argued that a change to a patient-oriented care system might involve a different kind of responsibility and decision making rather than improving the amount of responsibility they experience (Metcalf, 1986).

Regarding the appropriateness of the intervention, the question arises as to whether the implementation, i.e. the process, was according to the basic principles of organisational change as was discussed in chapter 3 . As such it is possible to make relationships between a number of relevant characteristics of the implementation and change principles. First, as normative-re-educative strategies and STS approach stress, participation of organisational members has to be established as much as possible (e.g. Chin $\&$ Benne, 1973). Thus it was noticed that on wards with work groups on ward-level the implementation of a resident-oriented care model appeared to be more successful. However, in all three organisations a top-down approach was used entailing a restricted participation of workers of the 'shop floor'. According to the literature, the optimal strategy depends on the phase of implementation and the type of change (Burke, 1982; Killman et al., 1986). As was pointed out, a top-down approach is often used in the implementation of patient-oriented care models since it is considered the most efficient approach to achieve a change in attitude accompanied by less distractions (Bekkers et al., 1994). However, in a top-down approach there is greater risk that hidden acceptance is lacking (Killman et al., 1986). The problems on the somatic ward of organisation A, as discussed in chapter 6 , can be set against this background. On this ward the supervisor used a strict top-down approach in giving information only. Lack of further involvement of the ward members was the direct cause for the failure of the project at the initial phase. In line with this, and as indicated in the literature, the leadership style of supervisors appeared to be an important success condition (Boekholdt, 1981; Van Zonneveld, 1993). For example, less willingness to change among nursing caregivers was shown on wards with difficulties in ward management. Hence, a high instrumental leadership style, the inability to delegate authority to ward sisters resulting in lack of role clarity and lack of supervisor support by means of coaching activities seem to be related with the less successful implementation on the psychogeriatric ward of organisation $B$. Second, as was pointed out in chapter 3 , re-education 
has to be considered important to achieve change not only in cognition, but also in norms and in self-perception of clients, and hence to establish a behavioural change (Lewin, 1951; Chin \& Benne, 1973; Koene et al., 1982; Bond et al., 1991c; Vlerick, 1996). Only in two out of three organisations were educational means used. And when they were used, they were restricted to a few daily periods or were evaluated as insufficient in terms of their content. Training therefore seemed to be not supportive enough for nursing caregivers in their change towards new roles and tasks. When educational instruments were used by supervisors such as training-on-the-job and learning-bydoing, these appeared to be important for a successful change on the experimental wards, which is in line with the indications in the literature (e.g. Trist, 1981; Karasek, 1992; Kuipers \& Van Eijnatten, 1996). Finally, in contrast with principles of Lawrence \& Lorsch (1967) and Hackman \& Oldham (1980) stressing a contingency between the change and the organisational environment, it can be argued that the change on the ward was not supported strongly enough by the rest of the organisation. The intervention did not explicitly involve organisation-wide policy with respect to education, personnel \& organisation or other supportive systems such as technical services. This finding is strengthened by the results from the interviews indicating the presence of a variety of distracting factors negatively interfering with the intervention. However, to support an implementation of job redesign on ward level, departments on organisational level affected by the change have to be involved and implementing other interventions during the innovation period should be applied with caution.

Furthermore, the presence of 'healthy' work aspects at baseline can be stated. As was 'clinically' reflected in the unadjusted scores, elements of a resident-oriented care model had already been introduced such as an integral multidisciplinary resident's dossier including some training concerning the use of the nursing process and the multidisciplinary meeting. Although the control group was selected on the grounds of having a regular nursing care model such as functional or team nursing, except for resident-assignment the differences between the experimental and control wards with respect to the other elements appeared to be clinically rather small. The largest clinical change in the experimental group was seen with respect to the first post-test of resident-assignment. So, in establishing a tailor-made intervention for improving the work situation a thorough investigation of the situation at baseline seem to be important.

\subsubsection{Research outcomes}

No support was found for positive effects on reactions such as job satisfaction and intrinsic work motivation. In general, in contrast to job satisfaction, only a few studies were found which investigated the effects of patient-oriented care models on work motivation (e.g. Kivimäki et al., 1995). However, based on the literature testing models in job redesign, there were grounds to include both outcomes in our research model (e.g. Boumans \& Landeweerd, 1992; Fox et al., 1993; Landeweerd \& Boumans, 1994; Parkes et al, 1994; De Jonge et al., 1996; De Jonge et al., 1999a). As discussed previously, implementation of patient-oriented care models are merely focused on structural work changes such as improving continuity and co-ordination of care. As a consequence, it is questionable whether a structural job redesign intervention has the poten- 
tial to arouse more intrinsically positive job-related reactions such as intrinsic work motivation. It might be argued that interventions focused on job content are more suitable to arouse positive reactions in this respect. For example, Janssen et al. (1999a) saw a clear linear association between intrinsic work motivation and quality of job content such as task identity and opportunities to be creative and to do the things one performs best. Thus, there are reasons not to focus solely on structural changes but on changes with respect to job content as well.

With respect to health complaints and frequency of sickness absence, the results appeared to be different. In this respect it can be argued that health complaints and frequency of sickness absence are two different concepts, which is confirmed by the low correlation in the pre-test $(r=0.029, \mathrm{p}=0.73)$. First, health complaints are measured as a perceived psychosomatic health condition, which might be more influenced by the current health situation. Changes in this respect may lead to more intra-individual variance rather than inter-individual variance. In contrast, frequency of sickness absence reflects a retrospectively summarised state of health over a longer period rather than a current health state and seems to be a more robust measure for assessing health. In this respect the literature indicates rather high correlations between perceived and objectively registered measures (Ten Vergert, 1987; Berkhout, 1990). Second, frequency of sickness absence is not only a reflection of the perceived severity of illness but also reflects a behavioural reaction influenced by various contextual factors and thus motivated towards choices about attendance or absence (Smulders, 1980). Hence, it might be argued that frequency of sickness absence is a more appropriate reaction on organisational change compared to health complaints.

In improving working conditions, it is interesting to consider reasons for intention to leave. According to Van der Windt, Calsbeek \& Hingstman (1998), about $10 \%$ of the nursing caregivers leave their health care setting on a yearly base. For the clinical health care sector totally, about half of the leaving nursing caregivers leave health care fore good and probably end their professional career. Among reasons for leaving that could have been prevented, the most important are better changes for growth, a better use of skills and positive career perspectives. More possibilities for working part-time are important for women. Finally, enrolled nurses in particular would benefit from better working conditions such as less work pressure and a better ward climate (Van der Windt et al., 1998). Thus, lessening work pressure seems to be of major importance for preventing this group from leaving. Characteristic for the occupational group of nursing caregivers are high job demands combined with low levels of autonomy and a work situation in which individuals work closely together (cf. De Jonge, 1995). So, one might argue that at the occupational level of enrolled nurses in nursing homes job autonomy and responsibility in particular are important in relation to the increasing quantitative as well as qualitative job demands. However, in reality autonomy and responsibility appear to be restricted (De Jonge, 1995; Berkhout et al., in preparation). This seems to play a role with regard to our results. In considering the high scores on social support compared to job autonomy in our study a comment of De Jonge (1995) is of importance. He argues that workplace social support is probably more significant in nursing than job autonomy. Workplace social support is inherent in the work of 
nursing caregivers due to their close collaboration in teams. Therefore, De Jonge (1995) speculates that due to the low levels of job autonomy, social and collective forms of autonomy become more important for individuals.

Finally, one may wonder whether there is only one way to Rome. In other words, are the routes to higher job satisfaction and intrinsic work motivation and less health complaints and frequency of sickness absence conclusive? A variety of factors may have an impact on psychological outcomes. In this regard, we have to consider our study population of which the large majority are women in their early thirties working parttime. These women often have many caring tasks towards their family members in addition to their work. These social contexts may have a major impact on their psychological and behavioural reactions too. It seems to be simplistic to assume that one mechanism only is at work rather than multiple sources, many of which are not related to organisational mode (e.g. Kelly, 1992; Kivimäki et al., 1995).

\subsubsection{Interventions of job redesign in nursing in general}

With interventions, many investments are made by organisations implementing them as well as by research institutes evaluating them. Although our results are limited, there are no conclusive empirical grounds for saying the implementation of residentoriented care has no impact at all. In the first place, it is questionable whether our expectations with regard to the results were not too high. Although cross-sectional studies on effects of job characteristics on psychological and behavioural outcomes using large study populations reveal more significant results, the strength of the associations appeared to be often moderate (e.g. Boumans, 1990; De Jonge, 1995). Therefore, for longitudinal intervention studies using a limited study population and the same psychological measures it is difficult to confirm the moderate findings of these crosssectional studies. In the second place, in the interviews and observations nursing caregivers indicated more responsibility, more job satisfaction and a higher quality of care. Nursing caregivers held a strong opinion that they did not want to go back to the old working method. Therefore, interventions stimulating more resident-oriented care have to be considered as valuable for improving working conditions. Finally, residentoriented care can be aligned with a wider social need for decentralised responsibility, professional status, and an individualised nurse-patient interaction (Bowers, 1989; Perälä, 1989; Thomas, 1994). Therefore, to reach high quality of work and care on the longer term such as resident-oriented care aims at, the absence of hard results should not be an argument for preventing us doing interventions in this respect. For researchers it is of major importance to strengthen their designs and conceptual frameworks.

The literature indicates that structural changes are far easier to achieve and to capture compared to more process aspects such as behaviour (e.g. Senge, 1990; Kapteyn, 1996). For individuals involved in change, structural changes are obvious to observe due to their clarity. In contrast, behavioural changes are established slowly and most of the time are rather unnoticed by the respondents themselves. In the tradition of organisational change, this phenomenon is known as the 'parable of the boiled frog' (e.g. Senge, 1990). The underlying assumption is that people tend to react obviously to sud- 
den environmental changes but not to slow, gradual changes just as the frog, which is not inclined to climb out of a pan filled with water while it is slowly heated. In the initial phase of an implementation in particular most changes will be reflected in small, concrete aspects only. Hence this may be why it is so difficult to capture intervention effects in relatively abstract and global concepts such as perceived job characteristics or psychological and behavioural reactions. Furthermore, like our study, most studies on patient-oriented care models focus on structural changes. In general, structural changes are easier to capture and therefore most measuring instruments are more sensitive to structural changes rather than to behavioural changes. In this respect, more effort should be made to design measuring instruments to capture behavioural changes as well. Change in perceptions might be better captured by asking respondents to make comparisons between their current (after the intervention) and former work situation (before the intervention).

In line with the previous discussion, an important question should be raised regarding the revenues of work redesign interventions in nursing in general (e.g. Heeremans et al., 1994; Janssen, 1996; Melchior, 1996). More precisely, to what extent can job enrichment in nursing be achieved within the current setting of clinical health care such as hospitals and nursing homes? It may be argued that an important part of the decisions take place on higher management levels or in the medical organisation. Hence, the margins for increasing job autonomy in the work of nursing caregivers are limited and possibilities for changing job content are restricted. In addition, the work context of nursing caregivers can be changed only in a limited way in changing some structural work preconditions such as assigning residents. It may be that job enrichment is still not established more fundamentally because nothing is changing in the underlying structural and cultural assumptions regarding job content and context. In this respect Jupp (1994) and Webb \& Pontin (1997) raised a point of interest in that nurses still view the organisation of care accordingly to the medical model. According to Johns (1990), the establishment of job enrichment in nursing is mainly dependent on the attitudes and capabilities of nursing caregivers themselves to manoeuvre the pervasiveness of routinisation and the socialised role of the nurse as the doctor's handmaiden. In this respect, it is instructive to imagine what would have been achieved if nursing had developed as a male profession long ago. As Wiegman (1996) describes, at the end of the nineteenth century both hospital boards, dominated by the medical profession viewed as a typical male profession, and society at large labelled the nursing profession as female. This greatly limited male's influence in nursing (Wiegman, 1998). Women rather than men were considered to have innate qualities for nursing (Wiegman, 1993 and 1998). At the end of the nineteenth century medical profession took power over nursing definitively. For a long period, nurses did not succeed in developing their occupation independently of the medical profession with a position alongside instead of under the doctor for 'thou becometh his assistant and thou completeth his work' (Wiegman, 1996). Dependence on the medical profession is illustrated by the fact that in clinical health care settings such as hospitals and nursing homes, entry to nursing care is the medical diagnosis. Furthermore, for their job performance nursing caregivers are far more dependent on the medical profession compared to other professional occupations such as physiotherapy and welfare. Developing as a professional 
occupation is problematic in nursing due to a continuing struggle of defining one's job domain. The lack of power makes professionalisation and an appreciated societal status accordingly a difficult process in the Netherlands and elsewhere (Wiegman, 1996). Only in the last decade have attempts been made to strengthen the position of nursing by strengthening its organisational structure, by renewing nursing education and by limiting problems on the labour market (Wiegman, 1998). In this respect, the foundation of the national centre of nursing care (Landelijk Centrum Verpleging \& Verzorging, LCVV) has been an important step towards improving the position of the nursing profession by nursing caregivers themselves. So, in changing job content and context and thus increasing job autonomy, a change is needed in the relationship between the medical and nursing professions.

\subsection{Implications}

\subsubsection{Introduction}

As already indicated, the intervention did have some limitations. In addition, some critical methodological and theoretical reflections were made. Based on this and on recent publications, some implications will be discussed for future research and for the implementation of resident-oriented care.

\subsubsection{Implications for future research}

With respect to problems in research methodology, Kasl (1987) points to the dilemma faced by many researchers that better research designs are more a function of the resources available to the investigator and less a reflection of his/her level of methodological sophistication. Despite the difficulties sometimes to achieve this, it needs to be stressed that experimental or quasi-experimental designs using one or more pre-tests, post-tests and control groups are to be preferred. However, in measuring organisational change in particular, the following remarks should be made. In using quantitative measuring methods only, we seem not to be able to capture organisational changes adequately. In this respect, method and data triangulation can be considered as a strategy of major importance. With regard to the qualitative side there is an opportunity for collecting 'in-depth', backstage information. In this respect particularly in-depth case studies seem to be appropriate. Therefore, future research should direct efforts towards a further elaboration of these methods. With regard to the quantitative side, this was important to gain insight into global changes as in our study of the structural changes. Furthermore, in using quantitative methods a controlled research design can be established. In this respect measurement of organisational change, often largely influenced by exogenous as well as endogenous variables, can be performed in a more valid way. Moreover, multivariate techniques offer the opportunity to correct as much as possible for confounders or effect modifiers. In choosing the statistical techniques, structural equation modelling seems to be a sound technique to be able to perform confirmatory analyses. When for reasons of insufficient sample sizes, use of this technique leads to unreliable estimates of the standard errors, more conventional exploratory multivariate 
techniques are indispensable for analysing the differences between the experimental and control groups.

Bearing in mind the inclination to adjust oneself to current situations, there is a need to focus on more small, concrete organisational changes. Therefore, instead of measuring abstract and global concepts such as job autonomy or responsibility, measuring instruments have to be comparative to capture change into more detail. Questions have to be asked with regard to the current situation of job autonomy, job demands, social support and responsibilities in comparison with the former situation. Questions also have to be focused on the nature of these concepts to identify their different aspects and the content of their changes.

Further, a specific recommendation can be made. Some dissatisfaction was indicated by nursing caregivers who, based on their qualification level, did not became a PNC. In analysing the data, we selected a homogeneous sample to exclude confounders as much as possible. No data were analysed for employees working on qualification level 2 , such as nursing aides, auxiliaries, nursing assistants and geriatric helpers according to the Dutch qualification structure for nursing caregivers (Commissie Kwalificatiestructuur, 1996). Compared to enrolled nurses, this group of nursing caregivers holds a different position on the nursing ward. Therefore, it seems to be important to gain more insight into the differences of the intervention effects for this group of nursing caregivers compared to caregivers working on qualification levels 3,4 and 5.

\subsubsection{Practical implications}

The interviews and observations revealed that PNCs saw their work as more demanding, showed insecurity about their role and tasks and did not always perform the coordinating tasks themselves. Furthermore, associate nurses experienced their role as secondary, which they perceived as less attractive. So, in this respect some recommendations can be made. First, a better fit between capacity and work expectations is needed. Before a job enrichment intervention, the competency levels of nursing staff should be examined thoroughly and if necessary, policy with respect to personnel recruitment and selection should be adjusted. Second, a change in roles, tasks and responsibilities of nursing caregivers has to be accompanied by a rigorous in-service education and training-on-the-job to improve the skills of nursing caregivers in planning, co-ordinating, and evaluating of care and to achieve a behavioural change towards a more resident-oriented attitude. Vlerick (1996) points to the importance of developing psychosocial skills in particular. In this respect education is a prerequisite for achieving change, but is still often neglected. Investing in training and education should be kept high on the priority list of organisations in preparing and achieving change. Educational efforts should not be focused on training of structural aspects only, but on achieving behavioural change too. To achieve this, training has to be practical and focused on small, concrete aspects. Here feedback can serve as an important medium. Training has to be an ongoing process of special meetings and training-onthe-job even after the intervention aims have been achieved. In our study direct coaching and training-on-the-job of nursing caregivers by supervisors in particular appeared 
to be a success condition. As such, direct supervision of the performance of nursing caregivers by the ward management is made possible. The close relationship between supervisor and supervised enables growth and support within a problem-solving method (Johns, 1990). Finally, intervision is an important instrument because of its principle of equality. Nursing caregivers can function as a mirror for colleagues in stimulating a resident-oriented attitude (e.g. Hawthorne, Roe and Woods, 1989).

As in other evaluation studies, ward management appeared to be a crucial factor for the success of the implementation (Bekkers et al., 1990; Melchior, 1996). Bekkers et al. (1990) noticed an increased turnover among supervisors during the implementation. Difficulty in the position of supervisors in change processes lies in their double role: on the one hand developing and steering the change on ward level while undergoing the change themselves on the other. Although stability in ward management is difficult to guarantee, the success of the implementation can be made less vulnerable by building in some conditions. First, before adopting a resident-oriented care model, the competency of management concerning the innovation should be examined. If necessary, policy with respect to recruitment and selection should be adjusted. Second, most interventions with respect to resident-oriented care are focused on the role and tasks of the PNCs. The role, tasks and leadership style of ward management, supervisor and ward sister, is mostly elaborated and discussed less concretely, as something which has to be performed prior to the implementation. Finally, these activities have to be followed by a rigorous training. On the one hand supervisors have to be trained to serve as trainers for PNCs; on the other they have to be trained themselves to be able to perform the role, tasks and leadership style according to the new working method. In achieving a behavioural change, in line with normative re-educative principles this education should be practical, rather than theoretical, with role-playing and trainingon-the-job.

Hoffart et al. (1995) gave evidence of the importance of congruency between the type of implementation and the organisational culture. In achieving a tailored intervention Van Zonneveld (1993) stresses the importance to pay attention to the current organisational conditions before the intervention. Although the literature stresses the importance of conducting a Strengths Weaknesses Opportunities Threats analysis (SWOT), this is often not sufficiently performed or even neglected. However, to deal with a diversity of nursing care models, a SWOT is of major importance at baseline not only for researchers evaluating interventions or for external agencies implementing them. In particular, it is important for organisations themselves to make choices consciously in line with their cultural values or deliberately in contrast with these values in trying to alter these. New organisational policy has to be in line with chosen principles. Thus implementing other interventions in parallel to a large scale intervention as the implementation of a resident-oriented care model should be prevented as much as possible.

Bond et al. (1991a) suggest an incremental implementation. In our study the implementation of a resident-oriented care model took place incrementally. First, an adjustment was made to the structure and tasks of nursing caregivers followed by the introduction of the nursing process. An incremental change is important to get used gradu- 
ally to the new working method and with this to guarantee its maintenance on the longer term. This provides an opportunity to build in sufficient flexibility. For, as Bond et al. (1991a) state, it is likely that wards will be at different points along different dimensions and will have achieved some criteria with less or more difficulty. Furthermore, for increasing the potential to realise the effects aimed at, interventions in nursing should be made more small-scale. This enlarges possibilities for making interventions more concrete by means of clear aims and actions accordingly.

To decrease insecurity in the functioning of PNCs and dissatisfaction of associate nurses, delegation of responsibility should take place in a sheltered environment. This enables the need for social support to be dealt with by ward management and colleagues (e.g. De Jonge, 1995). Based on STS principles, establishment of small-scale decentralised autonomous work groups may be a solution. In small-scale decentralised autonomous work groups, division takes place on work group level rather than on individual level. Besides their individual responsibility, PNCs and associate nurses as a work group possess a collective responsibility for the co-ordination and continuity of total nursing care of assigned residents. According to STS principles, the implementation of semi-autonomous work groups is an example of increasing social support within the structure of the work process to reduce occupational stress and enhance health (House, 1981). In this respect supervisors have a supportive function rather than one of showing authority or control (e.g. Gardell, 1982; De Jonge, 1995; Kuipers \& Van Eijnatten, 1996). Advantages of this work redesign method are the opportunity to deal with problems related to resident-oriented care models such as social isolation and job complexity and with problems related to functional nursing care models such as task fragmentation (e.g. De Jonge, 1995). It can be assumed that job autonomy is increased as a result of more self-regulation on group level such as division of tasks and determination of the work process. Social support too is fostered by increased opportunities for formal and informal task- or relation-oriented communication.

In the literature resident-oriented care is considered at the same time as a philosophy, a professional human-centred view and as an organisational design, a method (Koene et al., 1982; Bond et al., 1991a). However, in practice there is often a focus on structural changes only. In this respect we do not seem to be making much headway. We have to conclude that we do not have to be focused on structural changes only in order to achieve higher organisational aims such as more job autonomy, job satisfaction or intrinsic work motivation. Future implementations with regard to work redesign have to direct their efforts also to alternative ways for organising nursing care. In this respect the core of the nursing job has to be reconsidered as the key subject: patient-care and the nurse-patient relationship. As Menzies (1960) has described, this is the source of the anxiety and stress of nursing caregivers. It does not seem to be sufficient anymore to re-structure the system of the work organisation to foster a close, person-to-person and longer lasting nurse-patient contract. It seem to be of major importance to look at fundamental changes in the context of the nursing job on meso and macro level, i.e. in assumptions towards the task domain of nursing caregivers and its embedding in the rest of the organisation, as well as in the content of the nursing job on micro level, i.e. the performance of patient-care and attitudes accordingly. 


\section{SUMMARY}

The work of nursing caregivers can be characterised by high job demands and difficulties in job control. Negative effects of low job control in combination with high job demands have been proven to be problematic for the well-being and health of nursing caregivers. Therefore job redesign interventions aimed at job enrichment are of major importance. In nursing, implementation of models of patient- or resident-oriented care are examples of such job redesign interventions. The present thesis concerns the evaluation of the implementation of resident-oriented care in nursing homes.

Chapter 1 introduces the subject, the research aims and questions and conceptual framework. The study aimed to gain insight into three areas namely: (1) feasibility of resident-oriented care in nursing homes; (2) the success conditions of the implementation and (3) the effects on job characteristics of nursing caregivers and on their psychological and behavioural reactions. Answers were sought to the following three research questions:

1. To what extent are the various characteristics of resident-oriented care implemented?

2. What are the conditions for successfully implementing resident-oriented care?

3. What are the effects of the implementation of resident-oriented care on the job characteristics of nursing caregivers and on their psychological and behavioural reactions?

Chapter 2 stresses the technical part of job redesign, the "what". Theoretical models such as Hackman \& Oldham's Job Characteristics Model (JCM), Karasek's Job Demand-Control model (JDC) and Johnson \& Hall's Demand-Control Support model (DCS) as well as practical guidelines from the Socio-Technical Systems (STS) approach have proven important in generating knowledge with regard to job redesign interventions aimed at job enrichment. In general, implementation of patient-oriented care models is aimed at improving nursing caregivers' job characteristics and, as a result, at improving their psychological and behavioural reactions. The following four design characteristics of patient-oriented care models can be indicated: patient assignment, use of the nursing process, extension of tasks and improvement of communication. The concepts job autonomy, job demands and social support used in the DCS model of Johnson \& Hall (1988) can be considered important job characteristics influencing well-being and health. Responsibility is a main job characteristic of patientoriented care models. Therefore, these four job characteristics were considered important on which to evaluate the implementation of resident-oriented care models in nursing homes. Job satisfaction, intrinsic work motivation, health complaints and frequency of sickness absence can be considered important psychological and behavioural reactions of job enrichment. They have proven to be associated with the central concepts of the DCS model and are outcomes in other important analytical models such as the Job Characteristics model of Hackman \& Oldham (1980). Therefore, these four reactions were chosen to evaluate nursing caregiver's reactions on the implemen- 
tation of these models. Evaluation studies on this theme indicate the clearest effects with respect to patient assignment, responsibility and job satisfaction. The results with regard to the three job characteristics derived from the DCS model and to work motivation, health complaints and sickness absence have been less thoroughly investigated and are more ambiguous. Conceptual as well as methodological problems seem to be underlying factors. In evaluating the effects of resident-oriented care models in nursing homes, besides a theoretical framework, a sound methodological design is also needed. Use of a pre-test post-test design with a control group, a homogeneous study population, and use of method and data triangulation seem to be of major importance.

Chapter 3 discusses the social part of job redesign or the "how". Therefore processes of organisational change and important conditions in this respect are highlighted. Organisational change is focused on interventions within and between groups of individuals. For the development of strategies of organisational change, motivational theories are of importance. Strategies for organisational change can be oriented on organisational systems or on the change process itself and can vary in their emphasis on participation and involvement of people directly affected by the change. In particular, the normative-re-educative strategy, Action Research, and the intersystem approach bear resemblances to STS guidelines, which seem to be important for the implementation of resident-oriented care models. These concern: their emphasis on a sufficient degree and level of participation of people directly affected by the change; congruence between the nature of change on the one hand and the project and formal organisation on the other; participative and supportive roles of the change agent and the management; sound communication, information and evaluation means; and education and training focused on experience-based learning. Based on these principles, seven success conditions have been elaborated to gain more insight into the contribution of a number of implementation characteristics for implementing a resident-oriented care model successfully. In order to study the implementation characteristics and in this way the success conditions, the McKinsey 7-S model developed by Peters \& Waterman (1982) was used as a diagnostic model. We related the 7-S model to our elaborated success conditions by operationalising the seven factors, being structure, strategy, systems, staff, skills, style and shared values, accordingly.

Chapter 4 elaborates the research method. The study concerned a non-equivalent control group pre-test post-test design. Three nursing homes were included in the study. An experimental group, six wards implementing resident-oriented care, was compared with the control group, six wards without this implementation. To answer the research questions three measurements were taken over a period of 22 months: one pre-test and two post-tests at six and sixteen months after the start of the implementation. In the quantitative part of the study 210 (pre-test), 167 (post-test 1) and 147 (post-test 2) nursing caregivers of all 12 research wards filled in questionnaires. For the qualitative part, on the experimental wards interviews were performed with project co-ordinators and supervisors, participant observations were conducted, and residents' dossiers were charted. 
Chapter 5 handles the quantitative and qualitative results with respect to the design characteristics. With regard to "resident assignment", the quantitative results showed increases on five out of six experimental wards after the implementation. One hypothesised increase could not be confirmed due to a contamination effect on a control ward. The qualitative results confirmed the implementation of resident assignment in the experimental group. Resident assignment to so-called primary nursing caregivers (PNCs), who are employed at least $70 \%$ of a full-time job, has been implemented. In general, no residents were assigned to nursing caregivers with an employment percentage of less than $70 \%$, so-called associate nursing caregivers. Resident assignment was most observable during direct care given in the morning hours. In the case of high sickness absence or work pressure, this was difficult to achieve. Moreover, with regard to some direct care tasks a task-oriented division of care was still present. With regard to the "use of the nursing process", as was hypothesised, in the last post-test a significant increase was found in "use of nursing care plans and their evaluation" and in "taking nursing history, nursing problems, goals and actions" in the experimental group compared to the control group. The interviews and observations showed that in all organisations the implementation of the nursing process was combined with adjustments in the residents' dossiers. However, to bring the nursing process into practice appeared to be the most difficult part for ward sisters and nursing caregivers. Nursing care plans still were seldom complete or up-to-date and the realised care was not always congruent with the planned care. Furthermore, in the case of high work pressure less attention was given to the documentation in the residents' dossier. The quantitative results with respect to the two variables "tasks" was partly as hypothesised. On the psychogeriatric experimental wards more "resident-oriented tasks" were performed after the implementation compared to the psycho-geriatric control wards. In contrast, in the somatic group no significant results were found. However, more resident-oriented tasks were performed by PNCs of the total experimental group compared to nursing caregivers with an employment of $70 \%$ or more in the control group. This increase was indicative in the group associate nursing caregivers. No increase was found in the extent of "ward-oriented tasks". Although some effects were according to the expectations, the qualitative results identified some problems. It was observed that in case of high work pressure PNCs did not perform all basic care for their own allocated residents. In addition, co-ordinating tasks that should have been delegated to PNCs were still often performed by the ward sisters themselves, and PNCs did not always make use of these co-ordinating tasks themselves. With regard to the three variables "communication", a non-significant decrease of the "quality of communication forms" was indicated after the implementation. No changes were found on the two other variables "variety of resident-oriented communication forms" and "variety of ward-oriented communication forms". Moreover, in the group associate nursing caregivers less "variety of ward-oriented communication forms" was indicated. The qualitative results showed that in general the role of the ward sister was still prominent in the multidisciplinary meeting, in the doctors' consultations and in the case of difficult family contacts. The role of PNCs was more prominent in regular residents' and family contacts and towards paramedical disciplines. 
Chapter 6 presents the quantitative and qualitative results with respect to the implementation characteristics. In using quantitative analyses the most successful experimental wards with regard to the implementation of a resident-oriented care model including the largest change could be distinguished from the least successful wards. In relating the extent of the implementation of a resident-oriented care model to the implementation characteristics we were able to derive a number of success conditions. On the most successful experimental wards success conditions appeared to be: no delay in the action plan; absence of distracting factors; stability of the supervisor; final evaluations on ward level; willingness to change among nursing staff; and training-onthe-job by supervisors themselves. Furthermore, as was hypothesised, wards with supervisors using less instrumental leadership in the last phase of the implementation appeared to have implemented a resident-oriented care model more successfully. Both information quality and socio-emotional leadership style were not found to be success conditions.

Chapter 7 highlights the quantitative results regarding the job characteristics and the psychological and behavioural reactions. With regard to the job characteristics most of the intervention effects did not appear. With regard to job autonomy and responsibility no changes were found after the implementation in the experimental group. However, when the two underlying concepts of job autonomy were considered separately, an indication was found for an increase in contextual job autonomy after the implementation while no changes were seen with regard to content job autonomy. With regard to job demands the results differed. However, the hypothesis postulating an increase in job demands could not be confirmed. After the implementation, a trend was found for more job demands on the somatic experimental wards whereas on the psycho-geriatric experimental wards an indication was found for less job demands. No additional significant results were found with regard to the underlying concepts quantitative and qualitative job demands. The results with regard to social support were mixed too. On one of the psycho-geriatric experimental wards the postulated increase was confirmed. Further, only indicative increases as well as indicative decreases were found after the implementation. No significant results were found with regard to social support of supervisors and colleagues separately. With regard to the psychological and behavioural reactions the postulated increases in job satisfaction and intrinsic work motivation and decreases in health complaints could not be confirmed. However, with regard to frequency of sickness absence after the implementation an indication was found for less frequency of sickness absence in the experimental group. This result was confirmed in the group of PNCs.

Chapter 8 presents the main findings and some methodological and theoretical reflections in this respect. Based on the results it can be argued that the intervention regarding resident-oriented care appeared to be largely structural. No change took place with respect to more intrinsic job-related aspects such as content job autonomy, responsibility, job satisfaction and intrinsic work motivation. Methodologically our study had to confront some problems such as selection bias and contamination. In using multivariate techniques some of the problems could be highlighted afterwards. For evaluating organisational change, method and data triangulation used in our study appeared to 
be very suitable. In using quantitative methods, insight is achieved into more general changes such as structural changes. Further, in this way a controlled research design can be established. Qualitative methods offer the opportunity for collecting in-depth, backstage information. Theoretically, based on the limited significant results the following points arise for discussion. First, it can be questioned to what extent job content, largely determined by professional medical and nursing standards and the demands of residents, can be changed by a merely structural intervention such as the implementation of resident-oriented care. Second, healthy work aspects on baseline, restricted job control at the occupational level of enrolled nurses, and external factors influencing job satisfaction and work motivation seem to play an important role in the non-appearance of significant results. Third, it has to be doubted to what extent nursing caregivers were able to detect slow gradual changes in job autonomy or job satisfaction and to what extent measuring instruments were sensitive enough to capture them. Finally, in general underlying structural and cultural assumptions regarding job content and context seem to restrict the margins for job enrichment in nursing. Developing as a professional occupation with an appreciated societal status accordingly seems to be problematic for nursing also due to problems in defining one's own job domain. In line of these remarks the thesis closes with implications for future research and practical implications with regard to the work of nursing caregivers and interventions in this respect. 


\section{SAMENVATTING}

Het werk van verplegenden en verzorgenden kan worden gekarakteriseerd door hoge taakeisen en problemen met betrekking tot controle in het werk. Het is bewezen dat negatieve gevolgen van lage controle in combinatie met hoge takeisen problematisch zijn voor het welzijn en de gezondheid van verplegenden en verzorgenden. Taakherontwerp interventies gericht op taakverrijking zijn derhalve van belang. In de verpleegkunde vormen de implementatie van modellen voor patiënt- of bewonergerichte zorg voorbeelden van dergelijke taakherontwerp interventies. Dit proefschrift betreft een evaluatie van de implementatie van bewonergerichte zorg in verpleeghuizen.

Hoofdstuk $l$ introduceert het onderwerp van de studie, de onderzoeksdoelen, de vraagstellingen en het conceptueel model. Het onderzoek was gericht op het vergroten van inzicht in een drietal gebieden namelijk: (1) haalbaarheid van bewonergerichte zorg in verpleeghuizen; (2) de succescondities met betrekking tot de implementatie; en (3) de effecten op kenmerken van taken van verplegenden en verzorgenden en op hun psychologische en gedragsmatige reacties. Op de volgende drie onderzoeksvraagstellingen werd getracht een antwoord te geven:

1. In welke mate zijn de verschillende kenmerken van bewonergerichte zorg gë̈mplementeerd?

2. Wat zijn de condities voor een succesvolle implementatie van bewonergerichte zorg?

3. Wat zijn de effecten van de implementatie van bewonergerichte zorg op de taakkenmerken van verplegenden en verzorgenden en op hun psychologische en gedragsmatige reacties?

Hoofdstuk 2 benadrukt de technische kant van taakherontwerp, het "wat". Theoretische modellen zoals Hackman \& Oldham's Job Characteristics Model (JCM), Karasek's Job Demand-Control model (JDC) en Johnson \& Hall's Demand-Control Support model (DCS) als ook praktische richtlijnen van de Sociotechnische Systeem benadering (STS) hebben bewezen van belang te zijn voor het ontwikkelen van kennis met betrekking tot taakherontwerp interventies gericht op taakverrijking. In het algemeen is de implementatie van patiëntgerichte zorgmodellen gericht op de verbetering van de taakkenmerken van verplegenden en verzorgenden en daarmee op de verbetering van hun psychologische en gedragsmatige reacties. Vier ontwerpkenmerken van patiëntgerichte zorgmodellen kunnen worden aangewezen: patiënttoewijzing, gebruik van het verpleegkundig proces, uitbreiding van taken en verbetering van de communicatie. De concepten autonomie, takeisen en sociale steun van het DCS model van Johnson \& Hall (1988) kunnen als belangrijke taakkenmerken worden beschouwd die van invloed zijn op welzijn en gezondheid. Verantwoordelijkheid is een belangrijk taakkenmerk van patiëntgerichte zorgmodellen. Deze vier taakkenmerken werden derhalve van belang geacht voor de evaluatie van de implementatie van bewonergerichte zorgmodellen in verpleeghuizen. Arbeidstevredenheid, intrinsieke werkmotivatie, gezondheidsklachten en ziekteverzuimfrequentie zijn belangrijke psychologische en gedragsmatige 
reacties op taakverrijking. Zij hebben bewezen gerelateerd te zijn aan de centrale concepten van het DCS model en zijn uitkomsten andere analytische modellen zoals het taakkenmerkenmodel van Hackman \& Oldham (1980). Deze vier reacties werden derhalve gekozen ter evaluatie van de reacties van verplegenden en verzorgenden op de implementatie van deze zorgmodellen. Evaluatiestudies op dit thema laten de duidelijkste effecten zien ten anzien van bewonertoewijzing, verantwoordelijkheid en arbeidstevredenheid. De resultaten ten aanzien van de drie taakkenmerken uit het DCS model en ten aanzien van werkmotivatie, gezondheidsklachten, en ziekteverzuim zijn minder onderzocht en zijn onduidelijker. Zowel conceptuele als methodologische problemen lijken hieraan ten grondslag te liggen. Om de effecten van bewonergerichte zorgmodellen in verpleeghuizen te evalueren is naast een theoretisch kader, een degelijk methodologisch design nodig. Gebruik van een design met voor- en nametingen, een controle groep, een homogene onderzoekspopulatie en gebruik van methode- en data-triangulatie lijken in dit opzicht van belang te zijn.

Hoofdstuk 3 bediscussieert de sociale zijde van taakherontwerp of het "hoe". Processen van organisatieverandering en belangrijke condities staan in dit opzicht centraal. Organisatieverandering betreft interventies binnen en tussen groepen individuen. Voor de ontwikkeling van strategieën voor organisatieverandering zijn gedragsmatige en motivatietheorieën van belang. Strategieën voor organisatieverandering kunnen zijn gericht op organisatorische systemen of op het veranderingsproces zelf en zij variëren in het benadrukken van participatie en betrokkenheid van degenen die direct worden beïnvloed door de verandering. In het bijzonder de normatief-reëducatieve strategie, actiegericht onderzoek en het model van planmatige verandering vertonen gelijkenis met STS richtlijnen. Deze betreffen het benadrukken van: een voldoende mate en niveau van participatie van bij de verandering direct betrokkenen; overeenstemming tussen de inhoud van de verandering aan de ene kant en de projectstructuur en de formele organisatie aan de andere kant; op participatie en ondersteuning gerichte rollen van de veranderkundigen en de leidinggevenden; goede communicatie, informatie en evaluatie methoden; en bijscholing en training gericht op ervaring-gebaseerd-leren. Op basis van deze principes zijn zeven succescondities uitgewerkt om meer inzicht te verwerven in de bijdrage van een aantal implementatiekenmerken aan een succesvolle implementatie van bewonergerichte zorgmodellen. Voor het onderzoek naar de implementatiekenmerken en daarmee de succescondities is gebruik gemaakt van het McKinsey 7-S model, ontwikkeld door Peters \& Waterman (1982), als een diagnostisch model. Het 7-S model werd gerelateerd aan de uitgewerkte succescondities door operationalisatie van de zeven factoren structuur, strategie, systemen, staf, vaardigheden, leiderschapsstijl en gedeelde waarden.

Hoofdstuk 4 betreft de uitwerking van de onderzoeksmethode. De studie heeft een quasi-experimenteel onderzoeksdesign. Drie verpleeghuizen werden in de studie geïncludeerd. Een experimentele groep, zes afdelingen met de implementatie van een bewonergericht zorgmodel, werd vergeleken met een controle groep, zes afdelingen zonder deze implementatie. Ter beantwoording van de onderzoeksvragen werden drie metingen verricht in een periode van 22 maanden: één voormeting en twee nametingen 6 en 16 maanden na de start van de implementatie. Voor het kwantitatieve deel van de 
studie waren 210 (voormeting), 167 (nameting 1) en 147 (nameting 2) verplegenden en verzorgenden van alle 12 onderzoeksafdelingen betrokken bij het invullen van de schriftelijke vragenlijsten. Voor het kwalitatieve deel werden op de experimentafdelingen interviews gehouden met projectcoördinatoren en afdelingshoofden, participerende observaties verricht en bewonersdossiers bekeken.

Hoofdstuk 5 behandelt de kwantitatieve en kwalitatieve resultaten met betrekking tot de ontwerpkenmerken. Ten aanzien van bewonertoewijzing laten de kwantitatieve resultaten na de implementatie stijgingen zien op vijf van de zes experimentafdelingen. Een verwachte stijging werd niet bevestigd als gevolg van een contaminatie-effect op één van de controle afdelingen. De kwalitatieve resultaten bevestigen de implementatie van bewonertoewijzing in de experimentele groep. Bewonertoewijzing aan zogenoemde eerstverantwoordelijk verzorgenden (EVV'ers) met een dienstverband van minimaal $70 \%$ is ingevoerd. In het algemeen werden geen bewoners toegewezen aan verplegenden en verzorgenden met een dienstverband van minder dan $70 \%$, de zogenaamde niet-EVV'ers. Bewonertoewijzing bleek het meest zichtbaar te zijn tijdens de ochtendverzorging. Bij een hoog ziekteverzuim of hoge werkdruk bleek dit moeilijk te handhaven. Bovendien bleek een taakgerichte werkverdeling nog aanwezig te zijn ten aanzien van een aantal directe zorgtaken. Ten aanzien van het gebruik van het verpleegkundig proces waren in de laatste nameting verwachte stijgingen te zien in "het gebruik van verpleegplannen en de evaluatie daarvan" en in "het formuleren van de anamnese, verpleegproblemen, doelen en acties" in de experimentele groep in vergelijking tot de controle groep. De interviews en observaties lieten zien dat in alle organisaties de implementatie van het verpleegkundig proces werd gecombineerd met aanpassingen van de bewonersdossiers. Echter, het in de praktijk brengen van het verpleegkundig proces bleek voor teamleiders en voor verplegenden en verzorgenden het moeilijkste onderdeel te zijn. Zorgplannen waren nog zelden volledig of bijgewerkt en de gerealiseerde zorg bleek niet altijd overeen te komen met de geplande zorg. Verder, in het geval van hoge werkdruk werd minder aandacht besteed aan de verslaglegging in het bewonersdossier. De kwantitatieve resultaten ten aanzien van de twee variabelen taken waren deels verondersteld. Op de psychogeriatrische experimentafdelingen werden meer bewonergerichte taken uitgevoerd na de implementatie. Daarentegen werden in de somatische groep geen significante resultaten geboekt. Echter, binnen de totale experimentele groep werden door de EVV'ers meer bewonergerichte taken uitgevoerd in vergelijking met verplegenden en verzorgenden met een dienstverband van minimaal $70 \%$ van de controle groep. Deze stijging was trendmatig in de groep nietEVV'ers. Ten aanzien van de mate van "afdelingsgerichte taken" werd geen stijging gevonden. Hoewel sommige resultaten volgens de verwachting waren gaven de kwalitatieve resultaten enige problemen aan. Zo werd waargenomen dat in het geval van hoge werkdruk EVV'ers niet alle basiszorg zelf uitvoerden voor de hen toegewezen bewoners. Tevens bleek dat coördinerende taken die moesten worden gedelegeerd aan EVV'ers nog vaak door de teamleiders zelf werden uitgevoerd en bleken EVV'ers zelf niet altijd gebruik te maken van deze coördinerende taken. Van de drie variabelen communicatie werd ten aanzien van de "kwaliteit van de overlegvormen" geen significante maar wel trendmatige daling gevonden. Ten aanzien van de "gevarieerdheid van de bewonersgebonden overlegvormen" en de "gevarieerdheid van de afdelingsgebon- 
den overlegvormen" werden geen veranderingen gesignaleerd. Bovendien werd in de groep niet-EVV'ers minder "gevarieerdheid van de afdelingsgebonden overlegvormen" aangegeven. Uit de kwalitatieve resultaten kwam naar voren dat de rol van de teamleider nog steeds prominent was tijdens het multidisciplinair overleg, de artsenvisite en in het geval van moeilijke familiecontacten. De rol van de EVV'ers was meer prominent tijdens reguliere bewoners- en familiecontacten en naar paramedische disciplines.

Hoofdstuk 6 presenteert de kwantitatieve en kwalitatieve resultaten met betrekking tot de implementatiekenmerken. Door middel van de kwantitatieve analyses konden de meest succesvolle experimentafdelingen die, ten aanzien van de implementatie van een bewonergericht zorgmodel de grootste verandering vertoonden worden onderscheiden van de minst succesvolle afdelingen. Door de mate van implementatie van een bewonergericht zorgmodel te relateren aan de implementatiekenmerken konden een aantal succescondities worden afgeleid. Op de meest succesvolle experimentafdelingen kwamen de volgende succescondities naar voren: geen vertraging in de planning; afwezigheid van afleidende factoren; stabiliteit van het afdelingshoofd; eindevaluaties op afdelingsniveau; bereidheid tot verandering onder de verplegenden en verzorgenden; en training-on-the-job door afdelingshoofden zelf. Verder bleek dat, zoals verwacht, een bewonergericht zorgmodel met meer succes was geïmplementeerd op afdelingen met afdelingshoofden met een lagere mate van instrumenteel leiderschap in de laatste fase van de implementatie. Zowel informatiekwaliteit als een sociaalemotionele leiderschapstijl kwamen tenslotte niet als succescondities naar voren.

Hoofdstuk 7 belicht de kwantitatieve resultaten met betrekking tot de taakkenmerken en de psychologische en gedragsmatige reacties. Ten aanzien van de taakkenmerken kwamen de meeste interventie-effecten niet naar voren. Ten aanzien van autonomie en verantwoordelijkheid werden na de implementatie geen veranderingen in de experimentele groep gevonden. Echter, door de twee onderliggende concepten van autonomie afzonderlijk te bekijken werd na de implementatie een trendmatige stijging in structurerende autonomie gevonden, terwijl geen verandering werd gezien met betrekking tot operationele autonomie. Ten aanzien van taakeisen kwamen verschillende resultaten naar voren. De hypothese die een stijging postuleerde kon echter niet worden bevestigd. $\mathrm{Na}$ de implementatie werd op de somatische experimentafdelingen een trendmatige stijging gevonden terwijl op de psychogeriatrische experimentafdelingen een trendmatige daling werd aangetoond. Geen extra significante resultaten werden gevonden ten aanzien van de twee onderliggende concepten kwantitatieve en kwalitatieve taakeisen. De resultaten ten aanzien van sociale steun waren eveneens gemengd. Op één van de psychogeriatrische experimentafdelingen werd de verwachte stijging bevestigd. Verder werden zowel trendmatige stijgingen als dalingen gevonden na de implementatie. Ten aanzien van sociale steun van afdelingshoofden en collega's afzonderlijk werden geen significante resultaten gevonden. Ten aanzien van de psychologische en gedragsmatige reacties konden de gepostuleerde stijgingen in arbeidstevredenheid en intrinsieke werkmotivatie en dalingen in gezondheidsklachten niet worden bevestigd. Echter, een trendmatige daling werd gevonden in ziekteverzuimfrequentie na de implementatie. Dit resultaat werd bevestigd in de groep EVV'ers. 
Hoofdstuk 8 presenteert de belangrijkste bevindingen en enige methodologische en theoretische reflecties in dit kader. Op basis van de resultaten kan worden beargumenteerd dat de interventie grotendeels structureel van aard was. Er vond geen verandering plaats met betrekking tot meer intrinsieke werkgerelateerde aspecten zoals operationele autonomie, verantwoordelijkheid, arbeidstevredenheid en intrinsieke werkmotivatie. Methodologisch moest in onze studie met een aantal problemen rekening worden gehouden zoals selectiebias en contaminatie. Door het gebruik van multivariate technieken konden achteraf een aantal problemen worden belicht. Voor de evaluatie van een organisatieverandering bleek het gebruik van methode- en datatriangulatie zeer nuttig te zijn. Door middel van kwantitatieve technieken kan inzicht worden verkregen in meer algemene veranderingen zoals structurele veranderingen. Tevens kan hiermee een gecontroleerd design worden verkregen. Kwalitatieve methoden bieden de mogelijkheid voor het verzamelen van diepte-informatie achter de schermen. Theoretisch dient op basis van de beperkte significante resultaten het volgende naar voren te worden gebracht. Ten eerste moet worden gevraagd in welke mate de taakinhoud, die grotendeels wordt bepaald door de professionele medische en verpleegkundige normen en door de vraag van bewoners, kan worden veranderd door een voornamelijk structurele interventie zoals de implementatie van bewonergerichte zorg. Ten tweede: gezonde werkomstandigheden tijdens de voormeting, beperkte taakcontrole op het beroepsniveau van de ziekenverzorgenden en externe factoren die van invloed zijn op arbeidstevredenheid en intrinsieke werkmotivatie lijken medeverantwoordelijk te zijn voor het uitblijven van significante resultaten. Ten derde: het is twijfelachtig in welke mate verplegenden en verzorgenden in staat zijn geleidelijke veranderingen in autonomie of arbeidstevredenheid op te merken en in welke mate de meetinstrumenten gevoelig genoeg waren deze op te vangen. Tenslotte: in het algemeen lijken onderliggende structurele en culturele assumpties met betrekking tot takinhoud en context de marges voor taakverrijking in de verpleging te beperken. De ontwikkeling als een professioneel beroep met een overeenkomstige maatschappelijk gewaardeerde status blijkt in de verpleegkunde problematisch te verlopen mede als gevolg van problemen in de definiering van het eigen taakdomein. In het licht van deze opmerkingen eindigt het proefschrift met aanbevelingen voor toekomstig onderzoek en met praktische aanbevelingen met betrekking tot het werk van verplegenden en verzorgenden en interventies in dit kader. 


\section{REFERENCES}

Aiken, L.S. \& West, S.G. (1991). Multiple Regression: Testing and Interpreting Interactions. Newbury Park. California: Sage Publications.

Aird, B. \& Sale, M. (1990). Agents of change. Nursing Times, 86, 10, 43-46.

Alcock, D., Lawrence, J., Goodman, J. \& Ellis, J. (1993). Formative evaluation: implementation of primary nursing. Canadian Journal of Nursing Research, 25, 3, 15-28.

Aldag, R.J. \& Brief, A.P. (1978). Examination of alternative models of job satisfaction. Human Relations, 31 , 1, 91-98.

Aldag, R.J., Barr, S.H. \& Brief, A.P. (1981). Measurement of Perceived Task Characteristics. Psychological Bulletin, 90, 3, 415-431.

Alexander, C.S., Weisman, C.S. \& Chase, G.A. (1981). Evaluating Primary Nursing in hospitals: Examination of effects on nursing staff. Medical Care, 19, 1, 80-89.

Algera, J.A. (1981). Kenmerken van werk [Job characteristics]. Lisse: Swets \& Zeitlinger.

Algera, J.A. (1983). 'Objective' and perceived task characteristics as a determinant of reactions by task performers. Journal of Occupational Psychology, 56, 95-105.

Algera, J.A. (1997). Taakkenmerken [Task Characteristics]. In: Drenth, P.J.D., Thierry, Hk. \& Wolff, Ch.J. de (Eds.), Nieuw handboek arbeids- en organisatiepsychologie, deel 1 (pp. 237-266). Houten/Diegem: Bohn Stafleu Van Loghum.

Algera, J.A., Flier, H. van der \& Kamp, L.J.Th van der (1986). Causal modelling of quality of work. In: Debus, G. \& Schroiff, H.-W. (Eds.), The Psychology of Work and Organization (pp. 175-182). Amsterdam: Elsevier Science Publishers.

Allegro, J.T. \& Kanters, H.W. (1975). Een experiment betreffende het herstruktureren van taken in een gesimuleerde organisatie-setting [An experiment regarding redesign of tasks in a simulated setting]. Mens en Onderneming, 4, 189-207.

Andries, F., Kompier, M.A.J. \& Smulders, P.G.W. (1996). Do you think that your health or safety are at risk because of your work? A large European study on psychological and physical work demands. Work and Stress, 10, 2, 104-118.

Ariëns, J.C.A., Berkhout, A.J.M.B. \& Boumans, N.P.G. (1999). De effecten van bewonergericht verplegen en verzorgen op de kwaliteit van zorg, de tevredenheid en het welzijn [The effects of resident-oriented care on quality of care, satisfaction and well-being]. Verpleegkunde, 14, 3, 151-165.

Argyris, C. (1971). Management and Organizational Development. New York: McGraw Hill.

Argyris, C. \& Schon, D. (1978). Organizational Learning: A Theory of Action Perspective. Reading, Massachusetts: Addison-Wesley.

Athlin, E. \& Norberg, A. (1987). Caregivers' attitudes to and interpretations of the behaviour of severely demented patients during feeding in a patient assignment care system. International Journal of Nursing studies, $24,2,145-153$.

Bakker, F. de (1988). De beroepsinnovator in de verpleging. Ontwikkeling van een profielschets [The professional innovator of nursing. Development of a profile]. Lochem/Gent: De Tijdstroom.

Bekkers, F. (1993). Bewonergerichte verpleegmodellen in verpleeghuizen [Resident-oriented nursing care models in nursing homes]. Tijdschrift voor Ziekenverpleging, 15, 517-519.

Bekkers, F., Bakker, F. de, Dartel, H. van, Meerman, D. \& Vliet, J. van (1990). Invoering van patiëntgericht verplegen en de kwaliteit van de verpleegkundige zorg [Implementation of patient-oriented nursing and the quality of nursing care]. Assen: Van Gorcum.

Bekkers, F., Dijk, A. van \& Roekel, W. van (1994). Kwaliteitsverbetering door patiëntgericht verplegen [Quality improvement by patient-oriented nursing]. Utrecht: Lemma.

Bekkers, F. \& Hogeling, J. (1994). Invoering van bewonersgerichte zorg: verslag van een studieconferentie van de Hogeschool Nijmegen en Verpleeghuis Oranje Nassau's Oord [Implementation of patient-oriented care: report of a research study conference of Nijmegen School of Nursing and Oranje Nassau's Oord Nursing Home]. Nijmegen: Centrum voor Beroepsinnovatie en Methodiekontwikkeling, afdeling Dienstverlening en Onderzoek. 
Benne, K.D. \& Chin, R. (1986). Een typologie van veranderingsstrategieën [A typology of strategies of change]. In: Cozijnsen, A. J. \& Vrakking, W.J. (Eds.), Handboek voor strategisch innoveren: een internationale balans (pp. 51-70). Deventer: Kluwer.

Bennis, W.G., Benne, K.D. \& Chin, R. (1973). The Planning of Change (2nd edition). London, New York, Sydney, Toronto: Holt, Rinehart \& Winston.

Bent, J. van der \& Windt, W. van der (1998). Personeel in de gezondheidszorg 2. Feiten en prognoses [Personnel in health care 2. Facts and prognoses]. Utrecht: Nederlandse Zorgfederatie.

Bergers, G.P.A., Marcelissen, F.H.G. \& Wolff, Ch.J. de (1986). VOS-D. Vragenlijst Organisatiestress-D: handleiding [VOS-D. Work stress questionnaire Doetinchem]. Nijmegen: Katholieke Universiteit Nijmegen.

Berkhout, A.J.M.B. (1990). Modern Times. Een verslag van een onderzoek naar het werk en de werkbeleving van verpleegkundigen. Doctoraalscriptie [Modern Times. A report of a study into the work and work experience of nurses. Masters' thesis]. Maastricht: Rijksuniversiteit Limburg.

Berkhout, A.J.M.B., Boumans, N.P.G., Breukelen, G.J.P. van, Nijhuis, F.J.N. \& Huijer Abu-Saad, H. (1998a). Effects of resident-oriented care on job characteristics of nursing caregivers. Manuscript submitted for publication.

Berkhout, A.J.M.B., Boumans, N.P.G. \& Landeweerd, J.A. (1998b). Evaluatie van bewonergericht verplegen en verzorgen in verplecghuizen. Eindrapport [Evaluation of resident-oriented care in nursing homes. Final report]. Maastricht: Universiteit Maastricht.

Berkhout, A.J.M.B., Boumans, N.P.G., Nijhuis, F.J.N. \& Huijer Abu-Saad, H. (in preparation). Effects of resident-oriented care on job characteristics of nursing caregivers and on their psychological and behavioural reactions. In: Jonge, J. de, Vlerick, P., Büssing, A. \& Schaufeli, W.B. (Eds.) (in preparation), Organizational Psychology and Health Care at the Start of a New Millenium. Mering: Rainer Hampp Verlag. Editing procedure in progress (publication date: 2001).

Betz, M. (1981). Some hidden costs of primary nursing. Nursing \& Health Care, 2, 3, 150-154.

Blair, F., Sparger, G., Walts, L. \& Thompson, J. (1982). Primary nursing in the emergency department: nurse and patient satisfaction. Journal of Emergency Nursing, 8, 36-37.

Blenkarn, H., d'Amico, M. \& Virtue, E. (1988). Primary nursing and job satisfaction. Nursing Management, 19, 4, 41-42.

Boeije, H.R. (1994). Kwaliteit van zorg in verpleeghuizen: een onderzoek naar problemen en strategieën van verzorgenden [Quality of care in nursing homes: a study on problems and strategies of nursing caregivers]. Utrecht: De Tijdstroom.

Boeije, H.R., Dungen, A.W.L. van den, Pool, A., Grypdonck, M.H.F. \& Lieshout, P.A.H. van (1997). Een verzorgde toekomst. Toekomst scenario's voor verpleging en verzorging [A well-cared-for future. Future scenarios for nursing care]. Utrecht: De Tijdstroom.

Boekholdt, M.G. (1981). Invoeren van groepsverpleging: een organisatie veranderkundig onderzoek op enkele afdelingen van een algemeen ziekenhuis [Implementation of team nursing: a study of an organisational change on a few departments of a general hospital]. Utrecht: NZI nr. 81.273.

Boekholdt, M.G. (1983a). Een goed idee, en dan... (I) [A good idea, and then...(I)]. Tijdschrift voor Ziekenverpleging, 7, 194-198.

Boekholdt, M.G. (1983b). Een goed idee, en dan... (II) [A good idea, and then...(II)]. Tijdschrift voor Ziekenverpleging, 8, 235-239.

Boekholdt, M.G. (1990). Organisatievormen van verpleging [Organisational forms in nursing]. In: Gijn, M. van (Eds.), Wegwijs in de gezondheidszorg: handboek voor verpleegkundigen (p.138-147). Houten/Antwerpen: Bohn Stafleu Van Loghum.

Bond, S., Bond, J., Fowler, P. \& Fall, M. (1991a). Evaluating Primary Nursing (Part 1). Nursing Standard, 5, 36, 35-39.

Bond, S., Bond, J., Fowler, P. \& Fall, M. (199lb). Evaluating Primary Nursing (Part 2). Nursing Standard, 5, 37, 37-39.

Bond, S., Bond, J., Fowler, P. \& Fall, M. (199lc). Evaluating Primary Nursing (Part 3). Nursing Standard, 5, 38, 36-39.

Boumans, N.P.G. (1990). Het werk van verpleegkundigen in algemene ziekenhuizen: een onderzoek naar werkaspecten en hun invloed op verpleegkundigen. Dissertatie [Nurses' work in general hospitals: a study of work aspects and their influence on nurses. Dissertation]. Maastricht: Datawyse.

Boumans, N.P.G. \& Landeweerd, J.A. (1992). The role of social support and coping behaviour in nursing work: main or buffering effect? Work and Stress, 6, 2, 191-202.

Boumans, N.P.G. \& Landeweerd, J.A. (1999). Nurses' Well-being in a Primary Nursing Care Setting in the Netherlands. Scandinavian Journal of Caring Science, 13, 116-122. 
Bowers, L. (1989). The significance of Primary Nursing. Journal of Advanced Nursing, 14, 13-19.

Brannon, R.L. (1990). The reorganization of the nursing labor process: from team to primary nursing. International Health Services, 20, 3, 511-524.

Breaugh, J.A. (1985). The measurement of job autonomy. Human Relations, 38, 551-570.

Broadbent, D.E. (1985). The clinical impact of job design. British Journal of Clinical Psychology, 24, 33-44.

Brock, A. \& O'Sullivan, P. (1988). A study to determine the Relationship Between the Method of Organizing Nursing Care Delivery and Job Satisfaction of Nursing Personnel. Nursing Connections, 1, 1, 31-41.

Buchel, Y.H.M. \& Roestel, A.M.A. van (1986). Patiëntgericht verplegen: Effecten van een reorganisatie op verpleegafdelingen [Patient-oriented care: Effects of a reorganisation on nursing wards]. Tilburg: Maria Ziekenhuis.

Bucsink, E.G.H.M. (1993). Effecten van de invoering van integrerende verpleegkunde. Doctoraalscriptie [Effects of the implementation of integrated nursing. Masters' thesis]. Maastricht: Universiteit Maastricht.

Burke, W.W. (1982). Organisation development. Principles and practices. Boston/Toronto: Little, Brown \& Company.

Caplan, R.D., Cobb, S., French, J.R.P. Jr., Harrison, R.V. \& Pinneau, S.R. Jr. (1980). Job Demands and Worker Health. Ann Arbor, Michigan: University of Michigan.

Caplan, G. (1981). Mastery of stress: Psychosocial aspects. American Journal of Psychiatry, 138, 413-419.

Carayon, P. (1993). A longitudinal test of Karasek's job strain model among office workers. Work and Stress, 7, 299-314.

Carayon, P. \& Zijlstra, F. (1999). Relationship between job control, work pressure and strain: studies in the USA and in the Netherlands. Work and Stress, 13, 1, 32-48.

Carlsen, R.H. \& Malley, J.D. (1981). Job Satisfaction of Staff Registered Nurses in Primary and Team Nursing Delivery Systems. Research in Nursing and Health, 4, 251-260.

Chavassc, J. (1981). From task assignment to patient allocation: a change evaluation. Journal of Advanced Nursing, 6, 137-145.

Chavigny, K. \& Lewis, A. (1984). Team or Primary Nursing care? Nursing Outlook, 32, 6, 322-327.

Chin, R. (1973). The utility of system models and developmental models for practitioners. In: Bennis, W.G., Benne, K.D. \& Chin, R. (Eds.), The Planning of Change (pp. 297-312). London, New York, Sydney, Toronto: Holt, Rinchart \& Winston.

Chin, R. \& Benne, K.D. (1973). General strategies for effecting changes in human systems. In: Bennis, W.G., Benne, K.D. \& Chin, R. (Eds.), The Planning of Change (pp. 32-57). London, New York, Sydney, Toronto: Holt, Rinehart \& Winston.

Commissie Kwalificatiestructuur (1996). Gekwalificeerd voor de toekomst. Kwalificatiestructuur en cindtermen voor Verpleging en Verzorging [Qualification Structure Committee: Qualified for the future. Qualification structure and final terms for nursing care]. Zoctermeer/Rijswijk: Ministerie van Onderwijs, Cultuur en Wetenschappen en ministerie van Welzijn, Volksgezondheid en Sport.

Cook, T.D. \& Campbell, D.T. (1979). Quasi-Experimentation. Design \& Analysis Issues for Field Settings. Boston: Houghton Mifflin Company.

Cordery, J.L. \& Wall, T.D. (1985). Work Design and Supervisory Practice: A Model. Human Relations, 38, 5, 425-441.

Cozijnsen, A.J. \& Ezerman, G.C. (1986). Automatisering als beheerst implementatieproces [Automation as a controlled implementation process]. In: Cozijnsen, A. J. \& Vrakking, W.J. (Eds.), Handboek voor strategisch innoveren: een internationale balans (p. 255-267). Deventer: Kluwer.

Cozijnsen, A.J. \& Hoksbergen, R. (1986). Innoveren binnen schoolorganisaties [Innovation in school organisations]. In: Cozijnsen, A. J. \& Vrakking, W.J. (Eds.), Handboek voor strategisch innoveren: een internationale balans (p. 221-231). Deventer: Kluwer.

Cozijnsen, A.J. \& Vrakking, W.J. (1986). Vernieuwingen in de jaren ' 80 en '90 [Innovation in the eighties and nineties]. In: Cozijnsen, A. J. \& Vrakking, W.J. (Eds.), Handbock voor strategisch innoveren: een internationale balans (p. 19-28). Deventer: Kluwer.

Cozijnsen, A.J. \& Vrakking, W.J. (1995). Ontwerp en Invoering. Strategieën voor organisatieverandering [Design and implementation: Strategies for organisational change]. Alphen aan den Rijn/Diegem: Samson.

Cummings, T.G. \& Huse, E.F. (1989). Organisation Development and Change. St. Paul: West Publishing Company.

Davis, B.D., Billings, J.R. \& Ryland, R.K. (1994). Evaluation of nursing process documentation. Journal of Advanced Nursing, 19, 960-968. 
Degerhammer, M. \& Wade, B. (1991). The introduction of a new system of care delivery into a surgical ward in Sweden. International Journal of Nursing Studies, 28, 4, 325-336.

Dirken, J.M. (1967). Arbeid en stress: het vaststellen van aanpassingsproblemen in werksituaties [Work and stress: the determination of adaptation problems in work situations]. Groningen: Tjeenk Willink.

Doef, M. van der \& Maes, S. (1998). The job demand-control (-support) model and physical health outcomes: a review of the strain and buffer hypotheses. Psychology and Health, 13, 909-936.

Dwyer, D.J. \& Ganster, D.C. (1991). The effects of job demands and control on employee attendance and satisfaction. Journal of Organizational Behavior, 12, 595-608.

Eijnatten, F.M. van \& Zwaan, A.H. van der (1998). The Dutch IOR Approach to Organizational Design: An Alterlative to Business Process Re-engineering? Human Relations, 51, 3, 289-318.

Eindhoven, A. van (1979). Een systeem van eerstverantwoordelijke verpleegkundige [A system of primary responsible nurse]. Lochem: De Tijdstroom.

Emans, B. \& Boer, D.J. den (1988). Integrerende verpleegkunde en de relatic tussen verpleegkundigen en leidinggevenden [Integrated nursing and the relationship between nurses and management]. Acta Hospitalia, $28,1,5-15$.

Emery, F.E. \& Thorsrud, E. (1976). Democracy at Work. The report of the Norwegian industrial democracy program. Leiden: Martinus Nijhoff Social Sciences Divisions.

Estryn-Behar, M., Kaminski, M., Peigne, E., Bonnet, N., Vaichere, E., Gozlan, C., Azoulay, S. \& Giorgi, M. (1990). Stress at work and mental health status among femalc hospital workers. British Journal of Industrial Medicine, 47, 20-28.

Fairbanks, J.E. (1980). Primary Nursing: more data. Nursing Administration Quarterly, 5, 51-62.

Fletcher, B. \& Jones, F. (1993). A refutation of Karasek's demand-discretion model of occupational stress with a range of dependent measures. Journal of Organizational Behavior, 14, 319-330.

Frank, L.L \& Hackman, J.R. (1975). A Failure of Job Enrichment: The Case of the Change That Wasn't. Journal of Applied Behavorial Science, 11, 4, 413-436.

French, W. (1969). Organisation Development: Objectives, Assumptions, and Strategies. California Management Review, 12, 23-34.

Frese, M. (1989). Theoretical Models of Control and Health. In: Sauter, S.L., Hurrell, J.J.Jr. \& Cooper, C.L. (Eds.). Job Control and Worker Health (pp. 107-128). Chichester: Wiley \& Sons.

Frese, M. \& Zapf, D. (1988). Methodological Issues in the Study of Work Stress: Objective vs. Subjective Measurement of Work Stress and the Question of Longitudinal Studies. In: Cooper, C.L. \& Payne, R. (Eds.), Causes, Coping and Consequences of Stress at Work (pp. 375-411). Chichester: John Wiley \& Sons.

Fried, Y. \& Ferris, G.R. (1986). The Dimensionality of Job Characteristics: Some Neglected Issues. Journal of Applied Psychology, 71, 3, 419-426.

Fried, Y. \& Ferris, G.R. (1987). The validity of the job characteristics model: A review and meta-analysis. Personnel Psychology, 40, 287-322.

Fox, M.L., Dwyer, D.J. \& Ganster, D.C. (1993). Effects of stressful job demands and control on physiological and attitudinal outcomes in a hospital setting. Academy of Management Journal, 36, 2, 289-318.

Frohman, A., Sashkin, M. \& Kavanagh, M. (1976). Action Research as Applied to Organisation Development. Organisation and Administrative Sciences, 7, 129-142.

Furlong, S.L. (1994). Primary nursing: a new philosophy. British Journal of Nursing, 3, 13, 668-671.

Ganster, D.C. (1989). Worker Control and Well-Being: A Review of Research in the Workplace. In: Sauter, S.L., Hurrell, J.J.Jr. \& Cooper, C.L. (Eds.), Job Control and Worker Health (pp. 3-23). Chichester: John Wiley \& Sons.

Ganster, D.C. \& Fusilier, M.R. (1989). Control in the workplace. In: Cooper, C.L. \& Robertson, I.T. (Eds.), International Review of Industrial and Organizational Psychology (pp. 235-280). Chichester: John Wiley \& Sons.

Gardell, B. (1977). Autonomy and Participation at Work. Human Relations, 30, 6, 515-533.

Gardell, B. (1982). Worker participation and autonomy: a multi-level approach to democracy at the workplace. International Journal of Health Services, 12, 4, 527-558.

Gardner, K. (1991). A summary of findings of a five-year comparison study of Primary and Team Nursing. Nursing Research, 40, 2, 113-117.

Giovannetti, P. (1980). A comparison of team and primary nursing care systems. Nursing Dimensions, 7, 96100.

Giovannetti, P. (1986). Evaluation of primary nursing. In: Weilty, H., Fitzpatrick, J.J. \& Taunton, R.L. (Eds.), Annual Review of Nursing Research (Vol. 4, pp. 127-151). New York: Springer. 
Gray-Toft, P. \& Anderson, J.G. (1981). Stress among hospital nursing staff: its causes and effects. Social Science and Medicine, 15A, 639-647.

Graham, H. \& Liveslcy, B. (1983). Dying as a diagnosis: difficulties of communication and management in elderly patients. The Lancet, September 17, 670-672.

Grypdonck, M. (1980). Theory and research in a practice discipline: the case of nursing. Dissertation. Manchester: University of Manchester.

Gulowsen, J. (1979). A Measure of Work-Group Autonomy. In: Davis, L.E. \& Taylor, J.C. (Eds.), Design of Jobs. Santa Monica: Goodyear.

Guppy, A. \& Gutteridge, T. (1991). Job satisfaction and occupational stress in UK general hospital nursing staff. Work and Stress, 5, 4, 315-323.

Hackman, J.R. \& Lawler III, E.E. (1971). Employee reactions to job characteristics. Journal of Applied Psychology Monograph, 55, 259-286.

Hackman, J.R. \& Oldham, G.R. (1975). Development of the Job Diagnostic Survey. Journal of Applied Psychology, 2, 159-170.

Hackman, J.R. \& Oldham, G.R. (1976). Motivation through the design of work: test of a theory. Organizational Behavior and Human Performance, 16, 250-279.

Hackman, J.R. \& Oldham, G.R. (1980). Work redesign. Reading, Massachusetts: Addison-Wesley Publishing Company.

Harc, J., Pratt, C.C. \& Andrews, D. (1988). Predictors of burnout in professional and paraprofessional nurses working in hospitals and nursing homes. International Journal of Nursing Studies, 25, 2, 105-115.

Hawthorne, J., Roe C. \& Woods, D. (1989). The professional Practice Climate and Peer Review. Nursing Connections, 2, 1, 47-54.

Hecremans, J.G.M., Boumans, N.P.G., Algera, M. \& Landeweerd, J.A. (1994). Integrerende Verpleegkunde in de Praktijk: resultaten van een experiment in een algemeen ziekenhuis [Integrated Nursing into practice: Results of an experiment in a general hospital]. Maastricht: Rijksuniversiteit Limburg.

Hegedus, K.S. (1980). Primary Nursing: Evaluation of Professional Nursing Practice. Nursing Dimensions, 7, 4, 85-89.

Hegyvary, S.T. (1982). The Change to Primary Nursing. St. Louis: Mosby.

Herzberg, F., Mausner, B. \& Snyderman, B.B. (1959). The motivation to work. New York: John Wiley \& Sons.

Hipwell, A.E., Tyler, P.A. \& Wilson, C.M. (1989). Sources of stress and dissatisfaction among nurses in four hospital environments. British Journal of Medical Psychology, 62, 71-79.

Hoffart, N., Schultz, A.W. \& Ingersoll, G.L. (1995). Implementation of a professional practice model for nursing in a rural hospital. Health Care Management Review, 20, 3, 43-54.

Houkes, I., Janssen, P.P.M., Jonge, J. de \& Nijhuis, F.J.N. (1997). Verbanden tussen werkkenmerken en reacties: Een literatuurstudie naar specifieke determinanten van motivatie, gezondheid en verloop [Associations between job characteristics and reactions: A literature review on specific determinants of motivation, health and turnover]. Bedrijfsgezondheidszorgstudies, 12. Maastricht: Universiteit Maastricht.

House, J.S. (1981). Work, Stress and Social Support. Reading, MA: Addison Wesley.

Hurrell, J.J. Jr. \& McLaney, M.A. (1989). Control, Job demands, and Job Satisfaction. In: Sauter, S.L., Hurrell, J.J.Jr. \& Cooper, C.L. (Eds.), Job Control and Worker Health (pp. 97-103). Chichester: John Wiley \& Sons.

Janssen, P.P.M. (1992). Relatieve deprivatie in de middenloopbaanfase bij hoger opgeleide mannen: een vergclijking tussen drie leeftijdsgroepen. Dissertatie [Relative deprivation in midcareer among highly educated men: a comparison between three age groups. Dissertation]. Maastricht: Datawysc.

Janssen, P.P.M., Jonge, J. de \& Bakker, A.B. (1999a). Specific determinants of intrinsic work motivation, burnout and turnover intentions: a study among nurses. Journal of Advanced Nursing, 29, 6, 1360-1369.

Janssen, P.P.M., Schaufeli, W.B. \& Houkes, I. (1999b). Work-related and individual determinants of the three burnout dimensions. Work and Stress, 13, 1, 74-86.

Janssen, P.P.M., Nijhuis, F.J.N., Peeters, M.C.W. \& Jonge, J. de (1996). Intrinsieke werkmotivatie: een heroriëntatie op het begrip en een verklaring vanuit de motivatie- en taakkenmerken benadering [Intrinsic work motivation: a reconsideration of the concept and an explanation from the motivation- and job characteristics perspective]. Gedrag en Organisatie, 9, 5, 290-304.

Janssen, P.G.M. (1996). Differentiated practice and specialization in community nursing. Dissertation. Utrecht: NIVEL.

Jewell, S. (1996). Elderly patients' participation in discharge decision making: 1. British Journal of Nursing, 5, 15, 914-932. 
Johns, C. (1990). Autonomy of primary nurses: the need to both facilitate and limit autonomy in practice. Journal of Advanced Nursing, 155, 886-894.

Johnson, J.V. \& Hall, E.M. (1988). Job strain, work place social support and cardiovascular disease in Sweden: a cross-sectional study of a random sample of the Swedish working population. American Journal of Public Health, 78, 10, 1336-1342.

Johnson, J.V. \& Hall, E.M. (1994). Social Support in the Work Environment and Cardiovascular Disease. In: Shumaker, S.A. \& Czajkowski, S.M. (Eds.), Social support and cardiovascular disease (pp. 145-166). New York: Plenum Press.

Johnson, J.V., Hall, E.M., Ford, D.E., Mead, L.A., Levine, D.M., Wang, Nae-Yuh \& Klag, M.J. (1995). The Psychosocial Work Environment of Physicians. Journal of Occupational and Environmental Medicine, 37, $9,1151-1159$.

Johnson, J.V., Hall, E.M. \& Theorell, T. (1989). Combined effects of job strain and social isolation on cardiovascular diseasc, morbidity and mortality in a random sample of the Swedish male working population. Scandinavian Journal of Work, Environment, \& Health, 15, 271-279.

Joiner, C., Johnson, V. \& Corkrean, M. (1981). Is Primary Nursing the answer? Nursing Administration Quarterly, 5, 3, 69-76.

Jong, R.D. de, Voorendonk, R.H., Boogaarts, F.P., Blanc, P.M. le, Ouden, M.D. den \& Spuijbroek, P.A. (1996). De situationcle leiderschapstheoric: Garantie voor effectiviteit, satisfactic en gezondheid? [The situational leadership theory: Guarantee for effectiveness, satisfaction and health?]. Gedrag en Organisatic, 9, 5, 277289.

Jonge, J. de (1995). Job autonomy, well-being and health: a study among Dutch health care workers. Dissertation. Maastricht: Datawyse/Universitaire Pers.

Jonge, J. de, Blanc, P.M. Le, Sclraufeli, W.B. \& Linden, S. van der (1998). Verandering in werkkenmerken in relatie tot verandering in burnout en arbeidstevredenheid [Change in job characteristics in relation to change in burnout and job satisfaction]. Gedrag en Organisatic, 11, 3, 121-134.

Jonge, J. de, Breukelen, G.J.P. van, Landeweerd, J.A. \& Nijhuis, F.J.N. (1999a). Comparing Group and Individual Level Assessments of Job Characteristics in Testing the Job Demand-Control Model: A Multilevel Approach. Human Relations, 52, 1, 95-122.

Jonge, J. de, Janssen, P.P.M. \& Breukelen, G.J.P. van (1996). Testing the Demand-Control-Support Model among health-care professionals: a structural equation model. Work and Stress, 10, 3, 209-224.

Jonge, J. de, Janssen, P. \& Landeweerd, A. (1994). Effecten van werkdruk, autonomie, en sociale ondersteuning op de werkbeleving van verplegenden en verzorgenden [Effects of workload, autonomy, and social support on psychological outcomes of nurses and nurses' aides]. Verpleegkunde, 9, 1, 17-27.

Jonge, J. de, Kompier, M., Furda, J. \& Reuvers, M. (1997). Psychosociale werkkenmerken en gezondheid: een kritische beschouwing over het Demand-Control-Support-model [Psychosocial job characteristics and health: A critical examination of the demand-control-support model]. Nederlands Tijdschrift voor de Psychologie, 52, 47-56.

Jonge, J. de, Landeweerd, J.A. \& Nijhuis, F.J.N. (1995a). Constructie en validering van de vragenlijst ten behoeve van het project "autonomie in het werk" [Construction and validation of the questionnaire for the "job autonomy project"]. Studies Bedrij fsgezondheidszorg nummer 9 (tweede, gewijzigde druk). Maastricht: Rijksuniversiteit Limburg.

Jonge, J. de, Schaufeli, W.B. \& Furda, J. (1995b). Werkkenmerken: psychologische arbeidsvitamines? [Job characteristics: psychological work vitamins?]. Gedrag en Organisatie, 8, 4, 231-248.

Jonge, J. de, Mulder, M.J.G.P. \& Nijhuis, F.J.N. (1999b). The incorporation of different demand concepts in the job demand-control model: effects on health care professionals. Social Science \& Medicine, 48, $1149-1160$.

Jupp, M.R. (1994). Management review of nursing systems. Journal of Nursing Management, 2, 57-64.

Kaban, L. \& Thompson, G. (1990). Primary nursing on a psycho-geriatric unit. Nursing Management, 21, 7, 7981 .

Kahn, R.L. \& Antonucci, T. (1980). Convoys over the Life Course: Attachment, Roles and Social Support. In: Baltes, P.B. \& Brim, O. (Eds.), Life-Span Development and Behavior, Volume 3 (pp. 253-286). New York: Academic Press.

Kahn, R.L. \& Boysiere, P. (1994). Stress in organizations. In: Dunette, M.D., Hough, J.M. \& Triandis, H.C. (Eds.), Handbook of Industrial and Organizational Psychology (pp. 1-53). New York: Wiley.

Kapteyn, B. (1996). Probleemoplossing in organisaties. Theorie en praktijk [Problem solving in organisations. Theory and practice]. Houten/Diegem: Bohn Stafleu Van Loghum.

Karasek, R.A., Jr. (1979). Job Demands, Job Decision Latitude, and Mental Strain: Implications for Job Redesign. Administrative Science Quarterly, 24, 2, 285-308. 
Karasck, R. (1989). Control in the Workplace and its Health-related Aspects. In: Sauter, S.L., Hurrell, J.J. Jr. \& Cooper, C.L. (Eds.), Job Control and Worker Health (pp. 129-159). Chichester: Wiley \& Sons.

Karasek R. (1990). Lower health risk with increased job control among white-collar workers. Journal of Occupational Behavior, 11, 171-185.

Karasek, R. (1992). Stress prevention through work reorganization: A summary of 19 international case studies. Conditions of Work Digest, 11, 23-41.

Karasek, R.A. \& Theorell, T. (1990). Healthy work: stress, productivity and the reconstruction of working life. New York: Basic Books.

Karasek, R.A., Triantis, K.P. \& Chaudry, S.S. (1982). Coworker and supervisor support as moderators of associations between task characteristics and mental strain. Journal of Occupational Behaviour, 3, 181-200.

Kasl, S.V. (1987). Methodologies in Stress and Health: Past Difficulties, Present Dilemmas, Future Directions. In : Kasl, S.V. \& Cooper, C.L. (Eds.), Stress and Health: Issues in Research Methodology (pp. 307-318). Chichester: Wiley \& Sons.

Keiser, J. G. \& Bickle, I.M. (1980). Attitude Change as a Motivational Factor in Producing Behavior Change Related to Implementing Primary Nursing. Nursing Rescarch, 29, 5, 290-294.

Kelly, J. (1992). Does Job Re-design Theory Explain Job Re-design Outcomes? Human Relations, 45, 8, 753 774.

Killman, R.H., Saxton, M.J. \& Serpa, R. (1986). Issues in Understanding and Changing Culture. California Management Revicw, 28, 2, 87-94.

Kivimäki, M., Voutilainen, P. \& Koskinen, P. (1995). Job enrichment, work motivation and job satisfaction in hospital wards: testing the job characteristics model. Journal of Nursing Management, 3, 87-91.

Kleinbaum, D.G., Kupper, L.L., Muller, K.E. \& Nizam, A., (1998). Applied Regression Analysis and Multivariate methods. California: Brooks/Cole Publishing Company.

Koene, G., Grypdonck, M., Rodenbach, M.Th. \& Windey, T. (1982). Integrerende Verpleegkunde: wetenschap in praktijk [Integrated nursing: science in practice]. Lochem: De Tijdstroom.

Kompier, M.A.J. \& Marcelissen, F.H.G. (1991). Handboek werkstress. Systematische aanpak voor de bedrijfspraktijk [Handbook work stress. Systematic approach for the business practice]. Amsterdam: Nederlands Instituut voor Arbeidsomstandigheden.

Koopman, P.L. \& Pool, J. (1986). De bestuurbaarheid van besluitvormingsprocessen bij vemieuwing [The controllability of decision making processes during innovation]. In: Cozijnsen, A. J. \& Vrakking, W.J. (Eds.), Handboek voor strategisch innoveren: een internationale balans (p. 178-194). Deventer: Kluwer.

Kuipers, H. \& Amelsfoort, P. van (1990). Slagvaardig organiseren. Inleiding in de socio-techniek als integrale ontwerpleer [Decisive organising. Introduction in the socio-technique as an integral design theory]. Deventer: Kluwer.

Kuipers, H. \& Eijnatten, F.M. van (1996). Moderne sociotechniek, een stand van zaken [Modern sociotechnique, a state of the art]. In: Eijnatten, F.M. van (Eds.), Sociotechnisch ontwerpen (pp. 32-57). Utrecht: Lemma BV.

Landeweerd, J.A. \& Boumans, N.P.G. (1994). The effect of work dimensions and need for autonomy on nurses' work satisfaction and health. Journal of Occupational and Organizational Psychology, 67, 207-217.

Landsbergis, P.A. (1988). Occupational stress among health care workers: A test of the job demands-control model. Joumal of Organizational Bchavior, 9, 217-239.

Landsbergis, P.A., Schnall, P.L., Deitz, D., Friedman, R. \& Pickering, T. (1992). The Patterning of Psychological Attributes and Distress by "Job strain" and Social Support in a Sample of Working Men. Journal of Behavioral Medicine, 15, 4, 379-405.

Landsbergis, P.A. \& Vivona-Vaughan, E. (1995). Evaluation of an occupational stress intervention in a public agency. Journal of Organizational Behavior, 16, 1, 29-48.

Lawrence, P.R. \& Lorsch, J.W. (1967). Organization and Environment: Managing Differentiation and Integration. Boston: Division of Research, Harvard Business School.

Leppänen, R.A. \& Oikinuora, M.A. (1987). Psychological stress experienced by health care personnel. Scandinavian Journal of Work and Environmental Health, 13, 1-8.

Levert, A.J. (1973). Groepsverpleging in theorie en praktijk [Team nursing in theory and practice]. Het Ziekenhuis, 3, 5, 271-277.

Lewin, K. (1951). Field Theory in Social Science. New York: Harper and Row.

Likert, R. (1961). New Patterns of Management. New York: McGraw-Hill.

Likert, R. (1967). The Human Organization. New York: McGraw-Hill. 
Lippitt, R., Watson, J. \& Westley, B. (1958). The Dynamics of Planned Change. New York: Harcourt, Brace \& World.

Locke, E.A. (1969). What is job satisfaction? Organizational Behavior and Human Performance, 4, 309-336.

Loher, B.T., Noc, R.A., Moeller, N.L. \& Fitzgerald, M.P. (1985). A Meta-Analysis of the Relation of Job Characteristics to Job Satisfaction. Joumal of Applied Psychology, 70, 280-289.

MacDonald, M. (1988). Primary nursing: is it worth it? Journal of Advanced Nursing, 13, 797-806.

MacGuirc, J. (1989). An approach to evaluating the introduction of primary nursing in an acute medical unit for the elderly-I. Principles and practice. International Journal of Nursing Studies, 26, 3, 243-251.

MacGuire, J.M. \& Botting, D.A. (1990). The use of the ethnograph program to identify the perceptions of nursing staff following the introduction of primary nursing in an acutc medical ward for the elderly people. Journal of Advanced Nursing, 15, 1120-1127.

Manley, K., Cruse, S. \& Keogh, S. (1996). Job satisfaction of intensive care nurses practising primary nursing. A comparison with those practising total patient care. Nursing in Critical Care, 1, 1, 31-41.

Manthey, M. (1980). The Practice of Primary Nursing. Boston: Blackwell Scientific Publications.

Marram, G., Flynn, K., Abaravich, W. \& Carey, S. (1976). Cost effectiveness of Primary \& Team Nursing. Wakefield: Massachusetts.

Marram, G., Barrett, M.W. \& Bevis, E.O. (1979). Primary Nursing. A model for individualized care (second edition). St. Louis: The C.V. Mosby Company.

Maslow, A.H. (1954). Motivation and Personality. New York: Harper and Row.

Maso, I. (1989). Kwalitatief onderzock [Qualitative research]. Meppel/Amsterdam: Boom.

Mast, F., Roelink, M.E., Boumans, N.P.G. \& Berkhout, A.J.M.B. (1997). Bewonergericht verplegen in het verpleeghuis: het testen van cen meetinstrument [Resident-oriented care in the nursing home: the testing of a measuring instrument]. Verpleegkunde, 12, 3, 160-172.

McCormack, B. (1992). A case study identifying nursing staffs' perception of the delivery method of nursing care in practice on a particular ward. Journal of Advanced Nursing, 17, 187-197.

McGrath, A., Reid, N. \& Boore, J. (1989). Occupational stress in nursing. International Journal of Nursing Studies, 26, 4, 343-358.

McGrecvy, M. \& Coates, M.R. (1980). Primary nursing implementation using the project nurse and the nursing process from work. Journal of Nursing Administration, 2, 9-15.

McGregor, D. (1960). The Human Side of Enterprise. New York: McGraw-Hill.

McMahon, R. (1989). One to one. Nursing Times, 85, 2, 39-40.

McMahon, R. (1996). Individual vs. collective activity: a primary nursing paradox. British Journal of Nursing, 5 , 12, 760-763.

McPhail, A., Pikula, H., Roberts, J., Browne, G. \& Harper, D. (1990). Primary nursing: a randomized crossover trial. Western Journal of Nursing Research, 12, 2, 188-200.

Mead, D. (1990). Research report: collegial relationships among primary and associate nurses. Nursing Times, $17,86,68$.

Melamed, S., Kushnir, T. \& Meir, E.I. (1991). Attenuating the impact of job demands: Additive and interactive effects of perceived control and social support. Journal of Vocational Behavior, 39, 40-53.

Melchior, M.E.W. (1996). Burnout and Work in long-stay psychiatric nursing. Dissertation. Maastricht: Datawyse Universitaire Pers Maastricht.

Melchior, M.E.W., Halfens, R.J.G., Huijer Abu-Saad, H., Philipsen, H., Berg, A.A. van den \& Gassman, P. (1999). The effects of primary nursing on work-related factors. Journal of Advanced Nursing, 29, 1, 88-96.

Menzies, I.E.P. (1960). A Case-Study in the Functioning of Social Systems as a Defence against Anxiety. Human Relations, 13, 95-121.

Mercx, R.J.M. (1975). Groepsverpleging en groepsverpleging: cen organisatiekundige analysc en classificatic [Team nursing and team nursing: an organisational analysis and classification]. Tijdschrift voor Ziekenverpleging, 28, 181-187.

Metcalf, C.A. (1986). Job satisfaction and organizational change in a maternity hospital. International Journal of Nursing studies, 23, 4, 285-298.

Molleman, E. (1989). De organisatie van de verpleegkundige zorg in verandering: Een onderzoek naar de gevolgen van Integrerende Verpleegkunde. Proefschrift [The organisation of the nursing care during change: a study on the effects of Integrated Nursing. Dissertation]. Groningen: Drukkerij Rijksuniversiteit Groningen. 
Molleman, E. (1992). Decentralisation and participation. Shift in influence and the expansion of influence. Gedrag en Organisatic, 2, 79-93.

Moyle, P. (1998). Longitudinal influences of managerial support on employee well-being. Work and Stress, 12 , 1, 29-49.

Nievaard, A.C. (1982). Aspecten van verpleegsystemen en de begeleiding van ziekenhuispatiënten [Aspects of nursing care systems and the support of hospital patients]. Gezondheid en Samenleving, 3, 86-95.

Nunnally, N.C. (1978). Psychometric theory. New York: McGraw-Hill.

Parasuraman, S., Drake, B. \& Zammuto, R.F. (1982). The effect of Nursing Care Modalities and Shift Assignments on Nurses' Work Experiences and Job Attitudes. Nursing Research, 31, 6, 364-367.

Parkes, K.R. \& Rabenau, C. von (1993). Work Characteristics and Well-being Among Psychiatric Health-Care Staff. Journal of Community \& Applied Psychology, 3, 243-259.

Parkes, K.R., Mendham, C.A. \& Rabenau, C. von (1994). Social Support and the Demand-Discretion Model of Job Stress: Tests of Additive and Interactive Effects in Two Samples. Journal of Vocational Behavior, 44, 91-113.

Pascale, R.T. \& Athos, A.G. (1981). The Art of Japanese Management. Applications for American executives. New York: Warner Books.

Pearson, C.A.L. (1987). Participative Goal Setting as a Strategy for Improving Performance and Job Satisfaction: A Longitudinal Evaluation with Railway Track Maintenance Gangs. Human Relations, 40, 8, 473-488.

Peiró, J.M., González-Romá, V., Ramos, J. \& Zornoza, A. (1996). Relationships between leadership and professionals' job attitudes and perceptions: comparison of two leadership models. Work and Stress, 10, 3, $195-$ 208.

Perälä, M.-L. (1989). Nurse-Patient Interaction in Primary Nursing. Värd I Norden 2, 15, 9, $10-17$.

Perälä, M.-L. \& Hentinen, M. (1989). Primary nursing: opinions of nursing staff before and during implementation. International Journal of Nursing Studies, 26, 3, 231-242.

Perrewe, P.L. \& Ganster, D.C. (1989). The impact of job demands and behavioural control on experienced job stress. Journal of Organizational Bchavior, 10, 213-229.

Peters, T.J. \& Waterman, R.H. Jr. (1982). In Search of Excellence: Lessons from America's Best-Run Companies. New York: Harper and Row Publishers.

Polit, D.F. \& Hungler, B.P. (1999). Nursing Rescarch: Principles and methods (6th edition). Philadelphia: Lippincott Williams \& Wilkins.

Pontin, D. (1999). Primary nursing: a mode of care or a philosophy of nursing? Journal of Advanced Nursing, 29, 3, 584-591.

Reed, S.E. (1988). A comparison of nurse-related behaviour, philosophy of carc and job satisfaction in team and primary nursing. Journal of Advanced Nursing, 13, 383-395.

Rijk, A.E. de, Blanc, P.M. Le, Schaufeli, W.B. \& Jonge, J. de (1998). Active coping and need for control as moderators of the job demand-control model: Effects on burnout. Journal of Occupational and Organizational Psychology, $71,1-18$.

Roberts, L.E. (1980). Primary Nursing: Do paticnts like it? Are nurses satisfied? Docs it cost More? The Canadian Nurse, December, 20-23.

Roberts, K.H. \& Glick, W. (1981). The Job Characteristics Approach to Task Design: A Critical Review. Journal of Applied Psychology, 66, 2, 193-217.

Roodbol, P.F. (1993). Ervaren verantwoordelijkheid binnen integrerende verpleegkunde.'Doctoraalscriptie [Perceived responsibility in integrated nursing. Masters' thesis]. Maastricht: Universiteit Maastricht.

Scarpello, V. \& Campbell, J.P. (1983). Job satisfaction: are all parts there? Personnel Psychology, 36, $577-600$.

Schein, E. H. (1980). Organizational Psychology (third edition). Englewood Cliffs, N.J.: Prentice-Hall.

Schreurs, P.J.G. \& Taris, T.W. (1998). Construct validity of the demand-control model: a double crossvalidation approach. Work and Stress, 12, 1, 66-84.

Sellick, K.J., Russell, S. \& Beckmann, J.L. (1983). Primary Nursing: an evaluation of its effects on patient perception of care and staff satisfaction. International Journal of Nursing Studies, 20, 4, 265-273.

Senge, P.M. (1990). The Fifth Discipline: The Art \& Practice of The Learning Organisation. New York: Currency Doubleday.

Seymour, E. \& Buscherhof, J.R. (1991). Sources and consequences of satisfaction and dissatisfaction in nursing: findings from a national sample. International Journal of Nursing Studies, 28, 2, 109-124.

Shani, A.B. \& Bushe, G.R. (1987). Visionary action research: A consultation process perspective. Consultation, $6,1,3-19$. 
Shukla, R.K. (1982). Nursing care Structures and Productivity. Hospital \& Health Services Administration, November/December, 45-58.

SIG (1994). Gebruikershandboek Gegevensverwerking Verpleeghuizen SIVIS [Users' guide to data processing in nursing homes SIVIS]. Utrecht: Stichting Informatiecentrum voor de Gezondheidszorg.

Sitter, U. de, Hertog, J.F. den \& Dankbaar, B. (1997). From Complex Organizations with Simple Jobs to Simple Organizations with Complex Jobs. Human Relations, 50, 5, 497-534.

Smulders, P.G.W. (1980). Comments on Employee Absence/Attendance as a Dependent Variable in Organizational Research. Journal of Organizational Psychology, 65, 3, 368-37I.

Spector, P.E. (1985). Higher-order need strength as a moderator of the job scope-employec outcome relationship: A meta-analysis. Journal of Occupational Psychology, 58, 119-127.

Spector, P.E. (1986). Perceived Control by Employees: A Mcta-Analysis of Studies Concerning Autonomy and Participation at Work. Human Relations, 11, 1005-1016.

Spector, P.E. (1987a). Interactive effects of perceived control and job stressors on affective reactions and health outcomes for clerical workers. Work and Stress, 1, 2, 155-162.

Spector, P.E. (1987b). Method Variance as an Artifact in Self-Reported Affect and Perceptions at Work: Myth or Significant Problem? Journal of Applied Psychology, 72, 3, 438-443.

Spector, P.E. \& Jex, S.M. (1991). Relations of Job Characteristics From Multiple Data Sources with Employee Affect, Absence, Turnover Intentions, and Health. Journal of Applied Psychology, 76, 1, 46-53.

Staatsblad $(1996,80)$. Wet van 18 januari 1996 betreffende de kwaliteit van zorginstellingen (Kwaliteitswet Zorginstellingen) [Act of 18 January 1996 on quality of care institutions (Care Institutions Quality Act)]. Staatsblad van het Koninkrijk der Nederlanden. 's-Gravenhage: Sdu Uitgevers.

Staatsblad $(1999,184)$. Wet van 18 maart 1999, houdende bepalingen van de arbeidsomstandigheden (Arbeidsomstandighedenwet 1998) [Act of 18 March 1999 with regard to regulations of the working conditions (Working Conditions Act 1998)]. Staatsblad van het Koninkrijk der Nederlanden. 's-Gravenhage: Sdu Uitgevers.

Steckel, S.B., Barnfather, J. \& Owens, M. (1980). Implementing Primary Nursing within a Research Design. Nursing Dimensions, 7, 4, 78-81.

Steen, N., Firth, H.B.W. \& Bond, S. (1998). Relation Between Work Stress and Job Performance in Nursing: A Comparison of Models. Structural Equation Modelling, 5, 2, 125-142.

Stogdill, R.M. (1963). Manual for the leader behavior description questionnaire-form X11. Columbus: Bureau of Business Research, The Ohio State University.

Tabachnik, B.G. \& Fidell, L.S. (1989). Using multivariate statistics. New York: HarperCollins.

Taber, T.D. \& Taylor, E. (1990). A review and evaluation of the psychometric properties of the job diagnostic survey. Personnel Psychology, 43, 467-500.

Taylor, F.W. (1911). The Principles of Seientific Management. New York: Harper.

Theorell, T. \& Karasek, R.A. (1996). Current Issues Relating to Psychosocial Job Strain and Cardiovascular Disease Research. Journal of Occupational Health Psychology, 1, 1, 9-26.

Thierry, Hk. (1997). Motivatic en satisfactie [Motivation and satisfaction]. In: Drenth, P.J.D., Thierry, Hk. \& Wolff, Ch.J. de (Eds.), Nieuw Handboek arbeids- en organisatiepsychologic. Deel I (Studenteneditie). Houten/Diegem: Bohn Stafleu Van Loghum.

Thomas, L.H. (1992). Qualified nurse and nursing auxiliary perception of their work environment in primary, team and functional nursing wards. Journal of Advanced Nursing, 17, 373-382.

Thomas, L.H. (1993). Comparing qualified nurse and auxiliary roles. Nursing Times, 89, 38, 45-48.

Thomas, L.H. (1994). A comparison of the verbal interactions of qualified nurses and nursing auxiliaries in primary, team and functional nursing wards. International Journal of Nursing Studies, 31, 3, 231-44.

Thomas, L.H. \& Bond, S. (1991). Outcomes of nursing care: the case of primary nursing. International Journal of Nursing Studies, 28, 4, 291-314.

Trist, E.L., Higgin, G.W., Murray, H. \& Pollock, A.B. (1963). Organizational Choice. Capabilitics of groups at the coal face under changing technologies. London: Tavistock Institute of Human Relations.

Trist, E.L. (1981). The Sociotechnical Perspective: The Evolution of Sociotechnical Systems as a Conceptual Framework and as an Action Research Program. In: Ven, A.H. van de \& Joyce, W.F. (Eds.), Perspectives on Organisational Design and Bchavior (pp. 19-75). New York: John Wiley.

Turner, A.N. \& Lawrence, P.R. (1965). Industrial jobs and the worker. An investigation of response to task attributes. Boston: Harvard Graduate School of Business Administration.

Tweede Kamer der Staten-Generaal (1999). Zorgnota 2000 [Healthcare Memorandum 2000]. Tweede Kamer, vergaderjaar 1999-2000, 26801 , nrs. 1-2. 's-Gravenhage: Sdu Uitgeverij. 
Tyler, P.A., Carroll, D. \& Cunningham, S.E. (1991). Stress and well-being in nurses: a comparison of the public and private sectors. International Journal of Nursing Studies, 28, 2, 125-130.

Vahtera, J., Pentti, J. \& Uutela, A. (1996). The effect of objective job demands on registered sickness absence spells; do personal, social and job-related resources act as moderators? Work and Stress, 10, 4, 286-308.

Vergert, H.G.M. ten (1987). Ziekteverzuim in cen verpleeghuis. Doctoraalscriptie [Absence of sickness in a nursing home. Masters' thesis]. Maastricht: Rijksuniversiteit Limburg.

Verkooijen, H.E.C. \& Halfens, R.J.G. (1992). Het meten van de toepassing van het verpleegkundig proces [The measurement of the use of the nursing process]. Verpleegkunde, 2, 97-105.

Vlerick, P. (1996). Burnout and work organization in hospital wards: a cross-validation study. Work and Stress, $10,3,257-265$.

Vlerick, P. \& Goeminne, D. (1994). Onderzock naar de gevolgen van verpleegkundige functie-ontwerpen op de arbeidsbeleving [Study of the effects of nurses' job designs on job perception]. Gedrag en Organisatic, 7, 2, 101-114.

Vlist, R. van der (1997). Geplande verandering van organisaties en organisatie ontwikkeling in de jaren negentig [Planned change of organisations and organisation development in the nineties]. In: Drenth, P.J.D., Thierry, Hk. \& Wolff Ch.J. de (Eds.), Nieuw Handboek arbeids- en organisatiepsychologie. Deel II (Studenteneditie). Houten/Diegem: Bohn Stafleu Van Loghum.

Vogelaar, A.L.W. \& Vlist, R. van der (1995). Het Job Characteristics Model en taakherontwerp [The Job Characteristics Model and job redesign]. Gedrag en Organisatie, 8, 2, 65-87.

Vrakking, W.J. (1986). Doorvoeren van Megavernieuwingen [Implementation of mega innovations]. In: Cozijnsen, A. J. \& Vrakking, W.J. (Eds.), Handboek voor strategisch innoveren: een internationale balans (p. 161168). Deventer: Kluwer.

Vredenburgh, D.J. \& Trinkaus, R.J. (1983). An analysis of role stress among hospital nurses. Journal of Vocational Behavior, 23, 82-95.

Vroom, V.H. (1964). Work and motivation. New York: Wiley.

Wall, T.D. \& Clegg, C.W. (1981). A longitudinal field study of group work redesign. Journal of Occupational Behavior, 2, 31-49.

Wall, T.D., Martin Corbett, J., Martin, R., Clegg, C.W. \& Jackson, P.R. (1990). Advance manufacturing Technology, Work Design, and Performance: A Change Study. Journal of Applied Psychology, 75, 6, 691-697.

Wall, T.D., Jackson, P.R., Mullarkey, S. \& Parker, S.K. (1996). The demands-control model of job strain: A more specific test. Journal of Occupational and Organizational Psychology, 69, 153-166.

Wall, T.D. \& Martin, R. (1996). Job and Work Redesign. In: Cooper, C.L. \& Robertson, I.T. (Eds.), Key Reviews in Managerial Psychology (pp. 158-188). Chichester: Wiley.

Warr, P. B. (1990). Decision latitude, job demands, and employee well-being. Work and Stress, 4, 4, 285-294.

Warr, P. (1994). A conceptual framework for the study of work and mental health. Work and Stress, 8, 2, 84-97.

Warr, P., Cook, J. \& Wall, T. (1979). Scales for the measurement of some attitudes and aspects of psychological well-being. Journal of Occupational Psychology, 52, 2, 129-148.

Watson, D. \& Keltner Slack, A. (1993). General Factors of Affective Temperament and Their Relation to Job Satisfaction over Time. Organizational Behavior and Human Decision Processes, 54, 181-202.

Weaver, C.N. (1980). Job satisfaction in the United States in the 1970s. Journal of Applied Psychology, 65, 3, 364-367.

Webb, C. \& Pontin, D. (1996). Introducing primary nursing: nurses' opinions. Journal of Clinical Nursing, 5 , 351-358.

Webb, C. \& Pontin, D. (1997). Evaluating the introduction of primary nursing: the use of a care plan audit. Journal of Clinical Nursing, 6, 395-401.

Wiegman, N. (1993). Zusters in smetteloos wit: een blanco bladzijde in de Nederlandse geschiedschrijving? [Nurses in immaculate white: a blank page in Dutch history writing?]. Gewina, 16, 63-79.

Wiegman, N. (1996). 'Gij completeert zijn arbeid': over professionalisering van het verpleegkundig beroep (1880-1925) ['Thou completeth his work': with regard to professionalisation of the nursing profession (1880-1925)]. Gewina, 19, 269-312.

Wiegman, N. (1998). 'De verpleegster zij in de eerste plaats vrouw van karakter'. Ziekenverpleging als vrouwenzaak ['The nurse has to be a woman in the first place'. Nursing care as woman's case]. In: Daalen, $R$. van \& Gijswijt-Hofstra, M. (Eds.), Gezond en Wel. Vrouwen en de zorg voor gezondheid in de twintigste eeuw. Amsterdam: Amsterdam University Press.

Wijnen, G., Renes, W. \& Storm, P. (1988). Projectmatig werken [Project-like working]. Utrecht: Het Spectrum. 
Wilson, N.M. \& Dawson, P. (1989). A comparison of primary nursing and team nursing in a geriatric long-term carc sctting. International Journal of Nursing Studies, 26, 1, 1-13.

Windt, W. van der, Calsbeek, H. \& Hingstman, L. (1998). Verpleging en verzorging in kaart gebracht 1998 [Nursing care charted 1998]. Maarssen: Elsevier/De Tijdstroom \& Utrecht: Landelijk Centrum Verpleging \& Verzorging.

Windt, W. van der, Calsbeek, H. \& Hingstman, L. (1999). Verpleging en verzorging in kaart gebracht 1999 [Nursing care charted 1999]. Maarssen: Elsevier/De Tijdstroom \& Utrecht: Landelijk Centrum Verpleging \& Verzorging.

Wissema, J.G., Messer, H.M. \& Wijers, G.J. (1991). Angst voor veranderen? Een mythe! Of: hoe u veranderingsbereidheid op de werkvloer vergroot [Fear for changing? A myth! Or: how you can enlarge willingness to change on the shop floor]. Van Gorcum: Assen/Maastricht.

Zaltman, G. \& Linn, N. (1986). De aard van innovaties [The nature of innovations]. In: Cozijnsen, A. J. \& Vrakking, W.J. (Eds.), Handboek voor strategisch innoveren: een internationale balans (p. 29-33). Deventer: Kluwer.

Zonneveld, T. van (1993). Zorg voor verandering. Een studie van veranderingsprocessen in het algemene zickenhuis ter verhoging van de kwaliteit van zorg. Proefschrift [Caring for change. A study of change processes in the general hospital with a view on improving the quality of care. Dissertation]. Utrecht: Elinkwijk B.V. 
APPENDICES 



\section{Appendix 1 Description of the research variables}

Table 1.1 Description of the research variables on the pre-test

\begin{tabular}{|c|c|c|c|c|c|}
\hline Dimensions & Variables & $\begin{array}{l}\text { Number } \\
\text { of items }\end{array}$ & $\begin{array}{l}\text { Theore- } \\
\text { tical range }\end{array}$ & $\begin{array}{l}\text { Mean (SD) } \\
\text { pre-test }\end{array}$ & $\begin{array}{l}\text { Cronbach's } \alpha \\
\text { pre-test }\end{array}$ \\
\hline $\begin{array}{l}\text { Resident assign- } \\
\text { ment }\end{array}$ & Resident assignment & 10 & $1-5$ & $1.57(0.82)$ & 0.91 \\
\hline \multirow[t]{2}{*}{$\begin{array}{l}\text { Use of the nursing } \\
\text { process }\end{array}$} & $\begin{array}{l}\text { Use of nursing care plans and their } \\
\text { evaluation }\end{array}$ & 14 & $1-5$ & $3.34(0.76)$ & 0.88 \\
\hline & $\begin{array}{l}\text { Taking nursing history, nursing } \\
\text { problems, goals and actions }\end{array}$ & 9 & $1-5$ & $4.26(0.68)$ & 0.85 \\
\hline \multirow[t]{2}{*}{ Tasks } & Resident-oriented tasks & 8 & $1-5$ & $2.63(0.73)$ & 0.79 \\
\hline & Ward-oriented tasks & 7 & $1-5$ & $3.03(0.78)$ & 0.80 \\
\hline \multirow{3}{*}{ Communication } & Quality of communication forms & 14 & $1-5$ & $3.81(0.41)$ & 0.86 \\
\hline & $\begin{array}{l}\text { Variety of resident-oriented com- } \\
\text { munication forms }\end{array}$ & 9 & $1-5$ & $4.17(0.60)$ & 0.91 \\
\hline & $\begin{array}{l}\text { Variety of ward-oriented commu- } \\
\text { nication forms }\end{array}$ & 7 & $1-5$ & $3.21(0.55)$ & 0.68 \\
\hline Information quality & Information quality & 4 & $1-5$ & $3.48(0.64)$ & 0.88 \\
\hline \multirow[t]{2}{*}{ Leadership style } & Social-emotional leadership & 11 & $1-5$ & $3.96(0.58)$ & 0.88 \\
\hline & Instrumental leadership & 9 & $1-5$ & $2.85(0.53)$ & 0.75 \\
\hline Job autonomy & Job autonomy & 10 & $1-5$ & $2.78(0.54)$ & 0.82 \\
\hline Job demands & Job demands & 8 & $1-5$ & $3.00(0.66)$ & 0.88 \\
\hline Social support & Social support & 10 & $1-4$ & $3.31(0.38)$ & 0.84 \\
\hline Responsibility & Responsibility & 5 & $1-5$ & $4.05(0.54)$ & 0.84 \\
\hline Job satisfaction & Job satisfaction & 1 & $1-5$ & $4.20(0.72)$ & - \\
\hline $\begin{array}{l}\text { Intrinsic work moti- } \\
\text { vation }\end{array}$ & Intrinsic work motivation & 6 & $1-5$ & $4.02(0.44)$ & 0.66 \\
\hline Health complaints & Health complaints & 21 & $0-21$ & $3.56(3.49)$ & 0.82 \\
\hline $\begin{array}{l}\text { Frequency of sick- } \\
\text { ness absence }\end{array}$ & Frequency of sickness absence & i & $0-\infty$ & $0.82(1.22)^{3}$ & . \\
\hline
\end{tabular}

a) frequency of sickness absence of the last half year 


\section{Appendix 2 Factor analyses of the design characteristics}

Table 2.1 Factor analysis of the resident assignment scale ${ }^{\text {a }}$

\begin{tabular}{llcc}
\hline Item & Description & Factor $1^{\mathrm{b}}$ & Factor $2^{\mathrm{c}}$ \\
\hline assign1 & resident assignment to a PNC for a total admission period & 0.86 & -0.12 \\
assign6 & resident assignment from admission until discharge & 0.83 & -0.33 \\
assign5 & resident assignment for a longer period & 0.76 & \\
assign18 & PNC is the contact person for relatives & 0.75 & 0.22 \\
assign19 & relatives are informed about resident assignment & 0.74 & \\
assign14 & PNC is the contact person for other disciplines & 0.66 & 0.35 \\
assign17 & other disciplines are informed about resident assignment & 0.65 & 0.20 \\
assign9 & resident assignment per resident & 0.63 & \\
assign2 & PNC is responsible 24-hours per day & 0.61 & 0.14 \\
assign20 & resident assignment in the nursing care plan & 0.54 & \\
assign15 & PNC is present during doctors' visit & 0.50 & 0.50 \\
assign23 & resident assignment to ward sisters & 0.39 & 0.36 \\
assign16 & PNC takes initiatives towards other disciplines & 0.39 & 0.60 \\
assign11 & resident assignment based on personal preferences of PNCs & & 0.59 \\
assign13 & resident assignment based on skills, capacitics and experience & 0.10 & 0.58 \\
assign22 & in case of absence responsibilities are delegated by the PNC & 0.38 & 0.57 \\
assign21 & PNC performs direct care & 0.37 & 0.57 \\
assign4 & resident assignment per day & -0.14 & 0.56 \\
assign3 & PNC is responsible per shif & 0.33 & 0.52 \\
assign7 & resident assignment to a group of nursing caregivers & -0.23 & 0.51 \\
assign12 & resident assignment based on personal preferences of relatives & -0.13 & 0.50 \\
assign10 & resident assignment based on coincidence & 0.16 & 0.43 \\
assign8 & resident assignment per room & 0.11 & 0.43 \\
\hline
\end{tabular}

Eigen value factor $1: 8.31$ ( $36 \%$ explained variance; before rotation)

Eigen value factor $2: 2.48$ (11\% explained variance; before rotation)

Correlation factor 1 - factor 2: 0.28
a) Pattern matrix at pre-test after oblique rotation (Oblimin)
b) Resident assignment
c) Excluded due to content incoherence 
Table 2.2 Factor analysis of the use of the nursing process scale ${ }^{a}$

\begin{tabular}{llcc}
\hline Item & Description & Factor l $^{\mathrm{b}}$ & Factor $2^{\mathrm{c}}$ \\
\hline process24 & frequent evaluations of nursing problems and goals & 0.79 & -0.17 \\
process25 & nursing care plans adjusted based on evaluations & 0.79 & \\
process20 & nursing care plan based on continuous data collection & 0.75 & \\
process21 & nursing carc plan adjusted based on daily observations & 0.72 & 0.16 \\
process15 & nursing care plans are clear, unambiguous and concrete & 0.64 & 0.11 \\
process22 & nursing care plan adjusted before a next shift when situation changes & 0.63 & \\
process18 & every three months monodisciplinary care plans are checked/agreed & 0.61 & 0.20 \\
process14 & nursing care plans discussed with nursing caregivers if necessary & 0.53 & 0.20 \\
process16 & nursing care plans are charted and adjusted for the assigned resident & 0.53 & -0.16 \\
process17 & integration of monodisciplinary in multidisciplinary care plans & 0.53 & 0.30 \\
process26 & nursing care plans evaluated every three months with the resident & 0.52 & -0.11 \\
process23 & nursing goals include evaluation criteria & 0.49 & 0.19 \\
process13 & nursing care plans include planned evaluation moments & 0.46 & 0.46 \\
process19 & nursing report based on nursing problems and goals & 0.44 & 0.21 \\
process12 & nursing actions described in nursing care plan & 0.42 & 0.39 \\
process10 & nursing care plan charted together with residentrelatives & 0.40 & \\
process6 & nursing goals determined for every resident separately & & 0.77 \\
process7 & nursing goals determined on basis of nursing problems & & 0.74 \\
process8 & short term and long term nursing goals determincd & & 0.67 \\
process5 & nursing problems identified including causes & & 0.64 \\
process4 & nursing problems identified for all residents separately & -0.17 & 0.63 \\
process11 & nursing actions based on nursing problems and goals & 0.13 & 0.61 \\
process9 & nursing problems and goals based on resident's perspective & & 0.59 \\
process3 & taking nursing history by means of standardised subjects & & 0.59 \\
process1 & taking nursing history for every admitted resident & & 0.52 \\
process2 & taking nursing history for every readmitted resident & 0.11 & 0.23 \\
\hline
\end{tabular}

Eigen value factor $1: 8.60$ (33\% explained variance; before rotation)

Eigen value factor 2: 2.40 ( $9 \%$ explained variance; before rotation)

Correlation factor I - factor 2: 0.40

a) Pattern matrix at pre-test after oblique rotation (Oblimin)

b) Use of nursing care plans and their evaluation

c) Taking nursing history, nursing problems, goals and actions 
Table 2.3 Factor analysis of the tasks scale

\begin{tabular}{|c|c|c|c|}
\hline Item & Description & Factor $1^{b}$ & Factor $2^{c}$ \\
\hline tasks6 & performing a discharge talk with residents/relatives & -0.82 & -0.23 \\
\hline tasks 7 & taking care and managing discharge or transfer of residents & -0.77 & -0.13 \\
\hline tasks I 1 & mediating at conflicts between residents and other disciplines & -0.66 & \\
\hline lasks 10 & organising meetings with other disciplines at the request of residents & -0.65 & 0.17 \\
\hline tasks I & performing a nursing history talk with residents/relatives & -0.55 & \\
\hline tasks3 & discussing nursing care plans with residents/relatives & -0.54 & 0.21 \\
\hline tasks 5 & evaluating nursing care with residents/relatives & -0.46 & 0.24 \\
\hline tasks2 & charting and kecping up nursing care plans & -0.45 & 0.11 \\
\hline tasks 12 & informing residents/relatives about medication, test results etc. & -0.29 & 0.26 \\
\hline tasks 20 & developing ward-related vision and policy & & 0.79 \\
\hline tasks 18 & co-ordinating daily nursing care activities on the ward & & 0.70 \\
\hline tasks 19 & monitoring and developing quality of residents' care & & 0.69 \\
\hline tasks 16 & assigning resident-related activities & & 0.60 \\
\hline tasks21 & managing ward staff & -0.13 & 0.57 \\
\hline tasks 14 & presenting residents in the verbal report & & 0.53 \\
\hline tasks 17 & assigning non-resident related activities & -0.16 & 0.44 \\
\hline tasks9 & co-ordinating care between disciplines and residents & -0.41 & 0.42 \\
\hline tasks 22 & coaching nursing students and ward staff & -0.22 & 0.40 \\
\hline tasks8 & keeping contacts with other disciplines for benefit of residents' care & -0.32 & 0.39 \\
\hline tasks 13 & introducing the resident in the multidisciplinary meeting & -0.29 & 0.38 \\
\hline tasks 4 & performing direct nursing care & 0.22 & 0.37 \\
\hline tasks 15 & assigning residents & -0.14 & 0.22 \\
\hline
\end{tabular}

Eigen value factor 1: 6.35 (29\% explained variance; before rotation)

Eigen value factor 2: 1.84 ( $8 \%$ explained variance; before rotation)

Correlation factor $1-$ factor 2: -0.38

a) Pattern matrix at pre-test after oblique rotation (Oblimin)

b) Resident-oriented tasks

c) Ward-oriented tasks 
Table 2.4 Factor analysis of the communication scale ${ }^{a}$

$(n=210)$

\begin{tabular}{|c|c|c|c|c|}
\hline Item & Description & Factor $1^{b}$ & Factor $2^{c}$ & Factor $3^{d}$ \\
\hline $\operatorname{comm} 30$ & in the ward-oriented comm. people listen to one another & 0.82 & & -0.18 \\
\hline $\operatorname{comm} 32$ & issues in the ward-oriented comm. meet my expectations & 0.76 & & \\
\hline $\operatorname{comm} 31$ & discussed issues are useful in the ward-oriented comm. & 0.73 & & \\
\hline $\operatorname{comm} 29$ & opportunity to ask questions in the ward-oriented comm. & 0.72 & & \\
\hline comm27 & agreements in ward-oriented comm. are clear & 0.68 & & \\
\hline comm24 & issues in the resident-oriented comm. meet my expectations & 0.65 & 0.13 & \\
\hline comm22 & in the resident-oriented comm. people listen to one another & 0.64 & 0.16 & \\
\hline comm28 & all relevant issues are discussed in the ward-oriented comm. & 0.63 & & \\
\hline comm23 & discussed issues are useful in the resident-oriented comm. & 0.61 & 0.10 & -0.11 \\
\hline comm 33 & nurses' opportunities to be present at ward-oriented comm. & 0.53 & -0.13 & \\
\hline comm21 & opportunity to ask questions in the resident-oriented comm. & 0.50 & & \\
\hline comm26 & despite work pressure resident-oriented comm. take place & 0.44 & & 0.14 \\
\hline comm34 & despite work pressure ward-oriented comm. take place & 0.39 & & \\
\hline comml9 & agreements in resident-oriented comm. are clear & 0.38 & 0.17 & \\
\hline comm20 & relevant residents are discussed in resident-oriented comm. & 0.28 & 0.13 & 0.16 \\
\hline comm2 & resident-oriented comm. on resident's mental health & & 0.85 & -0.13 \\
\hline $\operatorname{comm} 3$ & resident-oriented comm. on resident's social health & 0.10 & 0.80 & -0.10 \\
\hline comm6 & resident-oriented comm. on resident's mental care & & 0.80 & \\
\hline $\operatorname{comm} 7$ & resident-oriented comm. on resident's social care & & 0.78 & \\
\hline comml & resident-oriented comm. on resident's physical health & & 0.78 & \\
\hline comm5 & resident-oriented comm. on resident's physical care & & 0.72 & \\
\hline comm4 & resident-oriented comm. on medical treatment and guidance & 0.22 & 0.72 & \\
\hline comm 9 & resident-oriented comm. on multidisciplinary care plan & & 0.59 & 0.13 \\
\hline comm8 & resident-oriented comm. on support of the relatives & & 0.52 & 0.29 \\
\hline comm 13 & ward-oriented comm. on administrative issues & & & 0.64 \\
\hline comml2 & ward-oriented comm. on domestic issues & & -0.27 & 0.62 \\
\hline commll & ward-oriented comm. on staffing and duty rosters & -0.24 & & 0.54 \\
\hline comml4 & ward-oriented comm. on mutual co-operation & & 0.12 & 0.54 \\
\hline comml7 & ward-oriented comm. on quality monitoring and development & 0.11 & 0.10 & 0.53 \\
\hline comml5 & ward-oriented comm. on development of visions & 0.13 & 0.15 & 0.48 \\
\hline comml8 & ward-oriented comm. on collegial support nursing caregivers & 0.15 & & 0.48 \\
\hline comm 25 & nurses' opportunities to be present at resident-oriented comm. & & & 0.45 \\
\hline comml0 & resident-oriented comm. on contacts residents and caregivers & -0.18 & 0.34 & 0.43 \\
\hline comm 16 & ward-oriented on comm. policy issues & 0.26 & & 0.37 \\
\hline
\end{tabular}

Eigen value factor $1: 7.40$ (22\% explained variance; before rotation)

Eigen value factor $2: 4.33$ (13\% explained variance; before rotation)

Eigen value factor $3: 2.49$ (7\% explained variance; before rotation)

Correlations factor 1 - factor 2: 0.19 ; factor 1 - factor 3: 0.10 ; factor 2 - factor $3: 0.22$
a) Pattern matrix at pre-test after oblique rotation (Oblimin)
b) Quality of communication forms
c) Variety of resident-oriented communication forms
d) Variety of ward-oriented communication forms 


\section{Appendix 3 Characteristics nursing homes and research wards}

Table 3.1 Characteristics of participating nursing homes in 1995

\begin{tabular}{llccr} 
& Number and type of research & Number of beds & Bed occupation & Fte's \\
\hline wards & & & \\
\hline Organisation A & 8 somatic & 268 & $99 \%$ & 160.6 \\
& 5 psycho-geriatric & 152 & & 104.1 \\
& 2 day-care & 38 & $99 \%$ & 9.5 \\
Organisation B & 6 somatic & 174 & & 110.8 \\
& 3 psycho-geriatric & 99 & \multirow{2}{*}{$100 \%$} & 57.2 \\
Organisation C' & 2 day-care & 36 & & 8.7 \\
& 4 somatic & 143 & & 97.3 \\
& 3 psycho-geriatric & 102 & & 65.0 \\
\hline
\end{tabular}

1) figures including annex

Table 3.2 Characteristics of participating research wards in 1995

\begin{tabular}{lllcc}
\hline & Number and type of research & Number of beds & Bed occupation & Fte's \\
\hline wards & & & \\
\hline Organisation A & I somatic experimental & 38 & $99 \%$ & 23.0 \\
& 1 somatic control & 38 & $99 \%$ & 23.0 \\
& 1 psycho-geriatric experimental & 31 & $99 \%$ & 22.5 \\
Organisation B & 1 psycho-geriatric control & 31 & $99 \%$ & 21.4 \\
& 1 somatic experimental & 30 & $100 \%$ & 20.0 \\
& 1 somatic control & 27 & $93 \%$ & 22.5 \\
& 1 psycho-geriatric experimental & 30 & $100 \%$ & 20.1 \\
Organisation C & 1 psycho-geriatric control & 34 & $100 \%$ & 23.6 \\
& 1 somatic experimental & 38 & $100 \%$ & 25.3 \\
& 1 somatic control & 38 & $100 \%$ & 28.3 \\
& 1 psycho-geriatric experimental & 36 & $100 \%$ & 22.9 \\
& 1 psycho-geriatric control & 36 & $100 \%$ & 24.0 \\
\hline
\end{tabular}




\section{Appendix 4 Demographic and ward characteristics pre-test and post-test samples}

Table 4.1 Age, full-time or part-time working and ward experience

\begin{tabular}{llllllllll}
\hline & \multicolumn{2}{c}{ Age (years) } & \multicolumn{4}{c}{ Employment degree (\%) } & \multicolumn{3}{c}{ Ward experience (years) } \\
& Mean & SD & $\mathrm{n}$ & Mcan & SD & $\mathrm{n}$ & Mean & SD & $\mathrm{n}$ \\
\hline Total & & & & & & & & & \\
$\quad$ Pre-test & 31.68 & 8.57 & 210 & 71.44 & 25.63 & 210 & 5.19 & 3.97 & 210 \\
$\quad$ Post-test 1 & 32.71 & 8.69 & 167 & 71.41 & 25.49 & 167 & 5.77 & 4.04 & 167 \\
$\quad$ Post-test 2 & 33.63 & 8.80 & 147 & 68.40 & 25.49 & 147 & 6.64 & 4.24 & 147 \\
Experimental & & & & & & & & & \\
$\quad$ Pre-test & 31.78 & 8.25 & 101 & 71.93 & 25.93 & 101 & 5.64 & 4.20 & 101 \\
$\quad$ Post-test 1 & 32.90 & 8.42 & 79 & 71.43 & 26.36 & 79 & 6.17 & 4.23 & 79 \\
$\quad$ Post-test 2 & 33.58 & 8.24 & 69 & 67.61 & 25.66 & 69 & 7.22 & 4.52 & 69 \\
Control & & & & & & & & & \\
$\quad$ Pre-test & 31.59 & 8.90 & 109 & 70.89 & 25.45 & 109 & 4.78 & 3.71 & 109 \\
$\quad$ Post-test 1 & 32.53 & 8.97 & 88 & 71.40 & 24.84 & 88 & 5.41 & 3.86 & 88 \\
$\quad$ Post-test 2 & 33.67 & 9.32 & 78 & 69.10 & 25.49 & 78 & 6.13 & 3.94 & 78 \\
\hline
\end{tabular}

Table 4.2 Gender, fixed or variable working times and function (frequencies and absolute figures)

\begin{tabular}{|c|c|c|c|c|c|c|c|c|c|}
\hline & \multirow{2}{*}{$\begin{array}{l}\text { Gender } \\
\text { Male }\end{array}$} & \multirow[b]{2}{*}{ Female } & \multirow[b]{2}{*}{$\mathrm{n}$} & \multicolumn{2}{|c|}{ Working times } & \multirow[b]{2}{*}{$\mathrm{n}$} & \multicolumn{2}{|c|}{ Function } & \multirow[b]{2}{*}{$\mathrm{n}$} \\
\hline & & & & Fixed & Variable & & RN & LPN & \\
\hline \multicolumn{10}{|l|}{ Total } \\
\hline Pre-test & $7 \% / 14$ & $93 \% / 196$ & 210 & $5 \% / 11$ & $95 \% / 199$ & 210 & $1 \% / 3$ & $99 \% / 207$ & 210 \\
\hline Post-test 1 & $5 \% / 9$ & $95 \% / 158$ & 167 & $8 \% / 14$ & $92 \% / 153$ & 167 & $2 \% / 3$ & $98 \% / 164$ & 167 \\
\hline Post-test 2 & $5 \% / 7$ & $95 \% / 140$ & 147 & $9 \% / 13$ & $91 \% / 134$ & 147 & $2 \% / 3$ & $98 \% / 144$ & 147 \\
\hline \multicolumn{10}{|l|}{ Experimental } \\
\hline Pre-test & $10 \% / 10$ & $90 \% / 91$ & 101 & $6 \% / 6$ & $94 \% / 95$ & 101 & $2 \% / 2$ & $98 \% / 99$ & 101 \\
\hline Post-test 1 & $10 \% / 8$ & $90 \% / 71$ & 79 & $9 \% / 7$ & $91 \% / 72$ & 79 & $3 \% / 2$ & $97 \% / 77$ & 79 \\
\hline Post-test 2 & $9 \% / 6$ & $91 \% / 63$ & 69 & $12 \% / 8$ & $88 \% / 61$ & 69 & $1 \% / 1$ & $99 \% / 68$ & 69 \\
\hline \multicolumn{10}{|l|}{ Control } \\
\hline Pre-test & $4 \% / 4$ & $96 \% / 105$ & 109 & $5 \% / 5$ & $95 \% / 104$ & 109 & $1 \% / 1$ & $99 \% / 108$ & 109 \\
\hline Post-test 1 & $1 \% / 1$ & $99 \% / 87$ & 88 & $8 \% / 7$ & $92 \% / 81$ & 88 & $1 \% / 1$ & $99 \% / 87$ & 88 \\
\hline Post-test 2 & $1 \% / 1$ & $99 \% / 77$ & 78 & $6 \% / 5$ & $94 \% / 73$ & 78 & $3 \% / 2$ & $97 \% / 76$ & 78 \\
\hline
\end{tabular}

Table 4.3 Education and number of PNCs (frequencies and absolute figures)

\begin{tabular}{|c|c|c|c|c|c|c|c|c|}
\hline & \multicolumn{5}{|l|}{ Education } & \multicolumn{3}{|l|}{ PNCs } \\
\hline & Low & Mid & High & Univ. & $\mathbf{n}$ & No & Yes & $\mathrm{n}$ \\
\hline \multicolumn{9}{|l|}{ Total } \\
\hline Pre-test & $34 \% / 72$ & $59 \% / 124$ & $6 \% / 13$ & $1 \% / 1$ & 10 & - & - & - \\
\hline Post-test 1 & $36 \% / 59$ & $57 \% / 95$ & $6 \% / 10$ & $1 \% / 1$ & 65 & $74 \% / 123$ & $26 \% / 44$ & 167 \\
\hline Post-test 2 & $29 \% / 42$ & $67 \% / 96$ & $4 \% / 5$ & $1 \% / 1$ & 44 & $75 \% / 110$ & $25 \% / 37$ & 147 \\
\hline \multicolumn{9}{|l|}{ Experimental } \\
\hline Pre-test & $40 \% / 40$ & $54 \% / 54$ & $6 \% / 6$ & $1 \% / 1$ & 101 & - & - & - \\
\hline Post-test I & $39 \% / 31$ & $53 \% / 42$ & $6 \% / 5$ & $1 \% / 1$ & 79 & $44 \% / 35$ & $56 \% / 44$ & 79 \\
\hline Post-test 2 & $35 \% / 24$ & $59 \% / 40$ & $4 \% / 3$ & $2 \% / 1$ & 68 & $46 \% / 32$ & $54 \% / 37$ & 69 \\
\hline \multicolumn{9}{|l|}{ Control } \\
\hline Pre-test & $29 \% / 32$ & $64 \% / 70$ & $6 \% / 7$ & - & 109 & - & - & - \\
\hline Post-test 1 & $32 \% / 28$ & $62 \% / 53$ & $6 \% / 5$ & - & 86 & $100 \% / 88$ & - & 88 \\
\hline Post-test 2 & $24 \% / 18$ & $74 \% / 56$ & $3 \% / 2$ & - & 76 & $100 \% / 78$ & - & 78 \\
\hline
\end{tabular}




\section{Appendix $5 \quad$ Final regression models design characteristics}

\subsection{Resident assignment}

Table 5.1 a Resident assignment: organisation A, somatic group

$\mathrm{n}=22$

\begin{tabular}{lrlrrrrr}
\hline & B & Std. Error & Beta & \multicolumn{1}{l}{$\mathrm{T}$} & Sig. ${ }^{1}$ & $\begin{array}{l}\text { Adjusted } \\
\mathrm{R}^{2}\end{array}$ & $\begin{array}{l}\text { Mean } \\
\text { square } \\
\text { residual }\end{array}$ \\
\hline constant & 5.579 & 0.933 & & 5.983 & 0.000 & & \\
type of group & 0.164 & 0.195 & 0.170 & 0.845 & 0.409 & 0.177 & 0.195 \\
gender ${ }^{2}$ & -1.040 & 0.465 & -0.456 & -2.235 & 0.038 & & \\
assignment & 0.197 & 0.153 & 0.258 & 1.288 & 0.214 & & \\
\hline
\end{tabular}

1) Two-tailed 2) Covariates are the pre-tests of the demographic characteristics and dependent variable at hand

Table 5.Ib Resident assignment: organisation A, psycho-geriatric group $\mathrm{n}=21$

\begin{tabular}{|c|c|c|c|c|c|c|c|}
\hline & B & Std. Error & Beta & $\mathrm{T}$ & Sig. ${ }^{\prime}$ & $\begin{array}{l}\text { Adjusted } \\
\mathrm{R}^{2}\end{array}$ & $\begin{array}{l}\text { Mean } \\
\text { square } \\
\text { residual }\end{array}$ \\
\hline constant & 1.221 & 0.242 & & 5.040 & 0.000 & & \\
\hline type of group & 3.076 & 0.174 & 0.962 & 17.661 & 0.000 & 0.957 & 0.115 \\
\hline assignment $^{2}$ & 0.106 & 0.166 & 0.035 & 0.641 & 0.530 & & \\
\hline
\end{tabular}

1) Two-tailed 2) Covariate is the pre-test of the dependent variable at hand

Table 5.1c Resident assignment: organisation B, somatic group

\begin{tabular}{|c|c|c|c|c|c|c|c|}
\hline & B & Std. Error & Beta & $T$ & Sig. ${ }^{\prime}$ & $\begin{array}{l}\text { Adjusted } \\
\mathrm{R}^{2}\end{array}$ & $\begin{array}{l}\text { Mean } \\
\text { square } \\
\text { residual }\end{array}$ \\
\hline constant & 1.102 & 0.187 & & 5.905 & 0.000 & & \\
\hline type of group & 2.707 & 0.176 & 0.933 & 15.392 & 0.000 & 0.946 & 0.120 \\
\hline assignment $^{2}$ & 0.176 & 0.087 & 0.123 & 2.030 & 0.062 & & \\
\hline
\end{tabular}

1) Two-tailed 2) Covariate is the pre-test of the dependent variable at hand

Table 5.1d Resident assignment: organisation B, psycho-geriatric group $\mathrm{n}=21$

\begin{tabular}{|c|c|c|c|c|c|c|c|}
\hline & B & Std. Error & Beta & $\mathrm{T}$ & Sig. ${ }^{\prime}$ & $\begin{array}{l}\text { Adjusted } \\
\mathrm{R}^{2}\end{array}$ & $\begin{array}{l}\text { Mean } \\
\text { square } \\
\text { residual }\end{array}$ \\
\hline constant & 1.505 & 0.639 & & 2.356 & 0.030 & & \\
\hline type of group & 2.108 & 0.431 & 1.008 & 4.888 & 0.000 & 0.672 & 0.376 \\
\hline assignment $^{2}$ & 0.287 & 0.256 & 0.231 & 1.122 & 0.277 & & \\
\hline
\end{tabular}

1) Two-tailed 2) Covariate is the pre-test of the dependent variable at hand 
Table 5.1e Resident assignment: organisation C, somatic group

\begin{tabular}{|c|c|c|c|c|c|c|c|}
\hline & B & Std. Error & Beta & $\mathrm{T}$ & Sig. ${ }^{\prime}$ & $\begin{array}{l}\text { Adjusted } \\
\mathrm{R}^{2}\end{array}$ & $\begin{array}{l}\text { Mean } \\
\text { square } \\
\text { residual }\end{array}$ \\
\hline constant & 1.468 & 0.190 & & 7.729 & 0.000 & & \\
\hline type of group & 2.992 & 0.112 & 0.948 & 26.631 & 0.000 & & \\
\hline $\begin{array}{l}\text { employment } \\
\text { degree }\end{array}$ & -0.005 & 0.002 & -0.088 & -2.533 & 0.018 & 0.969 & 0.080 \\
\hline assignment & 0.048 & 0.060 & 0.027 & 0.793 & 0.435 & & \\
\hline
\end{tabular}

1) Two-tailed 2) Covariates are the pre-tests of the demographic characteristics and dependent variable at hand

Table 5.1f Resident assignment: organisation C, psycho-geriatric group $\mathrm{n}=21$

\begin{tabular}{lcccrrrr}
\hline & B & Std. Error & Beta & T & Sig. ${ }^{\prime}$ & $\begin{array}{l}\text { Adjusted } \\
\mathrm{R}^{2}\end{array}$ & $\begin{array}{l}\text { Mean } \\
\text { square } \\
\text { residual }\end{array}$ \\
\hline constant & 0.055 & 0.606 & & 0.090 & 0.929 & & \\
type of grotp & 3.437 & 0.086 & 1.029 & 39.986 & 0.000 & & \\
gender ${ }^{2}$ & 0.191 & 0.124 & 0.040 & 1.539 & 0.143 & 0.991 & 0.027 \\
working hours & 0.342 & 0.139 & 0.060 & 2.451 & 0.026 & & \\
assignment & -0.056 & 0.267 & -0.005 & -0.210 & 0.837 & & \\
\hline
\end{tabular}

1) Two-tailed 2) Covariates are the pre-tests of the demographic characteristics and dependent variable at hand

\subsection{Use of the nursing process}

Table 5.2a Use of nursing care plans and their evaluation $n=143$

\begin{tabular}{|c|c|c|c|c|c|c|c|}
\hline & B & Std. Error & Beta & $\mathrm{T}$ & Sig. ' & $\begin{array}{l}\text { Adjusted } \\
\mathrm{R}^{2}\end{array}$ & $\begin{array}{l}\text { Mean square } \\
\text { residual }\end{array}$ \\
\hline constant & 1.281 & 0.484 & & 2.649 & 0.009 & \multirow{7}{*}{0.286} & \multirow{7}{*}{0.328} \\
\hline type of group & 0.246 & 0.100 & 0.182 & 2.467 & 0.015 & & \\
\hline org. dummy $\mathrm{X}$ & -0.580 & 0.129 & -0.383 & -4.502 & 0.000 & & \\
\hline org. dummy $Y$ & -0.091 & 0.117 & -0.066 & -0.779 & 0.437 & & \\
\hline age $^{2}$ & -0.091 & 0.007 & 0.297 & 3.380 & 0.001 & & \\
\hline employment degree & 0.005 & 0.002 & 0.188 & 2.083 & 0.039 & & \\
\hline nursing care plans & 0.384 & 0.077 & 0.384 & 5.009 & 0.000 & & \\
\hline & $\begin{array}{l}\text { R- } \\
\text { square } \\
\text { change }\end{array}$ & $\begin{array}{l}\mathrm{F} \\
\text { change }\end{array}$ & $\begin{array}{l}\text { Sig. F } \\
\text { change }\end{array}$ & & & & \\
\hline $\begin{array}{l}\text { org. dummy } X \\
\text { org. dummy } Y\end{array}$ & -0.116 & 11.561 & 0.000 & & & & \\
\hline
\end{tabular}
1) Two-tailed
2) Covariates are the pre-tests of the demographic characteristics and dependent variable at hand 
Table 5.2b Taking nursing history, nursing problems, goals and actions $n=145$

\begin{tabular}{|c|c|c|c|c|c|c|c|}
\hline & B & Std. Error & Beta & $\mathrm{T}$ & Sig. ${ }^{\prime}$ & $\begin{array}{l}\text { Adjusted } \\
\mathrm{R}^{2}\end{array}$ & $\begin{array}{l}\text { Mean square } \\
\text { residual }\end{array}$ \\
\hline constant & 2.011 & 0.503 & & 4.003 & 0.000 & \multirow{7}{*}{0.257} & \multirow{7}{*}{0.370} \\
\hline type of group & 0.308 & 0.104 & 0.219 & 2.956 & 0.004 & & \\
\hline org. dummy $\mathrm{X}$ & -0.575 & 0.138 & -0.365 & -4.168 & 0.000 & & \\
\hline org. dummy $Y$ & -0.073 & 0.122 & -0.051 & -0.599 & 0.550 & & \\
\hline age $^{2}$ & 0.013 & 0.007 & 0.164 & 1.861 & 0.065 & & \\
\hline employment degree & 0.006 & 0.002 & 0.246 & 2.756 & 0.007 & & \\
\hline nursing history & 0.337 & 0.079 & 0.320 & 4.286 & 0.000 & & \\
\hline & $\begin{array}{l}\text { R- } \\
\text { square } \\
\text { change }\end{array}$ & $\begin{array}{l}\mathrm{F} \\
\text { change }\end{array}$ & $\begin{array}{l}\text { Sig. F } \\
\text { change }\end{array}$ & & & & \\
\hline $\begin{array}{l}\text { org. dummy X } \\
\text { org. dummy Y }\end{array}$ & -0.108 & 10.446 & 0.000 & & & & \\
\hline
\end{tabular}

\subsection{Tasks}

Table 5.3a Resident-oriented tasks: somatic group $\mathrm{n}=76$

\begin{tabular}{|c|c|c|c|c|c|c|c|}
\hline & B & Std. Error & Beta & $\mathbf{T}$ & Sig. ' & $\begin{array}{l}\text { Adjusted } \\
\mathrm{R}^{2}\end{array}$ & $\begin{array}{l}\text { Mean square } \\
\text { residual }\end{array}$ \\
\hline constant & -2.801 & 2.953 & & -0.949 & 0.346 & \multirow{9}{*}{0.189} & \multirow{9}{*}{0.568} \\
\hline type of group & 0.099 & 0.211 & 0.059 & 0.469 & 0.641 & & \\
\hline org. dummy $\mathrm{X}$ & -1.970 & 0.706 & -1.007 & -2.790 & 0.007 & & \\
\hline org. dummy Y & -1.223 & 0.355 & -0.734 & -3.441 & 0.001 & & \\
\hline ward experience ${ }^{2}$ & -0.004 & 0.002 & -0.212 & -1.818 & 0.073 & & \\
\hline careload $^{3}$ & 0.727 & 0.366 & 0.620 & 1.985 & 0.051 & & \\
\hline $\begin{array}{l}\text { resident-oriented } \\
\text { tasks }{ }^{2}\end{array}$ & 0.281 & 0.118 & 0.254 & 2.385 & 0.020 & & \\
\hline & $\begin{array}{l}\text { R- } \\
\text { square } \\
\text { change }\end{array}$ & $\begin{array}{l}\mathbf{F} \\
\text { change }\end{array}$ & $\begin{array}{l}\text { Sig. F } \\
\text { change }\end{array}$ & & & & \\
\hline $\begin{array}{l}\text { org. dummy } X \\
\text { org. dummy } Y\end{array}$ & -0.129 & 5.974 & 0.004 & & & & \\
\hline
\end{tabular}

Table 5.3b Resident-oriented tasks: psycho-geriatric group $n=64$

\begin{tabular}{llllllll}
\hline & B & Std. Error & Beta & T & Sig. ${ }^{1}$ & $\begin{array}{l}\text { Adjusted } \\
\mathrm{R}^{2}\end{array}$ & $\begin{array}{l}\text { Mean } \\
\text { square } \\
\text { residual }\end{array}$ \\
\hline constant & 1.643 & 0.350 & & 4.697 & 0.000 & & \\
type of group & 0.915 & 0.169 & 0.542 & 5.415 & 0.000 & 0.389 & 0.443 \\
resident-oriented & 0.336 & 0.132 & 0.255 & 2.551 & 0.013 & & \\
tasks & & & & & & &
\end{tabular}
1) Two-tailed 2) Covariate is the pre-test of the dependent variable at hand 
Table 5.3c Resident-oriented tasks: PNC group versus control group $\geq 70 \%$ working

\begin{tabular}{|c|c|c|c|c|c|c|c|}
\hline & B & Std. Error & Beta & $\mathrm{T}$ & Sig. I & $\begin{array}{l}\text { Adjusted } \\
\mathrm{R}^{2}\end{array}$ & $\begin{array}{l}\text { Mean } \\
\text { square } \\
\text { residual }\end{array}$ \\
\hline constant & 3.461 & 0.482 & & 7.184 & 0.000 & \multirow{7}{*}{0.359} & \multirow{7}{*}{0.332} \\
\hline PNC group & 0.730 & 0.133 & 0.510 & 5.479 & 0.000 & & \\
\hline org. dummy X & -0.430 & 0.190 & -0.291 & -2.266 & 0.027 & & \\
\hline org. dummy Y & -0.272 & 0.187 & -0.184 & -1.456 & 0.150 & & \\
\hline education ${ }^{2}$ & -0.288 & 0.139 & -0.200 & -2.074 & 0.042 & & \\
\hline ward experience & -0.008 & 0.002 & -0.343 & -3.282 & 0.002 & & \\
\hline $\begin{array}{l}\text { resident-oriented } \\
\text { tasks }\end{array}$ & 0.110 & 0.105 & 0.101 & 1.047 & 0.299 & & \\
\hline & $\begin{array}{l}\text { R- } \\
\text { square } \\
\text { change }\end{array}$ & $\begin{array}{l}\mathrm{F} \\
\text { change }\end{array}$ & $\begin{array}{l}\text { Sig. F } \\
\text { change }\end{array}$ & & & & \\
\hline $\begin{array}{l}\text { org. dummy X } \\
\text { org. dummy Y }\end{array}$ & -0.043 & 2.569 & 0.084 & & & & \\
\hline
\end{tabular}

Table 5.3d Resident-oriented tasks: associate nursing group versus control group $<70 \%$ working $n=65$

\begin{tabular}{|c|c|c|c|c|c|c|c|}
\hline & B & Std. Error & Beta & $\mathrm{T}$ & Sig. ${ }^{1}$ & $\begin{array}{l}\text { Adjusted } \\
\mathrm{R}^{2}\end{array}$ & $\begin{array}{l}\text { Mean } \\
\text { square } \\
\text { residual }\end{array}$ \\
\hline constant & 1.745 & 0.422 & & 4.135 & 0.000 & & \\
\hline associate group & 0.312 & 0.234 & 0.155 & 1.330 & 0.188 & 0.127 & 0.891 \\
\hline $\begin{array}{l}\text { resident-oriented } \\
\text { tasks }^{2}\end{array}$ & 0.452 & 0.145 & 0.364 & 3.115 & 0.003 & & \\
\hline
\end{tabular}

1) Two-tailed 2) Covariate is the pre-test of the dependent variable at hand

Table 5.3e Ward-oriented tasks $n=138$

\begin{tabular}{llllllll}
\hline & B & Std. Error & Beta & $\mathrm{T}$ & Sig. ${ }^{1}$ & $\begin{array}{l}\text { Adjusted } \\
\mathrm{R}^{2}\end{array}$ & $\begin{array}{l}\text { Mean } \\
\text { square } \\
\text { residual }\end{array}$ \\
\hline constant & 1.994 & 0.239 & & 8.332 & 0.000 & & 0.427 \\
$\begin{array}{l}\text { type of group } \\
\text { ward-oriented } \\
\text { tasks }\end{array}$ & 0.098 & 0.111 & 0.070 & 0.880 & 0.380 & 0.126 & 0.000 \\
\hline
\end{tabular}

1) Two-tailed 2) Covariate is the pre-test of the dependent variable at hand 


\subsection{Communication}

Table 5.4a Quality of communication forms

$\mathrm{n}=139$

\begin{tabular}{|c|c|c|c|c|c|c|c|}
\hline & B & Std. Error & Beta & $\mathrm{T}$ & Sig. ${ }^{1}$ & $\begin{array}{l}\text { Adjusted } \\
\mathrm{R}^{2}\end{array}$ & $\begin{array}{l}\text { Mean } \\
\text { square } \\
\text { residual }\end{array}$ \\
\hline$\overline{\text { constant }}$ & 1.420 & 0.487 & & 2.917 & 0.004 & \multirow{8}{*}{0.279} & \multirow{10}{*}{0.102} \\
\hline type of group & -0.095 & 0.056 & -0.127 & -1.690 & 0.093 & & \\
\hline type of ward & -0.228 & 0.078 & -0.305 & -2.929 & 0.004 & & \\
\hline org. dummy $X$ & -0.303 & 0.088 & -0.362 & -3.439 & 0.001 & & \\
\hline org. dummy Y & 0.023 & 0.068 & 0.031 & 0.345 & 0.731 & & \\
\hline $\begin{array}{l}\text { employment } \\
\text { degree }^{2}\end{array}$ & 0.002 & 0.001 & 0.171 & 2.295 & 0.023 & & \\
\hline careload $^{3}$ & 0.099 & 0.047 & 0.239 & 2.099 & \multirow{4}{*}{$\begin{array}{l}0.038 \\
0.000\end{array}$} & & \\
\hline quality comm ${ }^{2}$ & 0.382 & 0.072 & 0.421 & \multirow{3}{*}{5.299} & & & \\
\hline & $\begin{array}{l}\text { R- } \\
\text { square } \\
\text { change }\end{array}$ & $\begin{array}{l}F \\
\text { change }\end{array}$ & $\begin{array}{l}\text { Sig. F } \\
\text { change }\end{array}$ & & & & \\
\hline $\begin{array}{l}\text { org. dummy X } \\
\text { org. dummy Y }\end{array}$ & -0.103 & 9.811 & 0.000 & & & & \\
\hline
\end{tabular}

Table 5.4b Variety of resident-oriented communication forms $\mathrm{n}=142$

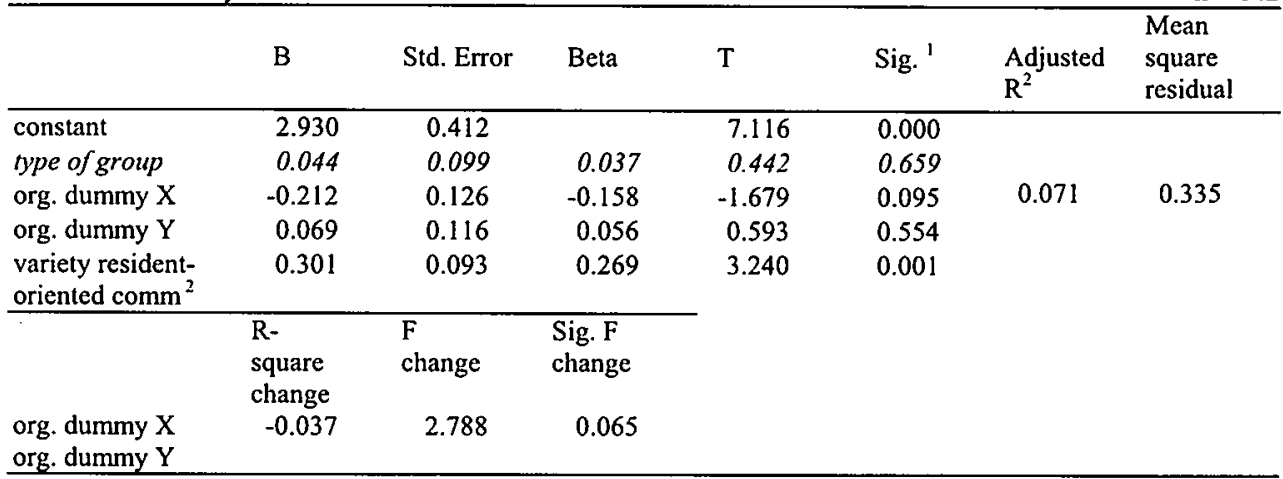

1) Two-tailed 2) Covariate is the pre-test of the dependent variable at hand 
Table 5.4c Variety of ward-oriented communication forms $\mathrm{n}=139$

\begin{tabular}{|c|c|c|c|c|c|c|c|}
\hline & B & Std. Error & Beta & $\mathbf{T}$ & Sig. ${ }^{\prime}$ & $\begin{array}{l}\text { Adjusted } \\
\mathrm{R}^{2}\end{array}$ & $\begin{array}{l}\text { Mean } \\
\text { square } \\
\text { residual }\end{array}$ \\
\hline constant & 3.302 & 0.313 & & 10.549 & 0.000 & \multirow{8}{*}{0.185} & \multirow{8}{*}{0.202} \\
\hline type of group & -0.047 & 0.080 & -0.047 & -0.587 & 0.559 & & \\
\hline type of ward & -0.181 & 0.079 & -0.182 & -2.302 & 0.023 & & \\
\hline org. dummy $\mathrm{X}$ & -0.399 & 0.106 & -0.358 & -3.758 & 0.000 & & \\
\hline org. dummy $Y$ & -0.225 & 0.098 & -0.223 & -2.295 & 0.023 & & \\
\hline education ${ }^{2}$ & -0.184 & 0.070 & -0.206 & -2.617 & 0.010 & & \\
\hline ward experience & -0.002 & 0.001 & -0.239 & -2.729 & 0.007 & & \\
\hline $\begin{array}{l}\text { varicty ward- } \\
\text { oriented comm }\end{array}$ & 0.258 & 0.078 & 0.265 & 3.325 & 0.001 & & \\
\hline & $\begin{array}{l}\text { R- } \\
\text { square } \\
\text { change }\end{array}$ & $\begin{array}{l}\mathrm{F} \\
\text { change }\end{array}$ & $\begin{array}{l}\text { Sig. F } \\
\text { change }\end{array}$ & & & & \\
\hline $\begin{array}{l}\text { org. dummy } X \\
\text { org. dummy } Y\end{array}$ & -0.084 & 7.085 & 0.001 & & & & \\
\hline
\end{tabular}

Table 5.4d Variety of ward-oriented communication forms: PNC group versus

\begin{tabular}{|c|c|c|c|c|c|c|c|}
\hline & B & Std. Error & Beta & $\mathrm{T}$ & Sig. ${ }^{1}$ & $\begin{array}{l}\text { Adjusted } \\
\mathrm{R}^{2}\end{array}$ & $\begin{array}{l}\text { Mean } \\
\text { square } \\
\text { residual }\end{array}$ \\
\hline constant & -0.046 & 0.953 & & -0.048 & 0.962 & \multirow{10}{*}{0.229} & \multirow{10}{*}{0.192} \\
\hline PNC group & 0.075 & 0.109 & 0.075 & 0.685 & 0.495 & & \\
\hline org. dummy $\mathrm{X}$ & -0.430 & 0.138 & -0.418 & -3.114 & 0.003 & & \\
\hline org. dummy $Y$ & -0.245 & 0.141 & -0.242 & -1.740 & 0.086 & & \\
\hline gender ${ }^{2}$ & 0.371 & 0.190 & 0.216 & 1.952 & 0.055 & & \\
\hline age & 0.014 & 0.007 & 0.238 & 2.101 & 0.039 & & \\
\hline employment degrce & 0.016 & 0.006 & 0.333 & 2.966 & 0.004 & & \\
\hline $\begin{array}{l}\text { variety ward- } \\
\text { oriented comm }\end{array}$ & 0.318 & 0.111 & 0.312 & 2.861 & 0.006 & & \\
\hline & $\begin{array}{l}\text { R- } \\
\text { square } \\
\text { change }\end{array}$ & $\begin{array}{l}\mathrm{F} \\
\text { change }\end{array}$ & $\begin{array}{l}\text { Sig. F } \\
\text { change }\end{array}$ & & & & \\
\hline $\begin{array}{l}\text { org. dummy X } \\
\text { org. dummy Y }\end{array}$ & -0.101 & 4.915 & 0.010 & & & & \\
\hline
\end{tabular}

Table 5.4e Variety of ward-oriented communication forms: associate nursing group versus control group $<70 \%$ working $\mathrm{n}=61$

\begin{tabular}{lrrrrrrr}
\hline & B & Std. Error & Beta & $\mathrm{T}$ & Sig. 1 & $\begin{array}{l}\text { Adjusted } \\
\mathrm{R}^{2}\end{array}$ & $\begin{array}{l}\text { Mean } \\
\text { square } \\
\text { residual }\end{array}$ \\
\hline constant & 2.775 & 0.325 & & 8.534 & 0.000 & & \\
$\begin{array}{l}\text { associate group } \\
\text { variety ward- }\end{array}$ & -0.286 & 0.101 & -0.339 & -2.830 & 0.006 & 0.199 & 0.144 \\
oriented comm $^{2}$ & 0.202 & 0.094 & 0.257 & 2.151 & 0.036 & & \\
\hline
\end{tabular}

1) Two-tailed 2) Covariate is the pre-test of the dependent variable at hand 


\section{Appendix 6 Final regression models job characteristics and psychological and behavioural reactions}

\subsection{Job autonomy}

Table 6.1a Job autonomy

$n=144$

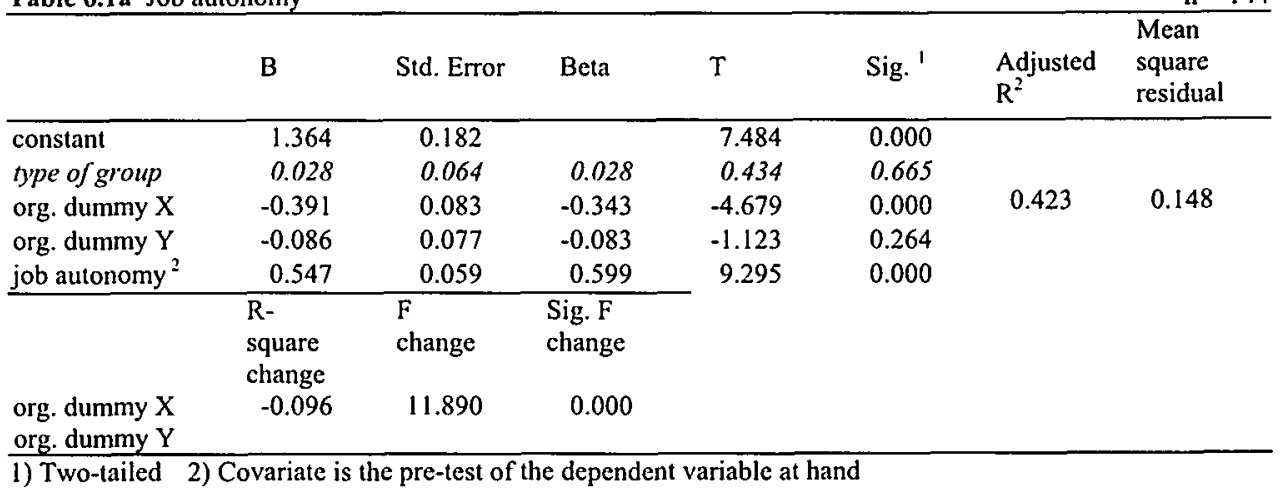

Table 6.1b Contextual job autonomy $n=143$

\begin{tabular}{|c|c|c|c|c|c|c|c|}
\hline & B & Std. Error & Beta & $\mathrm{T}$ & Sig. ${ }^{\prime}$ & $\begin{array}{l}\text { Adjusted } \\
\mathrm{R}^{2}\end{array}$ & $\begin{array}{l}\text { Mean } \\
\text { square } \\
\text { residual }\end{array}$ \\
\hline constant & -0.720 & 0.547 & & -1.317 & 0.190 & \multirow{9}{*}{0.454} & \multirow{9}{*}{0.178} \\
\hline type of group & 0.124 & 0.072 & 0.109 & 1.721 & 0.087 & & \\
\hline org. dummy X & -0.371 & 0.102 & -0.290 & -3.645 & 0.000 & & \\
\hline org. dummy Y & 0.029 & 0.088 & 0.025 & 0.331 & 0.741 & & \\
\hline working hours ${ }^{2}$ & 0.489 & 0.161 & 0.198 & 3.033 & 0.003 & & \\
\hline careload $^{3}$ & 0.092 & 0.044 & 0.147 & 2.089 & 0.039 & & \\
\hline $\begin{array}{l}\text { contextual job } \\
\text { autonomy }\end{array}$ & 0.552 & 0.055 & 0.635 & 9.953 & 0.000 & & \\
\hline & $\begin{array}{l}\text { R- } \\
\text { square } \\
\text { change }\end{array}$ & $\begin{array}{l}F \\
\text { change }\end{array}$ & $\begin{array}{l}\text { Sig. F } \\
\text { change }\end{array}$ & & & & \\
\hline $\begin{array}{l}\text { org. dummy } X \\
\text { org. dummy } Y \\
\end{array}$ & -0.071 & 9.273 & 0.000 & & & & \\
\hline
\end{tabular}




\begin{tabular}{|c|c|c|c|c|c|c|c|}
\hline & B & Std. Error & Beta & $\mathrm{T}$ & Sig. ${ }^{1}$ & $\begin{array}{l}\text { Adjusted } \\
\mathrm{R}^{2}\end{array}$ & $\begin{array}{l}\text { Mean } \\
\text { square } \\
\text { residual }\end{array}$ \\
\hline constant & 2.094 & 0.248 & & 8.442 & 0.000 & \multirow{7}{*}{0.263} & \multirow{7}{*}{0.244} \\
\hline type of group & 0.001 & 0.082 & 0.001 & 0.015 & 0.988 & & \\
\hline org. dummy $\mathrm{X}$ & -0.523 & 0.106 & -0.406 & -4.919 & 0.000 & & \\
\hline org. dummy Y & -0.159 & 0.096 & -0.136 & -1.647 & 0.102 & & \\
\hline \multirow[t]{2}{*}{$\begin{array}{l}\text { content job auton- } \\
\text { omy }^{2}\end{array}$} & 0.415 & 0.074 & 0.402 & 5.640 & 0.000 & & \\
\hline & $\begin{array}{l}\text { R- } \\
\text { square } \\
\text { change }\end{array}$ & $\begin{array}{l}\mathbf{F} \\
\text { change }\end{array}$ & $\begin{array}{l}\text { Sig. } F \\
\text { change }\end{array}$ & & & & \\
\hline $\begin{array}{l}\text { org. dummy X } \\
\text { org. dummy Y }\end{array}$ & -0.127 & 12.587 & 0.000 & & & & \\
\hline
\end{tabular}

1) Two-tailed 2) Covariate is the pre-test of the dependent variable at hand

\subsection{Job demands}

Table 6.2a Job demands, somatic group $\mathrm{n}=78$

\begin{tabular}{|c|c|c|c|c|c|c|c|}
\hline & B & Std. Error & Beta & $\mathrm{T}$ & Sig. ${ }^{1}$ & $\begin{array}{l}\text { Adjusted } \\
\mathrm{R}^{2}\end{array}$ & $\begin{array}{l}\text { Mean } \\
\text { square } \\
\text { residual }\end{array}$ \\
\hline constant & 6.729 & 1.906 & & 3.530 & 0.001 & \multirow{7}{*}{0.463} & \multirow{7}{*}{0.197} \\
\hline type of group & 0.179 & 0.121 & 0.148 & 1.483 & 0.142 & & \\
\hline org. dummy $\mathrm{X}$ & 0.722 & 0.416 & 0.514 & 1.737 & 0.087 & & \\
\hline org. dummy $\mathrm{Y}$ & 0.484 & 0.205 & 0.401 & 2.363 & 0.021 & & \\
\hline gender ${ }^{2}$ & -0.740 & 0.269 & -0.236 & -2.747 & 0.008 & & \\
\hline careload $^{3}$ & -0.519 & 0.217 & -0.614 & -2.390 & 0.019 & & \\
\hline job demands ${ }^{2}$ & 0.672 & 0.125 & 0.540 & 5.387 & 0.000 & & \\
\hline & $\begin{array}{l}\text { R- } \\
\text { square } \\
\text { change }\end{array}$ & $\begin{array}{l}\mathrm{F} \\
\text { change }\end{array}$ & $\begin{array}{l}\text { Sig. F } \\
\text { change }\end{array}$ & & & & \\
\hline $\begin{array}{l}\text { org. dummy } X \\
\text { org. dummy } Y\end{array}$ & -0.041 & 2.963 & 0.058 & & & & \\
\hline
\end{tabular}


Table 6.2b Job demands, psycho-geriatric group

$n=69$

\begin{tabular}{|c|c|c|c|c|c|c|c|}
\hline & B & Std. Error & Beta & $\mathrm{T}$ & Sig. ${ }^{1}$ & $\begin{array}{l}\text { Adjusted } \\
\mathrm{R}^{2}\end{array}$ & $\begin{array}{l}\text { Mean } \\
\text { square } \\
\text { residual }\end{array}$ \\
\hline constant & 2.163 & 0.969 & & 2.233 & 0.029 & \multirow{9}{*}{0.561} & \multirow{9}{*}{0.156} \\
\hline type of group & -0.225 & 0.116 & -0.190 & -1.933 & 0.058 & & \\
\hline org. dummy X & 0.766 & 0.137 & 0.595 & 5.590 & 0.000 & & \\
\hline org. dummy Y & 0.220 & 0.134 & 0.176 & 1.649 & 0.104 & & \\
\hline working hours ${ }^{2}$ & 0.432 & 0.216 & 0.171 & 1.999 & 0.050 & & \\
\hline careload $^{3}$ & -0.191 & 0.093 & -0.216 & -2.045 & 0.045 & & \\
\hline job demands ${ }^{2}$ & 0.633 & 0.094 & 0.697 & \multirow[t]{3}{*}{6.767} & \multirow[t]{3}{*}{0.000} & & \\
\hline & $\begin{array}{l}\text { R- } \\
\text { square } \\
\text { change }\end{array}$ & $\begin{array}{l}\mathrm{F} \\
\text { change }\end{array}$ & $\begin{array}{l}\text { Sig. F } \\
\text { change }\end{array}$ & & & & \\
\hline $\begin{array}{l}\text { org. dummy } X \\
\text { org. dummy } Y\end{array}$ & -0.227 & 17.563 & 0.000 & & & & \\
\hline
\end{tabular}

Table 6.2c Qualitative job demands

\begin{tabular}{|c|c|c|c|c|c|c|c|}
\hline & B & Std. Error & Beta & $\mathrm{T}$ & Sig. ${ }^{1}$ & $\begin{array}{l}\text { Adjusted } \\
\mathrm{R}^{2}\end{array}$ & $\begin{array}{l}\text { Mean } \\
\text { square } \\
\text { residual }\end{array}$ \\
\hline constant & 1.348 & 0.421 & & 3.203 & 0.002 & \multirow{8}{*}{0.236} & \multirow{8}{*}{0.278} \\
\hline type of group & 0.008 & 0.088 & 0.007 & 0.095 & 0.925 & & \\
\hline org. dummy $X$ & -0.278 & 0.119 & -0.206 & -2.325 & 0.022 & & \\
\hline org. dummy $Y$ & -0.163 & 0.109 & -0.133 & -1.496 & 0.137 & & \\
\hline working hours ${ }^{2}$ & 0.402 & 0.189 & 0.160 & 2.124 & 0.035 & & \\
\hline $\begin{array}{l}\text { qualitative job } \\
\text { demands }\end{array}$ & 0.341 & 0.070 & 0.378 & 4.859 & 0.000 & & \\
\hline & $\begin{array}{l}\text { R- } \\
\text { square } \\
\text { change }\end{array}$ & $\begin{array}{l}F \\
\text { change }\end{array}$ & $\begin{array}{l}\text { Sig. F } \\
\text { change }\end{array}$ & & & & \\
\hline $\begin{array}{l}\text { org. dummy } X \\
\text { org. dummy } Y\end{array}$ & -0.029 & 2.749 & 0.067 & & & & \\
\hline
\end{tabular}

Table 6.2d Quantitative job demands, somatic group $n=77$

\begin{tabular}{|c|c|c|c|c|c|c|c|}
\hline & B & Std. Error & Beta & $\mathrm{T}$ & Sig. ${ }^{1}$ & $\begin{array}{l}\text { Adjusted } \\
\mathrm{R}^{2}\end{array}$ & $\begin{array}{l}\text { Mean } \\
\text { square } \\
\text { residual }\end{array}$ \\
\hline constant & 8.780 & 2.193 & & 4.004 & 0.000 & \multirow{9}{*}{0.422} & \multirow{9}{*}{0.264} \\
\hline type of group & 0.177 & 0.144 & 0.132 & 1.227 & 0.224 & & \\
\hline org. dummy $X$ & 1.104 & 0.483 & 0.696 & 2.285 & 0.025 & & \\
\hline org. dummy $Y$ & 0.698 & 0.238 & 0.520 & 2.936 & 0.004 & & \\
\hline gender $^{2}$ & -0.979 & 0.382 & -0.232 & -2.564 & 0.012 & & \\
\hline careload $^{3}$ & -0.686 & 0.252 & -0.722 & -2.717 & 0.008 & & \\
\hline \multirow{2}{*}{$\begin{array}{l}\text { quantitative job } \\
\text { demands? }\end{array}$} & 0.602 & 0.131 & 0.482 & 4.583 & 0.000 & & \\
\hline & $\begin{array}{l}\text { R- } \\
\text { square } \\
\text { change }\end{array}$ & $\begin{array}{l}F \\
\text { change }\end{array}$ & $\begin{array}{l}\text { Sig. F } \\
\text { change }\end{array}$ & & & & \\
\hline $\begin{array}{l}\text { org. dummy } X \\
\text { org. dummy } Y\end{array}$ & -0.067 & 4.433 & 0.015 & & & & \\
\hline
\end{tabular}
1) Two-tailed 2) Covariates are the pre-tests of the demographic characteristics and dependent variable at hand
3) Covariate is the post-test 2 of the aggregated variable careload 
Table 6.2e Quantitative job demands, psycho-geriatric group

$n=69$

\begin{tabular}{|c|c|c|c|c|c|c|c|}
\hline & B & Std. Error & Beta & $\mathrm{T}$ & Sig. I & $\begin{array}{l}\text { Adjusted } \\
\mathrm{R}^{2}\end{array}$ & $\begin{array}{l}\text { Mean } \\
\text { square } \\
\text { residual }\end{array}$ \\
\hline constant & 2.923 & 1.121 & & 2.609 & 0.011 & \multirow{9}{*}{0.593} & \multirow{9}{*}{0.201} \\
\hline type of group & -0.268 & 0.132 & -0.191 & -2.037 & 0.046 & & \\
\hline org. dummy $\mathrm{X}$ & 0.954 & 0.151 & 0.629 & 6.334 & 0.000 & & \\
\hline org. dummy $Y$ & 0.223 & 0.148 & 0.151 & 1.509 & 0.136 & & \\
\hline working hours ${ }^{2}$ & 0.443 & 0.243 & 0.148 & 1.821 & 0.073 & & \\
\hline careload $^{3}$ & -0.268 & 0.109 & -0.257 & -2.460 & 0.017 & & \\
\hline $\begin{array}{l}\text { quantitative job } \\
\text { demands }{ }^{2}\end{array}$ & 0.626 & 0.090 & 0.682 & 6.930 & 0.000 & & \\
\hline & $\begin{array}{l}\mathrm{R}- \\
\text { square } \\
\text { change }\end{array}$ & $\begin{array}{l}\mathrm{F} \\
\text { change }\end{array}$ & $\begin{array}{l}\text { Sig. F } \\
\text { change }\end{array}$ & & & & \\
\hline $\begin{array}{l}\text { org. dummy X } \\
\text { org. dummy } Y\end{array}$ & -0.275 & 23.005 & 0.000 & & & & \\
\hline
\end{tabular}

\subsection{Social support}

Table 6.3a Social support: organisation A, model with interaction term (not corrected for post-test 2 careload)

\begin{tabular}{|c|c|c|c|c|c|c|c|}
\hline & B & Std. Error & Beta & $\mathrm{T}$ & Sig. ${ }^{1}$ & $\begin{array}{l}\text { Adjusted } \\
\mathrm{R}^{2}\end{array}$ & $\begin{array}{l}\text { Mean } \\
\text { square } \\
\text { residual }\end{array}$ \\
\hline constant & 2.710 & 0.257 & & 10.526 & 0.000 & \multirow{5}{*}{0.148} & \multirow{5}{*}{0.034} \\
\hline group $x$ ward & -0.039 & 0.028 & -0.195 & -1.415 & 0.164 & & \\
\hline type of group & 0.036 & 0.030 & 0.182 & 1.199 & 0.237 & & \\
\hline type of ward & -0.035 & 0.028 & -0.174 & -1.215 & 0.231 & & \\
\hline social support ${ }^{2}$ & 0.155 & 0.082 & 0.291 & 1.902 & 0.064 & & \\
\hline
\end{tabular}

1) Two-tailed 2) Covariate is the pre-test of the dependent variable at hand

Table 6.3b Social support: organisation A, final model $\mathrm{n}=47$

\begin{tabular}{lccccccc}
\hline & B & Std. Error & Beta & $\mathrm{T}$ & Sig. & $\begin{array}{l}\text { Adjusted } \\
\mathrm{R}^{2}\end{array}$ & $\begin{array}{l}\text { Mean } \\
\text { square } \\
\text { residual }\end{array}$ \\
\hline constant & 2.753 & 0.243 & & 11.171 & 0.000 & & \\
type of group $^{\text {social support }}{ }^{2}$ & 0.080 & 0.059 & 0.203 & 1.365 & 0.179 & & 0.035 \\
\hline
\end{tabular}

1) Two-tailed 2) Covariate is the pre-test of the dependent variable at hand

Table 6.3c Social support: organisation $B$, model with interaction term (not corrected for post-test 2 careload) $\mathrm{n}=39$

\begin{tabular}{|c|c|c|c|c|c|c|c|}
\hline & B & Std. Error & Beta & $\mathrm{T}$ & Sig. ' & $\begin{array}{l}\text { Adjusted } \\
\mathrm{R}^{2}\end{array}$ & $\begin{array}{l}\text { Mean } \\
\text { square } \\
\text { residual }\end{array}$ \\
\hline constant & 1.465 & 0.645 & & 2.274 & 0.029 & \multirow{5}{*}{0.478} & \multirow{5}{*}{0.080} \\
\hline group $x$ ward & 0.261 & 0.045 & 0.555 & 4.761 & 0.000 & & \\
\hline type of group & 0.044 & 0.045 & 0.114 & 0.979 & 0.334 & & \\
\hline type of ward & -0.218 & 0.054 & -0.560 & -4.027 & 0.000 & & \\
\hline social support ${ }^{2}$ & 0.496 & 0.191 & 0.363 & 2.605 & 0.014 & & \\
\hline
\end{tabular}

1) Two-tailed 2) Covariate is the pre-test of the dependent variable at hand 
Table 6.3d Social support: organisation B, model not corrected for post-test 2 careload (without interaction term) $n=39$

\begin{tabular}{lccccccc}
\hline & B & Std. Error & Beta & $\mathrm{T}$ & Sig. ${ }^{1}$ & $\begin{array}{l}\text { Adjusted } \\
\mathrm{R}^{2}\end{array}$ & $\begin{array}{l}\text { Mean } \\
\text { square } \\
\text { residual }\end{array}$ \\
\hline constant & 6.031 & 1.081 & & 5.578 & 0.000 & & \\
type of group & -0.388 & 0.137 & -0.499 & -2.832 & 0.008 & & 0.080 \\
type of ward $^{\text {careload }}{ }^{2}$ & -0.322 & 0.111 & -0.414 & -2.911 & 0.006 & 0.487 & \\
social support $^{3}$ & -0.424 & 0.089 & -0.850 & -4.761 & 0.000 & & \\
\hline
\end{tabular}

1) Two-tailed 2) Covariate is the post-test 2 of the aggregated variable careload 3) Covariate is the pre-test of the dependent variable at hand

Table 6.3e Social support: organisation B somatic group, final model (not corrected for post-test 2 careload)

\begin{tabular}{lrrrrrrr}
\hline & B & Std. Error & Beta & $\mathrm{T}$ & Sig. ${ }^{1}$ & $\begin{array}{l}\text { Adjusted } \\
\mathrm{R}^{2}\end{array}$ & $\begin{array}{l}\text { Mean } \\
\text { square } \\
\text { residual }\end{array}$ \\
\hline constant & -0.115 & 1.087 & & -0.106 & 0.917 & & 0.449 \\
type of group $^{2}$ & -0.297 & 0.120 & -0.445 & -2.468 & 0.026 & 0.065 \\
social support $^{2}$ & 1.089 & 0.336 & 0.584 & 3.244 & 0.005 & & \\
\hline
\end{tabular}

1) Two-tailed 2) Covariate is the pre-test of the dependent variable at hand

Table 6.3f Social support: organisation B psycho-geriatric group, final model (not corrected for post-test 2 careload)

\begin{tabular}{|c|c|c|c|c|c|c|c|}
\hline & B & Std. Enror & Beta & $\mathbf{T}$ & Sig. 1 & $\begin{array}{l}\text { Adjusted } \\
\mathrm{R}^{2}\end{array}$ & $\begin{array}{l}\text { Mean } \\
\text { square } \\
\text { residual }\end{array}$ \\
\hline constant & 1.395 & $0 . \overline{773}$ & & 1.803 & 0.089 & \multirow{3}{*}{0.510} & \multirow{3}{*}{0.072} \\
\hline type of group & 0.520 & 0.120 & 0.695 & 4.328 & 0.000 & & \\
\hline social support ${ }^{2}$ & 0.381 & 0.218 & 0.281 & 1.750 & 0.098 & & \\
\hline
\end{tabular}

1) Two-tailed 2) Covariate is the pre-test of the dependent variable at hand

Table 6.3g Social support: organisation B psycho-geriatric group, final model (without type of group) $\quad \mathbf{n}=20$

\begin{tabular}{lrrrrrrr} 
& B & Std. Error & Beta & T & Sig. ${ }^{1}$ & \multicolumn{1}{c}{$\begin{array}{l}\text { Adjusted } \\
\mathrm{R}^{2}\end{array}$} & $\begin{array}{l}\text { Mcan } \\
\text { square } \\
\text { residual }\end{array}$ \\
\hline constant $^{2}$ & 4.099 & 0.956 & & 4.289 & 0.000 & & 0.072 \\
carcload $^{2}$ & -0.243 & 0.056 & -0.695 & -4.328 & 0.000 & 0.510 & 0.072 \\
social support $^{3}$ & 0.381 & 0.218 & 0.281 & 1.750 & 0.098 & & \\
\hline
\end{tabular}

1) Two-tailed 2) Covariate is the post-test 2 of the aggregated variable careload 3) Covariate is the pre-test of the dependent variable at hand 
Table 6.3h Social support: organisation C, model with interaction term (not corrected for post-test 2 careload)

\begin{tabular}{lccccccc}
\hline & B & Std. Ertor & Beta & $\mathrm{T}$ & Sig. $^{\prime}$ & $\begin{array}{l}\text { Adjusted } \\
\mathrm{R}^{2}\end{array}$ & $\begin{array}{l}\text { Mean } \\
\text { square } \\
\text { residual }\end{array}$ \\
\hline constant & 1.589 & 0.310 & & 5.126 & 0.000 & & \\
group $x$ ward & 0.044 & 0.032 & 0.142 & 1.362 & 0.179 & & \\
type of group $^{\text {type of ward }}$ & -0.061 & 0.032 & -0.199 & -1.923 & 0.060 & 0.471 & 0.055 \\
social support $^{2}$ & -0.051 & 0.031 & -0.162 & -1.620 & 0.111 & & \\
\hline
\end{tabular}

1) Two-tailed 2) Covariate is the pre-test of the dependent variable at hand

Table 6.3i Social support: organisation $\mathrm{C}$, final model

\begin{tabular}{|c|c|c|c|c|c|c|c|}
\hline & B & Std. Error & Beta & $\mathrm{T}$ & Sig. ' & $\begin{array}{l}\text { Adjusted } \\
\mathrm{R}^{2}\end{array}$ & $\begin{array}{l}\text { Mean } \\
\text { square } \\
\text { residual }\end{array}$ \\
\hline$\overline{\text { constant }}$ & 2.583 & 0.466 & & 5.546 & 0.000 & & \\
\hline type of group & -0.125 & 0.062 & -0.204 & -2.019 & 0.048 & 0.427 & 0.054 \\
\hline careload $^{2}$ & -0.099 & 0.045 & -0.227 & -2.234 & 0.029 & & \\
\hline social support ${ }^{3}$ & 0.523 & 0.088 & 0.597 & 5.926 & 0.000 & & \\
\hline
\end{tabular}

$\begin{array}{lll}\text { 1) Two-tailed 2) Covariate is the post-test } 2 \text { of the aggregated variable careload } & \text { 3) Covariate is the pre-test }\end{array}$ of the dependent variable at hand

Table 6.3j Social support of supervisors: organisation A, model with interaction term (not corrected for post-test 2 careload)

\begin{tabular}{|c|c|c|c|c|c|c|c|}
\hline (not c & ected for & Std. Error & Beta & $\mathrm{T}$ & Sig. ${ }^{\prime}$ & $\begin{array}{l}\text { Adjusted } \\
\mathrm{R}^{2}\end{array}$ & $\begin{array}{l}\quad \mathbf{n}= \\
\text { Mean } \\
\text { square } \\
\text { residual }\end{array}$ \\
\hline constant & 2.481 & 0.247 & & 10.039 & 0.000 & \multirow{5}{*}{0.199} & \multirow{5}{*}{0.046} \\
\hline group $x$ ward & -0.028 & 0.033 & -0.116 & -0.849 & 0.401 & & \\
\hline type of group & -0.004 & 0.036 & -0.016 & -0.104 & 0.918 & & \\
\hline type of ward & -0.084 & 0.035 & -0.355 & -2.397 & 0.021 & & \\
\hline $\begin{array}{l}\text { social support su- } \\
\text { pervisors }\end{array}$ & 0.224 & 0.078 & 0.463 & 2.872 & 0.006 & & \\
\hline
\end{tabular}

1) Two-tailed 2) Covariate is the pre-test of the dependent variable at hand

Table 6.3k Social support of supervisors: organisation A, final model $n=46$

\begin{tabular}{|c|c|c|c|c|c|c|c|}
\hline & B & Std. Error & Beta & $\mathrm{T}$ & Sig. ${ }^{\prime}$ & $\begin{array}{l}\text { Adjusted } \\
\mathrm{R}^{2}\end{array}$ & $\begin{array}{l}\text { Mean } \\
\text { square } \\
\text { residual }\end{array}$ \\
\hline constant & 3.289 & 0.320 & & 10.267 & 0.000 & \multirow{4}{*}{0.216} & \multirow{4}{*}{0.045} \\
\hline type of group & 0.003 & 0.069 & 0.006 & 0.039 & 0.969 & & \\
\hline careload $^{2}$ & -0.093 & 0.035 & -0.373 & -2.644 & 0.011 & & \\
\hline $\begin{array}{l}\text { social support su- } \\
\text { pervisors }\end{array}$ & 0.231 & 0.074 & 0.478 & 3.132 & 0.003 & & \\
\hline
\end{tabular}
1) Two-tailed 2)
2) Covariate is the post-test 2 of the aggregated variable careload
3) Covariate is the pre-test of the dependent variable at hand 
Table 6.31 Social support of supervisors: organisation $B$, model with interaction term (not corrected for post-test 2 careload) $\mathrm{n}=39$

\begin{tabular}{lrrrrrrr}
\hline & B & Std. Error & Beta & $\mathrm{T}$ & Sig. & $\begin{array}{l}\text { Adjusted } \\
\mathrm{R}^{2}\end{array}$ & $\begin{array}{l}\text { Mean } \\
\text { square } \\
\text { residual }\end{array}$ \\
\hline constant & 0.775 & 0.927 & & 0.836 & 0.409 & & \\
group $\times$ ward & 0.301 & 0.061 & 0.526 & 4.969 & 0.000 & & 0.137 \\
type of group & 0.117 & 0.060 & 0.205 & 1.948 & 0.060 & & \\
type of ward & -0.340 & 0.072 & -0.595 & -4.707 & 0.000 & 0.591 & \\
gender & 0.549 & 0.284 & 0.212 & 1.935 & 0.062 & & \\
employment degree & 0.006 & 0.003 & 0.210 & 1.929 & 0.063 & & \\
social support su- & 0.205 & 0.198 & 0.129 & 1.035 & 0.308 & & \\
pervisors & & & & & & & \\
\hline
\end{tabular}

1) Two-tailed 2) Covariates are the pre-tests of the demographic characteristics and dependent variable at hand

Table 6.3m Social support of supervisors: organisation B, model corrected for careload (without interaction term)

$\mathrm{n}=39$

\begin{tabular}{|c|c|c|c|c|c|c|c|}
\hline & B & Std. Error & Beta & $\mathbf{T}$ & Sig. ${ }^{1}$ & $\begin{array}{l}\text { Adjusted } \\
\mathrm{R}^{2}\end{array}$ & $\begin{array}{l}\text { Mean } \\
\text { square } \\
\text { residual }\end{array}$ \\
\hline $\overrightarrow{\text { constant }}$ & 7.131 & 1.517 & & 4.701 & 0.000 & \multirow{7}{*}{0.591} & \multirow{7}{*}{0.137} \\
\hline type of group & -0.431 & 0.184 & -0.377 & -2.339 & 0.026 & & \\
\hline type of ward & -0.522 & 0.147 & -0.456 & -3.556 & 0.001 & & \\
\hline gender ${ }^{2}$ & 0.549 & 0.284 & 0.212 & 1.935 & 0.062 & & \\
\hline employment degree & 0.006 & 0.003 & 0.210 & 1.929 & 0.063 & & \\
\hline careload $^{3}$ & -0.592 & 0.119 & -0.806 & -4.969 & 0.000 & & \\
\hline $\begin{array}{l}\text { social support su- } \\
\text { pervisors }\end{array}$ & 0.205 & 0.198 & 0.129 & 1.035 & 0.308 & & \\
\hline \multicolumn{8}{|c|}{$\begin{array}{l}\text { 1) Two-tailed 2) Covariates are the pre-tests of the demographic characteristics and dependent variable at hand } \\
\text { 3) Covariate is the post-test } 2 \text { of the aggregated variable careload }\end{array}$} \\
\hline \multirow[t]{2}{*}{ Table $6.3 n$} & $\begin{array}{l}\text { upport of } \\
\text { ected fo }\end{array}$ & $\begin{array}{l}\text { ervisors: or } \\
\text { st-test } 2 \text { car }\end{array}$ & $\begin{array}{l}\text { nisation } \\
\text { ad) }\end{array}$ & atic gro & al mod & \multicolumn{2}{|r|}{$\mathrm{n}=18$} \\
\hline & B & Std. Error & Beta & $T$ & Sig. ${ }^{1}$ & $\begin{array}{l}\text { Adjusted } \\
\mathrm{R}^{2}\end{array}$ & $\begin{array}{l}\text { Mean } \\
\text { square } \\
\text { residual }\end{array}$ \\
\hline constant & -0.234 & 1.189 & & -0.197 & 0.846 & \multirow{3}{*}{0.457} & \multirow{3}{*}{0.110} \\
\hline type of group & -0.350 & 0.157 & -0.400 & -2.226 & 0.042 & & \\
\hline $\begin{array}{l}\text { social support su- } \\
\text { pervisors }\end{array}$ & 1.133 & 0.363 & 0.561 & 3.125 & 0.007 & & \\
\hline
\end{tabular}

1) Two-tailed 2) Covariate is the pre-test of the dependent variable at hand

Table 6.3o Social support of supervisors: organisation B psycho-geriatric group, final model (not corrected for post-test 2 careload)

\begin{tabular}{|c|c|c|c|c|c|c|c|}
\hline (not & ted f & Std. Error & Beta & $T$ & Sig. ${ }^{1}$ & $\begin{array}{l}\text { Adjusted } \\
\mathrm{R}^{2}\end{array}$ & $\begin{array}{l}\quad \mathbf{n}= \\
\text { Mean } \\
\text { square } \\
\text { residual }\end{array}$ \\
\hline constant & 2.011 & 1.106 & & 1.819 & 0.087 & & \\
\hline type of group & 0.827 & 0.176 & 0.758 & 4.711 & 0.000 & 0.517 & 0.151 \\
\hline $\begin{array}{l}\text { social support su- } \\
\text { pervisors } 2\end{array}$ & 0.085 & 0.303 & 0.045 & 0.281 & 0.782 & & \\
\hline
\end{tabular}

1) Two-tailed 2) Covariate is the pre-test of the dependent variable at hand 
Table 6.3p Social support of supervisors: organisation B- psycho-geriatric group, final model (without type of group)

$\mathrm{n}=\mathbf{2 0}$

\begin{tabular}{lrrrrrrr} 
& B & Std. Error & Bcta & $\mathrm{T}$ & Sig. ${ }^{\prime}$ & $\begin{array}{l}\text { Adjusted } \\
\mathrm{R}^{2}\end{array}$ \\
\hline constant & 6.310 & 1.273 & & 4.957 & 0.000 & $\begin{array}{l}\text { Mean } \\
\text { square } \\
\text { residual }\end{array}$ \\
careload $^{2}$ & -0.386 & 0.082 & -0.758 & -4.711 & 0.000 & 0.517 & 0.151 \\
social support su- $_{\text {pervisors }}^{3}$ & 0.085 & 0.303 & 0.045 & 0.281 & 0.782 & & \\
\hline
\end{tabular}

1) Two-tailed 2) Covariate is the post-test 2 of the aggregated variable careload 3) Covariate is the pre-test of the dependent variable at hand

Table 6.3q Social support of supervisors: organisation $C$, model with interaction term (not corrected for post-test 2 careload)

\begin{tabular}{|c|c|c|c|c|c|c|c|}
\hline & B & Std. Error & Beta & $\mathbf{T}$ & Sig. ${ }^{\prime}$ & $\begin{array}{l}\text { Adjusted } \\
\mathrm{R}^{2}\end{array}$ & $\begin{array}{l}\text { Mean } \\
\text { square } \\
\text { residual }\end{array}$ \\
\hline constant & 1.205 & 0.392 & & 3.074 & 0.003 & \multirow{5}{*}{0.358} & \multirow{5}{*}{0.095} \\
\hline group $x$ ward & 0.049 & 0.043 & 0.127 & 1.138 & 0.260 & & \\
\hline type of group & -0.037 & 0.043 & -0.097 & -0.876 & 0.385 & & \\
\hline type of ward & -0.072 & 0.042 & -0.183 & -1.705 & 0.094 & & \\
\hline $\begin{array}{l}\text { social support su- } \\
\text { pervisors }\end{array}$ & 0.624 & 0.113 & 0.601 & 5.532 & 0.000 & & \\
\hline
\end{tabular}

1) Two-tailed 2) Covariate is the pre-test of the dependent variable at hand

Table 6.3r Social support of supervisors: organisation C, final model $\mathrm{n}=57$

\begin{tabular}{|c|c|c|c|c|c|c|c|}
\hline & B & Std. Error & Beta & $\mathrm{T}$ & Sig. ${ }^{1}$ & $\begin{array}{l}\text { Adjusted } \\
\mathrm{R}^{2}\end{array}$ & $\begin{array}{l}\text { Mean } \\
\text { square } \\
\text { residual }\end{array}$ \\
\hline constant & 2.018 & 0.643 & & 3.138 & 0.003 & \multirow{4}{*}{0.402} & \multirow{4}{*}{0.09} \\
\hline type of group & -0.051 & 0.082 & -0.066 & -0.626 & 0.534 & & \\
\hline careload $^{2}$ & -0.122 & 0.058 & -0.221 & -2.107 & 0.040 & & \\
\hline $\begin{array}{l}\text { social support su- } \\
\text { pervisors }\end{array}$ & 0.724 & 0.122 & 0.625 & 5.925 & 0.000 & & \\
\hline
\end{tabular}

1) Two-tailed 2) Covariate is the post-test 2 of the aggregated variable careload 3) Covariate is the pre-test of the dependent variable at hand

Table 6.3s Social support of colleagues

$n=146$

\begin{tabular}{|c|c|c|c|c|c|c|c|}
\hline & B & Std. Error & Beta & $\mathrm{T}$ & Sig. ${ }^{1}$ & $\begin{array}{l}\text { Adjusted } \\
\mathrm{R}^{2}\end{array}$ & $\begin{array}{l}\text { Mean } \\
\text { square } \\
\text { residual }\end{array}$ \\
\hline constant & 2.087 & 0.215 & & 9.685 & 0.000 & \multirow{7}{*}{0.248} & \multirow{7}{*}{0.077} \\
\hline type of group & -0.045 & 0.046 & -0.071 & -0.976 & 0.331 & & \\
\hline org. dummy $X$ & -0.022 & 0.061 & -0.031 & -0.355 & 0.723 & & \\
\hline org. dummy $Y$ & 0.122 & 0.058 & 0.190 & 2.115 & 0.036 & & \\
\hline $\begin{array}{l}\text { social support col- } \\
\text { leagues }{ }^{2}\end{array}$ & 0.366 & 0.067 & 0.421 & 5.476 & 0.000 & & \\
\hline & $\begin{array}{l}\text { R- } \\
\text { square } \\
\text { change }\end{array}$ & $\begin{array}{l}\mathrm{F} \\
\text { change }\end{array}$ & $\begin{array}{l}\text { Sig. F } \\
\text { change }\end{array}$ & & & & \\
\hline $\begin{array}{l}\text { org. dummy X } \\
\text { org. dummy } Y\end{array}$ & -0.040 & 3.864 & 0.023 & & & & \\
\hline
\end{tabular}

1) Two-tailed 2) Covariate is the pre-test of the dependent variable at hand 
Appendices

\subsection{Responsibility}

Table 6.4 Responsibility $\mathrm{n}=145$

\begin{tabular}{lrrrrrrr}
\hline & B & Std. Error & Bcta & $T$ & Sig. ${ }^{\prime}$ & $\begin{array}{l}\text { Adjusted } \\
\mathrm{R}^{2}\end{array}$ & $\begin{array}{l}\text { Mean } \\
\text { square } \\
\text { residual }\end{array}$ \\
\hline constant & 2.888 & 0.475 & & 6.082 & 0.000 & & \\
type of group $^{2}$ & 0.008 & 0.077 & 0.007 & 0.097 & 0.923 & & \\
gender $^{2}$ & -0.408 & 0.185 & -0.164 & -2.203 & 0.029 & 0.278 & 0.207 \\
employment degree $^{\text {responsibility }}$ & 0.004 & 0.002 & 0.217 & 2.867 & 0.005 & & \\
\hline
\end{tabular}

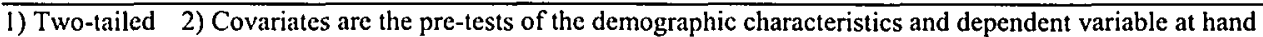

\subsection{Job satisfaction}

Table 6.5 Job satisfaction

\begin{tabular}{lrrcrcc}
\hline & $\mathrm{B}$ & Std. Error & $\chi^{2}$ (Wald) & Sig. & $-2 \log$ LR & Sig. $\log$ LR \\
\hline constant & -12.738 & 42.402 & 0.090 & 0.764 & - & - \\
type of group & -0.243 & 0.466 & 0.272 & 0.602 & - & - \\
gender $^{2}$ & 6.808 & 21.183 & 0.103 & 0.748 & 2.709 & 0.100 \\
working hours & -2.311 & 0.988 & 5.473 & 0.019 & 5.441 & 0.020 \\
employment de- & 0.017 & 0.010 & 2.890 & 0.089 & 3.030 & 0.082 \\
gree & & & & & & \\
job satisfaction & 2.665 & 0.510 & 27.297 & 0.000 & - & - \\
\hline
\end{tabular}

I) Two-tailed 2) Covariates are the pre-tests of the demographic characteristics and dependent variable at hand

\subsection{Intrinsic work motivation}

Table 6.6 Intrinsic work motivation $\mathrm{n}=145$

\begin{tabular}{|c|c|c|c|c|c|c|c|}
\hline & B & Std. Error & Beta & $T$ & Sig. ${ }^{\prime}$ & $\begin{array}{l}\text { Adjusted } \\
\mathrm{R}^{2}\end{array}$ & $\begin{array}{l}\text { Mean } \\
\text { square } \\
\text { residual }\end{array}$ \\
\hline constant & 1.898 & 0.481 & & 3.946 & 0.000 & \multirow{6}{*}{0.330} & \multirow{6}{*}{0.165} \\
\hline type of group & -0.029 & 0.068 & .0 .030 & -0.433 & 0.666 & & \\
\hline age $^{2}$ & 0.014 & 0.005 & 0.245 & 2.972 & 0.003 & & \\
\hline working hours & -0.470 & 0.160 & -0.217 & -2.934 & 0.004 & & \\
\hline employment degree & 0.006 & 0.002 & 0.339 & 3.910 & 0.000 & & \\
\hline $\begin{array}{l}\text { intrinsic work moti- } \\
\text { vation }\end{array}$ & 0.530 & 0.077 & 0.475 & 6.916 & 0.000 & & \\
\hline
\end{tabular}

1) Two-tailed 2) Covariates are the pre-tests of the demographic characteristics and dependent variable at hand 


\subsection{Health complaints}

Table 6.7 Health complaints $n=137$

\begin{tabular}{lrcrrrrr}
\hline & B & Std. Error & Beta & T & Sig. ${ }^{\text {Adjusted }}$ & $\begin{array}{l}\text { Mean } \\
\text { square } \\
\text { residual }\end{array}$ \\
\hline constant & 5.646 & 1.680 & & 3.360 & 0.001 & & \\
type of group & 0.328 & 0.367 & 0.051 & 0.895 & 0.373 & & \\
gender $^{2}$ & -2.581 & 0.831 & -0.176 & -3.107 & 0.002 & 0.579 & 4.436 \\
health complaints & 0.721 & 0.054 & 0.743 & 13.345 & 0.000 & & \\
\hline
\end{tabular}

1) Two-tailed 2) Covariates are the pre-tests of the demographic characteristics and dependent variable at hand

\subsection{Frequency of sickness absence}

Table 6.8a Frequency of sickness absence $\mathrm{n}=147$

\begin{tabular}{|c|c|c|c|c|c|c|c|}
\hline & B & Sid. Error & Beta & $\mathrm{T}$ & Sig. ' & $\begin{array}{l}\text { Adjusted } \\
\mathrm{R}^{2}\end{array}$ & $\begin{array}{l}\text { Mean } \\
\text { square } \\
\text { residual }\end{array}$ \\
\hline constant & 0.054 & 0.044 & & 1.214 & 0.277 & \multirow{4}{*}{0.149} & \multirow{4}{*}{0.033} \\
\hline type of group & -0.042 & 0.030 & -0.108 & -1.409 & 0.161 & & \\
\hline $\begin{array}{l}\text { employment } \\
\text { degree }^{h}\end{array}$ & 0.002 & 0.001 & 0.260 & 3.242 & 0.001 & & \\
\hline $\begin{array}{l}\text { frequency of sick- } \\
\text { ness absence }\end{array}$ & 0.219 & 0.077 & 0.231 & 2.858 & 0.005 & & \\
\hline
\end{tabular}

1) Two-tailed 2) Covariates are the pre-tests of the demographic characteristics and dependent variable at hand

Table 6.8b Frequency of sickness absence: PNC group versus control group $\geq 70 \%$ working $\mathbf{n}=79$

\begin{tabular}{|c|c|c|c|c|c|c|c|}
\hline & B & Std. Error & Beta & $\mathrm{T}$ & Sig. ${ }^{\prime}$ & $\begin{array}{l}\text { Adjusted } \\
\mathrm{R}^{2}\end{array}$ & $\begin{array}{l}\text { Mcan } \\
\text { square } \\
\text { residual }\end{array}$ \\
\hline constant & 0.280 & 0.059 & & 4.762 & 0.000 & \multirow{6}{*}{0.079} & \multirow{6}{*}{0.036} \\
\hline PNC group & -0.087 & 0.044 & -0.222 & -1.969 & 0.053 & & \\
\hline type of ward & 0.028 & 0.045 & 0.072 & 0.621 & 0.536 & & \\
\hline org. dummy $\mathrm{X}$ & -0.039 & 0.056 & -0.95 & -0.689 & 0.493 & & \\
\hline org. dummy $Y$ & -0.118 & 0.057 & -0.294 & -2.074 & 0.042 & & \\
\hline $\begin{array}{l}\text { frequency of sick- } \\
\text { ness absence }\end{array}$ & 0.276 & 0.102 & 0.324 & 2.703 & 0.009 & & \\
\hline & $\begin{array}{l}\mathrm{R}- \\
\text { square } \\
\text { change }\end{array}$ & $\begin{array}{l}\mathrm{F} \\
\text { change }\end{array}$ & $\begin{array}{l}\text { Sig. F } \\
\text { change }\end{array}$ & & & & \\
\hline $\begin{array}{l}\text { org. dummy X } \\
\text { org. dummy } Y\end{array}$ & -0.057 & 2.395 & 0.098 & & & & \\
\hline
\end{tabular}

1) Two-tailed 2) Covariate is the pre-test of the dependent variable at hand 
Table 6.8c Frequency of sickness absence: Associate nursing group versus control group $<70 \%$ working

\begin{tabular}{|c|c|c|c|c|c|c|c|}
\hline & B & Std. Error & Beta & $\mathrm{T}$ & Sig. ${ }^{1}$ & $\begin{array}{l}\text { Adjusted } \\
\mathrm{R}^{2}\end{array}$ & $\begin{array}{l}\text { Mean } \\
\text { square } \\
\text { residual }\end{array}$ \\
\hline$\overline{\text { constant }}$ & 0.917 & 0.356 & & 2.574 & 0.013 & \multirow{10}{*}{0.195} & \multirow{10}{*}{0.026} \\
\hline associate group & -0.005 & 0.040 & -0.015 & -0.136 & 0.892 & & \\
\hline type of ward & 0.187 & 0.071 & 0.524 & 2.636 & 0.011 & & \\
\hline org. dummy $\mathrm{X}$ & 0.176 & 0.075 & 0.353 & 2.336 & 0.023 & & \\
\hline org. dummy Y & 0.095 & 0.047 & 0.267 & 2.027 & 0.047 & & \\
\hline employment & 0.003 & 0.001 & 0.250 & 2.198 & 0.032 & & \\
\hline $\begin{array}{l}\text { degree } \\
\text { careload }^{3}\end{array}$ & -0.118 & 0.042 & -0.595 & -2.835 & 0.006 & & \\
\hline $\begin{array}{l}\text { frequency of sick- } \\
\text { ness absence } 2\end{array}$ & 0.309 & 0.139 & 0.267 & 2.233 & 0.029 & & \\
\hline & $\begin{array}{l}\mathrm{R}- \\
\text { square } \\
\text { change }\end{array}$ & $\begin{array}{l}\mathrm{F} \\
\text { change }\end{array}$ & $\begin{array}{l}\text { Sig. F } \\
\text { change }\end{array}$ & & & & \\
\hline $\begin{array}{l}\text { org. dummy X } \\
\text { org. dummy } Y\end{array}$ & -0.077 & 3.220 & 0.047 & & & & \\
\hline
\end{tabular}

\section{List of abbreviations used in appendices 4,5 and 6}

SD

n

B

Std. Error

Beta

$\mathrm{T}$

Sig.

Log LR

group $x$ ward

type of group

pnc group

associate group

type of ward

org. dummy $X$

org. dummy $Y$

gender

working hours

assignment

nursing care plans

nursing history

quality comm

variety resident-oriented comm variety ward-oriented comm standard deviation

number of cases

unstandardised beta

standard error

standardised beta

T-value

level of significance

Log likelihood ratio

interaction term type of group and type of ward

control group (0), experimental group (1)

control group $\geq 70 \%$ working (0), PNCs (1)

control group $<70 \%$ working $(0)$, associate nursing group (1)

somatic group (0), psycho-geriatric group (1)

organisation dummy $\mathrm{X}$ : A (0), B (1), C (0)

organisation dummy $Y$ : A (0), B (0), C (1)

pre-test gender: man (1), woman (2)

fixed working hours (1), variable working hours (2)

resident assignment

use of nursing care plans and their evaluation

taking nursing history, nursing problems, goals and actions

quality of communication forms

variety of resident-oriented communication forms

variety of ward-oriented communication forms 


\section{Appendix 7 Comparison pre-test sample and reference groups}

Table 7.1 Comparison pre-test sample and reference groups with regard to the research variables

\begin{tabular}{|c|c|c|c|c|c|c|}
\hline \multirow[t]{2}{*}{ Variable } & \multicolumn{2}{|c|}{$\begin{array}{l}\text { Pre-test scores popula- } \\
\text { tion of the study }\end{array}$} & \multicolumn{2}{|c|}{ Scores reference group } & \multirow[t]{2}{*}{$\begin{array}{l}\text { Type of reference group } \\
\text { (and author) }\end{array}$} & \multirow[t]{2}{*}{ Difference } \\
\hline & Mean & SD & Mean & SD & & \\
\hline Job autonomy & 2.78 & 0.54 & 2.67 & 0.62 & $\begin{array}{l}1386 \text { nursing caregivers } \\
\text { nursing homes (De } \\
\text { Jonge et al., 1995a) }\end{array}$ & Ns \\
\hline Job demands & 3.00 & 0.66 & 3.16 & 0.69 & $\begin{array}{l}1386 \text { nursing caregivers } \\
\text { nursing homes (De } \\
\text { Jonge et al., 1995a) }\end{array}$ & Ns \\
\hline Social support & 3.31 & 0.38 & 3.22 & 0.43 & $\begin{array}{l}1386 \text { nursing caregivers } \\
\text { nursing homes (De } \\
\text { Jonge et al., 1995a) }\end{array}$ & Ns \\
\hline Responsibility & 4.05 & 0.54 & 4.06 & 0.66 & $\begin{array}{l}1386 \text { nursing caregivers } \\
\text { nursing homes (De } \\
\text { Jonge et al., 1995a) }\end{array}$ & Ns \\
\hline Job satisfaction ' & 4.20 & 0.72 & 4.02 & 0.87 & $\begin{array}{l}1386 \text { nursing caregivers } \\
\text { nursing homes (De } \\
\text { Jonge et al., 1995a) }\end{array}$ & $\begin{array}{l}\text { Not com- } \\
\text { parable }\end{array}$ \\
\hline $\begin{array}{l}\text { Intrinsic work } \\
\text { motivation }\end{array}$ & 4.02 & 0.44 & 4.02 & 0.47 & $\begin{array}{l}156 \text { nurses general hos- } \\
\text { pitals (Janssen et al., } \\
1999 \text { a) }\end{array}$ & Ns \\
\hline Health complaints & 3.56 & 3.49 & 4.14 & 3.82 & $\begin{array}{l}1386 \text { nursing caregivers } \\
\text { nursing homes (De } \\
\text { Jonge et al., 1995a) }\end{array}$ & Ns \\
\hline $\begin{array}{l}\text { Frequency of sick- } \\
\text { ness absence }\end{array}$ & 0.82 & 1.22 & 1.18 & 1.31 & $\begin{array}{l}427 \text { nurses general hos- } \\
\text { pitals (Boumans, } 1990 \text { ) }\end{array}$ & $\begin{array}{l}\text { Not com- } \\
\text { parable }\end{array}$ \\
\hline
\end{tabular}

1) Item content slightly different 2) Frequency of sickness absence of the last half year (current study) versus one year (Boumans, 1990) 



\section{DANKWOORD / ACKNOWLEDGMENT}

Om het onderzoek naar bewonergericht verplegen en verzorgen in verpleeghuizen te kunnen uitvoeren en hiervan een proefschrift te schrijven heb ik veel mogen ontvangen. First of all, I want to thank my husband Paul. His unconditional support has been essential for bringing my job to a good end. Paul, your patience and tact ("when you don't want to go on holiday it's okay with me, but you need time for a little walk now"), endurance (stimulating me to work one weekend after the other), and love (giving me room to do the things which are important for me such as living in Maastricht while working there) are the best things a partner can wish.

Verder zijn er velen geweest die een bijdrage hebben geleverd aan het onderzoek en de totstandkoming van dit proefschrift. Als eerste wil ik de drie participerende verpleeghuizen St. Camillus in Roermond, Het Meulenbelt in Almelo en de Verpleegklinieken Heerlen (VKH) noemen, want zonder hun medewerking zou het onderzoek niet van de grond zijn gekomen. De bewoners en hun familie en directe relaties zeg ik dank voor de toestemming die zij hebben gegeven voor het verzamelen van de data. Ook wil ik de verplegenden en verzorgenden dankzeggen voor hun grote bereidheid om aan het onderzoek mee te werken en de "dikke vragenlijst" in te vullen. De afdelingshoofden van de experiment- en controle-afdelingen ben ik tevens veel dank verschuldigd. Zij hebben enorm veel werk verzet om de uitvoering van het onderzoek op hun afdelingen te coördineren. Het was hen nooit teveel om in het kader van de respons de laatste medewerker nog te stimuleren aan het onderzoek mee te werken. Een speciaal woord van dank gaat naar de projectcoördinatoren Ton van de Laar, Martin Lenferink en Margreet Hoogeveen. Zij baanden voor mij de weg in de organisatie, droegen zorg voor de contacten en regelden belangrijke zaken als slaapplaatsen en uniformen. Ton, Martin en Margreet: dank voor de fijne samenwerking en de collegiale hulp. Tevens dank ik de directies en de hoofden zorg voor het mogelijk maken van het onderzoek in hun organisaties.

Het voor de eerste keer doen van een onderzoek en het schrijven van een proefschrift betreft een leerproces. Ik was in het gelukkige bezit van goede begeleiders. Aan mijn co-promotor, dr. Nicolle Boumans een zeer speciaal woord van dank. Nicolle, je bent voor mij een voorbeeld. De discussies die je met me voerde over het werk van verplegenden en verzorgenden en je adviezen omtrent praktijkgericht onderzoek en de verslaglegging daarvan zijn voor mijn ontwikkeling als onderzoeker bepalend geweest. Je hebt mij tot het einde gestimuleerd door te zetten en mijn proefschrift af te ronden. Ik dank je voor je kennis, betrokkenheid en steun en tevens voor de gesprekken die we konden hebben over het leven met zijn vele facetten. Mijn promotoren, prof. dr. Huda Huijer Abu-Saad en prof. dr. Frans Nijhuis wil ik tevens mijn dank uitspreken. Huda, $i k$ dank je voor je leerzame en waardevolle adviezen. Als geen ander weet je inhoud te geven aan verpleegkundig onderzoek. Frans, jou dank ik voor de discussies over de kwaliteit van de arbeid in het algemeen en van verplegenden en verzorgenden in het bijzonder. Tevens wil ik een aantal mensen bedanken die ook een belangrijke inhoudelijke bijdrage hebben geleverd aan de totstandkoming van dit proefschrift. Allereerst betreffen dit $\mathrm{dr}$. Ab Landeweerd en dr. Margreet te Wierik, die als medebegeleiders samen met dr. Nicolle Boumans aan de wieg stonden van het project "Bewonergericht 
verplegen en verzorgen in verpleeghuizen". $A b$, dank voor het vertrouwen wat je in me stelde en het delen van je kennis en enthousiasme voor praktijkgericht onderzoek waarmee je mij steeds wist te motiveren. Margreet, ook jou dank ik voor je inzet bij de opzet van het onderzoek.

Tijdens de drie meetmomenten hebben aan de dataverzameling de onderzoeksassistenten Annelies Driessen, Henk Haagsma, Judy Hoekema en Frank van der Made en de studenten Hanneke Ariëns, Freek van Ham, Nynke de Jong, Frank Kardolus en Karles van Zwam een onmisbare bijdrage verleend. Hun actieve inzet en enthousiasme hebben ervoor gezorgd dat een hoge respons werd gerealiseerd. Het werk van dr. Jan de Jonge is een belangrijk voorbeeld geweest voor de huidige studie. Jan, dank voor je belangstelling voor ons onderzoek en voor de accuraatheid en snelheid waarmee je altijd daar waar nodig mijn vragen beantwoordde. In alle fasen van de dataverwerking is de bijdrage van dr. Gerard van Breukelen van groot belang geweest. Gerard, ik dank jou voor de tijd die je investeerde in het beantwoorden van mijn vragen over de juiste methodologische aanpak en statistische analyses en in het wegnemen van twijfels.

De leden van de beoordelingscommissie wil ik bedanken voor het beoordelen van het proefschrift. Met name prof. dr. Mieke Gryponck. Zij was niet alleen aan het eind als lid van de beoordelingscommissie betrokken maar ook als adviseur bij de opzet van het onderzoek. Zij heeft het model patiëntgericht verplegen en verzorgen in Nederland en België mede vorm gegeven. Mieke, ik ben vereerd geweest met je belangstelling voor ons onderzoek en je leerzame adviezen in dit kader.

Collegiale sociale steun is essentieel om het soms eenzame bestaan van een onderzoeker te compenseren. Van mijn oud-collega's van de sectie Verplegingswetenschap van de capaciteitsgroep Zorgwetenschappen heb ik veel wijsheden en steun ontvangen. Van Tiny (grote voorbeeld en vraagbaak tijdens het regelen van de laatste dingen), Inge (eerste kamergenoot) en Annemie (buurvrouw) heb ik veel geleerd over het doen van onderzoek. Ook vingen zij mijn buien op wanneer het eens niet lukte. Ook jullie, mijn andere oud-collega's van Verplegingswetenschap, dank ik voor de interesse, helpende hand en soms diepgaande discussies. Marianne, ik dank jou voor de vele literatuur die je voor me verzamelde en alle boeken die je steeds op het "nippertje" voor me moest verlengen. Het secretariaat VW (Heidi, Martha en Julie) dank ik voor het opvangen van het vele kopieerwerk en de telefoontjes.

Bij de huidige capaciteitsgroep BEOZ waar ik werkzaam ben, heb ik de onontbeerlijke steun gehad die nodig is voor de "laatste loodjes". Onze vakgroepvoorzitter prof. dr. Wim Groot wil ik bedanken voor de gelegenheid die hij me gaf in een korte tijd het proefschrift te kunnen voltooien. De leden van de projectgroep "Geïntegreerde zorg in verpleeghuizen" hebben mij de ruimte en de vrijheid gegeven om het proefschrift af te ronden. Aggie, Corné, Femke en Ingrid, jullie zijn goede maatjes geweest in deze voor mij spannende tijd. Tevens een oprecht woord van dank aan de collega's van de sectie Arbeid \& Gezondheid en de overige collega's van BEOZ voor hun niet ophoudende vragen naar de laatste stand van zaken, de steun bij het gestress rondom het maken van het boekje en de geruststellende woorden ("vrijdag de $13^{\text {de }}$, zou je dat wel doen?"). De collega's die reeds eerder vertrokken, Ad, Jolanda, Neeltje (mijn tweede kamergenoot), Thijs, Theo en Veron en de collega's van het Centre for Nursing Research, Inez en Katinka, dank ik voor hun vrolijkheid en het delen van onderzoeks- en levenswijsheden en ervaringen. Voor hen die de puntjes op de "i" hebben gezet een speciaal 
woord van dank. Veel werk is uit handen genomen door Isel van Noppen, die met veel zorg en geduld de lay-out verzorgde, Jan van Emmerik, die de geavanceerde kant ervan begeleidde en Claudia Bronner, die het monnikenwerk, het controleren van de referenties, voor haar rekening wilde nemen. Isel, Jan en Claudia, dank voor jullie bereidwilligheid en precisie. Bob Wilkinson dank ik voor de snelle wijze waarop hij de Engelse tekst corrigeerde tijdens de in Maastricht belangrijkste periode van het jaar, carnaval, en zijn "pekske"wilde verruilen voor de computer. Mustaq Khan, my third roommate, I want to thank for his patience with the huge number of books and articles I brought with me when entering his room. I loved our lively conversations about writing a thesis, Pakistan and Dutch health care, Muslim and Christian habits and faith.

Voor de financiële steun die ik mocht ontvangen gaat een bijzonder woord van dank naar het Landelijk Centrum Verpleging \& Verzorging, dat de uitvoering van het onderzoek financierde en het onderzoeksinstituut Health, dat het mede mogelijk maakte het onderzoek te kunnen afronden in een proefschrift.

Mijn paranimfen Nel Knols en Annemarie Asbreuk verdienen een bijzondere plaats. $\mathrm{Nel}$, in mijn eerste Maastrichtse periode waarin ik je leerde kennen als studiegenoot konden we al veel samen delen. Onze afspraak om één keer per jaar in "De Perroen" het verloop van onze carrières te evalueren hebben we niet stand gehouden. We zagen elkaar vaker. Toen ik opnieuw naar Maastricht kwam, hadden we wederom veel gemeen: naast het schrijven van een proefschrift en het delen van talloze andere ervaringen, ben je in onze discussies over historisch versus interventieonderzoek, kwalitatieve en kwantitatieve onderzoeksmethoden, je analytische blik op het werk en de positie van verpleegkundigen en je relativeringsvermogen voor mij belangrijk geweest. Ons beider drukte van de laatste tijd heeft waarschijnlijk gemaakt dat ook onze andere afspraak, het opzetten van een "frietentent" in Hoensbroek als een appeltje voor de dorst, nog steeds niet is nagekomen. Annemarie, "klein maar dapper" werden we als stafmedewerkers klinische en poliklinische zorg gezien toen we samen integrerende verpleging implementeerden in een algemeen ziekenhuis. Vanaf het eerste moment ben je belangrijk geweest door mij als niet-verpleegkundige met je brede praktijkervaring en je heldere en scherpe kijk in te wijden in het verpleegkundig beroep en de bijbehorende cultuur. Wat een toeval dat ik met je, nu manager van een verpleeghuis, wederom veel ervaringen heb uit te wisselen. Ik ben blij dat je opnieuw naast me staat. Dank aan jou Geert dat je haar wilde uitlenen.

Met mijn vrienden is wat goed te maken. Ik dank jullie voor het niet ophouden contact met me te zoeken en de steun die ik mocht ontvangen

Tenslotte, wil ik mijn vroegere buurvrouw en mijn familie bedanken. Mijn vroegere buurvrouw, mevrouw Janssen, dank ik dat zij gedurende drie jaar het mij heeft mogelijk gemaakt in Maastricht aan het onderzoek te werken en in Bennekom te wonen waar later Amsterdam nog aan werd toegevoegd. Mevrouw Janssen, door $u$ kon ik in alle rust de sleutel in het slot steken en het huis achter me laten. My family, mum and dad Scheerman, I want to thank for their wonderful support. Mum and dad, thank you for never stopping to ask me about the latest news ("did you make any progress this week?") and my health and well-being ("and how are you?"). De laatste regels zijn voor mijn vader en moeder die deze nooit zullen lezen. Hen dank ik dat zij mij altijd mijn gang hebben laten gaan en mij daarbij onvoorwaardelijk hebben gesteund. $\mathrm{Zij}$ zijn nooit opgehouden mij hun wijsheid door te geven. 



\section{CURRICULUM VITAE}

Afke Berkhout was born on December 3, 1957 in Wageningen, the Netherlands. After completing high school (VWO) in 1976, she began her studies at the Arnhem Conservatory in 1978. In 1984 she received her bachelor's degree in music. During this period and in the following years she worked as a music teacher at different schools of music. Subsequently, she studied health sciences at Maastricht University. After receiving her master's degree in 1991 she took up a position at the "Gelderse Vallei" general hospital where she implemented integrated nursing and provided support to the clinical and ambulatory staff on quality of care projects. Concurrently, she also worked as a part-time tutor at Maastricht University in Nursing Science and participated in writing the research proposal for the project "Resident-oriented care in nursing homes". Between 1995 and 1999 she was employed as a researcher on this project in the department of Nursing Science at Maastricht University. Since February 1999 she has been employed in the department Health, Organisation, Policy and Economics (HOPE), first as an assistant professor and researcher and currently as a researcher on the project "Evaluation of integrated care in nursing homes". 